FACULDADE DE FILOSOFIA, CIÊNCIAS E LETRAS - FFCLRP DEPARTAMENTO DE FÍSICA

PROGRAMA DE PÓS-GRADUAÇÃO EM FÍSICA APLICADA À MEDICINA E BIOLOGIA

\title{
Avaliação de Parâmetros Dosimétricos de Fontes de Braquiterapia Utilizando Simulação Monte Carlo e Dosimetria Gel Polimérica
}

Ana Luíza Quevedo Ramos da Silva

RIBEIRÃO PRETO - SP

2014 


\title{
Avaliação de Parâmetros Dosimétricos de Fontes de Braquiterapia Utilizando Simulação Monte Carlo e Dosimetria Gel Polimérica
}

Dissertação apresentada ao Departamento de Física da Faculdade de Filosofia, Ciências e Letras de Ribeirão Preto da Universidade de São Paulo, como parte das exigências para obtenção do título de Mestre em Ciências.

Área de concentração: Física Aplicada à Medicina e Biologia.

Orientadora: $\operatorname{Prof}^{\mathrm{a}}$. Dr ${ }^{\mathrm{a}}$. Patrícia Nicolucci.

\author{
VERSÃO CORRIGIDA \\ RIBEIRÃO PRETO - SP \\ 2014
}


Autorizo a reprodução e divulgação total ou parcial deste trabalho, por qualquer meio convencional ou eletrônico, para fins de estudo e pesquisa, desde que citada à fonte.

\section{Catalogação da Publicação}

Departamento de Física

Faculdade de Filosofia, Ciências e Letras de Ribeirão Preto da

Universidade de São Paulo

Da Silva, Ana Luíza Quevedo Ramos

Avaliação de Parâmetros Dosimétricos de Fontes de Braquiterapia Utilizando Simulação Monte Carlo e Dosimetria Gel Polimérica, 2014.

127 p.:il.; $30 \mathrm{~cm}$

Dissertação de Mestrado, apresentada ao Departamento de Física da Faculdade de Filosofia, Ciências e Letras de Ribeirão Preto da Universidade de São Paulo Área de concentração: Física Aplicada à Medicina e Biologia.

Orientadora: Prof ${ }^{\mathrm{a}}$.Dr ${ }^{\mathrm{a}}$. Patrícia Nicolucci

PALAVRAS-CHAVE: Braquiterapia, Dosimetria em Braquiterapia, Código PENELOPE, Gel MAGIC- $f$. 
Dedico esse trabalho aos meus pais, familiares e amigos... 


\section{Agradecimentos}

À Deus pelo presente da vida, por me conduzir diariamente.

À minha orientadora, Profa. Dra. Patrícia Nicolucci. Obrigada por todo ensinamento, discussões, reflexões e pela paciência. $\mathrm{O}$ seu profissionalismo, a sua dedicação e a sua competência, fizeram a diferença nesse trabalho e na minha vida, assim como na vida das pessoas que tem a oportunidade de conhecê-la. Obrigada por muitas vezes gastar dias e dias me explicando aquilo que eu já deveria saber... Quanta humildade e quanta sabedoria em uma pessoa só. Você é um exemplo pra todos nós. Obrigada, também, pela amizade, pelos seus conselhos. Foi uma grande alegria e uma grande honra ter a oportunidade de ser sua aluna.

Aos meus pais, Luiz Mário Ramos da Silva e Rosilene Ap. Quevedo da Silva, pelo amor incondicional e todo esforço. Chegar até aqui não foi fácil e vocês estavam comigo, sempre. Sem vocês nada disso também seria possível.

Ao meu irmão Renan, aos meus tios, primos e avós, que sempre estavam de braços abertos para me receber quando voltava pra casa, sempre dispostos a me apoiar. Obrigada pelo carinho de sempre. Em especial ao meu avô, Frederico Quevedo, que mesmo não estando mais presente fisicamente, tenho plena certeza que está comigo onde quer que eu vá. Que falta o senhor faz!

À Dra. Cassiana Viccari Sacilotto, Profa. Dra. Thatiane Alves Pianoschi Alva e Prof. Dr. Mirko Alva. Obrigada pela amizade, por toda ajuda, pelo carinho, pelos conselhos, pelo apoio de sempre. Amigos como vocês não cruzam a nossa vida duas vezes e eu tive a sorte de encontrá-los! Mesmo que a vida possa nos afastar, vou levá-los para sempre comigo.

Aos meus colegas de laboratório, Laura, Eduardo, Franciely, Gislaine e Cristiano, obrigada pela amizade, pelo carinho. Vocês são especiais! 
Às minhas amigas Sandra Andrade e Mariana Carballeda, obrigada pela amizade, pela cumplicidade. O apoio, o carinho e a amizade de vocês, apesar da distância, faz toda a diferença na minha vida.

Ao Hospital das Clínicas da Faculdade de Medicina de Ribeirão Preto (HCFMRP), por facilitar as irradiações e medidas de ressonância para a realização deste trabalho. Em especial aos físicos do setor de Radioterapia, ao Leandro Federiche Borges e ao Prof. Dr. Harley Francisco de Oliveira.

Aos professores do Departamento de Física dessa universidade, que tive a oportunidade de conviver durante esses anos, pelos ensinamentos. Aos funcionários, em especial ao Luiz Aziani, pelo suporte técnico disponibilizado e a Nilza Leoni Marino pela amizade.

E a todas as pessoas que direta ou indiretamente ajudaram a realizar este trabalho, muito obrigada. 


\section{RESUMO}

Da Silva, Ana Luíza Quevedo Ramos. Avaliação de Parâmetros Dosimétricos de Fontes de Braquiterapia Utilizando Simulação Monte Carlo e Dosimetria Gel Polimérica. 2014. 127f. Dissertação (Mestrado) - Departamento de Física, Faculdade de Filosofia, Ciências e Letras de Ribeirão Preto, Universidade de São Paulo, Ribeirão Preto, 2014.

A dosimetria em braquiterapia é importante para garantir a igualdade entre a dose entregue ao paciente e a dose planejada, porém a determinação experimental da dose é difícil devido ao alto gradiente de dose em regiões próximas à fonte. Nesse sentido, a dosimetria gel polimérica têm sido estudada como forma de se obter a distribuição tridimensional das doses dessas fontes.

O protocolo da Associação Americana de Físicos em Medicina, intitulado TG-43, propõe um formalismo para o cálculo de dose de fontes de braquiterapia através de parâmetros da atividade, anisotropia e geometria da fonte, além de atenuação e espalhamento da radiação produzida pela fonte. Porém, a determinação das funções dosimétricas necessárias para o cálculo da dose não é feita diretamente através de experimentos. Nessa linha, o Método Monte Carlo vêm sendo utilizado no cálculo dessas funções dosimétricas em braquiterapia.

Neste trabalho, foram determinados os parâmetros dosimétricos de duas fontes de braquiterapia, ${ }^{60} \mathrm{Co}$ e ${ }^{192} \mathrm{Ir}$, utilizando simulação Monte Carlo com o código PENELOPE, assim como as distribuições de dose utilizando dosimetria gel polimérica com o MAGIC- $f$. Os dados obtidos computacionalmente foram comparados com a literatura, obtendo-se concordância melhor que $98 \%$ em todos os parâmetros para a fonte de ${ }^{60} \mathrm{Co}$. Para a fonte de ${ }^{192} \mathrm{Ir}$, encontraram-se diferenças de até $22 \%$, embora quando os resultados deste trabalho foram comparados com o sistema de planejamento, o ajuste utilizado para o conjunto de pontos possui $\mathrm{R}^{2}$ de 0,9996 . A comparação das distribuições de dose da fonte de ${ }^{192} \mathrm{Ir}$ simuladas e determinadas com o gel polimérico MAGIC- $f$, apresentou concordância de $97 \%$ nos pontos englobados pela isodose de $50 \%$, quando o critério de $3 \%$ e $3 \mathrm{~mm}$ foi utilizado. Esses resultados evidenciam o potencial do uso da dosimetria gel polimérica e da simulação Monte Carlo com o código PENELOPE em dosimetria de fontes de braquiterapia de alta taxa de dose.

Palavras-chave: Braquiterapia, Dosimetria em Braquiterapia, Código PENELOPE, Gel MAGIC- $f$. 


\begin{abstract}
Da Silva, Ana Luíza Quevedo Ramos. Evaluation of Dosimetric Parameters of Brachytherapy Sources Using Monte Carlo Simulation and Polymer Gel Dosimetry. 2014. 127f. Thesis (Master) - Departamento de Física, Faculdade de Filosofia, Ciências e Letras de Ribeirão Preto, Universidade de São Paulo, Ribeirão Preto, 2014.
\end{abstract}

Dosimetry in brachytherapy is important to assure the conformity between the planned and the delivered dose to the patient. However, the experimental determination of dose is difficult in this technique due the high dose gradient in regions near the source. Hence, polymer gel dosimetry has been studied as a tool to obtain three-dimensional distribution dose for these sources.

A report of American Association of Medical Physics, entitled TG-43, proposes a formalism for dose calculation for brachytherapy sources through parameters such as activity, anisotropy and geometry of the source, and the attenuation and radiation scattering produced in the surrounding medium. However, the dosimetric functions needed for dose calculations are not directly determined through experiments. In this concern, the Monte Carlo method has been used in the calculation of these dosimetric funcions in brachytherapy.

In the present work, the dosimetric parameters for two brachytherapy sources, ${ }^{60} \mathrm{Co}$ e ${ }^{192} \mathrm{Ir}$, were determined using Monte Carlo simulation with PENELOPE code, and the dose distributions for the ${ }^{192}$ Ir source were determined using polymer gel dosimetry with MAGIC- $f$. Data obtained computationally were compared to literature, showing more than $98 \%$ agreement in all parameters for the ${ }^{60}$ Co source. For ${ }^{192} \mathrm{Ir}$, differences up to $22 \%$ were found to the literature, although when the results of this work were compared to the treatment planning system, a $\mathrm{R}^{2}$ equal to 0,9996 was found to the data fitting adjusting both data. The comparison of simulated dose distributions for ${ }^{192} \mathrm{Ir}$ and those determined with MAGIC- $f$ polymer gel showed that $97 \%$ of the points covered by $50 \%$ isodose are in agreement when gamma index criteria of $3 \%$ and $3 \mathrm{~mm}$ was used. These results indicate the potential use of polymer gel dosimetry with MAGIC- $f$ and Monte Carlo simulation with PENELOPE code in dosimetry of high dose rate brachytherapy sources.

Keywords: Brachytherapy, Dosimetry in Brachytherapy, PENELOPE code, MAGIC- $f$ gel. 


\section{Lista de Figuras}

Figura 1: Porcentagem de dose em profundidade em função da profundidade na água, para feixes de (a) elétrons e (b) fótons, para campo $10 \times 10 \mathrm{~cm}^{2}$ e distância fontesuperfície de $100 \mathrm{~cm}$ (Adaptado de PODGORSAK, 2005) ............................... 5

Figura 2: Distribuição dos casos tratados no ano de 2000, utilizando Teleterapia, no Hospital do Câncer AC Camargo (Adaptado de: http://slideplayer.com.br/slide/1232037/\#, acessado em 3 de janeiro de 2014) ................6

Figura 3: Distribuição de casos tratados no ano de 2000, utilizando Braquiterapia no Hospital do Câncer AC Camargo (Adaptado de http://slideplayer.com.br/slide/1232037/\# , acessado em 3 de janeiro de 2014) ............. 7

Figura 4: Aplicadores que são utilizados em tratamento de braquiterapia (a) ginecológica, uterina (b) de brônquios, traqueia, (c) de próstata e (d) superficial. .................................. 8

Figura 5: Sistema de coordenadas utilizado para cálculos de dosimetria em braquiterapia no protocolo TG-43 (NATH et al, 1995).

Figura 6: Tipos de dosímetros utilizados em Radioterapia (a) Câmara de ionização Tipo Farmer; (b) Dosímetros Termoluminescentes; (c) Filme radiocrômico.

Figura 7: Dosímetro gel polimérico.

Figura 8: Processo esquemático dos componentes e métodos utilizados na fabricação do gel MAGIC- $f$.

Figura 9: Tomógrafo RMN Philips 3.0 T, do HCFMRP, onde foram realizadas as leituras das amostras. 26

Figura 10: Estrutura do pacote de simulação Monte Carlo PENELOPE. 29

Figura 11: Códigos fonte do subdiretório FSOURCE. 30

Figura 12: Códigos fonte do subdiretório MAINS. 31

Figura 13: Estrutura referente ao diretório OTHER.

Figura 14: Arquivos necessários para a criação do arquivo executável usuario.exe. (PIANOSCHI, 2008)

Figura 15: Espectro simulado para fonte de ${ }^{192} \operatorname{Ir}$. 38

Figura 16: Geometria da fonte de ${ }^{192} \operatorname{Ir}$ (a) adaptado de (BALTAS et al, 1998); (b) construída com o pacote PENELOPE. 39

Figura 17: Dose Relativa em função da distância ao longo da direção radial, para a energia do ${ }^{192}$ Ir e diferença absoluta para a água e para o gel MAGIC- $f$.

Figura 18: Dose Relativa em função da distância ao longo da direção longitudinal, para a energia do ${ }^{192}$ Ir e diferença absoluta para a água e para o gel MAGIC- $f$. 44 
Figura 19: Mapa de distribuição de dose em plano transversal passando pelo centro da fonte de ${ }^{192} \mathrm{Ir}$, quando o material irradiado foi a água. .................................................. 45

Figura 20: Mapa de distribuição de dose em plano transversal passando pelo centro da fonte de ${ }^{192} \mathrm{Ir}$, quando o material irradiado foi a gel. ................................................... 45

Figura 21: Subtração do mapa da distribuição de dose da água e do gel, no plano

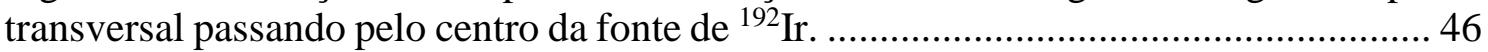

Figura 22: Dose relativa em função da distância radial para fonte de ${ }^{192} \mathrm{Ir}$ com e sem aplicador clínico.

Figura 23: Dose relativa em função da distância longitudinal para fonte de ${ }^{192} \mathrm{Ir}$ com e sem aplicador clínico. 48

Figura 24: Fator geométrico em função do ângulo calculados neste e fornecidos pelo protocolo TG-43.

Figura 25: Fator geométrico em função dos ângulos, para valores de $r$ no intervalo de $0,30 \mathrm{~cm}$ à $3,0 \mathrm{~cm}$ para uma fonte de $3,5 \mathrm{~mm}$ de comprimento, normalizados em $0,30 \mathrm{~cm}$ e $0^{\circ}$.

Figura 26: Curvas de isodoses, calculadas através de Simulação Monte Carlo, para três tipos de fontes de ${ }^{192} \operatorname{Ir}$ (a) VariSource, (b) New Varian e (c) microSelectron (adaptado de ANGELOPOULOS et al, 2000)

Figura 27: Valores da função de dose radial do artigo de referência e obtidos computacionalmente para a fonte de ${ }^{192} \mathrm{Ir}$.

Figura 28: Função de anisotropia em função do ângulo na distância de 0,5 cm para fonte de ${ }^{192}$ Ir obtidas por Williamson e colaboradores (WILLIAMSON e LI, 1995) e por simulação Monte Carlo.

Figura 29: Valores obtidos na simulação e referentes ao artigo, para a função de anisotropia com distância de 1,0 cm (WILLIAMSON e LI, 1995).

Figura 30: Valores obtidos na simulação e referentes ao artigo, para a função de anisotropia com distância de 2,0 cm (WILLIAMSON e LI, 1995).

Figura 31: Valores obtidos na simulação e referentes ao artigo, para a função de anisotropia com distância de 3,0 cm (WILLIAMSON e LI, 1995).

Figura 32: Tela do programa de planejamento BrachyVision utilizado no HCFMRP..... 64

Figura 33: Objetos simuladores utilizados nos experimentos desse trabalho (a) $4 \mathrm{ml}$ e (b) $175 \mathrm{ml}$.

Figura 34: Tubo Vacutainer ${ }^{\circledR}$ de $4 \mathrm{ml}$, preenchidos com o gel polimérico MAGIC- $f$, para irradiação na fonte de ${ }^{192} \operatorname{Ir}$ para calibração.

Figura 35: (a) Esquema de referência para a irradiação (b) Sistema dos tubos Vacutainer ${ }^{\circledR}$ inserido no cubo de acrílico com água para irradiação. 
Figura 36: Cofre onde está contida a fonte de ${ }^{192}$ Ir de alta taxa de dose, Varian, modelo GammaMed Plus

Figura 37: Vista (a) frontal e (b) lateral da caixa de acrílico utilizada nas leituras dos fantomas Vacutainer ${ }^{\circledR}$. 68

Figura 38: R2 em função da dose para o dosímetro gel MAGIC-f. ............................... 68

Figura 39: Aplicador inserido no objeto simulador e conectado ao cofre. 70

Figura 40: Imagem da leitura de ressonância utilizada no programa Image-J (a) Região analisada (b) perfil de intensidades referente à região selecionada. 70

Figura 41: Dose relativa em função da distância ao longo da direção radial para o gel e para simulação Monte Carlo.

Figura 42: Dose relativa em função da distância ao longo da direção radial, para a fonte de ${ }^{192} \mathrm{Ir}$, para a simulação Monte Carlo e sistema de planejamento Varian BrachyVision. 72

Figura 43: Imagens das distribuições de doses obtidas no plano transversal da fonte de ${ }^{192}$ Ir através da (a) Simulação Monte Carlo e (b) gel MAGIC- $f$. O Índice Gama que relaciona as duas imagens anteriores é mostrado em (c) para os critérios $3 \%$ e 3 mm.....74

Figura 44: Avaliação do Índice Gama no plano transversal da fonte de ${ }^{192}$ Ir para a região de isodoses maior que $50 \%$ para os critérios de $3 \%$ e $3 \mathrm{~mm}$.

Figura 45: Avaliação do Índice Gama no plano transversal da fonte de ${ }^{192}$ Ir para a região de isodoses maior que $50 \%$ para os critérios de $3 \%$ e $1 \mathrm{~mm}$.

Figura 46: Avaliação do Índice Gama no plano transversal da fonte de ${ }^{192}$ Ir para a região de isodoses maior que $50 \%$ para os critérios de $3 \%$ e $0,5 \mathrm{~mm}$. 76

Figura 47: Espectro simulado para fonte de ${ }^{60} \mathrm{Co}$. 78

Figura 48: Esquemas da fonte de ${ }^{60} \mathrm{Co}$ BEBIG (a) adaptado de (GRANERO et al, 2007); (b) construída através da simulação Monte Carlo com o código PENELOPE. 79

Figura 49: Dose Relativa em função da distância ao longo da direção radial, para a energia do ${ }^{60} \mathrm{Co}$ e diferença absoluta entre as doses relativas para a água e para o gel MAGIC- $f$. 80

Figura 50: Dose Relativa em função da distância ao longo da direção longitudinal, para a energia do ${ }^{60} \mathrm{Co}$ e diferença absoluta entre a água e o gel MAGIC- $f$.

Figura 51: Mapa de distribuição de dose em plano transversal passando pelo centro da fonte, quando o material irradiado foi a água.

Figura 52: Mapa de distribuição de dose em plano transversal passando pelo centro da fonte, quando o material irradiado foi o gel MAGIC- $f$. 
Figura 53: Mapa da subtração da distribuição de dose da água e do gel, para a energia do

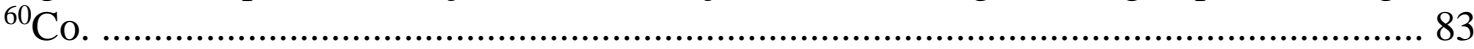

Figura 54: Função de dose radial em função da distância radial de Granero e colaboradores e obtidos computacionalmente (GRANERO, PÉREZ-CALATAYUD, BALLESTER, 2007). 85

Figura 55: Função de Anisotropia em função do ângulo para distância de 0,5 cm, simulado para a fonte de ${ }^{60} \mathrm{Co}$ e de Granero e colaboradores (GRANERO, PÉREZ-CALATAYUD, BALLESTER, 2007).

Figura 56: Função de Anisotropia em função do ângulo para distância de 1,0 cm, simulado para a fonte de ${ }^{60} \mathrm{Co}$ e de Granero e colaboradores (GRANERO, PÉREZ-CALATAYUD, BALLESTER, 2007).

Figura 57: Função de Anisotropia em função do ângulo para distância de 2,0 cm, simulado para a fonte de ${ }^{60} \mathrm{Co}$ e de Granero e colaboradores (GRANERO, PÉREZ-CALATAYUD, BALLESTER, 2007).

Figura 58: Função de Anisotropia em função do ângulo para distância de 3,0 cm, simulado para a fonte de ${ }^{60} \mathrm{Co}$ e de Granero e colaboradores (GRANERO, PÉREZ-CALATAYUD, BALLESTER, 2007). 


\section{Lista de Tabelas}

Tabela 1: Componentes e suas respectivas quantidades para a manufatura do gel

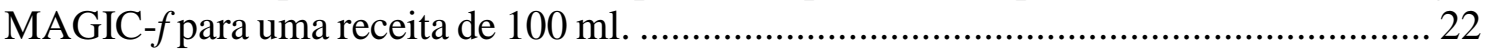

Tabela 2: Variáveis de entrada das simulações e suas respectivas funções. .................. 34

Tabela 3: Equações quadráticas na forma reduzida com os índices e as respectivas geometrias. Adaptada de (SALVAT et al, 2009).......................................................... 36

Tabela 4: Valores das quantidades relativas ao gel polimérico MAGIC- $f$. ..................... 40

Tabela 5: Valores das quantidades para a água. ......................................................... 41

Tabela 6: Fator geométrico fornecidos pelo TG-43 e obtidos nesse trabalho, para uma

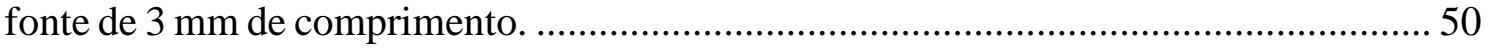

Tabela 7: Fatores geométricos obtidos para uma fonte de 3,5 mm de comprimento....... 51

Tabela 8: Parâmetros de ajuste de um polinômio de oitava ordem para a função de anisotropia na distância de $0,5 \mathrm{~cm}$ para fonte de ${ }^{192} \mathrm{Ir}$. ..................................................5

Tabela 9: Parâmetros de ajuste de um polinômio de oitava ordem para a função de anisotropia na distância de $1,0 \mathrm{~cm}$ para fonte de ${ }^{192} \mathrm{Ir}$..................................................5 59

Tabela 10: Parâmetros de ajuste de um polinômio de oitava ordem para a função de anisotropia na distância de $2,0 \mathrm{~cm}$ para fonte de ${ }^{192} \mathrm{Ir}$. ................................................ 61

Tabela 11: Parâmetros de ajuste de um polinômio de oitava ordem para a função de anisotropia na distância de 3,0 cm para fonte de ${ }^{192} \mathrm{Ir}$................................................... 62

Tabela 12: Parâmetros de ajuste de um decaimento exponencial de segunda ordem para os dados obtidos no sistema de planejamento e através da simulação Monte Carlo PENELOPE.

Tabela 13: Parâmetros de ajuste de um polinômio de sexta ordem para a função de anisotropia na distância de $0,5 \mathrm{~cm}$ para fonte de ${ }^{60} \mathrm{Co}$. 88

Tabela 14: Parâmetros de ajuste de um polinômio de sexta ordem para a função de anisotropia na distância de $1,0 \mathrm{~cm}$ para fonte de ${ }^{60} \mathrm{Co}$.

Tabela 15: Parâmetros de ajuste de um polinômio de sexta ordem para a função de anisotropia na distância de $2,0 \mathrm{~cm}$ para fonte de ${ }^{60} \mathrm{Co}$.

Tabela 16: Parâmetros de ajuste de um polinômio de sexta ordem para a função de anisotropia na distância de $2,0 \mathrm{~cm}$ para fonte de ${ }^{60} \mathrm{Co}$. 


\section{ÍNDICE}

Capítulo 1: Introdução ............................................................................................ 1

Capítulo 2: Aspectos Téorico-Experimentais ................................................................ 4

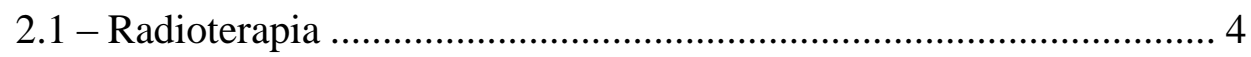

2.2 - Braquiterapia ................................................................... 7

2.3 - Dosimetria em Braquiterapia ..................................................... 9

2.4 - Funções Dosimétricas de Fontes de Braquiterapia ......................... 10

2.4.1 - Cálculo da Taxa de Dose ................................................. 11

2.4.2 - Intensidade de Kerma no Ar ........................................... 12

2.4.3 - Constante de Taxa de Dose .............................................. 14

2.4.4 - Fator Geométrico ............................................................ 15

2.4.5 - Função de Dose Radial .................................................. 16

2.4.6 - Função de Anisotropia .................................................. 17

2.5 - Dosímetros Utilizados em Braquiterapia ...................................... 17

2.6 - Dosimetria Gel Polimérica ................................................................ 20

2.6.1 - Resposta do Gel MAGIC-f após à irradiação .................... 23

2.6.2 - Leitura das Amostras por Ressonância ........................... 25

2.7 - Índice Gama ....................................................................... 27

2.8 - Método Monte Carlo ..................................................................... 27

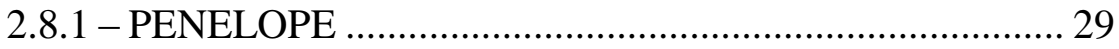

2.8.1.1 - Estrutura do Código .......................................... 29

2.8.1.2 - Estrutura do Programa ..................................... 33

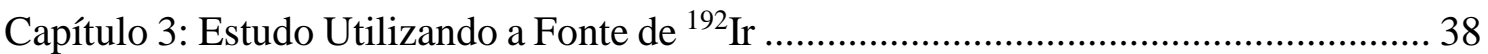

3.1 - Equivalência do gel MAGIC- $f$ com a água para a energia do ${ }^{192}$ Ir.. 39

3.2 - Parâmetros Dosimétricos para a Fonte de ${ }^{192} \operatorname{Ir~.............................~} 49$

3.2.1 - Fator Geométrico ......................................................... 49

3.2.2 - Função de Dose Radial ................................................. 54

3.2.3 - Função de Anisotropia .................................................... 56

3.3 - Dosimetria Gel com Fonte de ${ }^{192} \mathrm{Ir}$...............................................6 64

3.3.1 - Curva de Calibração ...................................................... 65

3.3.2 - Distribuição de Dose com MAGIC- $f$............................. 69

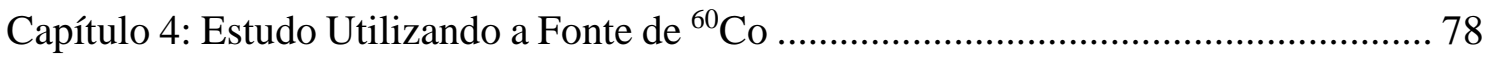

4.1 - Equivalência do gel MAGIC- $f$ com a água para a energia do ${ }^{60}$ Co. 79 
4.2 - Parâmetros Dosimétricos para a Fonte de ${ }^{60} \mathrm{Co}$ 84

4.2.1 - Fator Geométrico ........................................................ 84

4.2.2 - Função de Dose Radial .................................................... 84

4.2.3 - Função de Dose Anisotropia........................................... 86

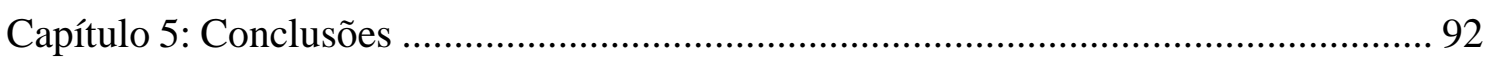

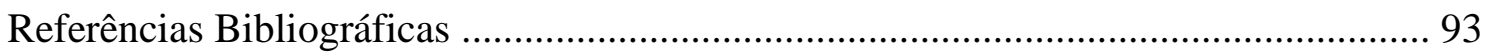

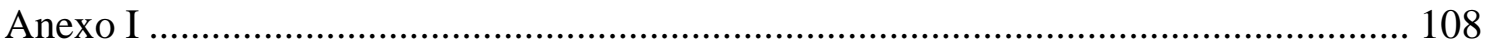

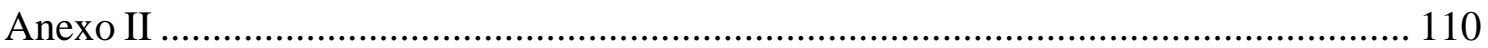




\section{Introdução}

A radioterapia é uma modalidade de tratamento que tem por objetivo controlar um volume tumoral, preservando as células sadias adjacentes ao tumor (OKUNO; YOSHIMURA, 2010). Para essa finalidade podem ser utilizados vários tipos de radiações, como fótons, prótons, elétrons, nêutrons (BURGER, 2003; MOHAN, 2013; PEREZ et al 2013). Dependendo do posicionamento do feixe com relação à região lesionada, são denominadas duas modalidades de tratamento: teleterapia e braquiterapia. A teleterapia é quando a fonte está posicionada à distância do volume tumoral e a braquiterapia é quando a fonte está próxima ou em contato com o tumor.

A braquiterapia permite administrar altas doses de radiação em volumes restritos do organismo, proporcionando maior controle da doença e menor toxicidade aos tecidos normais adjacentes (YI et al, 2010).

O protocolo da Associação Americana de Físicos em Medicina, denominado TG-43, propõe um formalismo para o cálculo de dose em braquiterapia (NATH et al, 1995). Nesse formalismo, o cálculo de dose necessita de parâmetros relacionados à atividade da fonte e de funções levando em consideração a atenuação e espalhamento da radiação produzida pela fonte, sua anisotropia e geometria (SADEGHI, SAIDI, TENREIRO, 2011). A função de anisotropia, a função de dose radial e o fator geométrico, utilizadas para o cálculo da dose, não são obtidas diretamente através de experimentos. Nesse sentido, o método Monte Carlo têm sido utilizado na obtenção dessas funções dosimétricas de fontes de radiações clínicas, bem como no estudo de doses em braquiterapia. (FONSECA-RODRIGUES, BEGALLI, QUEIROZ-FILHO, 2009; DESBIENS et al, 2013; ARYAL, MOLLOY, RIVARD, 2014; LESPERANCE, MARTINOV, THOMSON, 2014).

A realização de dosimetria em braquiterapia é de extrema importância para a qualidade no tratamento, uma vez que é necessário garantir a igualdade entre as doses planejada e entregue ao paciente (WILKINSON, 2006). Entretanto, a determinação experimental da dose em braquiterapia é complexa, devido ao alto gradiente de dose proporcionado por essas fontes, exigindo características especiais dos dosímetros utilizados para tal fim. Sendo assim, é necessário o uso de dosímetros que possuam alta resolução espacial, alta sensibilidade e pouca dependência energética (FAZLI, et al 2013). Os dosímetros comumente utilizados para tal fim são os dosímetros 
termoluminescentes e os filmes dosimétricos (SCHWOB, ORION, 2007; SHARMA, JURSINIC, 2013; LUCAS, AUBINEAU-LANIÈCE, LOURENÇO, 2014). Estes, porém, não apresentam as características necessárias de resolução espacial e possibilidade de obtenção de distribuições tridimensionais de dose (TEDGREN, HEDMAN, GRINDBORG, 2011; HAWORTH, BUTLER, WIFERT, 2013; MORRISON, GEETHA, SLOBODA, 2014).

Muitos sistemas dosimétricos estão sendo investigados para obtenção de distribuição tridimensional de doses, dentre eles os géis dosimétricos se apresentam como os mais promissores. Nesses tipos de géis, as informações dosimétricas ficam aprisionadas na matriz gelatinosa, sendo possível obter uma distribuição de dose tridimensional com alta resolução. Os primeiros géis desenvolvidos para fins dosimétricos em Radioterapia necessitavam de um ambiente livre de oxigênio em sua preparação, representando uma dificuldade de uso rotineiro, como o gel PAG, BANANA, BANG (MARYANSKI et al, 1993; BALDOCK et al, 1998; DEMPSEY, 2010). Para contornar esse problema, uma nova formulação desses géis foi proposta, onde o mesmo pode ser feito em condições atmosféricas ambientais. Essa nova formulação recebeu no nome de MAGIC, sendo que a principal diferença é a supressão do oxigênio através do Ácido Ascórbico e do Sulfato de Cobre (FONG, 2001; ALJAMAL, ZAKARIA, SHAMSUDDIN, 2013). Uma nova alteração foi realizada na formulação do gel MAGIC, onde foi acrescentado o formaldeído, com o intuito de fornecer a estabilidade mecânica para o gel em temperatura ambiente, alterando seu ponto de fusão para $69{ }^{\circ} \mathrm{C}$ e recebendo o nome de MAGIC- $f$ (PAVONI et al, 2010).

Diversas técnicas de leituras de dosímetros gel polimérico podem ser utilizadas, tais como: ultrassom, tomografia computadorizada por Raios $\mathrm{X}$, tomografia ótica e imagens de ressonância magnética (CHO et al, 2010; JOHNSTON, HILTS, CARRICK et al., 2012; KHOEI, TRAPP, LANGTON, 2013; QIAN et al, 2013; ABTAHI, AGHAMIRI, KHALAFI, 2014; JIRASEK, HILTS, 2014). Atualmente, a técnica mais utilizada em aplicações clínicas é a leitura utilizando imagem por ressonância magnética, uma vez que esta possui alta resolução espacial e permite obter alta resolução em dose (WATANABE, HITOSHI, 2011; VANDECASTEELE, DE DEENE, 2013a; VANDECASTEELE, DE DEENE, 2013b; VANDECASTEELE, DE DEENE, 2013c).

O objetivo deste trabalho foi realizar um estudo dosimétrico de duas fontes de braquiterapia, ${ }^{60} \mathrm{Co} \mathrm{e}{ }^{192} \mathrm{Ir}$, utilizando simulação Monte Carlo e dosimetria gel polimérica. Através dessas duas ferramentas foram obtidos parâmetros dosimétricos utilizados em 
cálculos de dose em braquiterapia e as distribuições de dose produzidas por essas duas fontes.

Para a fonte de ${ }^{60} \mathrm{Co}$ os resultados simulados com o código PENELOPE foram comparados com a literatura. Para a fonte de ${ }^{192}$ Ir foi realizado, adicionalmente, um estudo utilizando dosimetria gel polimérica. Os dados obtidos computacionalmente para a fonte de ${ }^{192} \mathrm{Ir}$ foram comparados com a literatura e o sistema de planejamento BrachyVision. Além disso, a comparação entre os resultados obtidos com a dosimetria gel polimérica e a simulação, foi realizada através do índice gama.

No segundo capítulo desse trabalho será realizada uma abordagem sobre os aspectos teórico-experimentais apresentados nesse estudo, tais como: Radioterapia, Braquiterapia, Dosimetria em Braquiterapia, Dosimetria Gel Polimérica, Índice Gama e Simulação Monte Carlo.

Os procedimentos computacionais referentes à determinação dos parâmetros dosimétricos da fonte de ${ }^{192} \mathrm{Ir}$, juntamente com os resultados da comparação com a literatura e discussões, serão apresentados no terceiro capítulo. Na sequência, será apresentado o estudo do gel polimérico MAGIC- $f$ realizado com a fonte de ${ }^{192}$ Ir de alta taxa de dose, seguida pela comparação através do índice gama e sistema de planejamento.

No quarto capítulo serão apresentados os procedimentos computacionais utilizados na determinação dos parâmetros dosimétricos da fonte de ${ }^{60} \mathrm{Co}$, os resultados e comparações com a literatura juntamente com as discussões.

As conclusões referentes ao estudo realizado, são mostradas no quinto capítulo. 


\section{2 - Aspectos Teórico-Experimentais}

Neste capítuloserão apresentados os aspectos teórico-experimentais envolvidos neste trabalho, tais como: Radioterapia, Braquiterapia, Dosimetria em Braquiterapia, Funções Dosimétricas de Fontes de Braquiterapia, Dosímetros Utilizados em Braquiterapia, Dosimetria Gel Polimérica, Índice Gama, Método Monte Carlo.

\section{1 - Radioterapia}

Para o ano de 2014, de acordo com o Instituto Nacional do Câncer (INCA), são esperados 394.500 mil casos novos de câncer no Brasil, sem contabilizar os casos de câncer de pele não melanoma. Contabilizando os casos de câncer, adicionando os do tipo pele não melanoma, são esperados 576.580 novos casos (INCA, 2014). Dos novos casos do tipo não melanoma, serão aproximadamente, 190 mil para o sexo feminino e 203 mil para o sexo masculino. Ainda de acordo com o INCA, o câncer de próstata será a incidência predominante para os homens (69 mil novos casos) e o câncer de mama será a incidência predominante para as mulheres (57 mil novos casos). As modalidades mais utilizadas no tratamento de tumores são a cirurgia, a Radioterapia e a quimioterapia, que podem ser utilizadas de forma exclusiva ou combinada.

A Radioterapia é uma modalidade de tratamento de tumores onde é utilizada radiação ionizante com finalidade de controlar ou, se possível, erradicar o volume tumoral, preservando as células sadias nas estruturas vizinhas ao tumor (OKUNO; YOSHIMURA, 2010). No planejamento do tratamento são estabelecidos fatores técnicos de forma a proporcionar altas doses no volume do tumor e doses abaixo da tolerância nos tecidos sadios adjacentes.

Diferentes tipos de radiações podem ser utilizadas em Radioterapia, tais como: elétrons, fótons, prótons, nêutrons (SYMONDS et al, 2012; MOHAN, MAHAJAN, MINSKY, 2013). Na figura 1 é apresentada a porcentagem de dose em profundidade (PDP) em função da profundidade na água, para feixes de elétrons e fótons tipicamente utilizados em Radioterapia. 


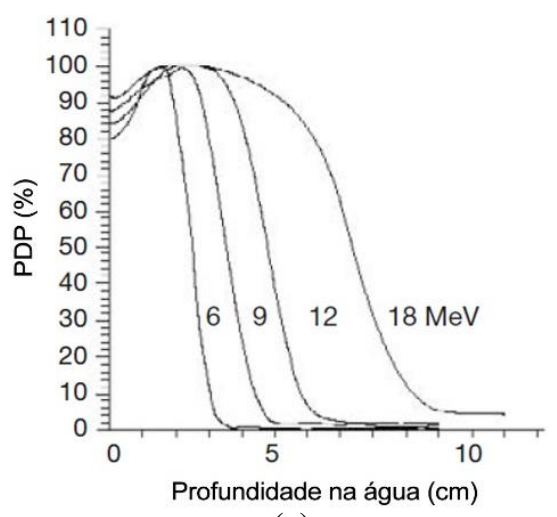

(a)

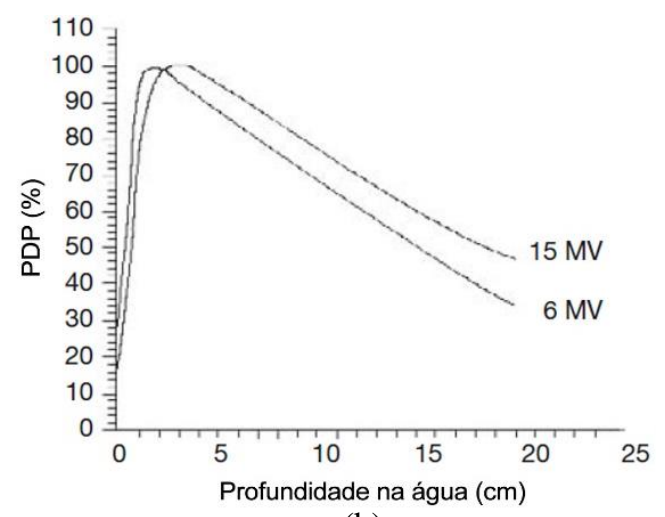

(b)

Figura 1: Porcentagem de dose em profundidade em função da profundidade na água, para feixes de (a) elétrons e (b) fótons, para campo $10 \times 10 \mathrm{~cm}^{2}$ e distância fonte-superfície de $100 \mathrm{~cm}$ (Adaptado de PODGORSAK, 2005).

Através da figura 1 é possível evidenciar a diferença na deposição de dose em profundidade desses dois tipos de radiação. À uma profundidade de $5 \mathrm{~cm}$, por exemplo, a dose depositada por um feixe de elétrons de $6 \mathrm{MeV}$ é praticamente nula, enquanto que para um feixe de fótons de $6 \mathrm{MV}$ a dose na mesma profundidade é de aproximadamente 90\% da dose máxima. Além disso, a figura 1 evidencia, ainda, as diferenças de deposição de dose em profundidade para um mesmo tipo de radiação, mas com diferentes energias. Desta forma, a escolha do tipo e energia da radiação devem levar em consideração a profundidade onde o tumor está localizado. Assim, se o tumor estiver localizado superficialmente, o mesmo poderá ser tratado com um feixe de elétrons ou um feixe de fótons de baixa energia. Caso o tumor esteja localizado em profundidade, um feixe de fótons de alta energia poderá ser indicado.

O posicionamento do feixe com relação ao tumor, independentemente se for utilizado feixe de fótons ou elétrons, denominará duas técnicas da Radioterapia. Se a fonte estiver à distância da região lesionada, a técnica será denominada Teleterapia. Porém se a fonte estiver próxima ou em contato à região lesionada, a técnica utilizada receberá o nome de Braquiterapia.

$\mathrm{Na}$ teleterapia, podem ser utilizadas unidades de raios-X de ortovoltagem, aparelhos de Cobalto-60 e aceleradores lineares. As unidades de raios-X de ortovoltagem possuem feixes de 50 à $300 \mathrm{kVp}$. Os aparelhos de Cobalto-60 utilizam energia de 1,25 MeV e a energia dos aceleradores lineares possuem energias máximas de 4 à $50 \mathrm{MeV}$. A diferença de energia e tipo do feixe produzido por esses aparelhos é o que determina em qual tratamento cada um será utilizado. Feixes de baixa energia, são 
utilizados em tratamentos onde as lesões são superficiais e feixes de energia maiores são utilizados em tratamentos onde os tumores estão localizados em profundidade maiores.

Os aceleradores lineares são os equipamentos mais utilizados no mundo, pois são versáteis, emitem raios-X e/ou feixes de elétrons com diversos valores de energias e podem variar a posição dos colimadores durante o tratamento. Aparelhos como esse têm a capacidade de realizar tratamento desde em tumores mais profundos até os tumores mais superficiais.

Na figura 2 é mostrada a distribuição dos casos tratados utilizando teleterapia no Hospital do Câncer Antonio Cândido Camargo (SP), no ano de 2000.

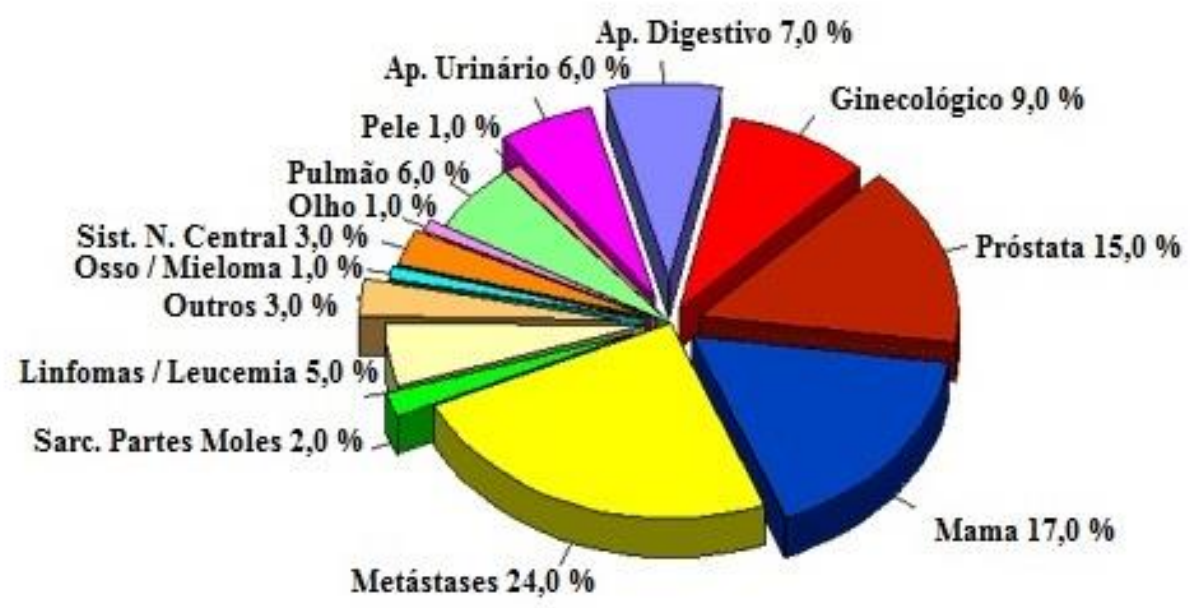

Figura 2: Distribuição dos casos tratados no ano de 2000, utilizando Teleterapia no Hospital do Câncer AC Camargo (Adaptado de: http://slideplayer.com.br/slide/1232037/\# , acessado em 3 de janeiro de 2014).

Para a braquiterapia, as fontes mais comumente utilizadas são ${ }^{192} \mathrm{Ir},{ }^{198} \mathrm{Au},{ }^{125} \mathrm{I}$. Essas fontes emitem, normalmente, fótons e partículas $\beta$ com energias variadas, além de possuírem diferentes características de tempo de decaimento, acarretando distribuições de doses particulares e sendo utilizadas em tratamentos específicos. Alguns tratamentos realizados com o auxílio da braquiterapia, são o de câncer de próstata (MANTINI et al, 2013), câncer de mama (CHAND et al, 2013), endométrio (GUINOT et al, 2012), além de lesões oftálmicas (OOTF Committee, 2013) e do sistema nervoso central (ICRU Report 72, 2004), como mostrado na figura 3. 


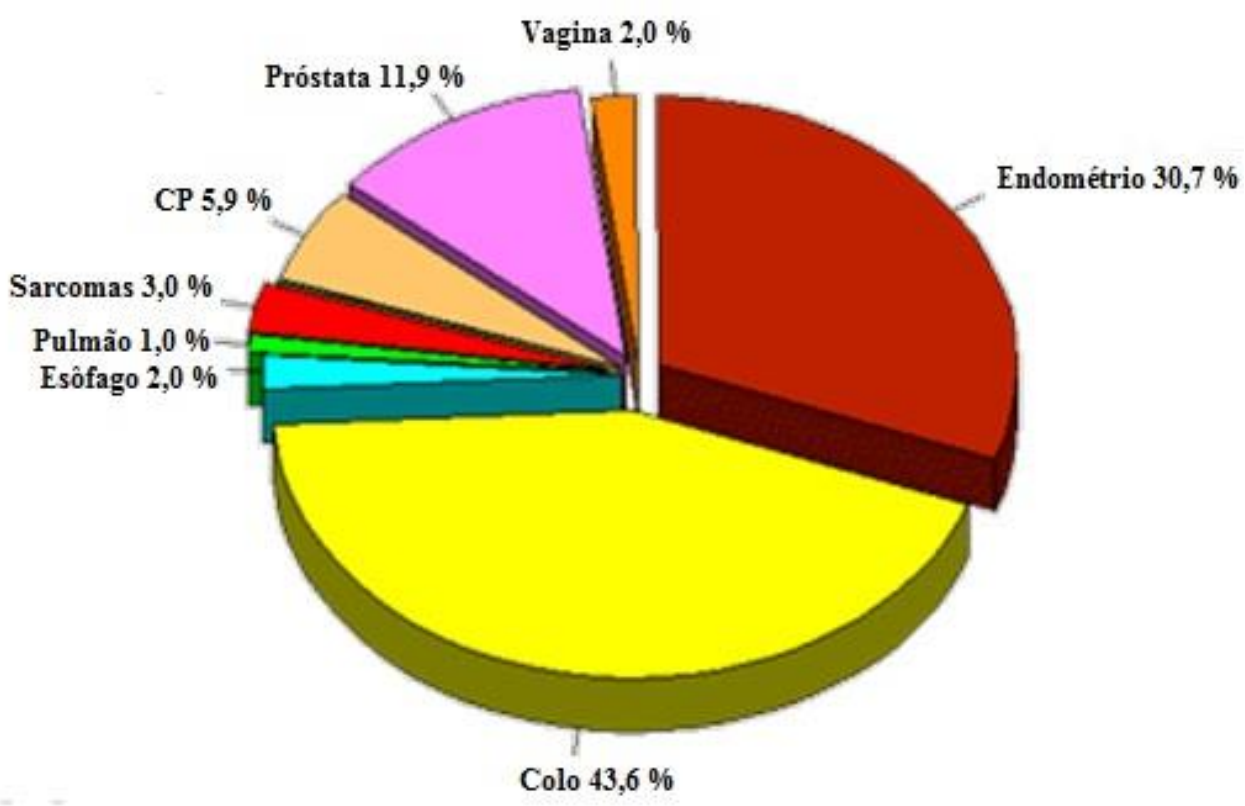

Figura 3: Distribuição de casos tratados no ano de 2000, utilizando Braquiterapia no Hospital do Câncer AC Camargo (Adaptado de http://slideplayer.com.br/slide/1232037/\# , acessado em 3 de janeiro de 2014).

Neste trabalho, as distribuições de doses resultantes de fontes de braquiterapia serão avaliadas, sendo importante o conhecimento de parâmetros técnicos e dosimétricos nesse tipo de tratamento.

\section{2 - Braquiterapia}

A braquiterapia permite administrar altas doses de radiação em volumes restritos do organismo, proporcionando maior controle da doença e menor toxicidade aos tecidos normais adjacentes (ESTEVES et al 2004, YI et al, 2010).

Segundo a taxa de dose proporcionada pela fonte utilizada, a braquiterapia pode ser classificada de duas formas: HDR (alta taxa de dose, do inglês high dose rate), quando a taxa de dose é de 4 à 20 cGy/h ou LDR (baixa taxa de dose, do inglês low dose rate), quando a taxa de dose é de 0,4 à $2 \mathrm{cGy} / \mathrm{h}$. As fontes de LDR estão sendo continuamente substituídas pelas fontes de alta taxa de dose, uma vez que no caso de braquiterapia HDR os elementos radioativos utilizados possuem uma alta atividade, resultando em um menor tempo total do tratamento.

Os tipos de implantes utilizados em braquiterapia, são: intracavitário, intersticial, intraluminal e superficial. No primeiro caso, o aplicador é inserido em cavidades já existentes no corpo. No implante intraluminal, como nos casos intracavitários, o aplicador 
é guiado por cavidades já existentes no corpo, porém em formatos tubulares. Na braquiterapia intersticial, as fontes são posicionadas no interstício dos tecidos, através de agulhas, fios ou cateteres. Já na braquiterapia superficial as fontes são posicionadas na própria superfície do corpo, em contato com a região lesionada, sendo que em alguns casos moldes são utilizados para adequar o implante corretamente à superfície.

Para guiar a fonte até o local em que será realizado o tratamento de braquiterapia, é necessário a utilização de aplicadores de braquiterapia. Alguns aplicadores são mostrados na figura 4 .

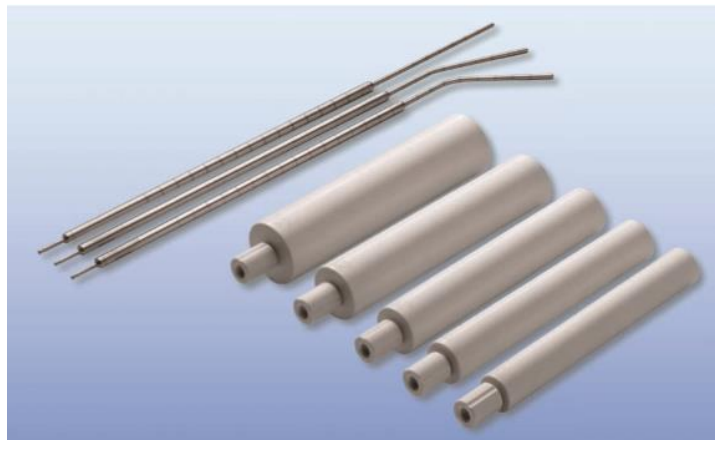

(a)

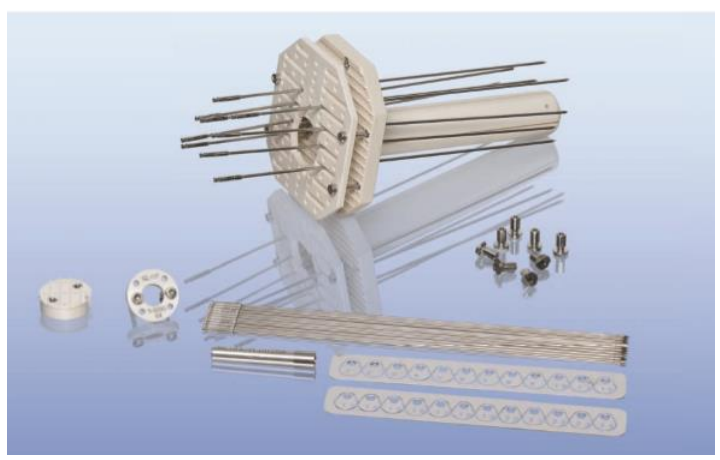

(c)

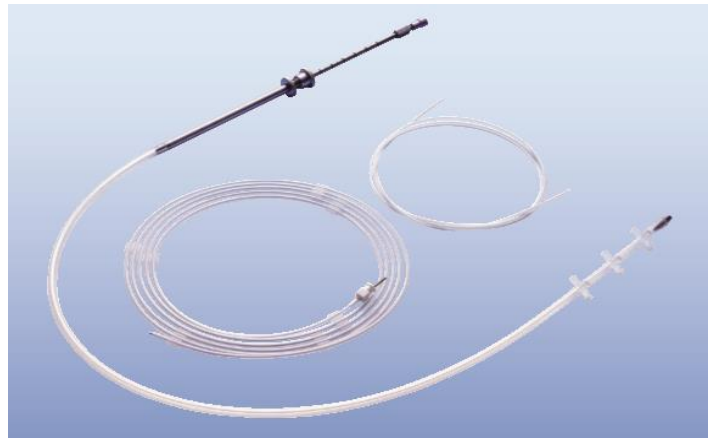

(b)

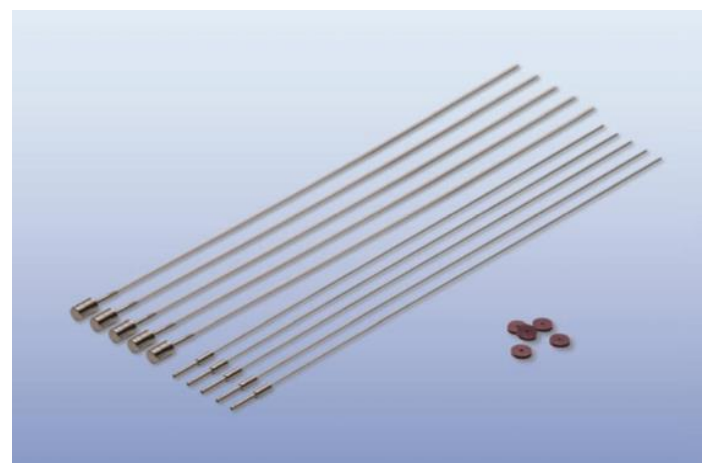

(d)

Figura 4: Aplicadores que são utilizados em tratamento de braquiterapia (a) ginecológica, uterina (b) de brônquios, traqueia, (c) de próstata e (d) superficial.

Os aplicadores mostrados na figura 4 (a) são utilizados em braquiterapia intracavitária, como por exemplo na vagina, no útero e endométrio. Já os aplicadores mostrados em (b) são específicos para braquiterapia intraluminal, podendo ser utilizados em tratamentos de brônquios, esôfago e traqueia, sendo flexíveis e especialmente desenhados para adaptação a esses locais. Os exemplos de aplicadores mostrados em (c) são utilizados em braquiterapia intersticial na região da pelve, da próstata e do reto. Os 
aplicadores mostrados em (d) são comumente utilizados em braquiterapia intraoperatória ou superficiais, como em tumores ósseos ou em implantes cirúrgicos, sendo possível adaptar-se à anatomia do paciente.

A combinação da energia, do tipo de partícula e do posicionamento da fonte durante o tratamento resultam em um alto gradiente de dose em distâncias muito pequenas da fonte. Além disso, à medida que a distância da fonte aumenta, a quantidade de radiação diminui rapidamente, diminuindo proporcionalmente a dose depositada à distância. Assim, a dosimetria em braquiterapia é de extrema importância para a qualidade do tratamento.

\section{3 - Dosimetria em Braquiterapia}

Para o sucesso em tratamentos em Radioterapia assegurar a igualdade entre o valor da dose prescrita e o valor da dose entregue ao paciente é de extrema importância (NATH el al, 1995). Nesse sentido, a Comissão Internacional de Unidades e Medidas de Radiação (ICRU, do inglês International Comission on Radiation Units and Measurements) recomenda que a incerteza total na entrega da dose esteja entre $-5 \%$ a $+7 \%$ (ICRU Report 62 1999). Para isso, diversos fatores serão analisados, tais como: testes de segurança, desempenho das máquinas e dosimetrias, com o objetivo de que os valores dosimétricos de referências não variem com o tempo (FURNARI, 2009; KLEIN et al, 2009).

No caso da braquiterapia, determinados testes de controle da qualidade são realizados periodicamente com o objetivo de assegurar que os valores dosimétricos de referências se mantenham ao longo do tempo. Alguns testes são realizados semanalmente, como a verificação do botão de emergência da sala, do botão de emergência do console, outros testes são realizados mensalmente, como autorradiografia da fonte, simulação de cateter obstruído, enquanto alguns testes são realizados trimestralmente ou a cada nova troca da fonte, como calibração, autorradiografia das paradas da fonte, verificação do tubos de transferência de fonte (FURNARI, 2009).

Em 1995 o Grupo de Trabalho 43 (TG-43) da Associação Americana de Físicos em Medicina (AAPM) propôs um formalismo para cálculo de dose em braquiterapia, utilizando as recomendações do ICWG (Interstitial Collaborative Working Group), onde as componentes para o cálculo da dose serão divididas em geometria, espalhamento, 
atenuação e anisotropia da fonte e das doses (NATH et al, 1995; SADEGHI, SAIDI, TENREIRO, 2011). Esse protocolo foi revisado em 2004, recebendo o nome de TG-43-U1, onde foram realizadas algumas alterações no formalismo original (RIVARD et al, 2004). Foram propostas algumas diretrizes na realização de dosimetria com TLDs e simulação Monte Carlo, onde os valores das funções dosimétricas propostas obtidas experimentalmente encontram-se próximos aos obtidos computacionalmente (SALATA et al, 2009).

Devido ao alto gradiente de dose em regiões próximas à fonte, a dosimetria em braquiterapia apresenta diversos desafios experimentais, uma vez que é necessário o uso de dosímetros que possuam alta sensibilidade, resolução espacial e baixa dependência energética (FAZLI, et al 2013). Dessa forma, os sistemas de planejamento em braquiterapia, utilizam os dados de parâmetros dosimétricos já pré-estabelecidos para fontes e objetos simuladores padrão, podendo levar à inacurácias nos cálculos de planejamento em braquiterapia (PARK, KIM, PARTK et al, 2009).

Visando melhorar a acurácia dos cálculos de planejamento e a determinação das funções dosimétricas das fontes, diversos algoritmos de cálculo têm sido estudados para aplicações em braquiterapia de alta taxa de dose (RIVARD, BEAULIEU, MOUTARDA, 2010). Nessa linha, a utilização da simulação Monte Carlo é uma importante ferramenta para a obtenção desses parâmetros dosimétricos, dentre eles: função de anisotropia, fator geométrico e função de dose radial (TANDERUP et al, 2010).

\section{4 - Funções Dosimétricas de Fontes de Braquiterapia}

Como mencionado anteriormente, as funções dosimétricas que são utilizados em braquiterapia de alta taxa de dose fazem parte de um formalismo proposto pela AAPM em 1995, foi denominado TG-43 e quando foi revisado em 2004 (RIVARD et al, 2004). Os protocolos de calibração de fontes de braquiterapia, propostos pela IAEA (do inglês, International Atomic Energy Agency), são: TECDOC-1079, intitulado Calibration of Brachytherapy Sources at Secondary Standard Dosimetry Laboratories (SSDLs) and Hospitals, e o TECDOC-1274, denominado Calibration of Photon and Beta Ray Sources Used in Brachytherapy. O primeiro deles, do ano 1999, descreve os métodos que são utilizados para calibrar fontes de braquiterapia que possuem valores de energia até o valor da energia do ${ }^{192} \operatorname{Ir}$ (que possui energia média de aproximadamente $397 \mathrm{keV}$ ), enquanto o 
segundo, publicado em 2002, descreve a padronização da calibração das fontes mais comumente utilizadas em braquiterapia, acrescentando fontes com emissão alfa e beta.

A calibração de fontes de braquiterapia é expressa em diferentes unidades em protocolos de dosimetria específicos. A AAPM recomenda que as fontes sejam expressas em termos de intensidade de kerma no ar $\left(\mathrm{S}_{\mathrm{K}}\right)$, enquanto que o ICRU 58 recomenda que as fontes sejam especificadas em termos de taxa de kerma no ar em uma profundidade de referência $\left(K_{a r}\left(\dot{d}_{r e f}\right)\right)_{a r}$ (ICRU Report 58, 1997; SUNTHARALINGAM, PODGORSAK, TÖLLI, 2005). Essas diferenças serão discutidas a seguir, juntamente com outras funções dosimétricas usadas em braquiterapia.

\subsection{1 - Cálculo da Taxa de Dose}

De acordo com o protocolo já mencionado, o TG-43, para fontes que possuem simetria esférica, a distribuição de dose bidimensional pode ser determinada em função do ângulo ao longo da fonte $(\theta)$ e da distância até o ponto de interesse ( $r$ ) (NATH et al, 1995). O sistema de coordenadas que é utilizado nos cálculos de dosimetria em braquiterapia nesse protocolo é mostrado na figura 5.

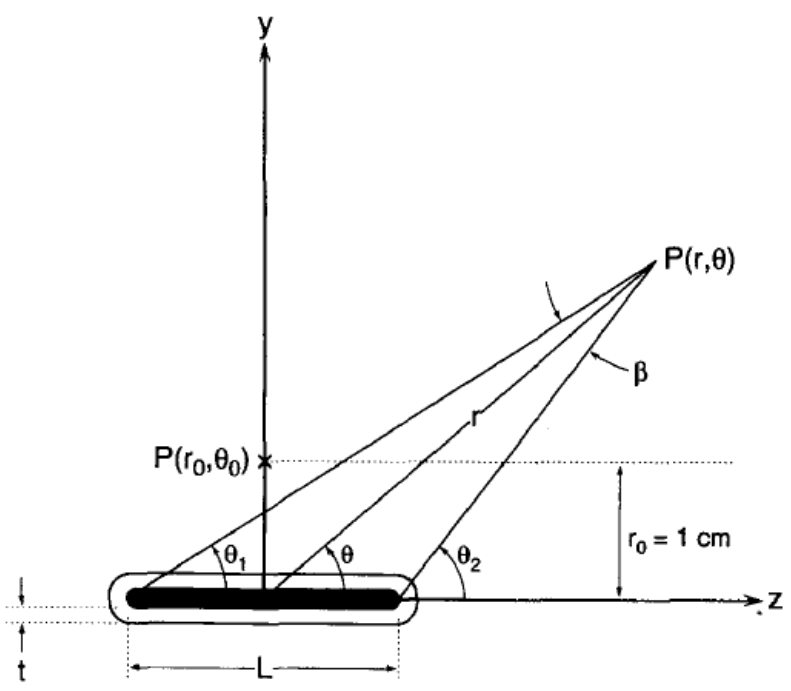

Figura 5: Sistema de coordenadas utilizado para cálculos de dosimetria em braquiterapia no protocolo TG-43 (NATH et al, 1995). 
Nesse sistema de coordenadas, L é o comprimento efetivo da fonte de braquiterapia; $\mathrm{P}(\mathrm{r}, \theta)$ é o ponto de interesse de cálculo da dose; $\mathrm{P}\left(\mathrm{r}_{0}, \theta_{0}\right)$ é o ponto de referência da dosimetria; $\beta$ é o ângulo subentendido por $\mathrm{P}(\mathrm{r}, \theta)$ entre o início e o final do comprimento efetivo da fonte.

O cálculo da taxa de dose em braquiterapia, proposto pelo TG-43, é dado pela equação (1):

$$
\dot{D}(r, \theta)=S_{K} \cdot \Lambda \cdot \frac{G_{L}(r, \theta)}{G_{L}\left(r_{0}, \theta_{0}\right)} \cdot g_{L}(r) \cdot F(r, \theta)
$$

onde $\mathrm{r}_{0}$ é a distância de referência, especificado pelo protocolo como $1 \mathrm{~cm}$ (RIVARD et $a l, 2004) ; \mathrm{r}$ é a distância do centro da fonte até o ponto de interesse (em centímetros); $\theta$ é o ângulo polar que especifica o ponto de interesse; $\theta_{0}$ é o ângulo de referência e define o plano transversal da fonte, especificado como $90^{\circ} ; \Lambda$ é a constante de taxa de dose (na água); $S_{\mathrm{K}}$ é a intensidade de kerma no ar (air-kerma strength); $G_{L}(r, \theta)$ é o fator geométrico; $g_{L}(r)$ é a função de dose radial; $F(r, \theta)$ é a função de anisotropia. Além de ser obtida experimentalmente, a taxa de dose pode ser calculada através de simulação Monte Carlo.

\subsection{2 - Intensidade de Kerma no Ar}

A calibração da fonte de braquiterapia deve ser realizada e ter rastreabilidade a laboratórios primários para que os cálculos de dose e aplicação do tratamento sejam precisas (SALVAJOLI, SOUHAMI, FARIA, 2013). Essa calibração da fonte em função da taxa de kerma no ar pode ser realizada com o auxílio de uma câmarade ionização calibrada no ar, e rastreável a um laboratório primário, ou através de uma câmara de ionização tipo poço também calibrada e rastreável a um laboratório primário (LNMRI, 2012).

Uma das grandezas utilizadas em calibração de fontes em radioterapia é a intensidade de kerma no ar. De acordo com o TG-43, a intensidade de kerma no ar é especificada em termos da taxa de kerma no ar ao longo do eixo transversal da fonte no espaço livre. A intensidade de kerma no ar é calculada através da equação (2): 


$$
S_{K}=\dot{K}(d) d^{2}
$$

onde $\mathrm{S}_{\mathrm{K}}$ é a intensidade de kerma no ar; $\dot{K}$ é a taxa de kerma no ar; $d^{2}$ é a distância calculada a partir do centro da fonte radioativa até o ponto de medida. Com relação à distância $d$ esta deverá ser grande o suficiente, para que a fonte possa ser tratada como pontual. Nesse protocolo a distância de referência para o cálculo de kerma no ar é $1 \mathrm{~m}$ (NATH et al, 1995). No Sistema Internacional, a unidade de $\mathrm{S}_{\mathrm{K}}$ é $\mathrm{Gym}^{2} \mathrm{~h}^{-1}$, fornecendo valores de taxa de kerma no ar numericamente iguais ao valor de referência da taxa de kerma no ar recomendada pelo ICRU 58 e ICRU 60 (ICRU Report 58, 1997; ICRU Report 60, 1998). A AAPM, no TG-43, define uma notação abreviada, como mostrada na equação (3):

$$
1 U=1 \mu G y m^{2}=1 c G y c m^{2} h^{-1},
$$

onde $1 \mathrm{U}$ é uma unidade de intensidade de kerma no ar.

Como $\mathrm{S}_{\mathrm{K}}$ é obtido a partir de medidas experimentais, se faz necessário uma correção quanto à atenuação e espalhamento dos fótons no ar e em qualquer outro meio próximo ao detector e a fonte, e em qualquer outro meio colocado entre o detector e a fonte (RIVARD et al, 2004; SILVA, 2010). Na primeira versão do TG-43 isso não era levado em consideração, fazendo que essa alteração fosse feita no TG-43-U1, onde a intensidade de kerma no ar passou a ser definida no vácuo, sendo denominada $\mathrm{K}_{\delta} \mathrm{e}$ definida para fótons com energia maior que a energia de corte $\delta$ (RIVARD et al, 2004). O valor da energia de corte, para fontes de braquiterapia com emissão de fótons de baixa energia é de $5 \mathrm{keV}$. A fórmula matemática utilizada para o cálculo dessa função é apresentada equação (4):

$$
S_{K}=\dot{K}_{\delta}(d) d^{2}
$$

onde $\dot{K}_{\delta}$ é a taxa de kerma de ar, definida no vácuo; $d$ é a distância do centro da fonte ao ponto de $\dot{K_{\delta}}$, no plano transversal à fonte. Pelo mesmo motivo já mencionado, esta distância deverá ser grande o suficiente se comparada com as dimensões da fonte, para que a fonte possa ser tratada como pontual. 
O ICRU 58 recomenda que a especificação de fontes de braquiterapia seja através de $\left(K_{a r}\left(\dot{d}_{r e f}\right)\right)_{a r}$ e a AAPM recomenda utilizar $S_{K}$. A relação entre essas grandezas é mostrada na equação 5 .

$$
S_{K}=d_{r e f}^{2}\left(\dot{k}_{a r}\left(d_{r e f}\right)\right)_{a r}
$$

onde $d_{r e f}$ é a distância de referência de $1 \mathrm{~m}$. Através da equação (5) é possível verificar que a diferença existente entre essas grandezas é a unidade em que a intensidade da fonte será expressa. Uma vez que se a taxa de kerma no ar de referência é, por exemplo, $1 \mu \mathrm{Gy} / \mathrm{h}$, então a intensidade que será expressa em função de intensidade de kerma no ar, será de $1 \mu \mathrm{Gym}^{2} \mathrm{~h}^{-1}$, ou ainda utilizando a recomendação da AAPM será 1U (SUNTHARALINGAM, PODGORSAK, TÖLLI, 2005)

\subsection{3 - Constante de Taxa de Dose}

A constante de taxa de dose $(\Lambda)$ inclui na sua formulação os efeitos da geometria da fonte, encapsulamento, auto-filtração e espalhamento na água em torno da fonte e seu valor numérico depende da intensidade de kerma no ar, determinado experimentalmente, bem como do material e do modelo da fonte (RIVARD et al, 2004; NATH et al, 1995). Essa grandeza é calculada através da equação (6).

$$
\Lambda=\frac{\dot{D}\left(r_{0}, \theta_{0}\right)}{S_{K}}
$$

onde $\dot{D}\left(r_{0}, \theta_{0}\right)$ representa a taxa de dose na água no ponto de referência à $1 \mathrm{~cm}$, ao longo do eixo transversal $\left(\theta_{0}=\pi / 2\right)$ e $S_{K}$ é a intensidade de kerma no ar. A unidade da constante de taxa de dose, utilizada no protocolo TG-43 é cGyh ${ }^{-1} U^{-1}$, mas devido à equação (3) ela poderá ser reduzida à $\mathrm{cm}^{-2}$.

Com o objetivo de identificar o cálculo e o padrão de calibração utilizado para determinar $\dot{D}\left(r_{0}, \theta_{0}\right)$, de acordo com o TG-43U1, a notação para a constante da taxa de dose, em 1999, passou a ser $\Lambda_{n n D, P q q S}$. Nessa notação, $n n$ é o ano em que foi calculada ou medida; $D$ é a taxa de dose de referência; $P$ é o laboratório onde foi realizada a calibração; $q q$ é o ano de calibração da fonte e $S$ denota a palavra padrão (do inglês standard) (RIVARD et al, 2004). 


\subsection{4 - Fator Geométrico}

O fator geométrico leva em consideração o efeito da distribuição do material radioativo dentro da cápsula na distribuição de dose, não contabilizando a absorção e espalhamento da radiação no encapsulamento da fonte. Fisicamente, as aproximações realizadas se baseiam na Lei do Inverso do Quadrado das distâncias para uma fonte extensa e homogênea. Nos cálculos desse parâmetro o espalhamento e a atenuação das partículas são omitidas. Esse fator permite melhorar a acurácia no cálculo da taxa de dose e poderá ser calculado através de uma estimativa, utilizando interpolação entre valores que já foram tabulados de taxas de dose em determinados pontos. (WILLIAMSON, LI, 1995; RIVARD et al, 2004; RICHTER, BAIER, FLENTJE, 2008)

As aproximações para fontes pontuais e lineares, utilizadas nos cálculos desse parâmetro, encontram-se nas equações de (7) à (9):

$$
\begin{gathered}
G_{P}(r, \theta)=r^{-2} \\
G_{L}(r, \theta)= \begin{cases}\frac{\beta}{L r \operatorname{sen} \theta}, \text { se } \theta \neq 0^{o} & \text { aproximação para fontes pontuais } \\
\left(r^{2}-L^{2} / 4\right)^{-1}, \text { se } \theta=0^{o}\end{cases}
\end{gathered}
$$

onde $\mathrm{G}_{\mathrm{P}}$ e $\mathrm{G}_{\mathrm{L}}$ são os fatores geométricos para fontes pontuais e lineares, respectivamente; $r$ é a distância do centro da fonte até a posição de interesse; L é o comprimento efetivo da fonte e $\beta$ é o ângulo (em radianos) que subentende a parte ativa da fonte com relação ao ponto de interesse $P$. De acordo com a figura 5, $\beta$ é a diferença entre $\theta_{2}$ e $\theta_{1}$ e é determinado em função de $\theta$. O TG-43 recomenda o uso do fator geométrico de fontes lineares para aproximações de distribuições de dose bidimensional e o uso do fator geométrico para fonte pontual para aproximações de distribuições de dose unidimensional.

De acordo com Nath, Meigooni e Mell (NATH, MEIGOONI E MELL, 1990), quando se deseja obter o valor do fator geométrico de uma fonte linear para pontos que estejam sob o eixo transversal, ou seja, para $\theta=\theta_{0}=\pi / 2$, o cálculo é realizado como mostrado na equação (10): 


$$
G_{L}\left(r, \theta_{0}\right)=\frac{2 t g^{-1}(L / 2 r \operatorname{sen} \theta)}{L r \operatorname{sen} \theta}
$$

Caso a fonte de braquiterapia analisada seja composta por mais de uma semente radioativa, o comprimento efetivo da fonte será dado pela equação (11):

$$
L_{e f}=\Delta S x N
$$

onde $L_{e f}$ é o comprimento efetivo da fonte; $\Delta S$ é a distância do centro de uma semente ao centro de outra semente; $N$ é o número de sementes.

\subsection{5 - Função de Dose Radial}

Essa função representa a diminuição da dose no plano transversal, levando em consideração os efeitos de absorção e espalhamento no meio desse eixo e excluindo a contribuição já considerada pela função geométrica (RICHTER, BAIER, FLENTJE, 2008). A função de dose radial é matematicamente calculada através da equação (12):

$$
g_{X}(r)=\frac{\dot{D}\left(r, \theta_{0}\right)}{\dot{D}\left(r_{0}, \theta_{0}\right)} \frac{G_{L}\left(r_{0}, \theta_{0}\right)}{G_{L}\left(r, \theta_{0}\right)},
$$

onde $\dot{D}$ é a taxa de dose e $\mathrm{G}_{\mathrm{L}}$ é o fator geométrico. Na equação (12), todos os índices denotados por "0" remetem à condição de referência e os parâmetros que não possuem índice, remetem à condição de interesse. A melhor maneira de se obter essa função é através de simulação Monte Carlo, devido à complicações experimentais em regiões muito próximas da fonte, principalmente para distâncias menores de $1 \mathrm{~cm}$.

No ponto de referência, $r_{0}=1 \mathrm{~cm}$ e $\theta_{0}=90^{\circ}$, o valor desse parâmetro dosimétrico igual é a 1 e os valores que são tabelados no TG-43 foram ajustados pela equação (13)

$$
g_{X}(r)=a_{0}+a_{1} r+a_{2} r^{2}+a_{3} r^{3}+a_{4} r^{4}+a_{5} r^{5}
$$


onde os parâmetros $a_{0}, a_{1}, a_{2}, a_{3}, a_{4}$ e $a_{5}$ são calculados através do ajuste de um polinômio de $5^{\mathrm{a}}$ ordem. Comumente, distâncias de 0,5 à $7,0 \mathrm{~cm}$ são utilizadas para $\mathrm{o}$ cálculo da função de dose radial para fontes que possuem baixa energia e de até $15 \mathrm{~cm}$ para fontes de alta energia.

\subsection{6 - Função de Anisotropia}

Essa função descreve a anisotropia da distribuição de dose em torno da fonte de radiação, incluindo efeitos de atenuação e espalhamento, descrevendo a variação da dose em função do ângulo relativo ao plano transversal. Essa função é calculada através da equação (14):

$$
F(r, \theta)=\frac{\dot{D}(r, \theta)}{\dot{D}\left(r, \theta_{0}\right)} \frac{G_{L}\left(r, \theta_{0}\right)}{G_{L}(r, \theta)}
$$

Enquanto essa função no plano transversal essa função uniforme, fora desse plano mesma é diretamente proporcional à $r$. Através de simulação Monte Carlo é possível o cálculo desse parâmetro. $\mathrm{O}$ valor dessa função diminui em determinadas situações, sendo elas: à medida que o ângulo se aproxima de $0^{\circ}$ ou $180^{\circ}$; a espessura do encapsulamento aumenta e a energia do fóton diminui (RIVARD et al, 2004). Geralmente, para tabulação da função de anisotropia, utilizam-se distâncias de $0,25 \mathrm{~cm}$ à 7,0 cm para fontes de baixa energia e de até 15,0 cm para fontes de alta energia. Para fontes que possuem simetria em relação ao eixo transversal, os ângulos para os quais são calculados esse parâmetro variam de $0^{\circ}$ à $90^{\circ}$. Porém, para fontes que são assimétricas com relação ao eixo transversal, os ângulos compreendidos para a Função de Anisotropia variam de $0^{\circ}$ à $180^{\circ}$.

\section{5 - Dosímetros Utilizados em Braquiterapia}

Atualmente, muitos sistemas dosimétricos têm sido estudados com o objetivo de determinação experimental de dose em sistemas de planejamento em radioterapia, dentre eles a câmara de ionização, dosímetros termoluminescentes (TLDs) filmes radiocrômicos e dosímetro gel polimérico (ROMANO et al, 1996; MCJURY et al, 2000; PERONI et al, 
2007; DEMPSEY, 2010; HAWORTH et al, 2013). Porém, dosimetria em braquiterapia é de grande complexidade, devido ao alto gradiente de dose em regiões muito próximas à fonte, ao tamanho dos dosímetros utilizados experimentalmente e à alta dependência energética dos mesmos (KARAISKOS et al, 1998).

Existem diversos tipos e tamanhos de câmaras de ionização para o uso em Radioterapia, tais como: tipo Farmer, poço e com placas plano-paralelas. Uma câmara de ionização do tipo Farmer é mostrada na figura 6(a). Na utilização da câmara de ionização possíveis desvantagens podem ser baixa resolução espacial e baixa sensibilidade As medidas obtidas através desse tipo de instrumento são pontuais. Na dosimetria de feixes de fótons de alta energia normalmente são recomendadas a utilização de câmara de ionização tipo cilíndrica na dosimetria de referência (TRS 398, 2001). Quando esse dosímetro é utilizado, devem ser empregados alguns fatores de correção, tais como: fator de calibração, correção para polarização, recombinação e diferença de energia com que o dosímetro foi calibrado.

Os TLDs também podem utilizados para a obtenção de doses relativas ou absolutas, para fontes de braquiterapia com emissão de fótons de baixa energia. $\mathrm{O}$ mais comum é a utilização de Fluoreto de Lítio (LiF) para a medição de dose, já que esse possui baixa dependência energética (KISIELEWICZ et al, 2010). Na figura 6(b) são apresentados alguns dosímetros termoluminescentes. Quando esse dosímetros são utilizados com fótons de energia menor que $100 \mathrm{keV}$, devem ser realizadas correções nas respostas, já que os mesmos não são equivalentes à água nessa energia (ICRU 72, 2004). A vantagem desses dosímetros é que vários deles podem ser expostos, simultaneamente, além de serem pequenos. Uma desvantagem é o desaparecimento do sinal após a leitura. Assim como para a câmara de ionização, as informações fornecidas pelos TLDs são unidimensionais, além de serem dosímetros inapropriados para medidas em pequenas distâncias da fonte radioativa da fonte radioativa devido ao seu tamanho (na ordem de milímetros).

Outra alternativa para medidas experimentais em braquiterapia é o uso de filmes radiocrômicos (RCF, do inglês Radiochromic Film), que permitem medidas bidimensionais, sendo o mais comumente utilizado o GafChromic, como mostrado na figura $8 \mathrm{c}$.

O filme mostrado na figura 6(c), foi utilizado na dosimetria da fonte de ${ }^{192} \mathrm{Ir}$ do Hospital das Clínicas da Faculdade de Medicina de Ribeirão Preto (HCFMRP), quando houve a troca dessa fonte de braquiterapia. É possível notar que quando irradiado, a 
coloração do filme é alterada devido a um corante que é polimerizado (MARTISKIKOVÁ, JÄKEL, 2010). Esse tipo de filme possui alta resolução espacial, sendo maior que 1200 linhas por milímetro (SCHUMER et al, 1999); é equivalente em água para fótons com energia maior que $100 \mathrm{keV}$ (NIROOMAND-RAD et al, 1998); possui um número atômico baixo e espessura fina, aproximadamente 0,26 $\mathrm{mm}$ (KLASSEN et al, 1997); não depende da taxa de dose, podendo ser utilizado para dosimetria em regiões de alto gradiente de dose (ICRU 72, 2004).

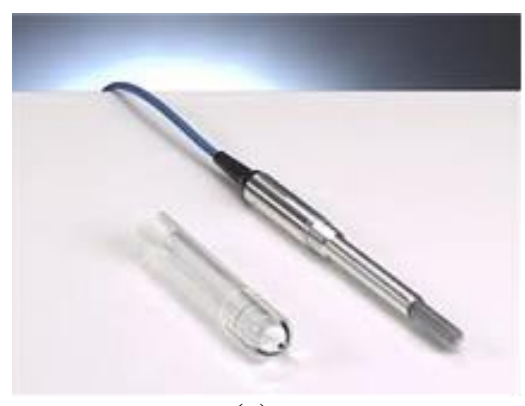

(a)

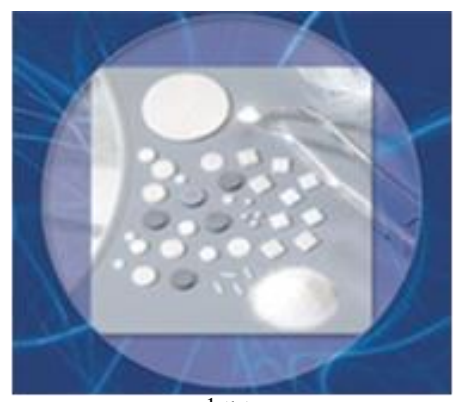

${ }^{1}(\mathrm{~b})$

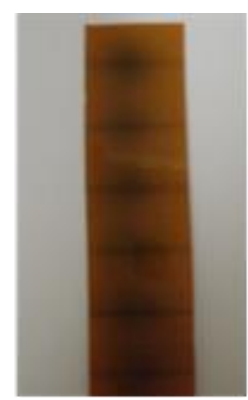

(c)

Figura 6: Tipos de dosímetros utilizados em Radioterapia (a) Câmara de ionização Tipo Farmer; (b) Dosímetros Termoluminescentes (1) Retirados a partir de (http://www.radpro-int.com/dosimeters); (c) Filme radiocrômico.

Embora cada dosímetro apresentado até agora possua vantagens particulares, esses não conseguem cumprir, simultaneamente, condições chamadas "ideais" para um dosímetro em Radioterapia, que são elas: possuir baixa dependência energética; ser capazes de obter distribuição de dose tridimensional e a possibilidade do uso em regiões que possuam valores de alto gradiente de dose.

Com isso, a dosimetria gel polimérica tem ganhado um grande destaque nessas aplicações, visto que possui uma alta sensibilidade e resolução espacial, proporcionando uma distribuição de dose tridimensional (WONG et al, 2007). Trata-se de um dosímetro tecido-equivalente, não-dependente da energia para elétrons e fótons de baixa energia (BALDOCK et al, 2010) e exibe uma dependência energética muito pequena em altas energias (WONG et al 2007). Na figura 7 é apresentado um objeto simulador contendo gel polimérico. 


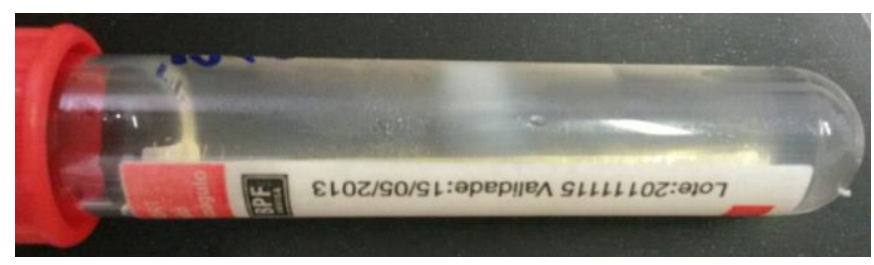

Figura 7: Dosímetro gel polimérico

Na figura 7 , nota-se uma região próxima ao centro do objeto simulador, mais esbranquiçada, que é devido à polimerização iniciada na irradiação do gel.

\section{6 - Dosimetria Gel Polimérica}

A utilização de gel polimérico em técnicas dosimétricas vem sendo estudada desde a década de 1950, começando com a investigação de Day e Stein. Esses pesquisadores analisavam o gel que continha o Fenol de Folin e quais eram as mudanças químicas que a radiação produzia no gel, observando a mudança da sua coloração após a irradiação (DAY, STEIN, 1950). Ainda na década de 50, foram estudados sistemas poliméricos de polimetacrilato com o objetivo de utilizá-los em dosimetria de radiação, analisando os efeitos da radiação ionizante no composto (ALEXANDER et al, 1954). No mesmo período, Hoecker e Watkins avançaram no estudo da polimerização em líquidos a partir da irradiação (HOECKER E WATKINS, 1958).

Outro composto proposto por Day foi a utilização de soluções e gel Fricke, nas medidas de distribuições de dose em aplicações de radioterapia e radiocirurgia estereotáxica (DAY, 1990; LOW et al, 1993). Esse gel é uma solução que contém íons ferrosos $\left(\mathrm{Fe}^{2+}\right)$ que, expostos à radiação ionizante, oxidam-se, transformando-se em íons férricos $\left(\mathrm{Fe}^{3+}\right)$, produzindo um sinal no dosímetro. A leitura do mesmo pode ser feita através de Imagens de Ressonância Magnética (do inglês Magnetic Resonance Imaging, MRI), mas sua resolução espacial é limitada devido a difusão de $\left(\mathrm{Fe}^{3+}\right)$ no gel (BALCOM et al, 1995).

Na década de 1990, foi estudado o gel polimérico BANANA (do inglês, Bis Acrylamide Nitrous oxide ANd Agarose), composto de Bis-Acrilamida e Agarose e que poderia ser usado como dosímetro (MARYANSKI et al, 1993). Logo após, estudos mostraram que a agarose poderia ser substituída por gelatina. A partir dessa mudança, o 
gel passou a ser chamado BANG (do inglês, Bis Acrylamide Nitrogen and Gelatin) (MARYANSKI et al, 1994).

O uso desses géis poliméricos deu origem a um novo método de dosimetria proposto, com a utilização de um gel polimérico onde os monômeros estão dispersos na matriz gelatinosa e é possível obter as informações de dose em três dimensões (MARYANSKI et al, 1996; KAWAMURA et al, 2013). Para isso, muitos géis poliméricos têm sido estudados para medidas de distribuições de dose e aplicações em radioterapia (TURONOK et al, 2013; VANDECASTEELE, DE DEENE, 2013c; HASSANI, 2014). Porém, o que impede a aplicação desses dosímetros na clínica é a manipulação experimental dos componentes, uma vez que é necessária uma quantidade muito pequena de oxigênio durante a sua manufatura até o momento de estocagem.

Um novo tipo de formulação de gel polimérico foi proposto, onde a manufatura era permitida em condições atmosféricas ambientes (normóxico) e os monômeros se encontram na matriz gelatinosa. Esse novo gel, composto de Água Milli-Q, Gelatina, Sulfato de Cobre, Ácido Ascórbico e Ácido Metacrílico, foi denominado MAGIC (do inglês Methacrylic and Ascorbic acid in Gelatin Initiated by Copper) (FONG et al, 2001) Nesse material o Sulfato de Cobre juntamente com o Ácido Ascórbico, se ligam ao oxigênio da solução, suprimindo o efeito do oxigênio na polimerização (DE DEENE et al, 2002; PAVONI, 2009).

O gel utilizado nesse trabalho é o MAGIC-f (do inglês Methacrylic Ascorbic Acid and Gelatine Initiated by Cooper Solution with formaldehyde), que possui a mesma composição do MAGIC, porém acrescido de Formaldeído, com o intuito de fornecer a estabilidade mecânica para o gel e alterando seu ponto de fusão para $69^{\circ} \mathrm{C}$ (FERNANDES et al, 2008; PAVONI et al, 2010).

Esse gel possui diversas vantagens com relação aos outros já estudados, tais como: supressão do oxigênio pelo ácido ascórbico, resultando em um gel polimérico com vantagens práticas para possíveis aplicações na clínica; menor toxicidade, devido à presença da Hidroquinona (quando utilizada em alguns testes ou formulações específicas) e do Ácido Metacrílico; alta resolução espacial e sensibilidade, sendo o capaz de proporcionar uma distribuição de dose tridimensional (DEENE et al 1998, CARTHWRIGHT, 2010). Os componentes e o processo para a fabricação do mesmo, são mostrados na figura 8 . 


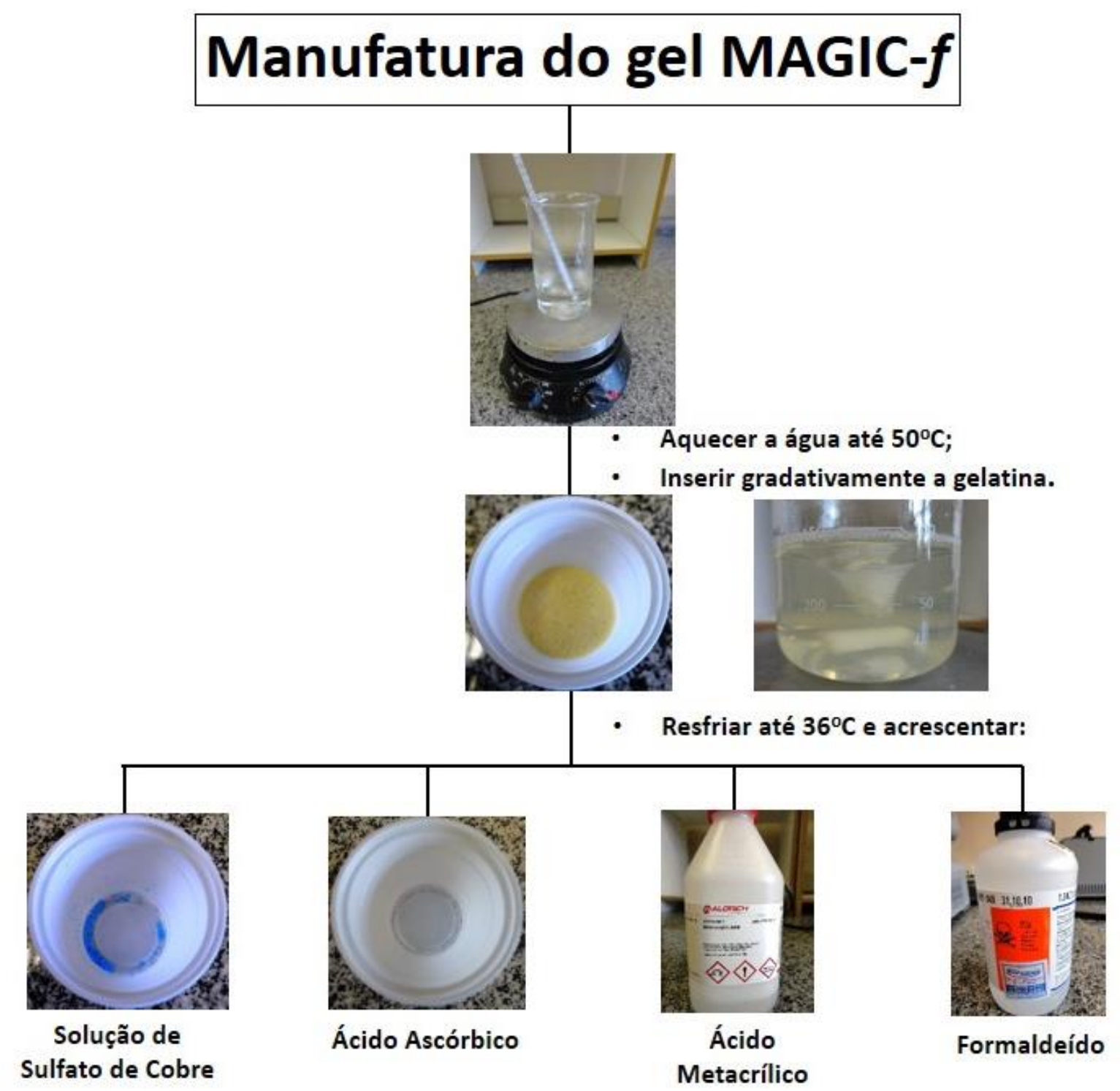

Figura 8: Processo esquemático dos componentes e métodos utilizados na fabricação do gel MAGIC- $f$.

A manufatura desse gel não é complexa e os componentes e suas quantidades para uma solução de $100 \mathrm{ml}$ do gel polimérico, são mostrados na tabela 1 .

Tabela 1: Componentes e suas respectivas quantidades para a manufatura do gel MAGIC- $f$ para uma receita de $100 \mathrm{ml}$.

\begin{tabular}{ll}
\hline Quantidade & Componente \\
\hline $8,2 \mathrm{~g}$ & Gelatina \\
\hline $84 \mathrm{ml}$ & Água Milli-Q \\
\hline $2 \mathrm{ml}$ solução & $\left\{\begin{array}{l}100 \mathrm{ml} \text { Água Milli-Q } \\
100 \mathrm{ml} \mathrm{CuSO}_{4} 5 \mathrm{H}_{2} \mathrm{O}\end{array}\right.$ \\
\hline $35,2 \mathrm{mg}$ & Ácido Ascórbico \\
\hline $5,9 \mathrm{ml}$ & Ácido Metacrílico \\
\hline $3 \mathrm{ml}$ & Formaldeído \\
\hline
\end{tabular}


Na manufatura do gel, primeiramente, água foi colocada em um béquer e aquecida até a temperatura de $50^{\circ} \mathrm{C}$. Quando essa temperatura foi atingida, acrescentou-se gradativamente a gelatina. Após finalizar o polvilhamento da gelatina, a solução foi resfriada à $36^{\circ} \mathrm{C}$ e, então, o restante dos componentes foi acrescentado. A ordem do restante dos componentes foi sempre respeitada, na seguinte sequência: Solução de Sulfato de Cobre, Ácido Ascórbico, Ácido Metacrílico e Formol. Finalizada a manufatura do gel, o mesmo foi inserido em objetos simuladores e colocados na geladeira. Os objetos simuladores utilizados foram tubos Vacutainer ${ }^{\circledR}$ e recipientes cúbicos. Quando o gel foi inserido no objeto simulador, uma camada de filme plástico de PVC foi colocada na superfície do gel antes do fechamento do mesmo, para evitar o contato do oxigênio com o gel. O gel foi estocado até o momento das irradiações em uma geladeira à $10^{\circ} \mathrm{C}$ e, para o transporte dos objetos simuladores para a irradiação e para as leituras de ressonância, foi utilizada uma caixa térmica, para que o mesmo não derretesse.

\subsection{1 - Resposta do Gel MAGIC-f após a irradiação}

Como já foi mencionado na tabela 1 , o gel MAGIC- $f$ é formado na sua grande maioria, aproximadamente $90 \%$, de água. A partir do instante em que o gel é irradiado são formados radicais livres $(\mathrm{H}$ e $\mathrm{OH})$ através da dissociação das moléculas da água, ocorre a chamada radiólise (BUSHONG, 1993). As equações (15) à (18) retratam esse processo:

$$
\begin{gathered}
\mathrm{H}_{2} \mathrm{O} \rightarrow \mathrm{H}_{2} \mathrm{O}^{+}+e^{-} \\
\mathrm{H}_{2} \mathrm{O}^{+}+\mathrm{H}_{2} \mathrm{O} \rightarrow \mathrm{H}_{3} \mathrm{O}^{+}+\mathrm{OH}^{-} \\
\mathrm{H}_{3} \mathrm{O}^{+}+e^{-} \rightarrow \mathrm{H}^{+}+\mathrm{H}_{2} \mathrm{O} \\
e^{-}+\mathrm{H}_{2} \mathrm{O}^{+} \rightarrow \mathrm{H}^{+}+\mathrm{OH}^{-}
\end{gathered}
$$

As equações (15) à (18) podem ser sintetizadas através da equação (19):

$$
\mathrm{H}_{2} \mathrm{O} \underset{K_{d}}{\rightarrow} 2 R^{\bullet}
$$


onde $\mathrm{K}_{\mathrm{d}}$ é denominada taxa de reação e é proporcional ao valor da dose recebida. A partir do momento em que o gel é irradiado, inicia-se o processo de polimerização (MCJURY et al, 2000). Com o passar do tempo, os polímeros interagem com outros monômeros que estão alocados no gel, aumentando o tamanho da sua cadeia. A equação (20) representa esse crescimento:

$$
R M_{n}^{\bullet}+M_{n} \underset{K_{p}}{\rightarrow} R M_{m+n}^{\bullet}
$$

onde $\mathrm{R}$ é o radical, $\mathrm{M}$ é o monômero radical, $\mathrm{K}_{\mathrm{p}}$ é a taxa de crescimento do polímero. Porém se na solução já existe a formação de polímeros, ou seja para $\mathrm{M}_{\mathrm{n}}$ com $\mathrm{n}>1$, haverá a formação de um polímero radical, onde a ligação dupla (presente no Ácido Metacrílico) será o alvo das ligações dos monômeros radicais (PAVONI, 2009).

A polimerização será finalizada quando dois radicais se combinarem, como mostrado na equação (21):

$$
R^{\bullet}+R^{\bullet} \rightarrow R R=I,
$$

onde I é uma molécula iniciadora estável.

Os radicais monomérico ou polimérico também podem reagir, como mostrado na equação (22):

$$
R M_{m}^{\bullet}+R M_{n}^{\bullet} \rightarrow I+M_{m+n}
$$

Como é possível observar os produtos dessas reação são um polímero estável e uma molécula iniciadora. A formação de peróxidos a partir da radiólise, ligando-se a outros radicais, pode ser uma razão finalização do processo de polimerização. Essa formação de peróxido se dá na presença de oxigênio, por isso é preciso evitar a presença do mesmo no gel polimérico. 


\subsection{2 - Leitura das Amostras por Ressonância}

A partir do momento em que o gel é irradiado, como já mencionado, é iniciado o processo da polimerização. Esse processo é proporcional ao valor da dose depositada, sendo possível observá-la visualmente, através de uma região esbranquiçada no gel (MCJURY et al, 2000). Essa mudança visual representa uma modificação da matriz do material, podendo ser quantificada através da aquisição das Imagens de Ressonância Magnética (do inglês Magnetic Resonance Imaging) (CHO et al, 2010), de tomografias computadorizadas (JOHNSTON et al, 2012; QIAN et al, 2013) e por ultrassom (KHOEI et al, 2013).

Quando o gel é irradiado, o movimento da água ao redor das cadeias poliméricas é alterado, consequentemente modificando o movimento dos prótons presentes na molécula da água. Em imagem por ressonância magnética nuclear, o sinal de um pixel da imagem pode ser relacionado ao tempo de relaxação transversal, T2, dos prótons da amostra, através da equação (23):

$$
S \propto e^{\frac{-t}{T 2}} \cdot e^{i w t}
$$

onde $S$ é o valor do sinal da ressonância, $t$ o tempo de repetição dos pulsos de excitação na aquisição da imagem. Conforme o aumento do valor da dose depositada, devido à diminuição do movimento dos prótons, a intensidade do sinal obtido nas imagens de ressonância magnética nuclear também diminui (PETROKOKKINOS, 2009; DE DEENE, 2013).

O sinal da ressonância também pode ser relacionado com o tempo ao eco da sequência de imagem utilizada e com a taxa de relaxação transversal, R2 (DE DEENE et $a l, 1998)$. Essa relação é mostrada na equação 24:

$$
\ln (S) \alpha T E . R 2
$$

onde $T E$ é o tempo ao eco da sequência de imagem.

Utilizando-se uma sequência de aquisição com um valor de tempo ao eco prédefinido, é possível calcular a intensidade do sinal pixel a pixel, determinando o valor de R2 e possibilitando o cálculo da dose mediante uma curva de calibração (DE DEENE, 
1998; KIRASEK, HILTS, MCAULEY, 2010; KIRASEK, HILTS, 2014). Dessa forma, através da ressonância magnética nuclear, pode-se quantificar a distribuição de dose nos objetos simuladores irradiados.

Neste trabalho, as leituras das amostras foram feitas através de imagens de ressonância magnética, no tomógrafo RMN Philips 3.0 T, no HCFMRP. O tomógrafo no qual foram realizadas as leituras das amostras é mostrado na figura 9.

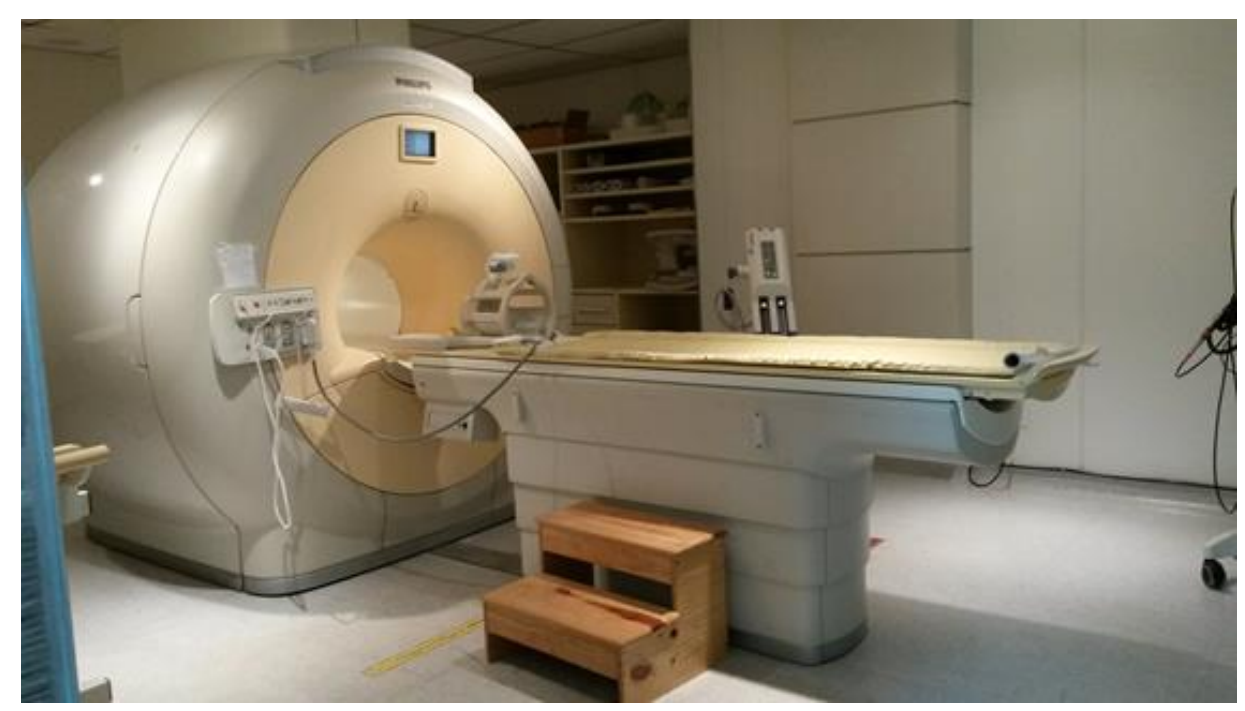

Figura 9: Tomógrafo RMN Philips 3.0 T, do HCFMRP, onde foram realizadas as leituras das amostras.

As medidas foram feitas usando relaxometria em T2 em uma bobina de cabeça. Foi utilizada uma sequência multi spin-eco com 16 ecos, com tempo de repetição (TR) de $6000 \mathrm{~ms}$. Durante a leitura dos objetos simuladores, estes foram inseridos em uma caixa de acrílico com dimensões de $18 \mathrm{~cm}$ x $11 \mathrm{~cm}$ x $10 \mathrm{~cm}$, com capacidade de 50 tubos. A fim de minimizar o efeito da diferença de susceptibilidade magnética em relação ao ar, essa caixa foi preenchida com uma solução de $0,3 \%$ de $\mathrm{MnCl}_{4} \mathrm{H}_{2} \mathrm{O}$ e $0,2 \%$ de $\mathrm{NaCl}$.

A espessura das fatias para a aquisição das imagens de MRI variou de $2 \mathrm{~mm}$ à $4 \mathrm{~mm}$ (dependendo do experimento). As matrizes das imagens eram compostas de $256 \mathrm{x}$ 256 (pixels), possuindo extensão no formato DICOM. Com um programa desenvolvido pelo grupo de pesquisa na plataforma MATLAB ${ }^{\circledR}$, foi possível obter os mapas de R2, pixel a pixel. Esse programa desenvolvido carrega cada imagem obtida na ressonância magnética, juntamente com seus TE, calculando o logaritmo natural do sinal $[\mathrm{S}(\mathrm{t})]$. 


\section{7 - Índice Gama}

Trata-se de um método que compara de maneira quantitativa duas distribuições de dose ponto a ponto (STATHAKIS et al, 2014), onde uma distribuição é utilizada como referência e a outra será avaliada. Esse método foi primeiramente proposto por Low e colaboradores (LOW et al, 1998) e utiliza dois critérios nas comparações: um com relação à distância de concordância entre o mesmo valor de dose das duas distribuiçõoes e outro com relação à diferença de dose ponto a ponto. O critério com relação à distância é denominado DTA (do inglês, distance-to-agreement) e o referente à diferença de dose recebe o nome de DD (do inglês, dose difference). O Índice Gama é calculado através da equação (25):

$$
\Gamma\left(\boldsymbol{r}_{m}, \boldsymbol{r}_{c}\right)=\sqrt{\frac{r^{2}\left(r_{m}, r_{c}\right)}{\Delta d_{M}^{2}}+\frac{\delta^{2}\left(r_{m}, r_{c}\right)}{\Delta D_{M}^{2}}},
$$

onde $r\left(r_{m}, r\right)=\left|r-r_{m}\right|$, em que $r_{m}$ é o ponto da distribuição avaliada; $\delta\left(r_{m}, r\right)=D(r)-D_{m}\left(r_{m}\right)$ é a diferença de dose entre as posições de $r$ e $r_{m} ; \Delta D_{M}^{2}$ é o DD e $\Delta d_{M}^{2}$ é o DTA.

Toda vez que o valor do Índice Gama for menor ou igual a um significa que os pontos que foram avaliados concordam dentro de tolerâncias estabelecidas para os valores de DD e DTA. Porém, se o valor for maior que 1, significa que o ponto avaliado nas duas distribuições ultrapassaram a tolerância que foi estipulada. Desta forma, o índice gama com valores menores ou igual a um, representam distribuições compatíveis dentro da tolerância e índice gama maior que um representam distribuições de dose diferentes. Em Radioterapia as tolerâncias comumente utilizadas são 3\% e 3 mm (ALI et al, 2011).

\section{8 - Método Monte Carlo}

O Método Monte Carlo (MMC), criado na década de 1940, é de um método numérico que utiliza uma sequência de números aleatórios para a realização de simulações em diversas áreas e aplicações, tais como: economia, engenharia, ciências físicas e biológicas (KALOS, WHITLOCK, 1986; MURPHY, 2004; GOULD, 
TOBOCHNIK, CHRISTIAN, 2006; RIVARD et al, 2010; MODE, 2011; CANDELAJUAN et al, 2013). Nessas simulações é observado o comportamento de um número grande de eventos individuais e, quanto maior o número de partículas simuladas, menor é a incerteza da estimativa da grandeza de interesse. Portanto, como a incerteza da grandeza determinada está relacionada com o número de eventos simulados, uma desvantagem do método pode ser o tempo para a realização das simulações (KALOS, WHITLOCK, 1986).

Especificamente no uso do método Monte Carlo para o transporte de radiação em um material e seu uso em Radioterapia, o interesse pode ser a determinação de parâmetros dosimétricos, a análise do espectro de uma fonte radioativa, o cálculo da dose absorvida em um determinado órgão, entre outros (ROGERS, 2006; RIVARD et al 2010; CANDELA-JUAN et al, 2013; WOOTEN et al, 2014).

No fenômeno do transporte da radiação com a matéria cada interação é tratada como um evento probabilístico, onde cada partícula pode interagir gerando radiação secundária, espalhando radiação ou depositando energia no sistema. Desta forma, a cascata de eventos de interação de cada partícula, degrada sucessivamente o valor da energia da partícula, até que essa seja totalmente absorvida e uma nova partícula primária seja simulada (SALVAT, FERNÁNDEZ-VAREA, SEMPAU, 2009).

Para fótons na faixa de energia de interesse em Radioterapia, os principais processos de interação da radiação com a matéria são: efeito fotoelétrico, espalhamento incoerente (Compton) e produção de pares. No caso da produção de pares e efeito fotoelétrico há transferência da energia do fóton para a matéria, enquanto no espalhamento incoerente há transferência de parte dessa energia para o meio, espalhando um fóton com a energia residual. Em materiais tecido-equivalente e energias utilizadas clinicamente em Radioterapia, os processos predominantes são o efeito fotoelétrico e espalhamento incoerente. Porém, à medida que os valores de energia e número atômico (Z) crescem, a produção de pares passa a ser um efeito dominante no processo (JOHNS, CUNNINGHAM, 1983; ATTIX, 1991).

Atualmente, existem diversos pacotes para a realização de simulações computacionais para aplicações em Radioterapia, tais como: PENELOPE (SEMPAU, 2003), EGS (LOVE, LEWIS, AL-AFFAN, 1998), MCNP (FOSTER, 2004), GEANT (CHAMPION et al, 2014). Esses pacotes têm sido extensamente comparados entre si com o intuito de analisar a qualidade de seus resultados em cálculos de dose absorvida (YE et al, 2004; CHIAVASSA et al, 2005; YORIYAZ, 2009; KOIVUNORO, 2012). 


\subsection{1 - PENELOPE}

O pacote de Simulação Monte Carlo PENELOPE (do inglês, PENetration and Energy LOss of Positrons and Electrons), que foi utilizado nesse trabalho, é distribuído gratuitamente pela Agência de Energia Nuclear (Nuclear Energy Agency) e engloba diversos códigos computacionais escritos em FORTRAN 77 (CRD, 2002; LLOVET et al, 2005; SALVAT et al, 2006;). O pacote simula o transporte de elétrons, fótons e pósitrons em materiais arbitrários e possibilita a utilização de valores de energia de $100 \mathrm{eV}$ à $1 \mathrm{GeV}$, em geometrias e materiais definidos pelo usuário (SEMPAU et al, 2003). O PENELOPE possui um banco de dados de seções de choque para materiais envolvendo elementos de números atômicos de 1 à 92 , e outros 180 compostos e misturas de interesse em Física Radiológica.

Uma particularidade desse código é a implementação de um algoritmo de transporte de partículas carregadas, denominado classe II ou algoritmo misto (SATIF 4, 1998). No caso das partículas amostradas serem fótons, a simulação é feita de forma detalhada. Porém, quando é realizada simulação de elétrons ou pósitrons, a simulação é feita através do processo misto, com a simulação detalhada no caso de eventos de interação fortes ou condensada para os espalhamentos fracos. No caso da simulação ser detalhada, o ângulo de espalhamento e a perda de energia são utilizados para o transporte de cada passo individual da partícula. Na forma condensada, um grande número de interações fracas serão agrupadas em um só evento, existindo a chance do aparecimento de erros nas grandezas calculadas devido à condensão (SALVAT, FERNÁNDEZVAREA, SEMPAU, 2009).

\subsubsection{1 - Estrutura do Código}

Na figura 10 é mostrada a estrutura do pacote de simulação PENELOPE, utilizado nesse trabalho. O pacote é composto de cinco diretórios principais e os mesmos são compostos por outros subdiretórios.

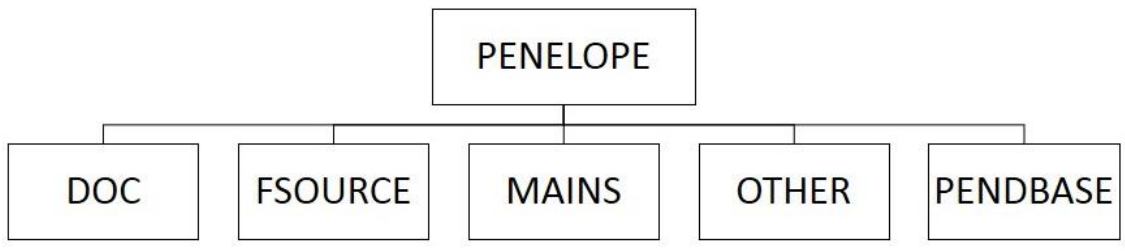

Figura 10: Estrutura do pacote de simulação Monte Carlo PENELOPE. 
No diretório DOC encontram-se arquivos de informações destinadas ao usuário, como o manual do pacote. Neste manual estão contidas informações a respeito do código, entre elas: conceitos básicos de simulação Monte Carlo, interações de fótons, interações e mecanismos de transporte de elétrons e pósitrons, construções das geometrias, estrutura e operação do código. No capítulo de conceitos básicos são abrangidos conceitos de teoria de probabilidade, integração por Monte Carlo, transporte de radiação, incertezas estatística, redução de variância. No segundo capítulo do manual são abordados temas com respeito às interações de fótons, detalhando a implementação do efeito fotoelétrico, espalhamento Coerente e Incoerente, produção de pares e coeficientes de atenuação. Da mesma forma, no capítulo três as interações de elétrons e pósitrons são abrangidas, detalhando a implementação de colisões elásticas e inelásticas, emissão de Bremsstrahlung e aniquilação de pósitron. No capítulo cinco, que se refere à construção das geometrias utilizadas nas simulações, são mostrados detalhes de eixos de coordenadas, rotação e translação nesses eixos, exemplos e equações que formam as superfícies quádricas, utilizadas nas implementações realizadas pelo usuário. No último do manual, é evidenciada a estrutura e a forma de operação do pacote PENELOPE, sendo descritas as funções, variáveis e os conceitos necessários nas simulações, seguida de exemplos dos programas principais utilizados no código, que são apresentados no diretório FSOURCE.

\section{Diretório FSOURCE}

O diretório FSOURCE possui os códigos fontes do pacote PENELOPE, conforme mostrado na figura 11.

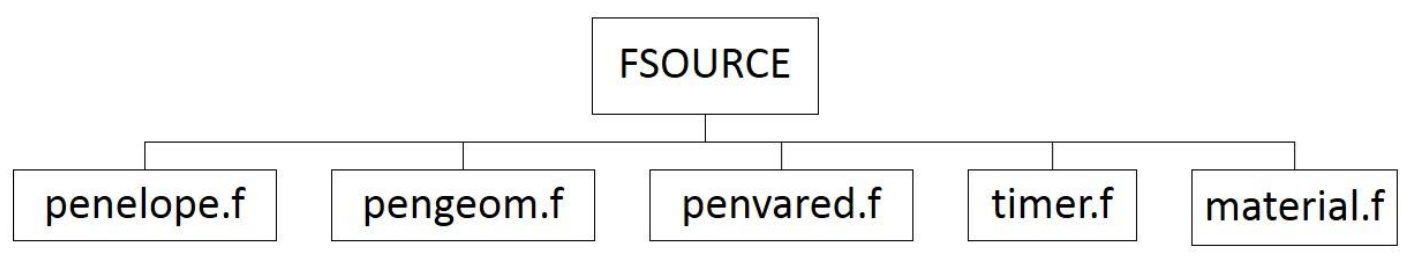

Figura 11: Códigos fonte do subdiretório FSOURCE.

No código fonte penelope.f são definidas as sub-rotinas que executam as simulações responsáveis pelo transporte das partículas e rotinas numéricas. Essas subrotinas representam o modelo físico do transporte da radiação implementado pelo pacote, 
definindo portanto a exatidão do código. No código pengeom. $f$ estão as sub-rotinas que são responsáveis por controlar a geometria de cada simulação realizada. As sub-rotinas que contém técnica de redução variacional, compõe o penvared.f. $\mathrm{O}$ código timer.f são responsáveis por controlar o tempo da simulação. O programa denominado material.f, também é fornecido juntamente com o pacote, sendo responsável por gerar os arquivos de dados das seções de choque de cada material utilizado nas simulações.

Um programa principal é necessário para coordenar as sub-rotinas dos programas apresentados e gerar um arquivo executável da simulação. Alguns exemplos que compõe o diretório MAINS são mostrados a seguir.

\section{Diretório MAINS}

Na figura 12 são mostrados os subdiretórios e arquivos necessários para a compilação dos mesmos, referentes ao diretório MAINS.

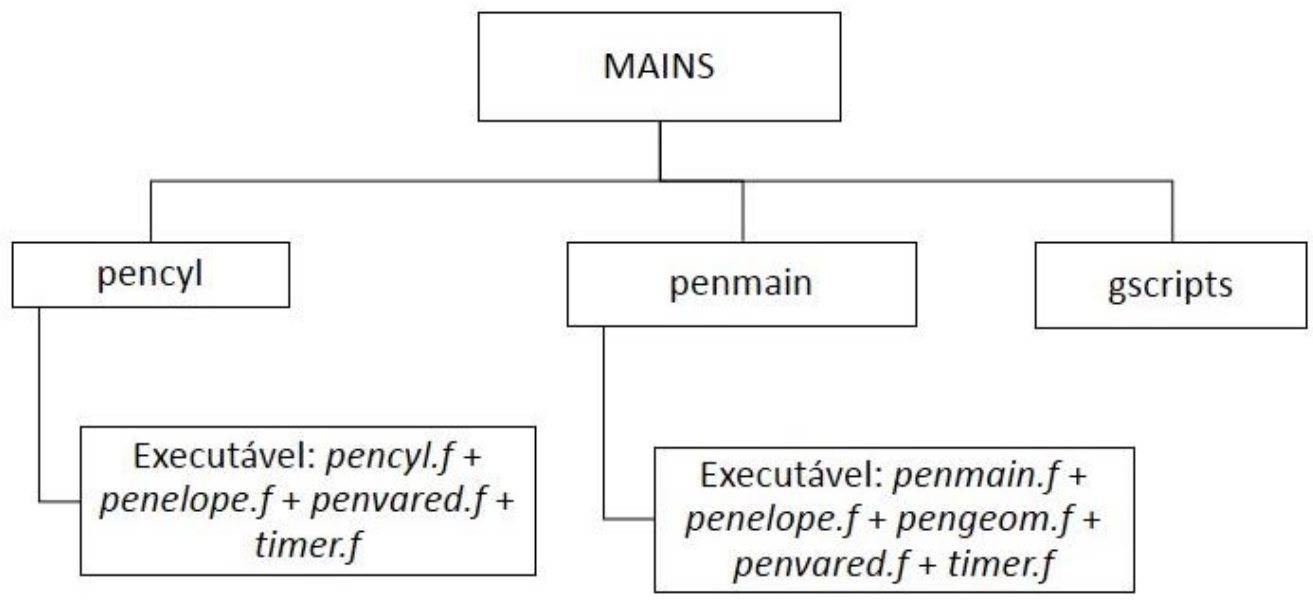

Figura 12: Códigos fonte do subdiretório MAINS.

O código pencyl é específico para aplicações de transporte de elétrons e fótons em superfícies cilíndricas. Ele é bastante utilizado no estudo de câmaras de ionização planares, detectores de cintilação cilíndricos e detectores de estado sólido. No código penmain estão contidas as informações referentes ao transporte de partículas em geometrias quadráticas, permitindo simulações em aplicações mais gerais. Nesses dois códigos são gerados arquivos de saída, com informações detalhadas da simulação, tais como: número de partículas simuladas, velocidade da simulação (número de partículas por segundo), média de energia depositada em cada corpo, entre outras informações 
especificadas pelo usuário. O subdiretório gscripts, contém as distribuições geradas por pencyl e penmain.

O arquivo executável da simulação, utilizando o pencyl ou penmain, é obtido compilando um desses códigos com os arquivos: pencyl.f, penelope.f, penvared.f e timer.f. Esse arquivo executável receberá informações da geometria, da fonte e dos materiais utilizados para compor uma simulação.

\section{Diretório OTHER}

O diretório OTHER, contém códigos complementares para aplicações específicas, bem como aplicativos complementares de visualização, como mostrados na figura 13.

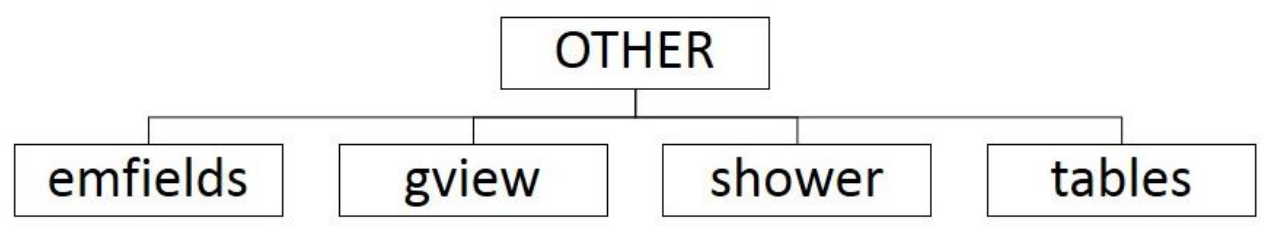

Figura 13: Estrutura referente ao diretório OTHER.

No subdiretório emfields está contido o código de sub-rotinas penfield.f, cuja função é simular o transporte de elétrons ou pósitrons quando estão sob influência de campo magnetoestático ou eletrostático (externos). Em gview estão contidos os aplicativos GVIEW2D e GVIEW3D, que são os visualizadores bidimensionais e tridimensionais, respectivamente, das geometrias utilizadas nas simulações. O aplicativo shower.exe ilustra o transporte da radiação de forma didática, mostrando na tela a trajetória de elétrons e fótons. No subdiretório tables está o programa tables.f, cuja função é gerar as tabelas com os dados de interações, como por exemplo os valores de seções de choque e stopping powers restritos para um determinado material. 


\section{Diretório PENDBASE}

No diretório PENDBASE está o subdiretório pdfiles, que contém a base de dados das probabilidades de interação para os materiais de número atômico de 1 à 92, prédefinidos pelo código, e outros 180 materiais de interesse dosimétrico. Caso o usuário deseje utilizar algum composto que não esteja no banco de dados do PENELOPE, o usuário tem a opção de montar esse composto, utilizando o arquivo material.exe. Para construir esse arquivo, o usuário deverá fornecer algumas informações referentes à composição química do material (elementos, índice estequiométrico ou fração de peso de cada elemento) e a densidade de massa de cada material.

\subsubsection{2 - Estrutura do Programa}

Os códigos penelope.f, pengeom. $f$, penvared.f e timer.f possuem o objetivo de controlar a simulação a ser realizada. Para iniciar a simulação, o usuário deverá criar um arquivo executável, comumente chamado de usuario.exe. Esse arquivo executável será criado a partir da edição de um arquivo FORTRAN, usuario.f, juntamente com os arquivos que controlam a simulação. Na figura 14, é mostrada um esquema da criação desse arquivo executável.

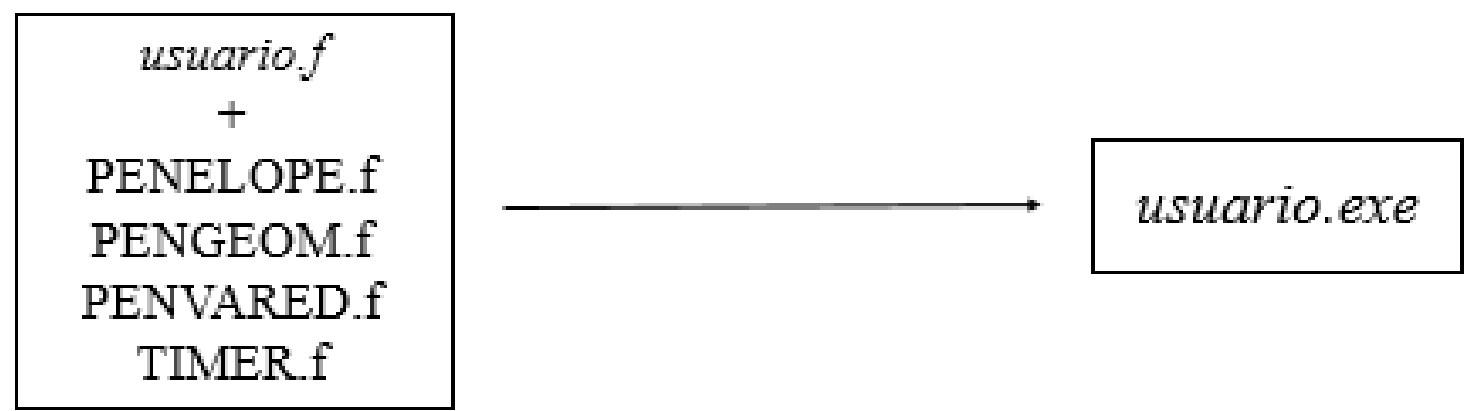

Figura 14: Arquivos necessários para a criação do arquivo executável usuario.exe. (PIANOSCHI, 2008)

Para iniciar uma simulação, o usuário necessita do arquivo executável criado usuario.exe, do arquivo dos parâmetros da simulação, entrada.in, do arquivo da geometria, geometria.geo e do arquivo dos materiais envolvidos na simulação, 
material.mat. Finalizada a simulação é gerado um arquivo que contém as informações de saída escolhidas pelo usuário, denominado penmain.dat. Dentre essas informações, podem estar contido o espectro de partículas que entram ou saem de um determinado corpo, o número de partículas transmitidas, a dose depositada, bem como suas incertezas.

\section{Parâmetros de Entrada da Simulação}

No arquivo entrada.in, o usuário definirá diversas características da simulação, tais como: o tipo de partícula do feixe primário (elétron, fóton ou pósitron), o tipo da fonte (extensa, cônica ou puntual), o espectro de energia da fonte e as suas respectivas probabilidades, dentre outras informações. No ANEXO I (Arquivo entrada.in) é apresentado um modelo da estrutura desse arquivo utilizado nas simulações. As informações mais importantes desse arquivo são mostrados na tabela 2.

Tabela 2: Variáveis de entrada das simulações e suas respectivas funções.

\begin{tabular}{ll}
\hline Variáveis & \multicolumn{1}{c}{ Função } \\
\hline KPAR & Tipo de partícula primária (elétron, fóton ou pósitron). \\
\hline $\mathrm{E}$ & $\begin{array}{l}\text { Energia da partícula simulada }(\mathrm{eV}) \text {. O usuário pode definir uma fonte monoenergética ou } \\
\text { fornecer os valores das probabilidades de um espectro de energia. }\end{array}$ \\
\hline $\mathrm{XAT}, \mathrm{Y}, \mathrm{Z}:$ & Materiais onde as partículas se movem. \\
\hline $\mathrm{U}, \mathrm{V}, \mathrm{W}$ & Coordenadas das partículas $(\mathrm{cm})$. \\
\hline $\mathrm{EABS}$ & $\begin{array}{l}\text { Energia de corte da simulação, representando o maior valor de energia que a partícula possui } \\
\text { antes de ser localmente absorvida. }\end{array}$ \\
\hline $\mathrm{C} 1$ & $\begin{array}{l}\text { Parâmetro de condensação de histórias utilizado no algoritmo misto. Essa variável é } \\
\text { proporcional à deflexão angular média de partículas carregadas (valores de 0,05 à 0,2). }\end{array}$ \\
\hline $\mathrm{C} 2$ & $\begin{array}{l}\text { Parâmetro de condensação de histórias utilizado no algoritmo misto. Essa variável é } \\
\text { proporcional à perda fracional de energia entre eventos fortes consecutivos (valores de 0,05 } \\
\text { à 0,2) }\end{array}$ \\
\hline WCC & Energia de corte (eV) para as colisões inelásticas de partículas carregadas (fortes). \\
\hline WCR & Energia de corte (eV) para emissão de bremsstrahlung. \\
\hline
\end{tabular}

Os valores das variáveis EABS, C1, C2, WCC e WCR, chamados parâmetros de transporte, devem ser fornecidos pelo usuário para cada material utilizado na simulação. Como já mencionado na tabela 1, o parâmetro $\mathrm{C} 1$ é a deflexão angular média, que é produzida através do espalhamento elástico ao longo do caminho de partículas carregadas entre os eventos fortes (elásticos) consecutivos e C2 é proporcional a perda fracional de 
energia entre esses eventos fortes consecutivos. Quanto mais os valores de C1 e C2 estejam próximos de 0 , maior é a exatidão da simulação, porém é menor seu desempenho.

\section{Construção das Geometrias}

A geometria das simulações é dividida em corpos homogêneos, onde um corpo é definido como um volume limitado entre superfícies quádricas, simétricas em torno do eixo-z e obedecem a equação (26):

$$
F(x, y, z)=A_{x x} x^{2}+A_{x y} x y+A_{x z} x z+A_{y y} y^{2}+A_{y z} y z+A_{z z} z^{2}+A_{x} x+A_{y} y+A_{z} z+A_{0}=0 .
$$

Através da equação (26) pode-se construir diversas superfícies, dentre elas: planos, esferas, cilindros, cones. Cada superfície quadrática poderá ser representada através de equações implícitas ou de forma reduzida (SALVAT et al, 2009). Na forma reduzida, a equação (26) é escrita de acordo com a equação (27):

$$
F_{\Gamma}(x, y, z)=I_{1} x^{2}+I_{2} y^{2}+I_{3} z^{2}+I_{4} z=0 .
$$

Na equação (27) os índices de 1 à 5 podem assumir os valores $-1,0$ ou 1 . Na tabela 3 tem-se alguns exemplos das equações na forma reduzida, juntamente com seus índices e a figura da respectiva quadráticas a que se refere. 
Tabela 3: Equações quadráticas na forma reduzida com os índices e as respectivas geometrias. Adaptada de (SALVAT et al, 2009).

\begin{tabular}{lllllllll}
\hline Forma Reduzida & Índices & Quádrica \\
$x^{2}+y^{2}+z^{2}-1=0$ & 1 & 1 & 1 & 0 & -1
\end{tabular}

$$
x^{2}-y^{2}-1=0 \quad 1-1 \quad 0 \quad 0-1 \quad \text { Cilindro }
$$

Hiperbólico

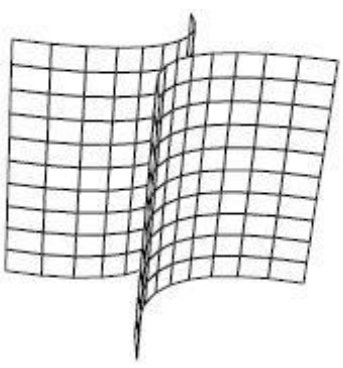

$$
x^{2}+y^{2}-z^{2}=0 \quad 11-100 \quad \text { Cone }
$$

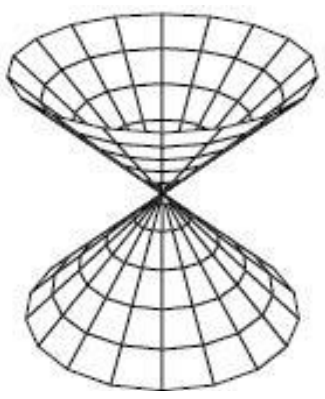

Na versão do PENELOPE 2008, utilizado nesse trabalho, pengeom. $f$ permite que a geometria utilizada contenha até 5000 corpos com 9999 superfícies limitantes. No ANEXO II deste trabalho (Arquivo geometria.geo) é apresentado um arquivo com um exemplo da geometria de uma fonte que foi utilizada na simulações, para exemplificar a construção das geometrias no pacote PENELOPE.

Neste trabalho foram obtidas as funções dosimétricas de acordo com a American Association of Physicists in Medicine Task Group 43 (NATH et al, 1995, MOWLAVI et al, 2008), para duas fontes de braquiterapia, utilizando simulação Monte Carlo com 
pacote PENELOPE. Os valores obtidos foram comparados com dados já existentes na literatura, visando contribuir com o controle da qualidade em braquiterapia. 


\section{3- Estudo Utilizando Fonte de ${ }^{192} \mathrm{Ir}$}

A fonte de ${ }^{192}$ Ir é mais comumente utilizada em implantes intersticiais temporários com aplicadores na forma de fios. Esse material é um emissor de raios gama, possui aproximadamente 40 picos de energia, com energia média de $397 \mathrm{keV}$ e meia vida de aproximadamente 74 dias (GOETSCH et al, 1991; SAVAJOLI, SOUHAMI, FARIA 2013).

Nos estudos por simulação realizados nesse trabalho, o espectro de radiação emitido pelo Irídio foi modelado pelas 17 linhas de emissão de fótons mais prováveis compreendidas no intervalo de energias de $65 \mathrm{keV}$ à $1378 \mathrm{keV}$, com energia mais provável de 316,5 keV (ZILIO et al, 2004). O espectro de radiação primário da fonte de ${ }^{192}$ Ir simulada nesse trabalho é apresentado na figura 15.

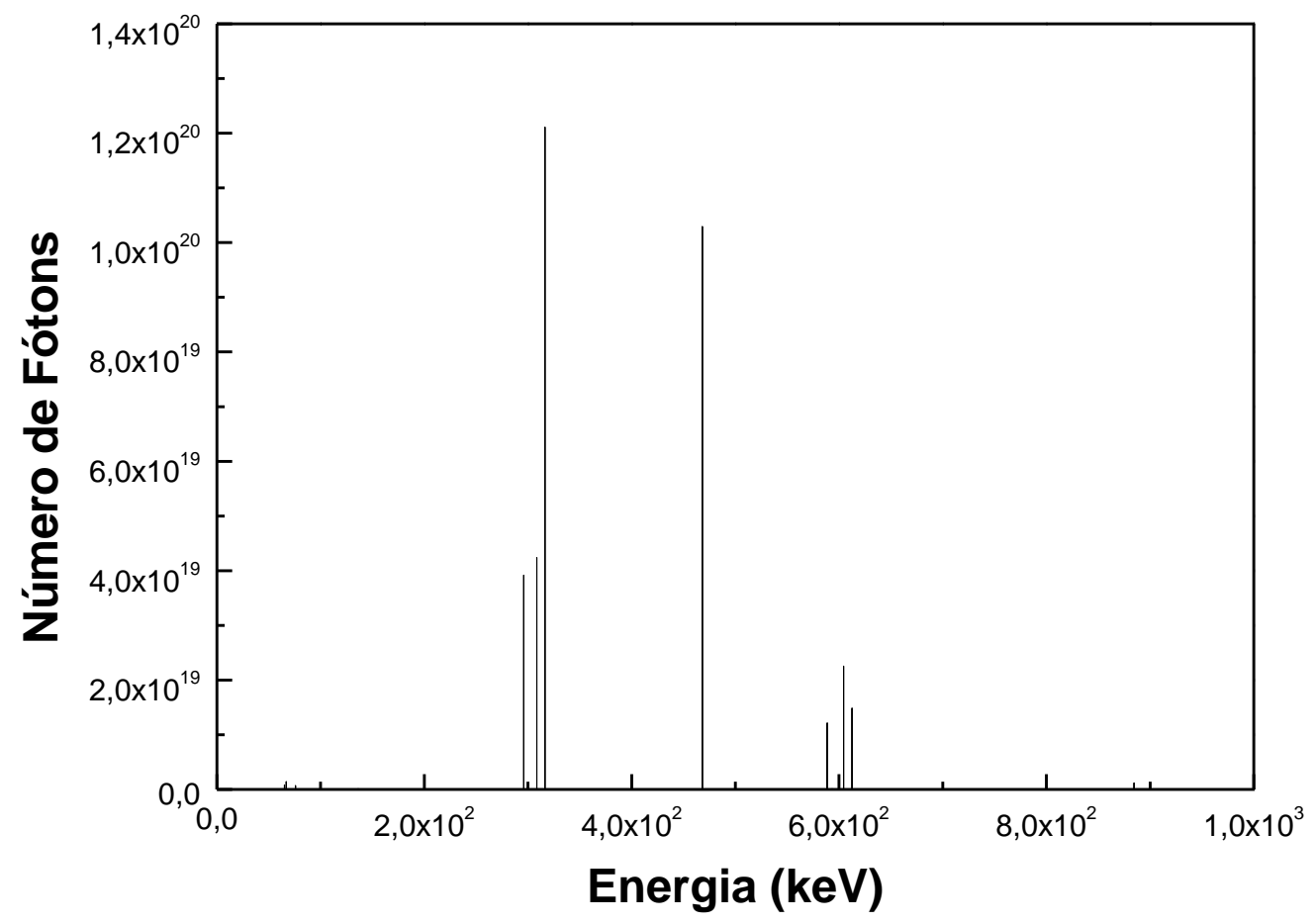

Figura 15: Espectro simulado para fonte de ${ }^{192} \mathrm{Ir}$.

A fonte clínica ${ }^{192} \mathrm{Ir}$, Varian modelo GammaMed Plus é utilizada em tratamentos de braquiterapia. Essa fonte possui parte ativa com raio de $0,03 \mathrm{~cm}$ e $0,35 \mathrm{~cm}$ de comprimento. O encapsulamento feito de aço inoxidável AISI 316L, possui raio de $0,045 \mathrm{~cm}$ e comprimento de $0,452 \mathrm{~cm}$ (dimensões obtidas através do certificado da fonte de ${ }^{192} \mathrm{Ir}$, fornecido pelo HCFMRP). Nas simulações realizadas nesse trabalho, essa fonte 
foi modelada da seguinte forma: parte ativa de raio $0,03 \mathrm{~cm}$ e comprimento $0,35 \mathrm{~cm}$; encapsulamento de aço inoxidável AISI $316 \mathrm{~L}$, com raio de $0,055 \mathrm{~cm}$ e comprimento de $0,5 \mathrm{~cm}$; o cabo dessa fonte, também de aço inoxidável AISI $316 \mathrm{~L}$, possui raio de $0,055 \mathrm{~cm}$ e comprimento de $150 \mathrm{~cm}$ (BALTAS et al, 1998). A figura 16 apresenta um esquema da geometria com os eixos de coordenadas, como os utilizados nesse trabalho e a geometria construída no PENELOPE e visualizada no gview2d.

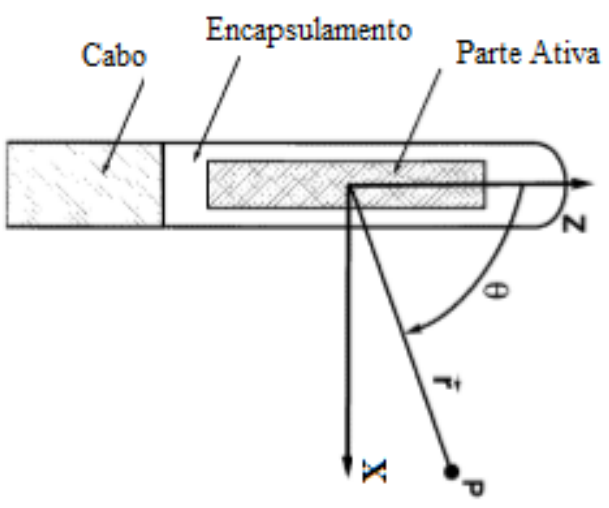

(a)

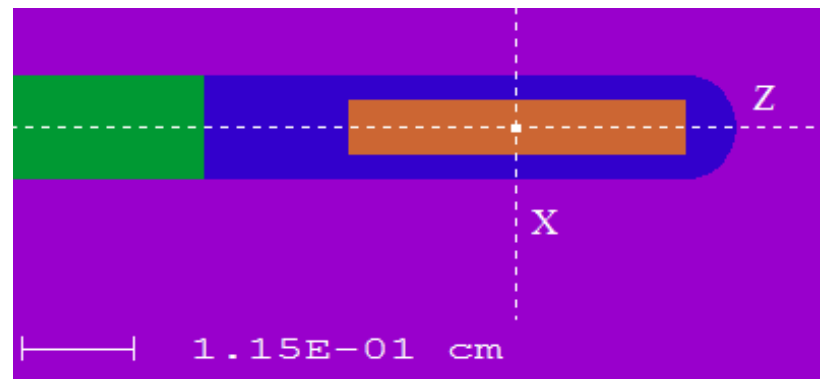

Corpo 1: Parte ativa

Corpo 2: Encapsulamento Corpo 3: Cabo

(b)

Figura 16: Geometria da fonte de ${ }^{192} \operatorname{Ir}$ (a) adaptado de (BALTAS et al, 1998); (b) construída com o pacote PENELOPE.

\section{1 - Equivalência do gel MAGIC-f com a água para a energia do ${ }^{192} \mathrm{Ir}$}

A análise da equivalência de um dosímetro com a água pode ser avaliada em termos do número atômico efetivo, dose relativa, densidade eletrônica, dependendo da aplicação desejada (SELLAKUMAR, SAMUEL, SUPE, 2007; UN, 2013). 
Nesse trabalho, analisou-se a equivalência do gel MAGIC- $f$ com a água através das comparações de: números atômicos efetivos $\left(\mathrm{Z}_{\mathrm{EF}}\right)$ dos dois materiais; valores da densidade eletrônica do gel relativa à agua $\left(\rho_{e}^{W}\right)$ dose relativa ao longo das direções radial e longitudinal da fonte, produzida pela fonte de ${ }^{192} \mathrm{Ir}$ juntamente com os mapas de distribuição de dose obtidos para os dois materiais.

A análise de $\left(Z_{\mathrm{EF}}\right)$ e $\left(\rho_{e}^{w}\right)$ serão realizadas através de cálculo utilizando os componentes dos dois materiais, enquanto que as distribuições de dose serão analisadas através de simulação Monte Carlo desses dois materiais, tanto para a fonte de Irídio quanto para a fonte de Cobalto.

\section{Cálculo do Número Atômico Efetivo e Densidade Eletrônica}

A equivalência do gel com a água, analisada através do $Z_{\mathrm{EF}}$, é determinada pela equação (28) (KHAN, 2003):

$$
\begin{gathered}
Z_{E F}=\left(a_{1} Z_{1}^{2,94}+a_{2} Z_{2}^{2,94}+a_{3} Z_{3}^{2,94}+\cdots+a_{n} Z_{n}^{2,94}\right)^{1 / 2,94} \\
a_{n}=\left(\frac{N_{A} Z_{n}}{A_{n}}\right) w_{n}
\end{gathered}
$$

onde $a_{1}, a_{2}, a_{3}, \ldots, a_{n}$ são as contribuições fracionais de cada elemento ao número total de elétrons na mistura; $Z_{1}, Z_{2}, Z_{3}, \ldots, Z_{n}$ são os números atômicos de cada elemento; $N_{A}$ é o número de Avogadro $\left(6,02 \times 10^{23}\right)$ mol por grama; $A_{n}$ é a massa atômica $(\mathrm{g}) ; w_{n}$ é a fração de peso de cada componente.

O valor das quantidades relativas ao gel polimérico, é mostrado na tabela 4.

Tabela 4: Valores das quantidades relativas ao gel polimérico MAGIC-f.

\begin{tabular}{llllllll}
\hline Elementos & $\mathrm{H}$ & \multicolumn{1}{c}{$\mathrm{C}$} & $\mathrm{N}$ & \multicolumn{1}{c}{$\mathrm{O}$} & \multicolumn{1}{c}{$\mathrm{S}$} & \multicolumn{1}{c}{$\mathrm{Cu}_{\mathrm{ii}}$} \\
\hline$Z$ & 1 & 6 & 7 & 8 & 16 & 29 \\
\hline$A$ & 1,0079 & 12,0107 & 14,007 & 15,9994 & 32,0650 & 63,5460 \\
\hline${ }^{\mathrm{a}} w$ & 0,1062 & 0,0751 & 0,0139 & 0,8021 & $2,5800 \times 10^{-6}$ & $5,0800 \times 10^{-6}$ \\
\hline$a$ & 0,1912 & 0,0681 & 0,0126 & 0,7281 & $2,3772 \times 10^{-6}$ & $4,2088 \times 10^{-6}$
\end{tabular}

a Dados obtidos a partir de (LUCI et al, 2003).

O valor de $Z_{E F}$ encontrado para o gel MAGIC- $f$ foi de 7,307 . Na literatura, os valores de $\mathrm{Z}_{\mathrm{EF}}$ encontrados para esse gel polimérico são próximos, tais como: 7,20 (LUCI 
et al, 2003); 7,37 (SELLAKUMAR, SAMUEL, SUPE, 2007); 7,40 (PANTELIS et al, 2004).

Da mesma forma, os valores das quantidades que foram necessárias para encontrar $Z_{E F}$ da água, encontram-se na tabela 5 .

Tabela 5: Valores das quantidades para a água

\begin{tabular}{lll}
\hline Elementos & $\mathrm{H}$ & $\mathrm{O}$ \\
\hline$Z$ & 1 & 8 \\
\hline$A$ & 1,0079 & 15,9994 \\
\hline${ }^{\mathrm{b}} w$ & 0,1111 & 0,8889 \\
\hline$a$ & 0,1987 & 0,8012
\end{tabular}

${ }^{\mathrm{b}}$ Dados obtidos a partir de (LUCI et $\overline{a l, 2003) .}$

Através da equação (28) o valor de $Z_{E F}$ encontrado para a água foi 7,420 . Comparando-se os valores de $Z_{E F}$ da água e do gel, foi encontrada uma diferença relativa de $1,52 \%$.

Outra comparação realizada entre a água e o gel MAGIC- $f$, foi através da densidade eletrônica do gel relativa à água $\left(\rho_{e}^{w}\right)$ (DE DEENE et al, 2006). Para isso, o valor da densidade eletrônica para a água e para o gel, foi determinado através das equações (30) e (31):

$$
\begin{gathered}
\rho_{e}=\rho_{m} N_{A}\left(\sum_{n} a_{n} Z_{n} / A_{n}\right), \\
a_{i}=\frac{\left(Z_{n} w_{n} / A_{n}\right)}{\sum_{n} w_{n} Z_{n} / A_{n}},
\end{gathered}
$$

onde $\rho_{m}$ é a densidade do material; $N_{A}$ o número de Avogadro $\left(6,02 \times 10^{23}\right)$ (mol por grama); $Z_{i}$ o número atômico de cada material; $A_{i}$ a massa atômica $(\mathrm{g})$. Dessa forma, o valor de $\left(\rho_{e}^{w}\right)$ encontrado foi de 1,038. A partir dessas duas análises realizadas, foi possível verificar a equivalência do gel com a água, e consequentemente com o tecido mole, através do número atômico efetivo e densidade eletrônica.

\section{Distribuição de Dose Simuladas}

Nas simulações as seções de choque para a água foram obtidas a partir do banco de dados do PENELOPE, enquanto que para o gel um arquivo de material específico foi 
construído utilizando-se as frações em peso dos constituintes do material, conforme a tabela 4 .

O objeto simulador utilizado nas simulações era cúbico, de $30 \mathrm{~cm}$ de lado, homogêneo, preenchido com água ou com gel. Em todos os casos, a fonte foi posicionada no centro do objeto simulador e foi escolhida uma distância total de $6 \mathrm{~cm}$ em cada direção do eixo cartesiano para a obtenção dos valores de dose. O volume do objeto simulador foi dividido em pixels para a amostragem da dose ao longo do volume. Foram definidos 101 pixels em cada eixo de coordenadas, sendo que um deles foi posicionado no centro do eixo de coordenadas e cada pixel teve dimensões 0,0594 por $0,0594(\mathrm{~cm})^{2}$.

No arquivo de entrada, modificado para as simulações utilizando a fonte de ${ }^{192} \mathrm{Ir}$, a quantidade de pixels colocada para obter os valores de dose, foi de 100 em cada eixo de coordenada (gridbn igual a 100 nos eixos $x$, y e $z$ ). Porém, como o PENELOPE obtém um pixel na posição da origem dos eixos de coordenadas, para existir simetria entre esses eixos, o pacote sempre utiliza um número ímpar de pixels nas simulações. Portanto, embora seja fixado o número 100 pixels nos três eixos, será obtido 101 divisões, ou seja, o intervalo da aquisição do valor da dose em cada ponto obtido será de $0,0594 \mathrm{~cm}$.

Nessas simulações não foi incluída na geometria o aplicador clínico utilizado nos tratamentos de braquiterapia. O número de partículas primárias em cada simulação permaneceu constante em $10^{9}$ partículas e os parâmetros de simulação escolhidos, foram: energia de corte para fótons e elétrons igual a $10 \mathrm{keV}, \mathrm{C} 1$ e C2 (parâmetros de condensão de histórias) igual a 0,1, otimizando o tempo de simulação e mantendo detalhadas as simulações de eventos fortes.

Para análise dos resultados obtidos, foram construídos gráficos de dose relativa ao longo das direções radial e longitudinal da fonte, juntamente com mapas de distribuição de dose. Para esses mapas, em todos os casos, os planos passam pelo centro da fonte. Na figura 17 são apresentadas as doses relativas em função da distância ao longo da direção do eixo $\mathrm{X}$ da fonte para a água e para o gel, bem como as diferenças absolutas entre as doses relativas entre os dois materiais 


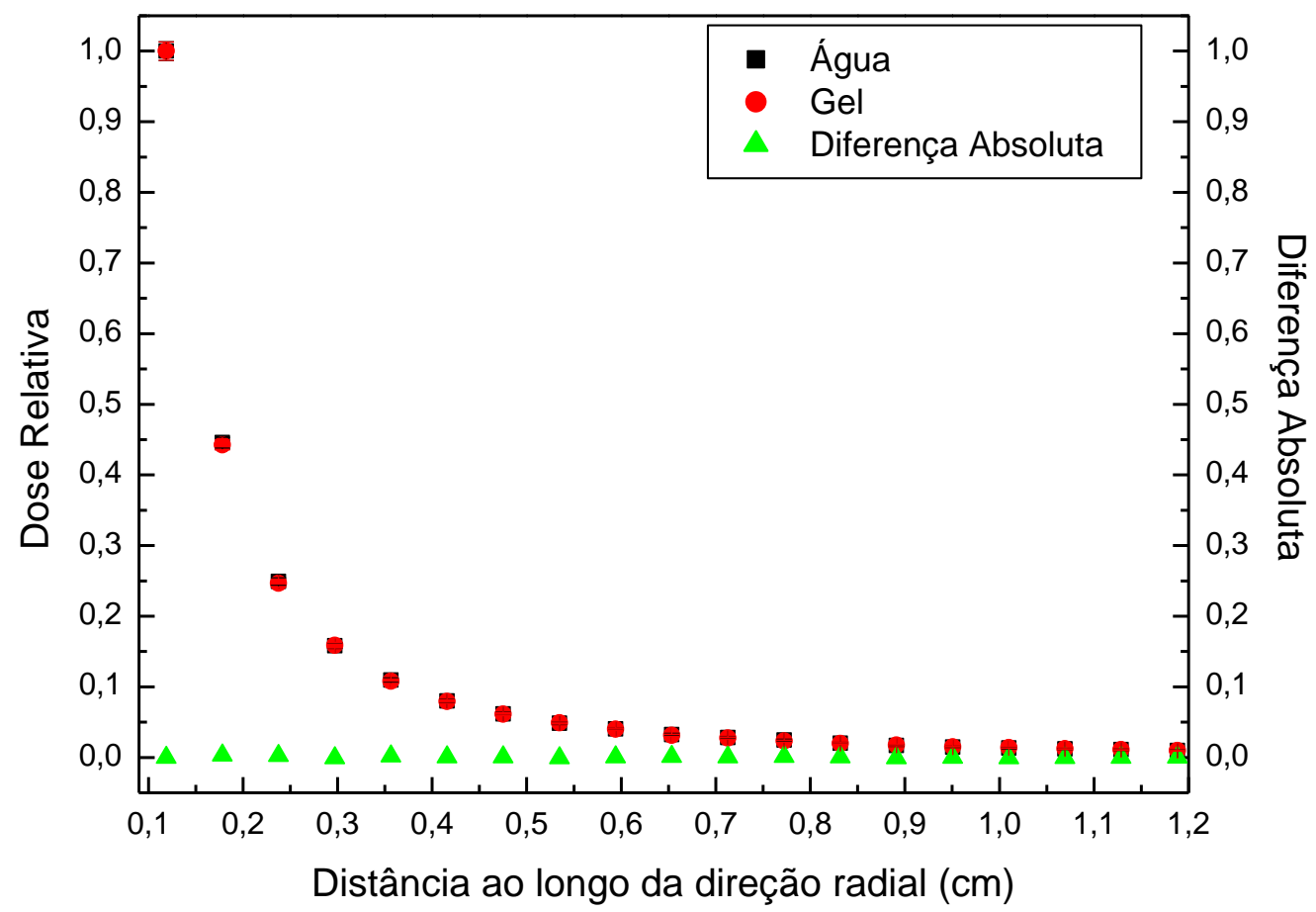

Figura 17: Dose Relativa em função da distância ao longo da direção radial, para a energia do ${ }^{192}$ Ir e diferença absoluta para a água e para o gel MAGIC- $f$.

$\mathrm{Na}$ figura 17 são mostradas as doses para os pixels localizados fora da fonte, e portanto no meio atenuador. Essa metodologia será utilizada na análise de todas as distribuições de dose simuladas. O máximo desvio encontrado nas doses simuladas foi de 1,32\% para a simulação da água e de $1,30 \%$ para a simulação do gel, com máxima diferença absoluta encontrada entre as doses relativas para os dois materiais de 0,003 em $0,178 \mathrm{~cm}$, ao longo dessa direção. A dose relativa diminuiu, aproximadamente, $55 \%$ já nos dois primeiros pixels analisados, correspondendo à distâncias de $0,118 \mathrm{~cm}$ para 0,178 $\mathrm{cm}$, para os dois materiais analisados. Em aproximadamente 1,2 $\mathrm{cm}$ a dose é praticamente nula, em ambos os casos.

A mesma análise foi realizada na direção longitudinal, ou seja a distância ao longo da direção do eixo $\mathrm{Z}$ no plano passando pelo centro da fonte radioativa, sendo as doses relativas e suas diferenças mostradas na figura 18. 


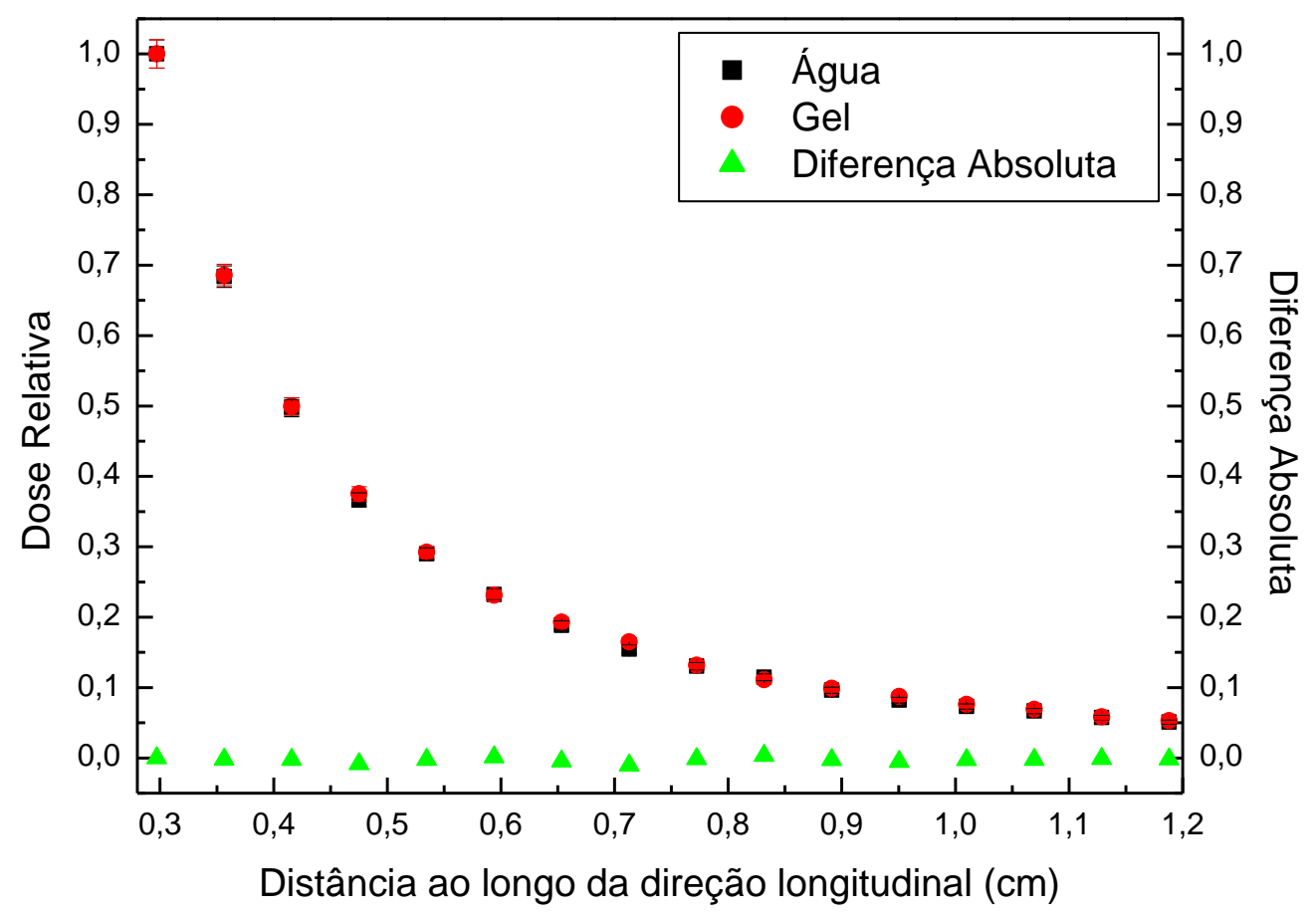

Figura 18: Dose Relativa em função da distância ao longo da direção longitudinal, para a energia do ${ }^{192}$ Ir e diferença absoluta para a água e para o gel MAGIC- $f$.

Através da figura 18 é possível observar que a máxima diferença absoluta encontrada entre as doses relativas foi de $0,004 \mathrm{em} 0,831 \mathrm{~cm}$ e o máximo desvio encontrado, tanto para a água, quanto para o gel, foi de $2,01 \%$, evidenciando uma boa exatidão nas simulações. A dose relativa diminuiu aproximadamente $31 \%$ do primeiro para o segundo pixel correspondendo as posições $0,297 \mathrm{~cm}$ e $0,356 \mathrm{~cm}$, para a água e para o gel. Em aproximadamente 1,2 cm, a dose é praticamente nula em ambos os casos.

Como citado anteriormente, na continuidade da análise da equivalência do gel MAGIC- $f$ com a água, foram construídos mapas da distribuição de dose, em planos passando pelo centro da fonte. Em todas as distribuições de dose analisadas os pixels que compreendem a fonte foram retirados por completo desses mapas, ou seja, para o lugar onde estaria posicionada a fonte, a dose é definida como zero.

A figura 19 mostra o mapa da distribuição de dose para a água. Embora a distribuição de dose tenha sido determinada de $-3 \mathrm{~cm}$ à $+3 \mathrm{~cm}$, foi delimitada a distância de $-0,7 \mathrm{~cm}$ à $+0,7 \mathrm{~cm}$, uma vez que para valores maiores que esses, a dose era praticamente nula. Com um total de 101 pontos em cada eixo, cada pixel nos mapas de distribuição de dose apresentados também corresponde à 0,0594 por $0,0594(\mathrm{~cm})^{2}$. A mesma análise foi realizada para a distribuição do gel, como mostrada na figura 20. No intuito de verificar a equivalência de ambos os materiais, foi realizada a subtração entre o mapa da 
distribuição de dose da água pela distribuição de dose no gel, pixel a pixel, conforme mostrado na figura 21.

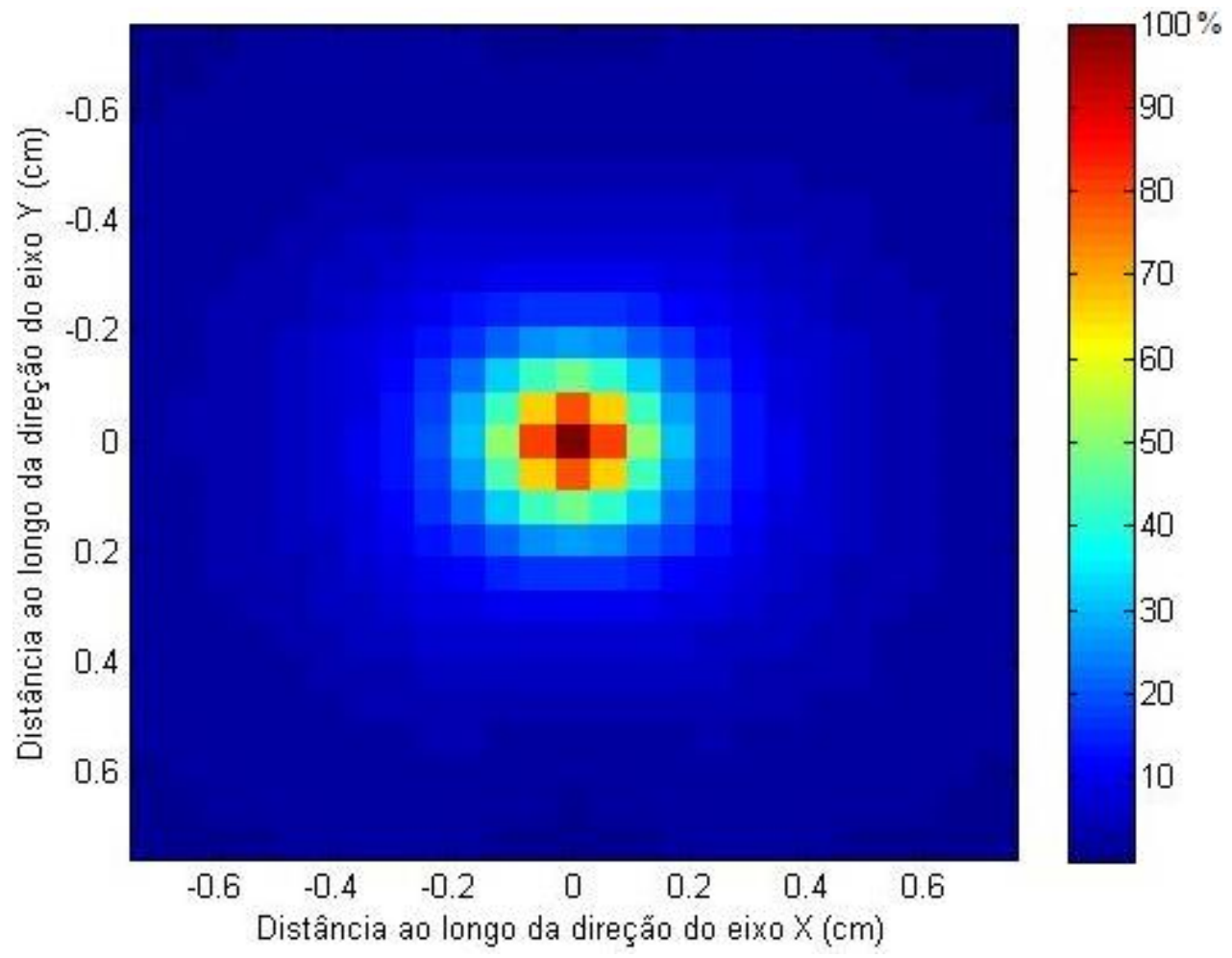

Figura 19: Mapa de distribuição de dose em plano transversal passando pelo centro da fonte de ${ }^{192} \mathrm{Ir}$, quando o material irradiado foi a água.

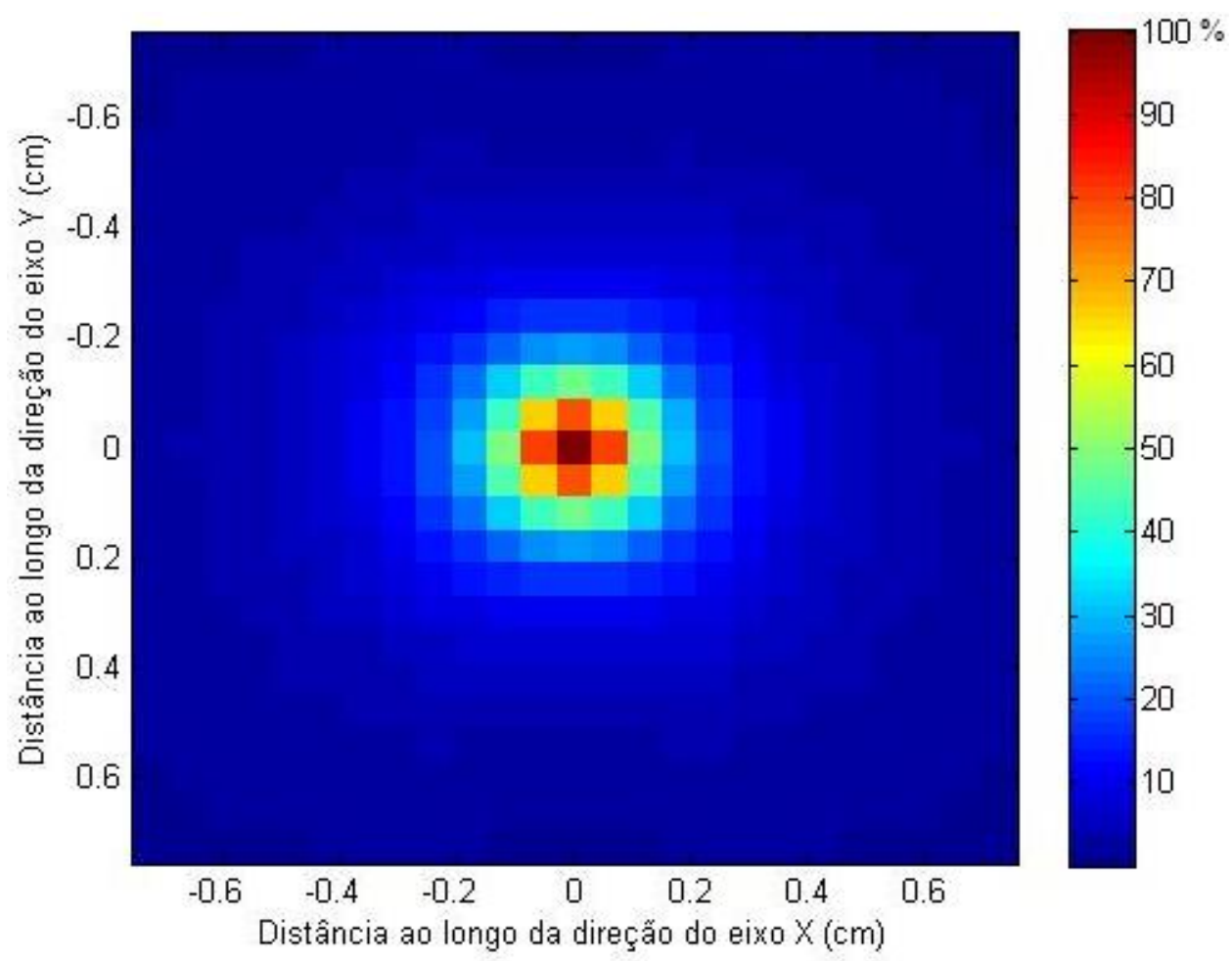

Figura 20: Mapa de distribuição de dose em plano transversal passando pelo centro da fonte de ${ }^{192} \mathrm{Ir}$, quando o material irradiado foi a gel. 


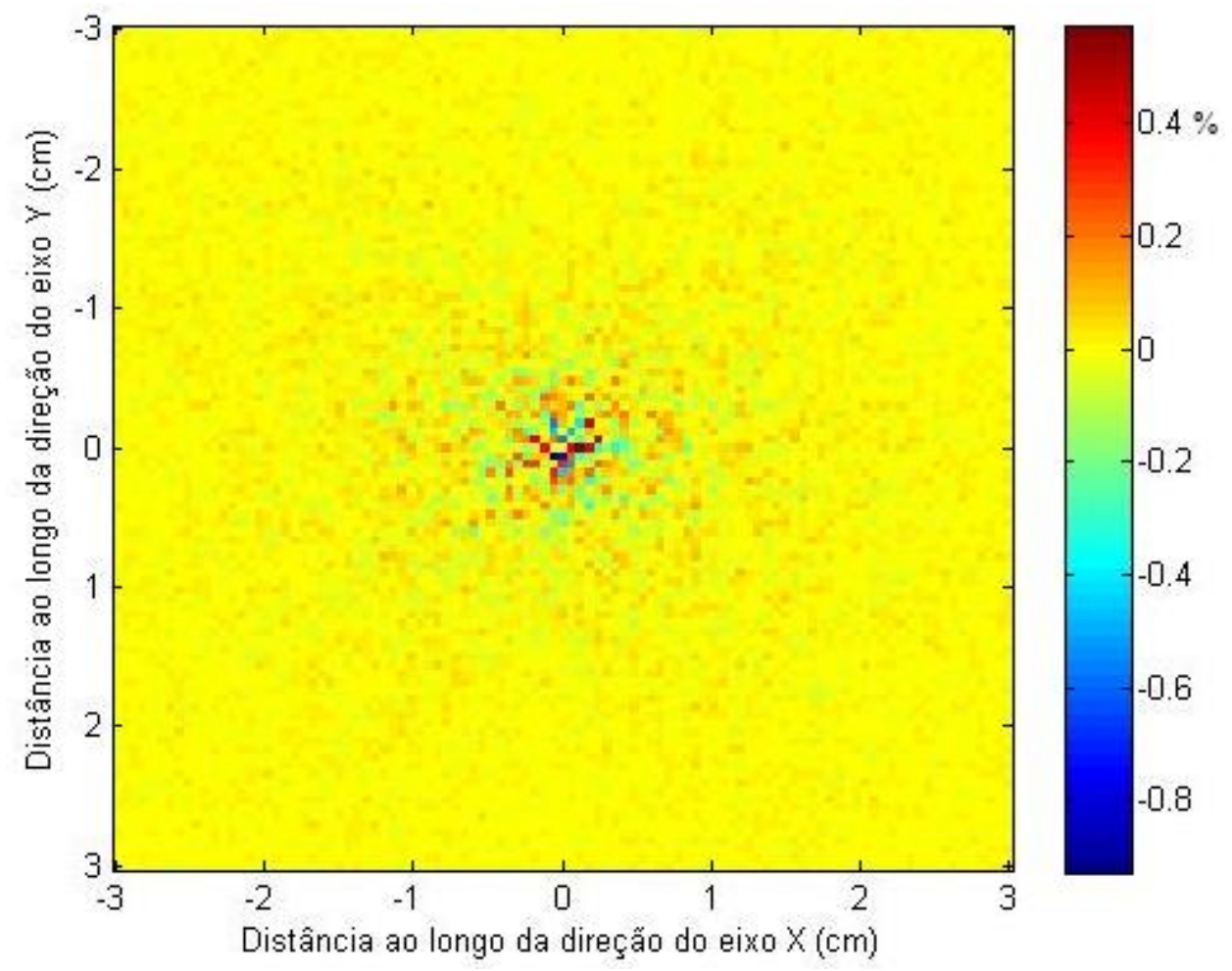

Figura 21: Subtração do mapa da distribuição de dose da água e do gel, no plano transversal passando pelo centro da fonte de ${ }^{192} \mathrm{Ir}$.

Embora nas figuras 19 e 20 a região mostrada nas distribuições foi de aproximadamente $-0,7 \mathrm{~cm}$ à $+0,7 \mathrm{~cm}$, no mapa da subtração das doses, a distância foi de $-3,0 \mathrm{~cm}$ à $+3,0 \mathrm{~cm}$ para mostrar a equivalência entre ambos os materiais em toda a região simulada. Através dessa análise, foi obtida uma diferença percentual máxima de 0,92\%, evidenciando a equivalência do gel polimérico MAGIC- $f$ com a água. Essa equivalência evidencia que o gel pode ser adequado como dosímetro em aplicações clínicas.

\section{Simulação da distribuição de dose com aplicador clínico}

Os resultados mostrados na seção anterior mostram a equivalência do gel com a água, para a energia do ${ }^{192} \mathrm{Ir}$, entretanto em aplicações clínicas o posicionamento dessa fonte é realizado através do uso de um aplicador composto por um cabo e uma agulha, ambos de alto número atômico.

Para avaliar a influência do aplicador nas distribuições de dose, foram realizadas simulações incluindo aplicador de aço inoxidável AISI 316L com comprimento de $20 \mathrm{~cm}$ e diâmetro de $0,165 \mathrm{~cm}$ no modelo da fonte clínica de ${ }^{192} \mathrm{Ir}$. Nessas simulações, a 
atenuação por parte do aplicador foi comparada com simulações da fonte sem o aplicador. Essas simulações foram realizadas em um objeto simulador cúbico de $30 \mathrm{~cm}$ de lado sendo preenchido somente por água. Os parâmetros de condensão de histórias e número de partículas primárias foram mantidos iguais aos descritos na seção anterior.

Na figura 22 é apresentada a comparação entre a dose relativa para essas simulações ao longo da direção radial no plano transversal passando pelo centro da fonte.

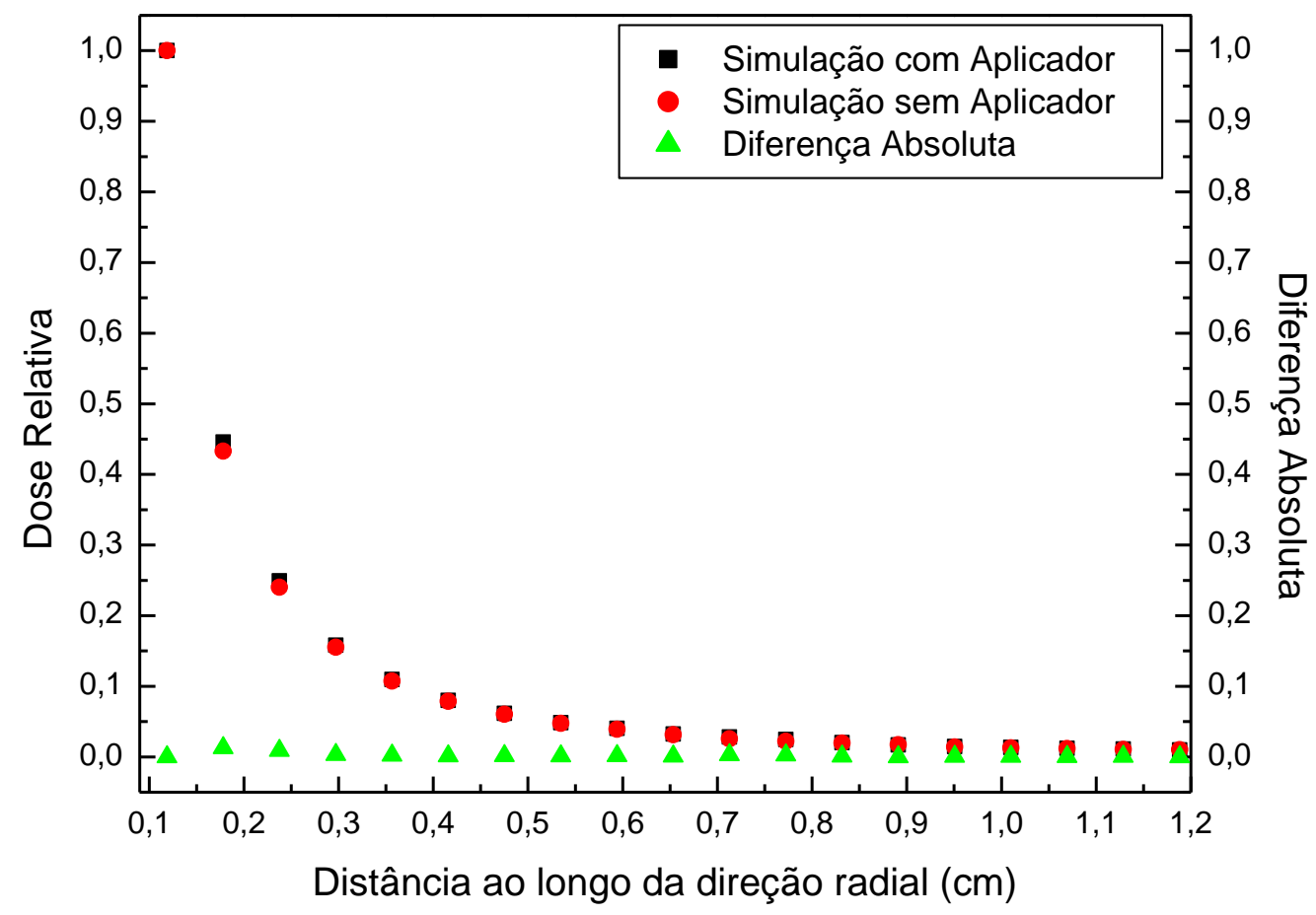

Figura 22: Dose relativa em função da distância radial para fonte de ${ }^{192} \mathrm{Ir}$ com e sem aplicador clínico.

O maior desvio nas doses encontrado para a simulação com aplicador foi de $0,26 \%$ enquanto que para os dados sem aplicador o máximo desvio encontrado foi de $0,39 \%$. A maior diferença absoluta encontrada entre as doses relativas nessas simulações foi de 0,004 em $0,178 \mathrm{~cm}$, mostrando que a contribuição por parte do aplicador é praticamente inexistente na direção radial no plano passando pelo centro da fonte.

As distribuições de dose de ambas as simulações, com e sem aplicador, porém na direção longitudinal passando pelo plano central da fonte são apresentadas na figura 23 . Nessa figura são apresentadas as doses para os pixels fora da fonte e do aplicador, com coordenadas positivas (direção positiva do eixo Z). 


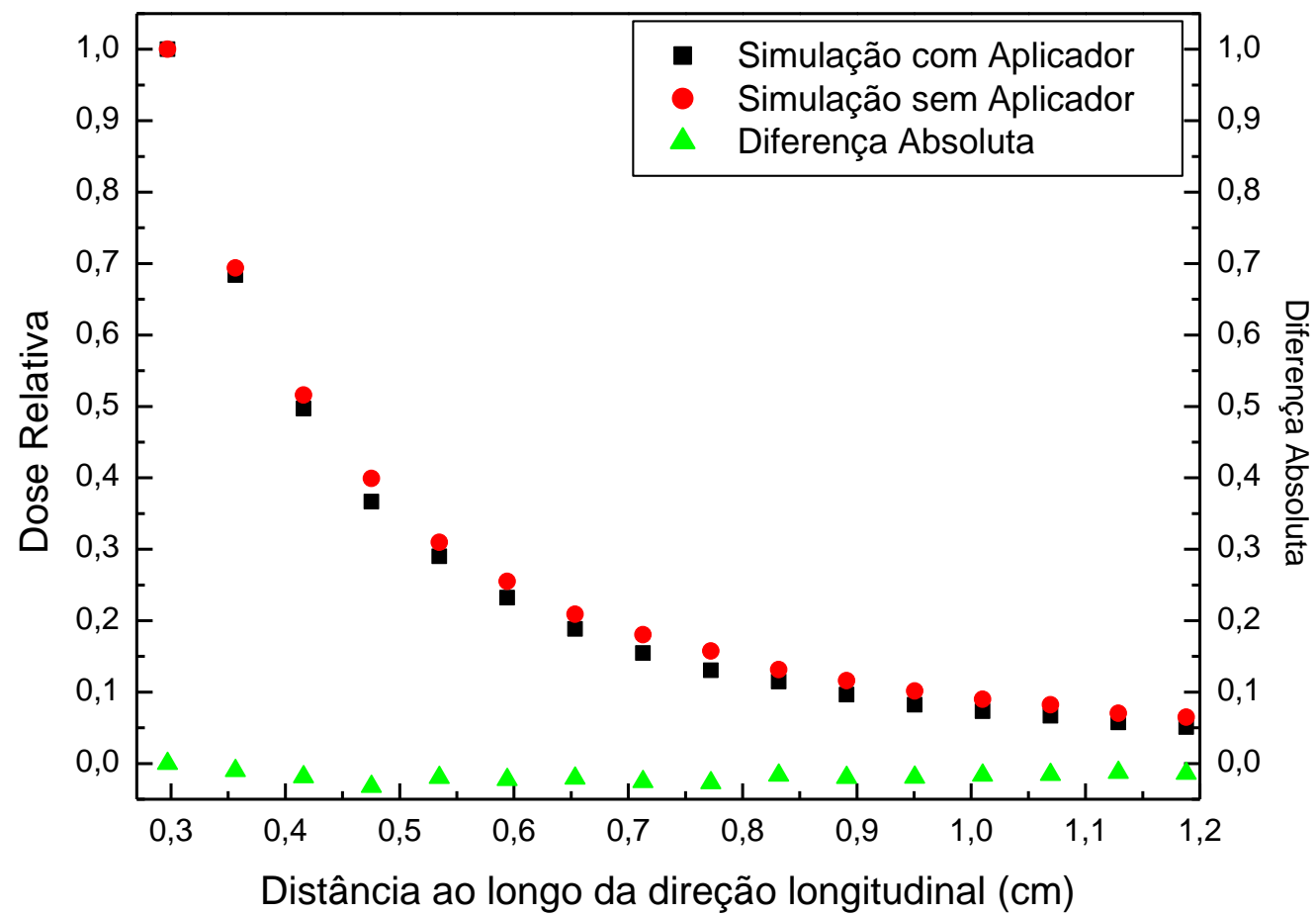

Figura 23: Dose relativa em função da distância longitudinal para fonte de ${ }^{192} \mathrm{Ir}$ com e sem aplicador clínico.

O maior desvio encontrado para simulação com aplicador foi de 3,10\% enquanto que para a simulação sem aplicador o máximo desvio encontrado foi de 1,97\% nas doses. A maior diferença absoluta encontrada entre as doses relativas na comparação ao longo da direção longitudinal, foi de aproximadamente $0,032 \mathrm{em} 0,475 \mathrm{~cm}$.

Nas comparações realizadas com as simulações que continham e as que não continham o aplicador, nas duas direções verificadas, foi possível observar que a contribuição por parte do aplicador utilizado nesse tipo de tratamento de braquiterapia, é baixa. Desta forma, para a determinação dos parâmetros dosimétricos da fonte de ${ }^{192} \mathrm{Ir}$, a agulha do aplicador não foi inserida na geometria simulada, porém manteve-se o cabo de aço em todas as análises. 


\section{2 - Parâmetros Dosimétricos para a Fonte de ${ }^{192} \mathrm{Ir}$}

Nessa seção serão apresentados os parâmetros dosimétricos definidos no TG-43, para o formalismo no cálculo de dose em braquiterapia, sendo eles: Fator Geométrico, Função de Dose Radial e Função de Anisotropia.

\subsection{1 - Fator Geométrico}

O fator geométrico não leva em consideração a absorção e o espalhamento dos fótons na estrutura da fonte, ou seja, a variação da dose relativa obtida através desse fator será devida apenas às características geométricas da fonte analisada. As duas fontes analisadas nesse trabalho, ${ }^{192} \mathrm{Ir}$ e ${ }^{60} \mathrm{Co}$, possuem o mesmo comprimento da parte ativa, que é de $0,35 \mathrm{~cm}$, portanto o fator geométrico será o mesmo para ambas as fontes.

O ângulo $\theta$ é para o cálculo do fator geométrico é definido em reação ao vetor $r$ e o eixo Z. À medida que $r$ se aproxima do eixo $\mathrm{X}, \theta$ é crescente até $90^{\circ}$, apresentando simetria também na parte ativa da fonte de $90^{\circ}$ à $180^{\circ}$, conforme mostrado na figura 16 .

No protocolo TG-43, tomado como referência nesse trabalho, não é citada explicitamente a fórmula para o cálculo de $\beta$, necessária para obter o fator geométrico. A equação utilizada para o cálculo de $\beta$ citada pelo protocolo é mostrada na equação 32 :

$$
\beta=\theta_{2}-\theta_{1}
$$

onde $\beta$ é o ângulo (em radianos) que subentende a parte ativa da fonte com relação ao ponto de interesse $P ; \theta_{2}$ e $\theta_{1}$ são os dois ângulos dos extremos da parte ativa da fonte, com relação ao ponto de interesse, conforme mostrado na figura 7; $r$ é a distância do centro da fonte até a posição de interesse e L é o comprimento efetivo da fonte. De acordo com a figura $5, \beta$ é a diferença entre $\theta_{2}$ e $\theta_{1}$ e é determinado em função de $\theta$. O protocolo apenas apresenta uma tabela já com os valores calculados do fator geométrico multiplicado pelo quadrado de $r$, para uma fonte linear de $3 \mathrm{~mm}$ de comprimento.

Neste trabalho, o ângulo $\beta$ é calculado de acordo com a equação (33): 


$$
\beta=\theta_{2}-\theta_{1}=\operatorname{tg}^{-1}\left(\frac{r \operatorname{sen} \theta}{r \cos \theta-\frac{L}{2}}\right)-\operatorname{tg}^{-1}\left(\frac{r \operatorname{sen} \theta}{r \cos \theta+\frac{L}{2}}\right)
$$

Quando o ponto de interesse está sob o eixo radial da fonte, o fator geométrico pode ser escrito como:

$$
G_{L}\left(r, \theta_{0}\right)=\frac{2 t g^{-1}\left(\frac{L}{2 r \operatorname{sen} \theta}\right)}{\operatorname{Lrsen} \theta}
$$

Com o objetivo de validar a equações (33) e (34), utilizadas para o cálculo de $\beta$ e do fator geométrico, foram reproduzidos dados do fator geométrico para pontos especificados do TG-43. Os valores contidos nesse protocolo, juntamente com os valores obtidos neste trabalho, são mostrados na tabela 6 e na figura 24 .

Tabela 6: Fator geométrico fornecidos pelo TG-43 e obtidos nesse trabalho, para uma fonte de $3 \mathrm{~mm}$ de comprimento.

\begin{tabular}{ccccccc}
\hline \multirow{2}{*}{$\begin{array}{c}\text { Angulos } \\
\text { (graus) }\end{array}$} & \multicolumn{2}{c}{$\mathbf{r}=\mathbf{0 , 5} \mathbf{~ c m}$} & \multicolumn{2}{c}{$\mathbf{r}=\mathbf{1 , 0} \mathbf{~ c m}$} & \multicolumn{2}{c}{$\mathbf{r}=\mathbf{2 , 0} \mathbf{~ c m}$} \\
\cline { 2 - 7 } & TG-43 & Obtidos & TG-43 & Obtidos & TG-43 & Obtidos \\
\hline $\mathbf{0}$ & 1,099 & 1,099 & 1,023 & 1,023 & 1,006 & 1,006 \\
\hline $\mathbf{1 0}$ & 1,094 & 1,094 & 1,022 & 1,022 & 1,006 & 1,006 \\
\hline $\mathbf{2 0}$ & 1,081 & 1,081 & 1,019 & 1,019 & 1,005 & 1,005 \\
\hline $\mathbf{3 0}$ & 1,062 & 1,062 & 1,015 & 1,015 & 1,004 & 1,004 \\
\hline $\mathbf{4 0}$ & 1,039 & 1,039 & 1,010 & 1,010 & 1,002 & 1,002 \\
\hline $\mathbf{5 0}$ & 1,018 & 1,018 & 1,005 & 1,005 & 1,001 & 1,001 \\
\hline $\mathbf{6 0}$ & 0,9160 & 0,9985 & 0,9999 & 0,9999 & 1,000 & 1,000 \\
\hline $\mathbf{9 0}$ & 0,9715 & 0,9715 & 0,9926 & 0,9926 & 0,9980 & 0,9980 \\
\hline
\end{tabular}

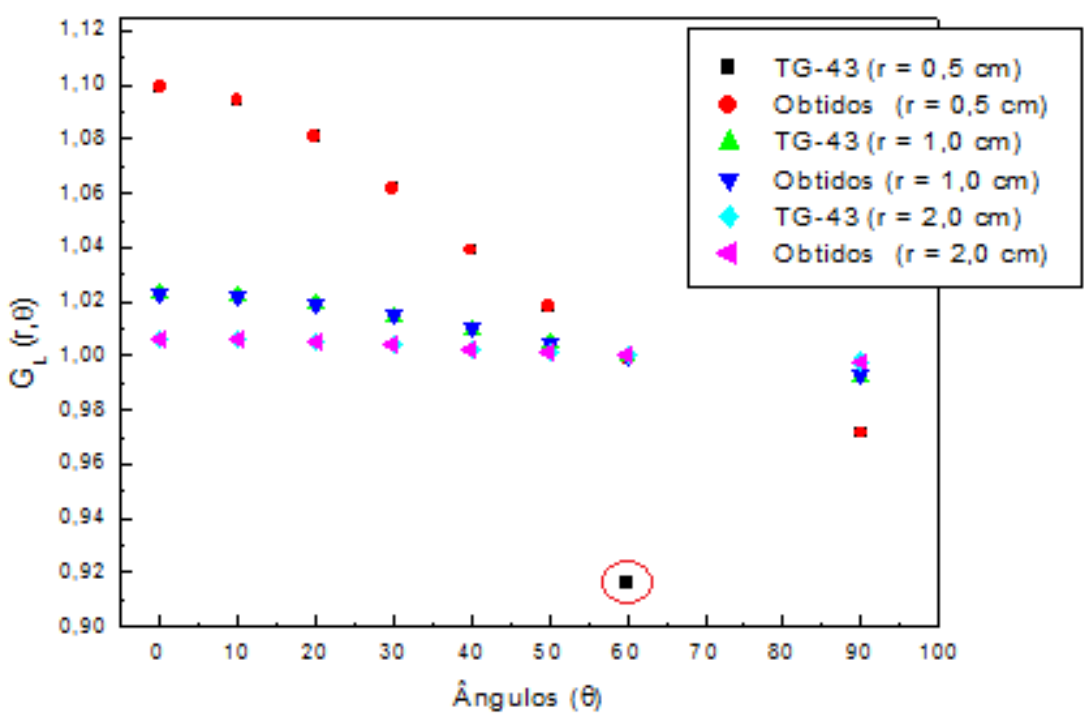

Figura 24: Fator geométrico em função do ângulo calculados neste e fornecidos pelo protocolo TG-43. 
Como é possível notar, a única diferença encontrada foi com relação ao ângulo de $60^{\circ}$, para a distância radial de $0,5 \mathrm{~cm}$, que está denotada com um círculo vermelho na figura 24. A diferença encontrada para esse ângulo foi de aproximadamente 8,3\%. Porém, Rivard (RIVARD, 1999) e King, Anderson e Mills (KING, ANDERSON, MILLS, 2001) reportaram sobre a discrepância do valor do fator geométrico, quando $r=0,5 \mathrm{~cm}$ e $\theta=60^{\circ}$. A diferença encontrada em ambos os artigos mencionados foi a mesma que a obtida neste trabalho, sendo o valor correto de 0,9985 e não de 0,9160 , como mencionado pelo TG-43. Com relação aos outros valores, nenhuma diferença foi encontrada. Portanto, para o cálculo do fator geométrico, serão utilizadas as equações (33) e (34).

Na tabela 7 são apresentados os valores de $\mathrm{G}_{\mathrm{L}}(\mathrm{r}, \theta)$ e $\mathrm{G}_{\mathrm{L}}(\mathrm{r}, \theta)$ multiplicado por $r^{2}$, para uma fonte de 3,5 $\mathrm{mm}$ de comprimento equivalente às fontes GammaMed Plus e BEBIG Co0.A86, analisadas nesse trabalho.

Tabela 7: Fatores geométricos obtidos para uma fonte de 3,5 $\mathrm{mm}$ de comprimento.

\begin{tabular}{cccccccc}
\hline Ângulos (graus) & \multicolumn{2}{c}{$\mathrm{r}=0,5 \mathrm{~cm}$} & $\mathrm{r}=1,0 \mathrm{~cm}$ & \multicolumn{2}{c}{$\mathrm{r}=2,0 \mathrm{~cm}$} & \multicolumn{2}{c}{$\mathrm{r}=3,0 \mathrm{~cm}$} \\
\cline { 2 - 8 } & $\mathrm{G}_{\mathrm{L}}$ & $\mathrm{G}_{\mathrm{L} \cdot \mathrm{r}^{2}}$ & $\mathrm{G}_{\mathrm{L}}$ & $\mathrm{G}_{\mathrm{L}}$ & $\mathrm{G}_{\mathrm{L} \cdot \mathrm{r}^{2}}$ & $\mathrm{G}_{\mathrm{L}}$ & $\mathrm{G}_{\mathrm{L}} \cdot \mathrm{r}^{2}$ \\
\hline 0 & 4,5584 & 1,1396 & 1,03159 & 0,25193 & 1,00772 & 0,11149 & 1,00341 \\
\hline 5 & 4,55108 & 1,13777 & 1,03125 & 0,25191 & 1,00764 & 0,11149 & 1,00338 \\
\hline 10 & 4,52958 & 1,13239 & 1,03024 & 0,25185 & 1,0074 & 0,11148 & 1,00328 \\
\hline 15 & 4,49524 & 1,12381 & 1,02861 & 0,25175 & 1,00702 & 0,11146 & 1,00311 \\
\hline 20 & 4,45010 & 1,11252 & 1,02640 & 0,25162 & 1,0065 & 0,11143 & 1,00288 \\
\hline 25 & 4,39663 & 1,09916 & 1,02370 & 0,25146 & 1,00586 & 0,11140 & 1,00260 \\
\hline 30 & 4,33742 & 1,08435 & 1,02060 & 0,25128 & 1,00512 & 0,11136 & 1,00227 \\
\hline 35 & 4,27512 & 1,06878 & 1,01721 & 0,25107 & 1,0043 & 0,11132 & 1,00191 \\
\hline 40 & 4,21209 & 1,05302 & 1,01365 & 0,25058 & 1,00232 & 0,11128 & 1,00153 \\
\hline 45 & 4,15037 & 1,03759 & 1,01002 & 0,25064 & 1,00254 & 0,11124 & 1,00113 \\
\hline 50 & 4,09178 & 1,02295 & 1,00643 & 0,25041 & 1,00165 & 0,11119 & 1,00074 \\
\hline 55 & 4,03760 & 1,00940 & 1,00299 & 0,25019 & 1,00079 & 0,11116 & 1,00047 \\
\hline 60 & 3,98915 & 0,99729 & 0,99982 & 0,24999 & 0,99999 & 0,11111 & 0,99999 \\
\hline 65 & 3,94681 & 0,98670 & 0,99688 & 0,24981 & 0,99926 & 0,11107 & 0,99967 \\
\hline 70 & --------- & --------- & 0,99453 & 0,24970 & 0,99881 & 0,11104 & 0,99939 \\
\hline 75 & --------- & --------- & 0,99257 & 0,24953 & 0,99813 & 0,11101 & 0,99917 \\
\hline 80 & --------- & --------- & -------- & 0,24944 & 0,99776 & 0,11100 & 0,99900 \\
\hline 85 & -------- & --------- & --------- & -------- & -------- & 0,11098 & 0,99890 \\
\hline 90 & 3,84771 & 0,96193 & 0,98998 & 0,24936 & 0,99745 & 0,11099 & 0,99887 \\
\hline
\end{tabular}

Como já mencionado anteriormente, a parte ativa da fonte é simétrica com relação ao eixo $\mathrm{X}$, recebendo os mesmos valores do fator geométrico de $90^{\circ}$ à $180^{\circ}$. Para determinados valores de distâncias radiais e ângulos, não foi possível determinar o valor do fator geométrico. Isso porque para esses valores, o denominador da equação (33) tende a zero, devido à combinação das funções trigonométricas utilizadas e o comprimento 
efetivo da fonte. O ângulo em que ocorre essa descontinuidade aumenta, conforme $r$ também aumenta. O protocolo TG-43 fornece alguns valores dos fatores geométricos para uma fonte com comprimento efetivo de $3 \mathrm{~mm}$, possuindo intervalo de até $20^{\circ}$ entre os ângulos analisados. Desta forma, a partir dos dados do protocolo, não é possível observar os ângulos em que existe essa descontinuidade. No intuito de verificar os valores dos ângulos em que essas descontinuidades ocorrem, os valores dos fatores geométricos foram calculados em um intervalo de $5^{\circ}$ entre os ângulos analisados, evidenciando as regiões próximas a essa descontinuidade.

A figura 25 mostra os valores dos fatores geométricos para uma fonte de $3,5 \mathrm{~mm}$ de comprimento para distâncias radias de $0,3 \mathrm{~cm}$ à $3,0 \mathrm{~cm}$.

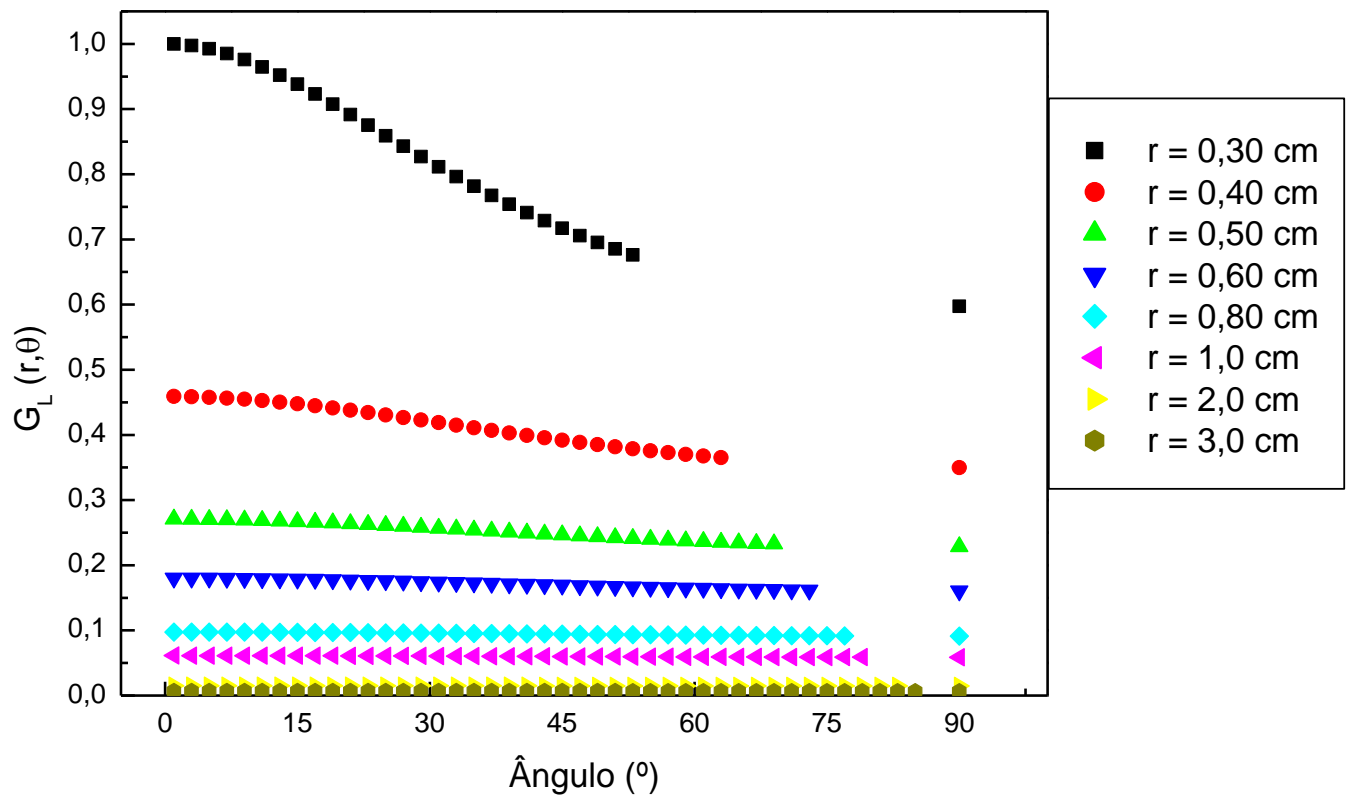

Figura 25: Fator geométrico em função dos ângulos, para valores de $r$ no intervalo de $0,30 \mathrm{~cm}$ à $3,0 \mathrm{~cm}$ para uma fonte de $3,5 \mathrm{~mm}$ de comprimento, normalizados em $0,30 \mathrm{~cm}$ e $0^{\circ}$.

O aumento dos ângulos em que fator geométrico pode ser calculado até que ocorra a descontinuidade, dependendo do valor de $r$, pode estar relacionado com o aumento do ângulo em que ocorre o "abaulamento" nas curvas de isodose produzidas pela fonte (mostrado em vermelho na figura 26). Na figura 26, em (a), (b) e (c) são mostradas curvas de isodose para a explicação dessa descontinuidade. 


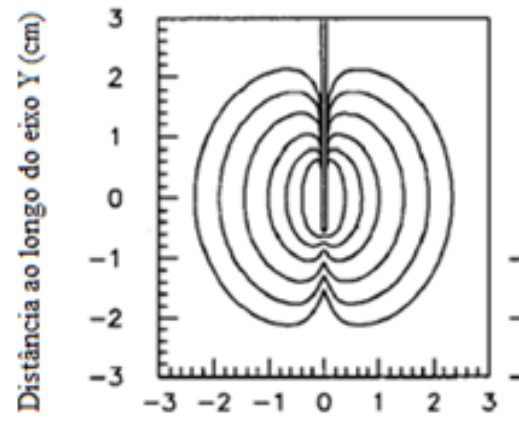

(a)

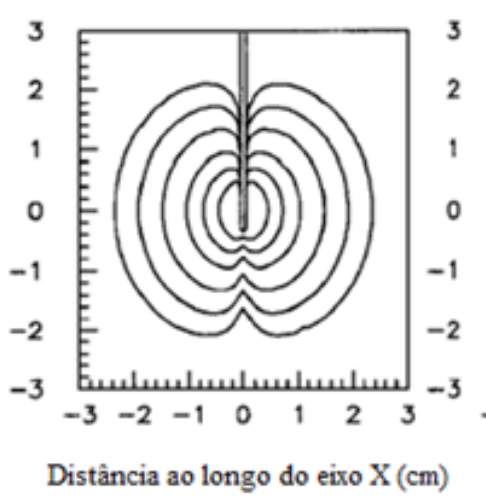

(b)

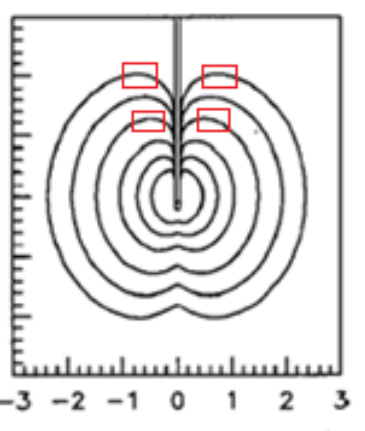

(c)

Figura 26: Curvas de isodose, calculadas através de Simulação Monte Carlo, para três tipos de fonte de ${ }^{192} \mathrm{Ir}$ (a) VariSource, (b) New Varian e (c) microSelectron (adaptado de ANGELOPOULOS et al, 2000).

Para qualquer um dos modelos da fonte de ${ }^{192}$ Ir apresentados, os valores das taxas de dose, começando da externa para a interna, são de 20,30, 50, 100, 200 e 500 cGy/h. É possível observar que conforme $r$ aumenta, o ângulo do "abaulamento" nas curvas de isodose também aumenta.

A literatura possui artigos de mesmo comprimento efetivo da fonte aos do protocolo $(3,0 \mathrm{~mm})$, mas não foi encontrada referência dos valores dos fatores geométricos para fontes de 3,5 $\mathrm{mm}$ que pudessem ser comparados. Nos artigos encontrados, os autores apenas evidenciam a fórmula de $\mathrm{G}_{\mathrm{L}}$ em função de $\beta$, sem explicitar a equação utilizada para o cálculo de $\beta$, apresentando diretamente os resultados dos parâmetros dosimétricos calculados, tais como função de dose radial e função de anisotropia, sem apresentar os resultados de $\mathrm{G}_{\mathrm{L}}$.

O fator geométrico é um dos fatores que contribuem para estimar a dose em torno da fonte analisada, de acordo com o protocolo TG-43. Quando esse fator é utilizado na fórmula para o cálculo da dose, o mesmo é normalizado pelo ângulo e posição de referência em braquiterapia, que são $90^{\circ}$ e $1 \mathrm{~cm}$ respectivamente, tornando-se um termo multiplicativo na fórmula (KING, ANDERSON, MILLS, 2001). Nesse caso, as fontes de braquiterapia de alta taxa de dose são aproximadas como sendo fontes lineares, sendo desprezada a dimensão radial da fonte, enquanto que para as que possuem uma única semente, são aproximadas como sendo fontes pontuais (KARAISKOS et al, 2000). Alguns sistemas de planejamentos, tais como Nucletron e Plato BPS, utilizam a aproximação de fontes pontuais nos cálculos de fator geométrico ao redor das fontes (DASKALOV, LÖFFLER, WILLIAMSON, 1998; KARAISKOS et al, 2000).

Na literatura analisada, o trabalho de Karaiskos e colaboradores (KARAISKOS et $a l, 2000)$ discute que a aproximação para fonte pontual, para fontes de braquiterapia que 
possuam uma única semente, possui elevada exatidão em distâncias radiais muito menores que a fonte. Essa exatidão também é mantida quando a distância radial levada em consideração é maior que o dobro do comprimento efetivo da fonte analisada. Porém, ainda no mesmo estudo, Karaiskos e colaboradores evidenciam um erro maior que $50 \%$ se a distância radial para uma fonte de braquiterapia for menor que o dobro do comprimento efetivo da fonte. Já em aproximações de fontes lineares, os erros encontrados são menores que $1 \%$ quando a distância radial é a metade do comprimento efetivo da fonte, ou seja, o erro é proporcional à razão entre a distância radial levada em consideração e o comprimento efetivo da fonte analisada. Portanto, dependendo da distância de interesse utilizada e do comprimento efetivo da fonte, o tipo de aproximação da fonte determinará a exatidão no cálculo da determinação da dose. Consequentemente, quanto melhor a precisão dos valores calculados nas funções trigonométricas e, portanto no fator geométrico, melhor será a estimativa da dose calculada.

\subsection{2 - Função de Dose Radial}

A função de dose radial revela o comportamento da dose ao longo das distâncias ao longo das distâncias no plano transversal. Fisicamente, são levados em consideração, os efeitos de absorção e espalhamento no meio ao longo do eixo transversal da fonte, excluindo a queda na dose devido à função geométrica.

Medidas de dose realizadas em objetos simuladores plásticos, equivalentes à água, podem ter elevada exatidão, mas em regiões próximas a fonte de braquiterapia essas medidas são difíceis de ser realizadas, devido ao alto gradiente de dose proporcionado pela fonte (MAINEGRA, CAPOTE, LÓPEZ, 2000). Um estudo realizado por Williamson e Nath (WILLIAMSON e NATH, 1991), mostra ainda, que água sólida não é capaz de reproduzir o espalhamento de água líquida para níveis de energia menores, o que pode resultar em uma baixa estimativa na penetração da radiação na água. As câmaras de ionização, utilizadas atualmente, apresentam algumas dificuldades, tais como: baixa resolução espacial e baixa sensibilidade. O método Monte Carlo com pacote PENELOPE, que contém uma grande biblioteca de seções de choque de fóton e já foram altamente testadas, torna-se uma forma plausível para obter funções dosimétricas, mais especificamente nesse caso, a função de dose radial.

De acordo com a equação (12), no cálculo dessa função estão envolvidos: taxa de dose no ponto de interesse, taxa de dose no ponto de referência, fator geométrico no ponto 
de interesse e fator geométrico no ponto de referência. Portanto um dos fatores que contribuirá com a incerteza calculada para a função da dose radial serão as incertezas obtidas nessas taxas de dose.

Nesse trabalho, os valores da função de dose radial foram determinadas de $0,5 \mathrm{~cm}$ à 3,0 cm, seguindo o protocolo TG-43. Foi utilizado um objeto simulador cúbico de $30 \mathrm{~cm}$ de lado, energia de corte de fótons e elétrons de $10 \mathrm{keV}$, os parâmetros de condensão de histórias (C1 e C2) com valor de 0,1 e o número de histórias simuladas foi mantido constante em $10^{9}$. Os resultados obtidos computacionalmente foram comparados com o artigo de Williamson e Li (WILLIAMSON e LI, 1995), que também utilizou em seu formalismo o TG-43. Esse artigo, tomado como sendo de referência para a comparação dos dados, utilizou de $5 \times 10^{5}$ à $4 \times 10^{6}$ histórias simuladas em uma esfera com água de diâmetro $30 \mathrm{~cm}$. Embora o tamanho do objeto simulador utilizada nesse trabalho tenha sido de $30 \mathrm{~cm}$ de lado, foi escolhido comparar apenas distâncias de $0,5 \mathrm{~cm}$ à $3,0 \mathrm{~cm}$, assim como nos outros parâmetros dosimétricos. Os valores da função de dose radial obtidas computacionalmente e os valores do artigo de referência, são apresentados na figura 27.

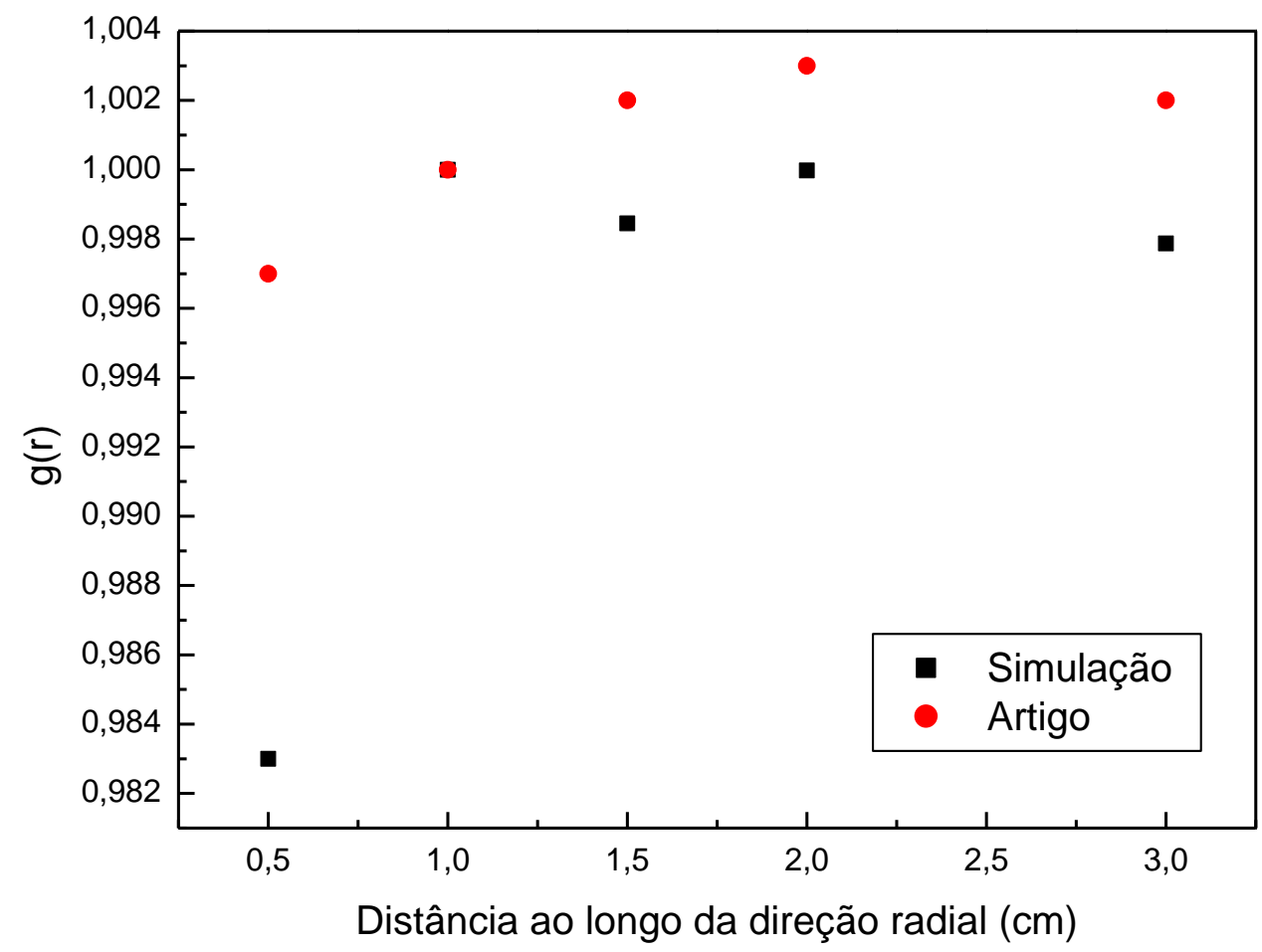

Figura 27: Valores da função de dose radial do artigo de referência e obtidos computacionalmente para a fonte de ${ }^{192} \mathrm{Ir}$.

Como é possível observar através da figura 27, os valores da função radial obtidos através da simulação Monte Carlo, apresentam boa concordância com relação ao artigo 
de referência. Os valores obtidos variaram de 0,983 à 1,000 enquanto que os valores do artigo variaram de 0,997 à 1,003. A maior diferença relativa encontrada foi de, aproximadamente, $1,4 \%$ em $0,5 \mathrm{~cm}$ e a incerteza de todos os valores é menor que $1 \%$.

Um dos motivos que pode acarretar essa variação, é o tamanho do pixel utilizado na simulação, que foi mantido constante em 0,0594 $\mathrm{cm}$. Embora esse seja um valor pequeno para cada pixel, onde foi possível obter informações dosimétricas detalhadas a respeito da fonte analisada, ele contém um valor médio da dose depositada pelas partículas nesse volume. Isso quer dizer que, para qualquer ponto que esteja compreendido no volume desse cubo, a dose será considerada a mesma, ocasionando esse comportamento. O grupo de Karaiskos e colaboradores (KARAISKOS et al, 1995) também utiliza o método Monte Carlo nos cálculos de parâmetros dosimétricos e realizou um estudo a respeito da influência do tamanho do objeto simulador nos cálculos da função de dose radial. Eles verificaram que, para valores próximos à margem do objeto simulador, foram encontradas incertezas maiores que $15 \%$ no cálculo da função de dose

radial e, para pontos distantes da margem, também foram encontradas diferenças, da ordem de $5 \%$.

Embora o formato e o tamanho dos objetos simuladores sejam diferentes, no artigo utilizado para comparação, na região onde os dados foram comparados houve uma diferença de até $1,4 \%$, apresentando boa concordância com a literatura analisada.

\subsection{3 - Função de Anisotropia}

A função de anisotropia mostra a variação da dose em função do ângulo relativo ao plano transversal da fonte. Esse parâmetro dosimétrico leva em consideração efeitos de atenuação e espalhamento no meio em torno da fonte.

Nesse trabalho, os valores da função de anisotropia foram determinados utilizando um objeto simulador cúbico de $30 \mathrm{~cm}$ de lado, preenchido com água, energia de corte de fótons e elétrons de $10 \mathrm{keV}$, os parâmetros de condensão de histórias (C1 e C2) com valor de 0,1 e o número de histórias simuladas foi $10^{9}$. Esse parâmetro dosimétrico foi calculado para distâncias que variaram de $0,25 \mathrm{~cm}$ à $3 \mathrm{~cm}$ e foram posteriomente comparados com valores existentes na literatura.

O artigo utilizado para comparação foi de Williamson e Li (WILLIAMSON e LI, 1995), que utiliza o MCPT (do inglês Monte Carlo photon-transport) escrito em FORTRAN-77 e simula absorção fotoelétrica, produção de pares, espalhamento 
incoerente e incoerente. Esse artigo escolhido utiliza uma fonte com as mesmas especificações que a analisada nesse trabalho, onde a mesma está localizada simetricamente sob o eixo Z, sendo o eixo Y o plano transversal, ou seja, perpendicular ao eixo longitudinal da fonte. O número de histórias simuladas nesse artigo estão entre $5 \times 10^{5}$ e $4 \times 10^{6}$.

Como é possível observar através da equação (14), as únicas grandezas que adicionam incertezas no cálculo desse parâmetro dosimétrico são os valores das taxas de dose, uma vez que as grandezas envolvidas no cálculo do fator geométrico são o comprimento efetivo da fonte e funções trigonométricas.

Os valores calculados para a função de anistropia, utilizando simulação Monte Carlo, e os valores do artigo de referência, para a distância de $0,5 \mathrm{~cm}$, são mostrados na figura 28.

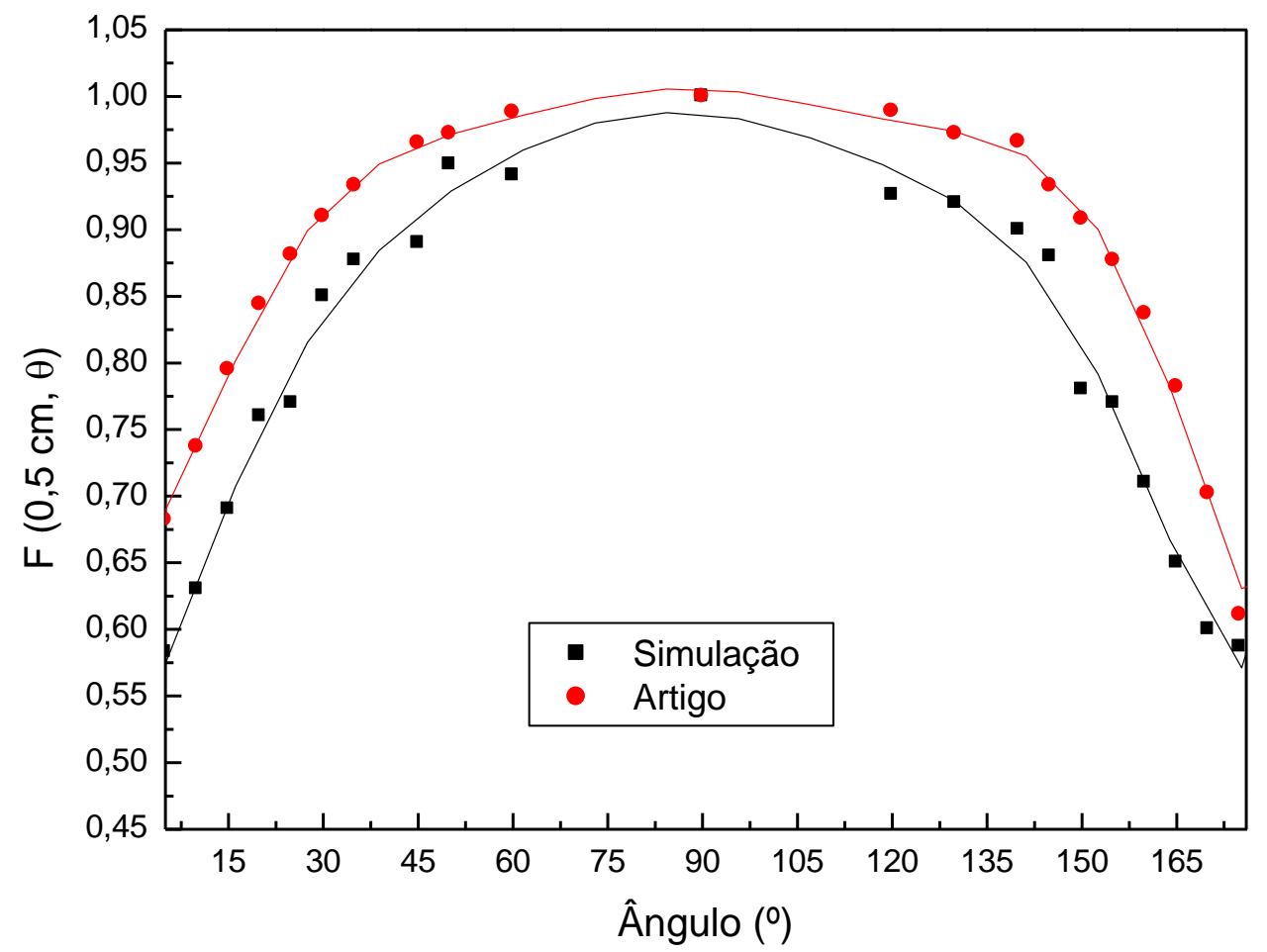

Figura 28: Função de anisotropia em função do ângulo na distância de $0,5 \mathrm{~cm}$ para fonte de ${ }^{192} \mathrm{Ir}$ obtidas por Williamson e colaboradores (WILLIAMSON e LI, 1995) e por simulação Monte Carlo.

Os dados apresentados por Williamson e Li (WILLIAMSON e LI, 1995), e os obtidos computacionalmente neste trabalho, possuem tendências semelhantes. Como é possível observar na figura 28, os valores da função de anisotropia obtidos na simulação variaram de 0,52 à 1,00 enquanto que os valores do artigo ficaram entre 0,61 à 1,00. A maior diferença relativa encontrada na comparação dos resultados obtidos na simulação 
com os dados do artigo de referência foi de aproximadamente $22 \%$, que correspondente ao ângulo de $0^{\circ}$. A incerteza obtida nesse trabalho é de aproximadamente $1 \%$ para os valores da função de anisotropia para a distância de 0,5 . Um ajuste polinomial de oitava ordem, que obedece à equação (35), foi utilizado nos dois conjuntos de pontos.

$$
Y=A+B 1 x+B 2 x^{2}+B 3 x^{3}+B 4 x^{4}+B 5 x^{5}+B 6 x^{6}+B 7 x^{7}+B 8 x^{8},
$$

onde $Y$ são os valores da função de anisotropia e $x$ são os valores dos ângulos considerados. Os valores dos parâmetros A, B1, B2, B3, B4, B5, B6, B7, B8 e R2 são mostrados na tabela 8 .

Tabela 8: Parâmetros de ajuste de um polinômio de oitava ordem para a função de anisotropia na distância de $0,5 \mathrm{~cm}$ para fonte de ${ }^{192} \mathrm{Ir}$.

\begin{tabular}{ccc}
\hline Parâmetros & \multicolumn{2}{c}{ Valores } \\
\cline { 2 - 3 } & $(0,6684 \pm 0,0093)$ & $(0,5230 \pm 0,0190)$ \\
\hline A & $(-0,0040 \pm 0,0008)$ & $(0,0082 \pm 0,0058)$ \\
\hline B1 & $(0,0011 \pm 0,0002)$ & $(0,0010 \pm 0,0001)$ \\
\hline B2 & $(-5,1603 \pm 1,1048) \times 10^{-5}$ & $(-2,8194 \pm 0,2461) \times 10^{-5}$ \\
\hline B3 & $(1,0801 \pm 0,2290) \times 10^{-6}$ & $(6,2825 \pm 0,4656) \times 10^{-7}$ \\
\hline B4 & $(-1,2459 \pm 0,2637) \times 10^{-8}$ & $(-7,6355 \pm 0,5362) \times 10^{-9}$ \\
\hline B5 & $(8,1024 \pm 1,7046) \times 10^{-11}$ & $(5,2195 \pm 0,3465) \times 10^{-11}$ \\
\hline B6 & $(-2,7791 \pm 0,5783) \times 10^{-13}$ & $(-1,8796 \pm 0,1175) \times 10^{-13}$ \\
\hline B7 & $(3,9010 \pm 0,8014) \times 10^{-16}$ & $(2,7669 \pm 0,1629) \times 10^{-13}$ \\
\hline B8 & 0,9963 & 0,9879 \\
\hline R $^{2}$ & &
\end{tabular}

Da mesma forma como foram analisados os valores da função de anisotropia para a distância de $0,5 \mathrm{~cm}$, os resultados para 1,0 cm são mostrados na figura 29 . 


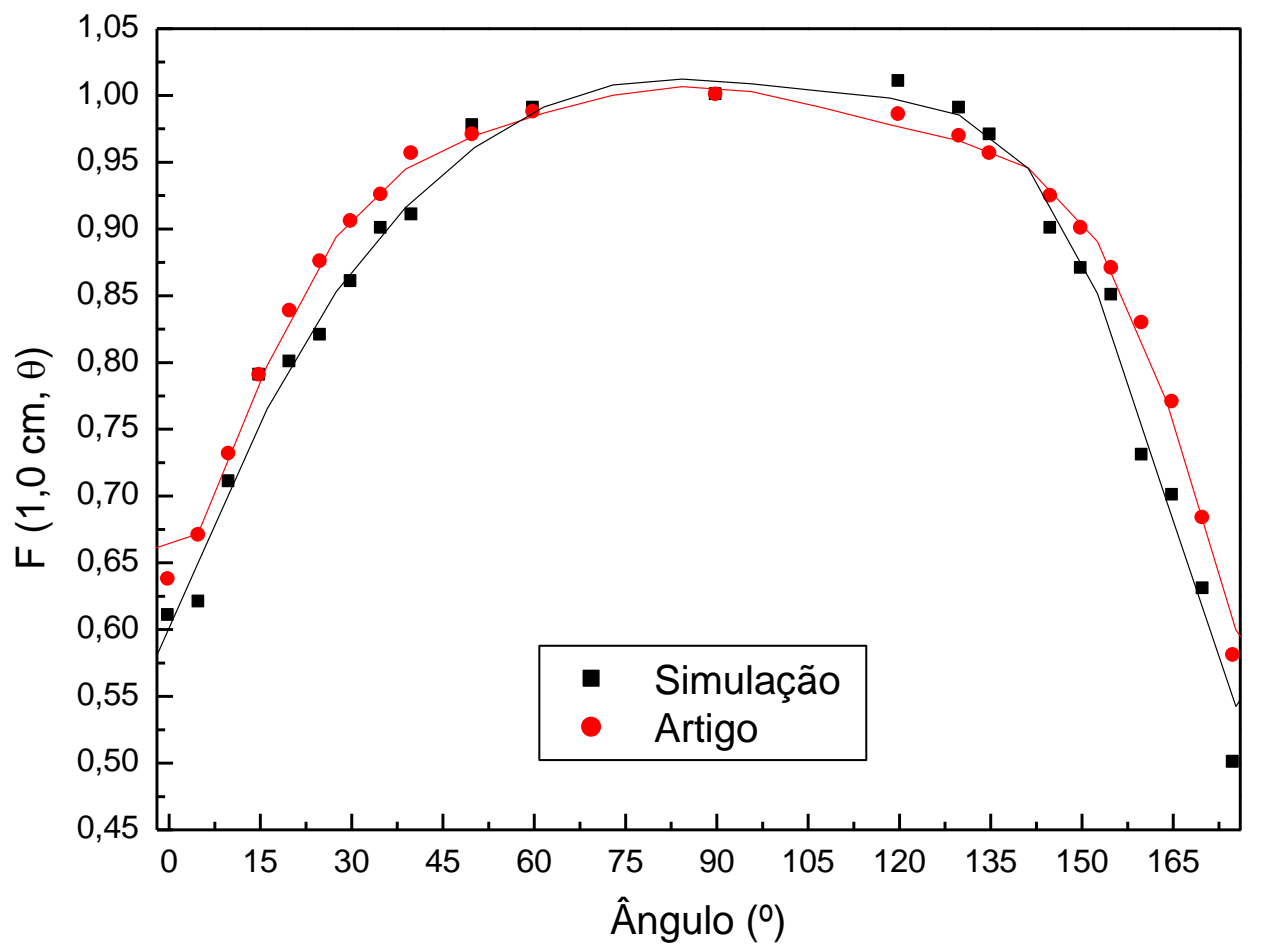

Figura 29: Valores obtidos na simulação e referentes ao artigo, para a função de anisotropia com distância de 1,0 cm (WILLIAMSON e LI, 1995).

Através da figura 28 é possível observar que os dois conjuntos de dados possuem comportamento semelhante. Os valores da função de anisotropia para a simulação estão compreendidos entre 0,50 e 1,01 e os valores do artigo variaram entre 0,55 e 1,00. A maior diferença relativa encontrada, comparando-se os dados do artigo e da simulação, foi de aproximadamente $13,8 \%$ no ângulo de $175^{\circ}$ enquanto que a incertezas de todos os valores são menores que $1 \%$. Um polinômio semelhante ao utilizado para a distância de 0,5 cm também foi utilizado para essa distância analisada. Os valores dos parâmetros de ajuste são mostrados na tabela 9 .

Tabela 9: Parâmetros de ajuste de um polinômio de oitava ordem para a função de anisotropia na distância de 1,0 cm para fonte de ${ }^{192} \mathrm{Ir}$.

\begin{tabular}{ccc}
\hline \multirow{2}{*}{ Parâmetros } & \multicolumn{2}{c}{ Valores } \\
\cline { 2 - 3 } & $(0,6359 \pm 0,0094)$ & $(0,5976 \pm 0,0238)$ \\
\hline A & $(0,0045 \pm 0,0029)$ & $(0,0107 \pm 0,0072)$ \\
\hline B1 & $(0,0008 \pm 0,0002)$ & $(0,0008 \pm 0,0001)$ \\
\hline B2 & $(-4,0278 \pm 1,1158) \times 10^{-5}$ & $(-1,0058 \pm 0,2832) \times 10^{-5}$ \\
\hline B3 & $(8,7412 \pm 2,3206) \times 10^{-7}$ & $(2,6898 \pm 0,5829) \times 10^{-7}$ \\
\hline B4 & $(-1,0281 \pm 0,2675) \times 10^{-8}$ & $(-3,7783 \pm 0,6721) \times 10^{-9}$ \\
\hline B5 & $(6,7631 \pm 1,7296) \times 10^{-11}$ & $(2,9279 \pm 0,4345) \times 10^{-11}$ \\
\hline B6 & $(-2,3341 \pm 0,5866) \times 10^{-13}$ & $(-1,1707 \pm 0,1473) \times 10^{-13}$ \\
\hline B7 & $(3,2834 \pm 0,8127) \times 10^{-16}$ & $(1,8729 \pm 0,2041) \times 10^{-16}$ \\
\hline B8 & 0,9966 & 0,9840 \\
\hline R & &
\end{tabular}


Na figura 30 estão contidos os dois conjuntos de dados referentes aos obtidos computacionalmente e do artigo de referência para a distância de 2,0 cm.

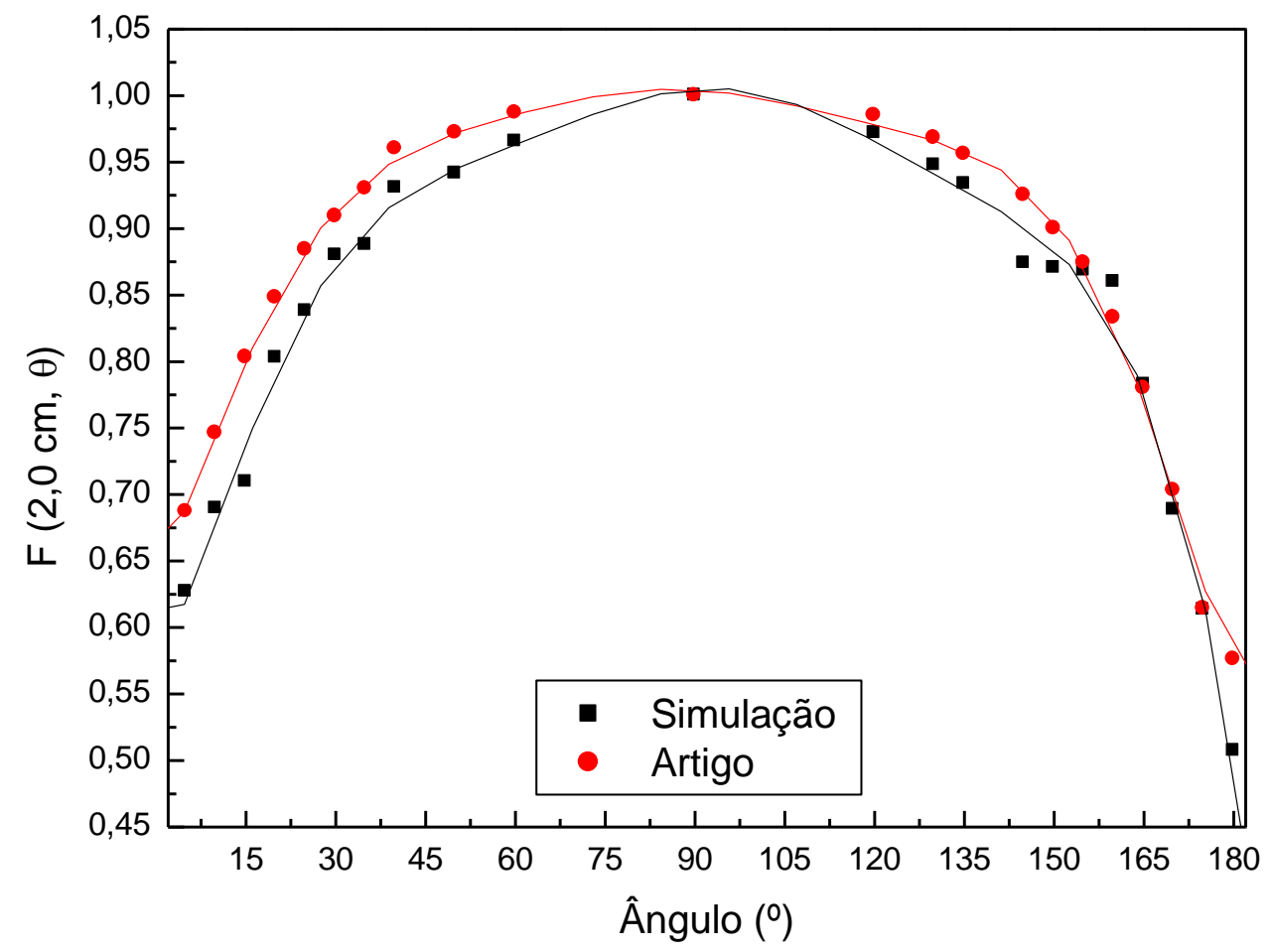

Figura 30: Valores obtidos na simulação e referentes ao artigo, para a função de anisotropia com distância de 2,0 cm (WILLIAMSON e LI, 1995).

Analisando a figura 30 é possível observar que, assim como nas distâncias de 0,5 e 1,0 cm, os dois conjuntos de dados possuem comportamento semelhante. Os valores da função de anisotropia obtidos variam de 0,51 à 1,00 e os valores do artigo estão entre 0,58 e 1,00. A maior diferença relativa encontrada, comparando-se os dados do artigo e da simulação, foi de aproximadamente $11,9 \%$ no ângulo de $180^{\circ}$ e a incerteza do fator de anisotropia em cada ângulo é menor que $10 \%$. O mesmo ajuste, utilizado para a distância de $0,5 \mathrm{~cm}$ também foi utilizado para essa distância analisada. Os valores dos parâmetros encontrados, são mostrados na tabela 10 . 
Tabela 10: Parâmetros de ajuste de um polinômio de oitava ordem para a função de anisotropia na distância de 2,0 cm para fonte de ${ }^{192} \mathrm{Ir}$.

\begin{tabular}{ccc}
\hline Parâmetros & \multicolumn{2}{c}{ Aalores } \\
\cline { 2 - 3 } & $(0,6451 \pm 0,0072)$ & $(0,5827 \pm 0,0166)$ \\
\hline A & $(0,0068 \pm 0,0022)$ & $(0,0040 \pm 0,0005)$ \\
\hline B1 & $(0,0010 \pm 0,0002)$ & $(0,0010 \pm 0,0004)$ \\
\hline B2 & $(-3,0661 \pm 0,8532) \times 10^{-5}$ & $(-4,0371 \pm 0,1962) \times 10^{-5}$ \\
\hline B3 & $(6,7512 \pm 0,1774) \times 10^{-7}$ & $(8,1747 \pm 0,4081) \times 10^{-7}$ \\
\hline B4 & $(-7,9588 \pm 0,2046) \times 10^{-9}$ & $(-8,8951 \pm 0,4706) \times 10^{-9}$ \\
\hline B5 & $(5,2310 \pm 1,3225) \times 10^{-11}$ & $(5,3657 \pm 0,3042) \times 10^{-11}$ \\
\hline B6 & $(-1,8025 \pm 0,4486) \times 10^{-14}$ & $(-1,6857 \pm 1,0319) \times 10^{-13}$ \\
\hline B7 & $(2,5310 \pm 0,6214) \times 10^{-16}$ & $(2,1444 \pm 0,1429) \times 10^{-16}$ \\
\hline B8 & 0,9978 & 0,9901 \\
\hline$R^{2}$ & &
\end{tabular}

Na figura 31 são mostrados os dados obtidos através da simulação Monte Carlo, juntamente com os dados do artigo de referência para a distância de $3,0 \mathrm{~cm}$.

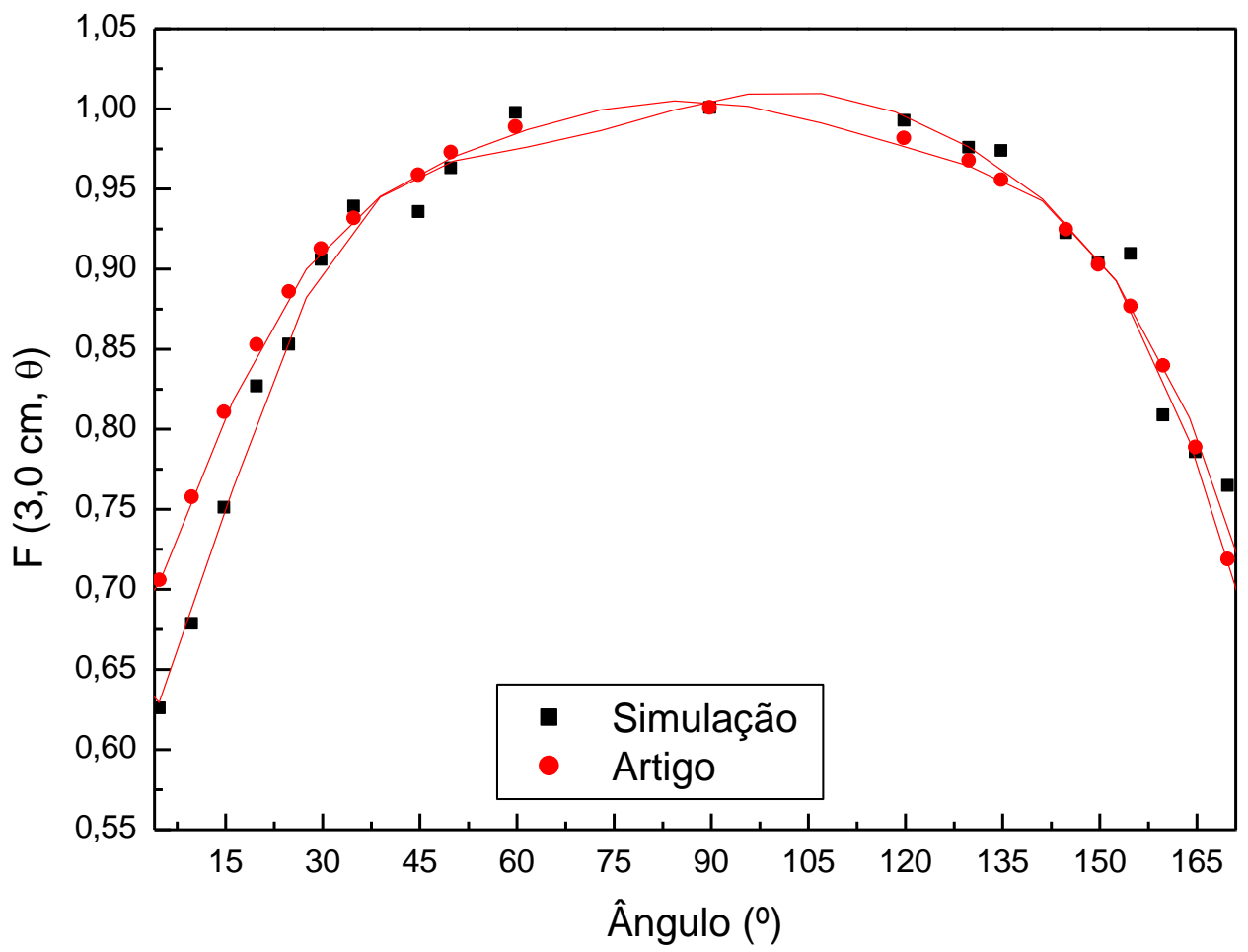

Figura 31: Valores obtidos na simulação e referentes ao artigo, para a função de anisotropia com distância de 3,0 cm (WILLIAMSON e LI, 1995).

Como para as outras distâncias, na distância de 3,0 cm é possível notar que os resultados obtidos computacionalmente também possuem a mesma tendência dos dados do artigo de referência. Enquanto os dados computacionais desse trabalho ficaram entre 0,61 e 1,00, os dados do artigo de referência variaram entre 0,60 e 1,00. No ângulo de $5^{\circ}$ 
foi encontrado a máxima diferença relativa entre os pontos analisados, que foi de 11,3\%. A incerteza do fator de anisotropia para essa distância é menor que $10 \%$.

Para a distância de 3,0 cm, foi realizado um ajuste de $8^{a}$ ordem para os dois conjuntos de dados, onde obteve-se os parâmetros mostrados na tabela 11 .

\begin{tabular}{|c|c|c|}
\hline \multirow{3}{*}{ Parâmetros } & cm para & nte de ${ }^{192}$ Ir. \\
\hline & \multicolumn{2}{|c|}{ Valores } \\
\hline & Artigo & Simulação \\
\hline A & $(0,6623 \pm 0,0057)$ & $(0,6083 \pm 0,0173)$ \\
\hline B1 & $(0,0071 \pm 0,0017)$ & $(0,0040 \pm 0,0001)$ \\
\hline $\mathrm{B} 2$ & $(0,0004 \pm 0,0001)$ & $(0,0012 \pm 0,0004)$ \\
\hline B3 & $(-2,5666 \pm 0,6789) \times 10^{-5}$ & $(-5,1212 \pm 0,2037) \times 10^{-5}$ \\
\hline B4 & $(5,7792 \pm 0,1404) \times 10^{-7}$ & $(9,7091 \pm 0,4214) \times 10^{-7}$ \\
\hline B5 & $(-6,921 \pm 0,1614) \times 10^{-9}$ & $(-1,0059 \pm 0,4843) \times 10^{-9}$ \\
\hline B6 & $(4,6030 \pm 1,041) \times 10^{-11}$ & $(5,8718 \pm 0,3125) \times 10^{-11}$ \\
\hline B7 & $(-1,5996 \pm 0,3531) \times 10^{-14}$ & $(-1,8151 \pm 0,1056) \times 10^{-13}$ \\
\hline B8 & $(2,2596 \pm 0,4892) \times 10^{-16}$ & $(2,3104 \pm 0,1468) \times 10^{-16}$ \\
\hline $\mathrm{R}^{2}$ & 0,9978 & 0,9901 \\
\hline
\end{tabular}

Para todos os valores de distâncias analisadas, a função de anisotropia é crescente até $90^{\circ}$ e depois tem seu valor diminuído. Isso quer dizer que para um mesmo valor de $r$, quando este está sob o eixo z, o parâmetro dosimétrico é menor que para pontos ao longo do eixo X. Quando o vetor $\vec{r}$ é rotacionado, aproximando-se de $90^{\circ}$, o fator de anisotropia vai se aproximando de um valor máximo. Conforme o ângulo de rotação aumenta, chegando próximo ao cabo, o valor desse fator em questão diminui.

Em todos os conjuntos de dados obtidos nesse trabalho, foi possível observar uma tendência de um mesmo valor do fator de anisotropia para ângulos que estejam relativamente próximos. Um dos motivos que pode acarretar esse comportamento é o tamanho do pixel utilizado nas simulações. Como já mencionado, o tamanho do pixel é um cubo de lado $0,0594 \mathrm{~cm}$ e o valor da taxa de dose fornecido nas simulações é uma média da taxa de dose depositada no volume desse pixel. Isso quer dizer que, para qualquer ponto que esteja compreendido no volume desse cubo, o valor da taxa de dose é o mesmo. Como foram escolhidos valores de ângulos muito próximos, há a possibilidade de dois pontos com mesma distância radial e ângulos diferentes, coincidir no mesmo pixel. Conforme o valor da distância aumenta, a possibilidade de coincidir no mesmo pixel também aumenta, como é possível observar nas distâncias de 2,0 cm e $3,0 \mathrm{~cm}$. 
Wu e colaboradores (WU et al, 2014) reproduziu sob as mesmas condições o trabalho de Williamson e Li, utilizando o código MCNPX (do inglês Monte Carlo NParticle eXtended). Eles encontraram uma diferença de 4,6\% no fator de anisotropia para a distância de $1 \mathrm{~cm}$ em ângulos menores que $5^{\circ}$ e de $2,5 \%$ quando o ângulo variou de $5^{\circ}$ à $180^{\circ}$. Porém, para distâncias maiores que $1 \mathrm{~cm}$, a diferença encontrada foi de $2 \%$. Alguns dos motivos que podem ocasionar a diferença entre os estudos é o número de partículas simuladas, o tamanho e a composição do objeto simulador utilizado. No caso do artigo de referência, foi utilizado um objeto simulador de formato esférico com $30 \mathrm{~cm}$ de diâmetro, enquanto que nesse trabalho foi utilizado um objeto simulador de formato cúbico de lado $30 \mathrm{~cm}$. Embora os tamanhos e os formatos desses objetos simuladores sejam diferentes, foi encontrado um mesmo comportamento da função de anisotropia em função dos ângulos e das distâncias. A maior diferença relativa encontrada entre o artigo de referência e os dados obtidos nesse trabalho foi de aproximadamente 13,8\% para o ângulo de $175^{\circ} \mathrm{em}$ uma distância de $1,0 \mathrm{~cm}$, porém todos os dados obtidos apresentam a mesma tendência obtida na literatura. 


\section{3 - Dosimetria Gel com Fonte de ${ }^{192} \mathrm{Ir}$}

Os experimentos realizados nesse trabalho foram feitos no HCFMRP. A fonte utilizada foi de ${ }^{192}$ Ir de alta taxa de dose, Varian, modelo GammaMed Plus. Primeiramente os planos de tratamento foram montados, de acordo com a geometria e a dose desejada em cada objeto simulador, no sistema de planejamento BrachyVision, da Varian, utilizado no setor de braquiterapia. Na figura 32 é mostrada uma tela do sistema de planejmanto utilizado no setor de braquiterapia do HCFMRP.

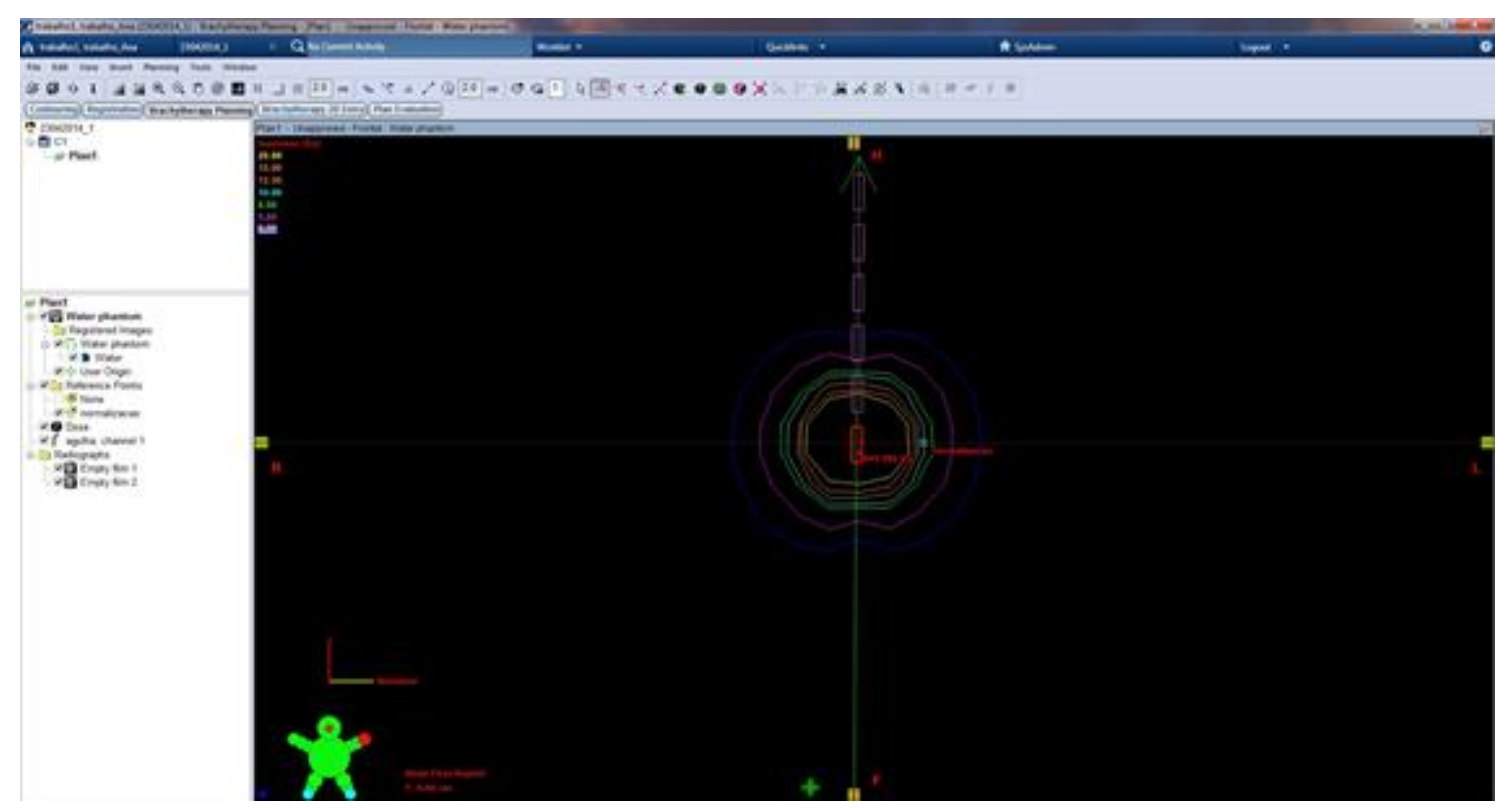

Figura 32: Tela do programa de planejamento BrachyVision utilizado no HCFMRP.

Nas irradiações foi necessário utilizar um aplicador igual ao utilizado no estudo computacional da fonte de ${ }^{192}$ Ir. Esse aplicador é de aço inoxidável AISI 316L com comprimento de $20 \mathrm{~cm}$ e diâmetro de $0,165 \mathrm{~cm}$ e também é utilizado nos tratamentos de braquiterapia. A agulha foi sempre posicionada verticalmente, no centro de cada objeto simulador e em todas as irradiações realizadas a normalização da dose no sistema de planejamento será feita em $0,9 \mathrm{~cm}$.

Nessa parte experimental do trabalho foram utilizados dois tipos de objetos simuladores: um de capacidade de $4 \mathrm{ml}$ e outro de capacidade de $175 \mathrm{ml}$. O tubo menor será utilizado na construção da curva de calibração e o segundo objeto simulador será utilizado na avaliação das doses ao longo do volume. Os dois objetos simuladores mencionados são apresentados na figura 33. 


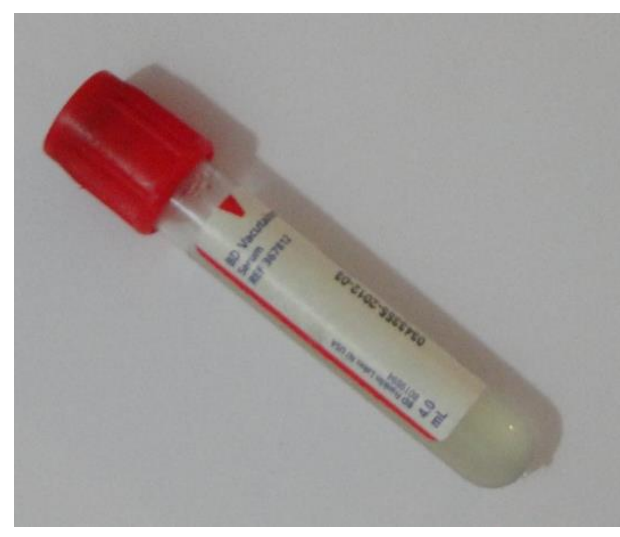

(a)

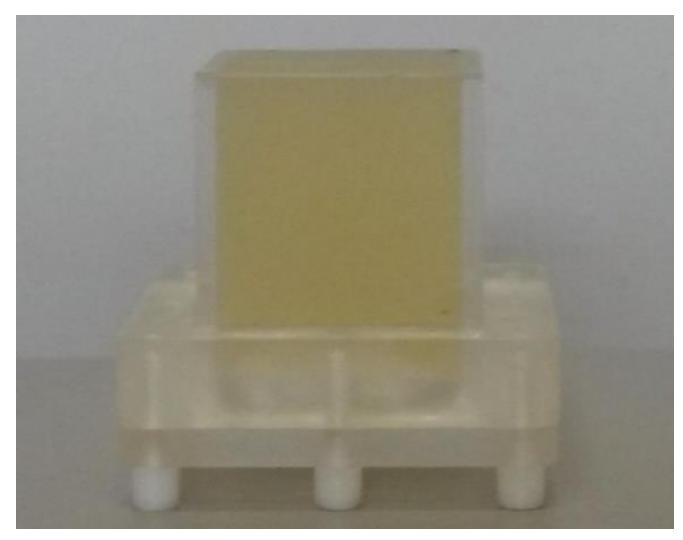

(b)

Figura 33: Objetos simuladores utilizados nos experimentos desse trabalho (a) $4 \mathrm{ml} \mathrm{e} \mathrm{(b)} 175 \mathrm{ml}$.

O objeto simulador mostrado na figura 33(a), tubo de coleta de sangue Vacutainer $^{\circledR}$, possui altura de $6,5 \mathrm{~cm}$ e diâmetro de $1 \mathrm{~cm}$, enquanto que o objeto simulador da figura 32(b) possui dimensões de $5 \times 5 \times 7 \mathrm{~cm}^{3}$. O segundo objeto simulador é feito de acrílico e possui na base inferior uma tampa que foi retirada no momento da irradiação para inserção da agulha e fechada logo em seguida.

\subsection{1 - Curva de Calibração}

Com o intuito de se verificar a resposta do gel em função da dose, foram

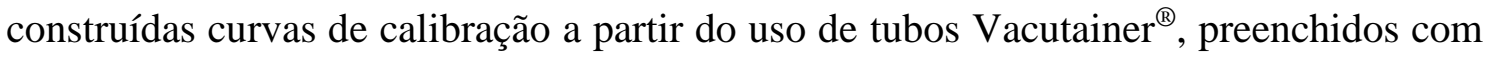
o gel polimérico MAGIC- $f$, conforme mostrado na figura 34. Os tubos foram armazenados na geladeira até o momento da irradiação e finalizada a irradiação até o momento da leitura. 


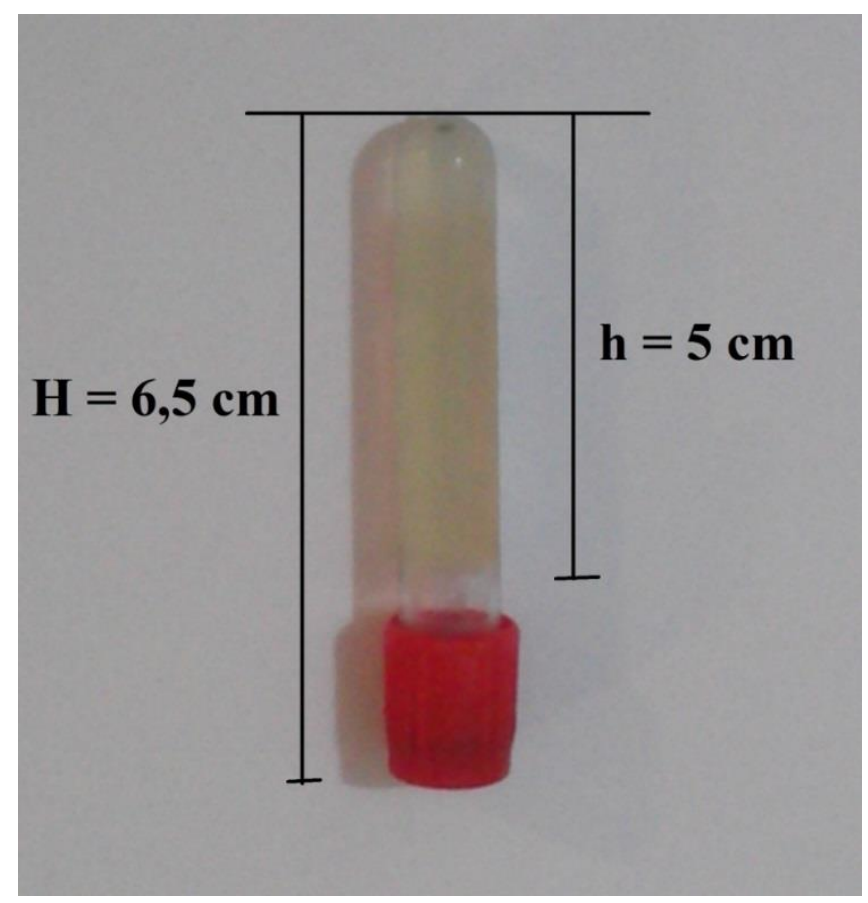

Figura 34: Tubo Vacutainer® de $4 \mathrm{ml}$, preenchidos com o gel polimérico MAGIC- $f$, para irradiação na fonte de ${ }^{192}$ Ir para calibração.

Para a calibração os valores das doses foram compreendidos entre 0 à 20 Gy. Para cada dose foram irradiados 3 tubos, denominados A, B e C (apenas para questão de referência) e a agulha (aplicador) colocada no centro à $0,9 \mathrm{~cm}$ de cada tubo, conforme mostrados na figura 34(a). Para garantir a condição de espalhamento durante a irradiação, o sistema foi inserido em um cubo de acrílico de 30x30x30 $\mathrm{cm}^{3}$, em que se acrescentou água até a altura de $20 \mathrm{~cm}$. Na figura 35 (b) é apresentado o sistema, composto de 3 tubos Vacutainer® juntamente com o aplicador, inserido no objeto simulador de acrílico utilizados nas irradiações de calibração.

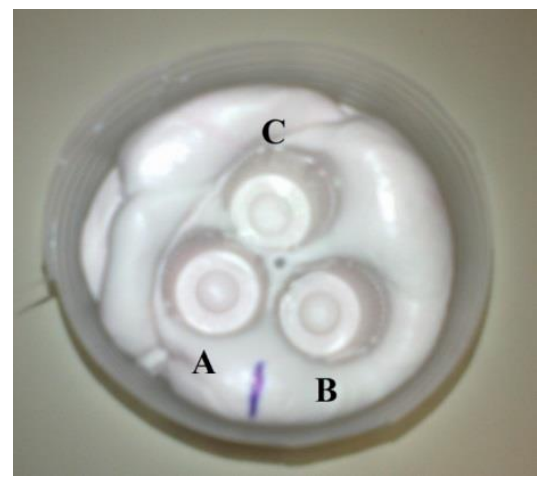

(a)

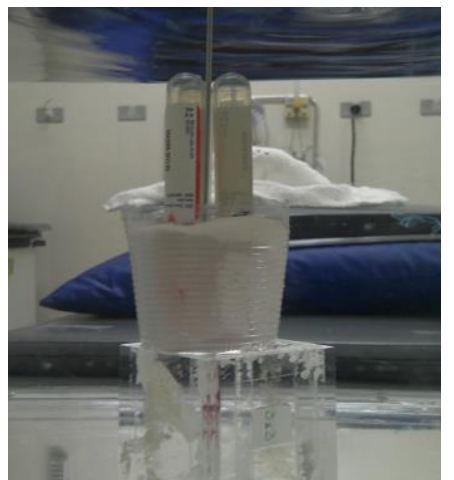

(b)

Figura 35: (a) Esquema de referência para a irradiação (b) Sistema dos tubos Vacutainer® inserido no cubo de acrílico com água para irradiação 
A fonte de ${ }^{192}$ Ir de alta taxa de dose, utilizada nesse trabalho, fica armazenada em um cofre, que é apresentado na figura 36.

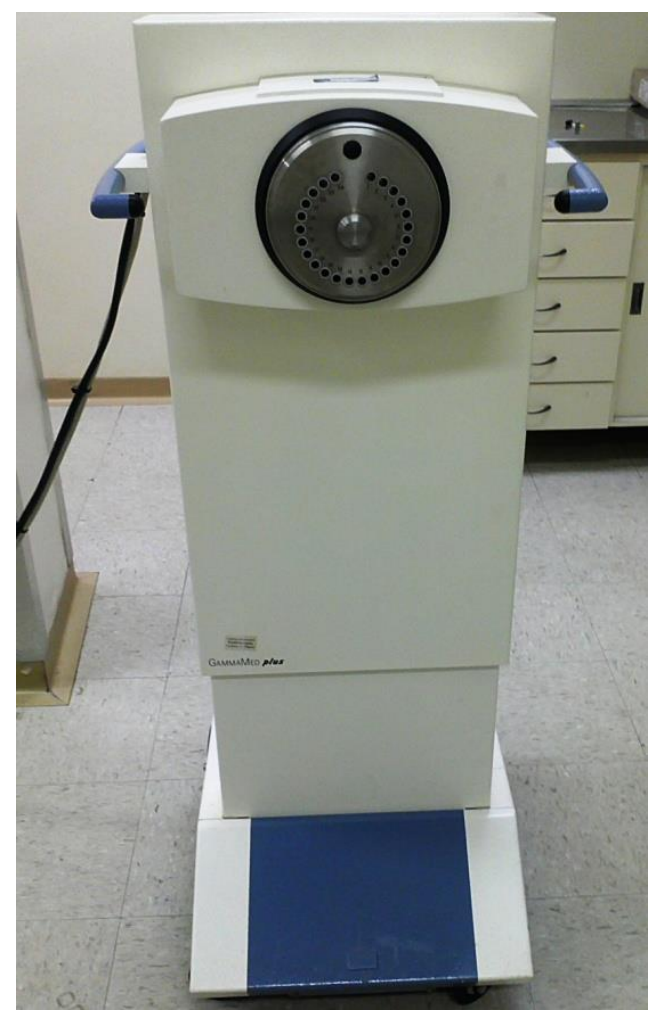

Figura 36: Cofre onde está contida a fonte de ${ }^{192}$ Ir de alta taxa de dose, Varian, modelo GammaMed Plus.

Terminada a irradiação, todos os objetos simuladores eram estocados novamente na geladeira. Após 24 horas da irradiação, foi realizado a leitura do gel, como será descrito a seguir.

A leitura de cada amostra foi realizada através de imagem de ressonância magnética, utilizando uma sequência multi spin-eco com 16 ecos, com tempo de repetição (TR) de 6000 ms, no tomógrafo RMN Philips 3.0 T, no HCFMRP. Durante a leitura, os tubos foram inseridos em uma caixa de acrílico, com dimensões de $12 \mathrm{~cm}$ x $17 \mathrm{~cm} \mathrm{x}$ $14 \mathrm{~cm}$, como mostrado na figura 37. A fim de minimizar o efeito da susceptibilidade magnética dos tubos em relação ao ar, essa caixa foi preenchida com uma solução de $0,3 \%$ de $\mathrm{MnCl}_{4} \mathrm{H}_{2} \mathrm{O}$ e $0,2 \%$ de $\mathrm{NaCl}$. As leituras das amostras nesse trabalho, foram realizadas 24 horas após a irradiação. 


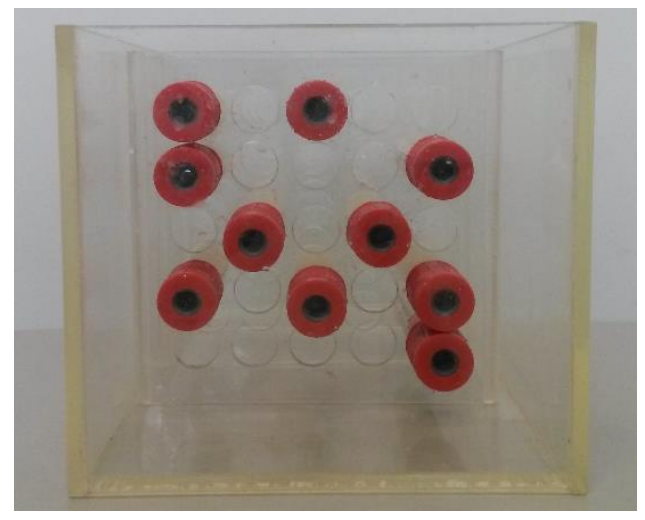

(a)

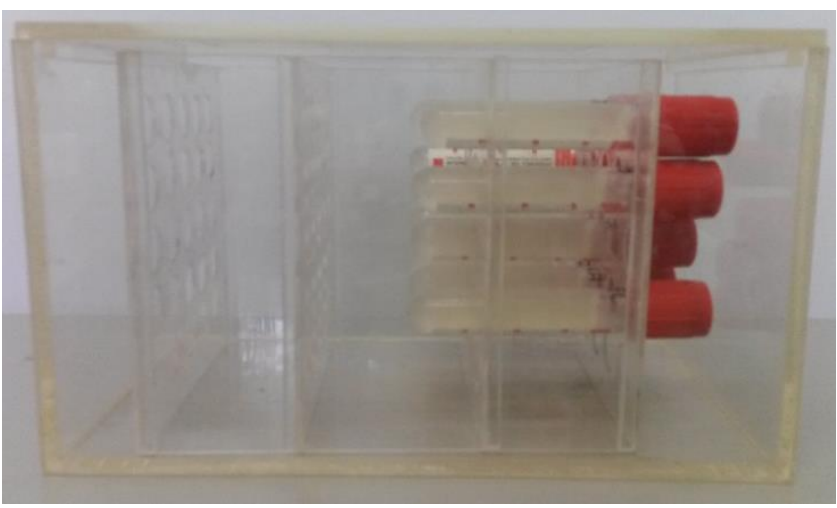

(b)

Figura 37: Vista (a) frontal e (b) lateral da caixa de acrílico utilizada nas leituras dos fantomas Vacutainer®.

Essas imagens são obtidas no formato DICOM, usando relaxometria em T2 e através do programa desenvolvido pelo grupo de pesquisa, na plataforma MATLAB ${ }^{\circledR}$, foi possível obter os mapas de R2 pixel a pixel relacionando-os com a dose.

Os valores de R2 para o dosímetro gel MAGIC- $f$ em função das doses de calibração, obtidos após 24 horas da irradiação, são mostrados na figura 38.

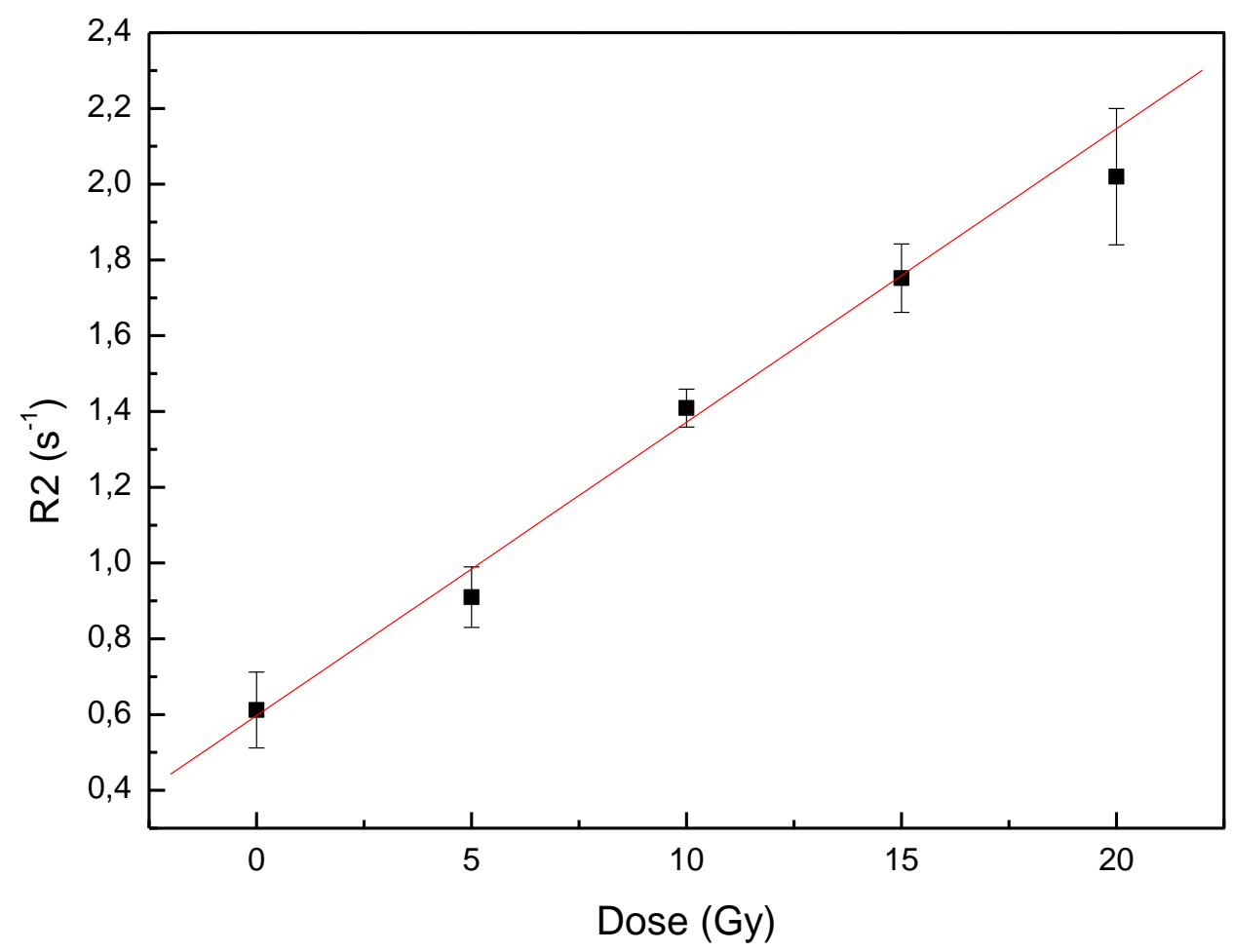

Figura 38: R2 em função da dose para o dosímetro gel MAGIC- $f$

A figura 38 é uma curva típica de calibração que foi repetida todos os dias em cada estudo. 
Foi realizado um ajuste linear nos valores de R2 em função da dose, onde foi obtido um coeficiente de correlação de 0,996 . Durante a realização desse trabalho, outros testes foram feitos, restringindo os valores da dose de 0 à $10 \mathrm{~Gy}$. Nesse intervalo de dose não foi observado um comportamento linear dos valores de R2 para valores de dose até 5 Gy. Uma das hipóteses para que isso tenha acontecido é que todas as vezes em que foram realizadas as irradiações, o valor da atividade da fonte estava alta (aproximadamente $8 \mathrm{Ci}$ ). A alta atividade da fonte faz com que o processo de iniciação da polimerização não é finalizado, existindo a quebra das ligações entre os monômeros e portanto diminuindo o sinal

Um outro estudo realizado nesse trabalho, foi com relação ao comportamento do valor de R2, em dois intervalos de leitura distintos após a irradiação: 24 horas e 8 dias. As duas curvas de dose-resposta apresentam valores lineares para doses até 20 Gy. Para a leitura realizada 24 horas após a irradiação, os valores de R2 estão compreendidos entre $0,4 \mathrm{~s}^{-1}$ e $2,5 \mathrm{~s}^{-1}$, enquanto que os valores das leituras realizadas após 8 dias variam de $1,0 \mathrm{~s}^{-1}$ à 4,3 $\mathrm{s}^{-1}$. Comparando-se os valores, observou-se um aumento de em média $40 \%$ nas leituras após 8 dias, para os valores doses compreendidas de 5 à $20 \mathrm{~Gy}$. Isso indica que a polimerização, iniciada a partir da irradiação, ainda não foi finalizada após 24 horas. Nesse sentido, para aplicações clínicas, é necessário estabelecer um protocolo de leitura do gel. Neste trabalho, foi escolhido um tempo de leitura das amostras de 24 horas.

\subsection{2 - Distribuição de Dose com MAGIC- $f$}

Nesta seção será apresentada uma comparação entre as distribuições de utilizando o gel MAGIC- $f$ e as distribuições obtidas através da simulação Monte Carlo.

$\mathrm{Na}$ avaliação da distribuição de dose da fonte de ${ }^{192} \mathrm{Ir}$, a posição do aplicador também foi mantida no centro do objeto simulador e conectado ao cofre em que a fonte fica armazenada, conforme mostrado na figura 39. 


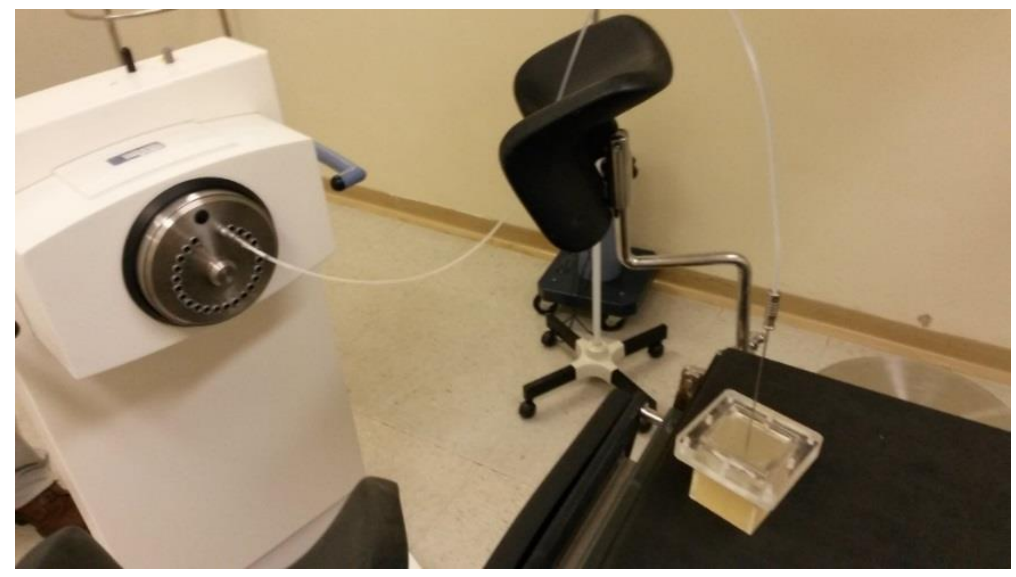

Figura 39: Aplicador inserido no objeto simulador e conectado ao cofre.

A comparação entre as distribuições de dose experimentais e simuladas serão realizadas através do programa Image-J e do Índice Gama. A ferramenta utilizada para análise das doses na distância radial, foi o programa Image-J. Esse programa é de domínio público e comumente utilizado em processamento de imagens. A análise das doses nos planos do volume irradiado foi realizada com o Índice Gama.

\section{Análise na Direção Radial}

A vantagem da análise das doses realizadas na direção radial é a ausência de critérios de aceitação na comparação entre os pontos. Nessas análises, foi selecionada uma região central, passando pela fonte, da imagem de um objeto simulador irradiado com 20 Gy. Na figura 40 é mostrada uma região analisada (a) e o perfil de intensidades fornecido pelo programa (b).

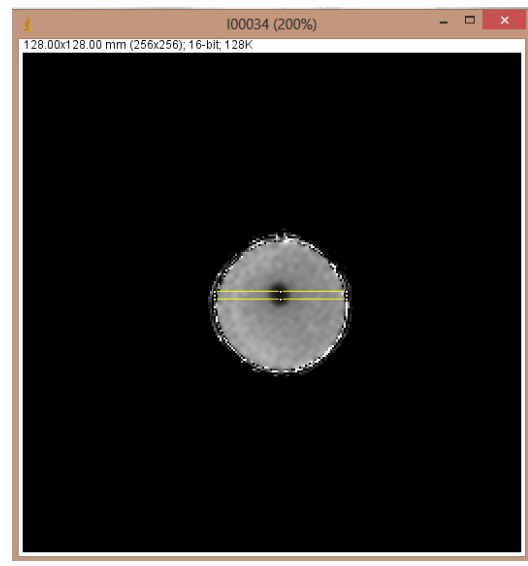

(a)

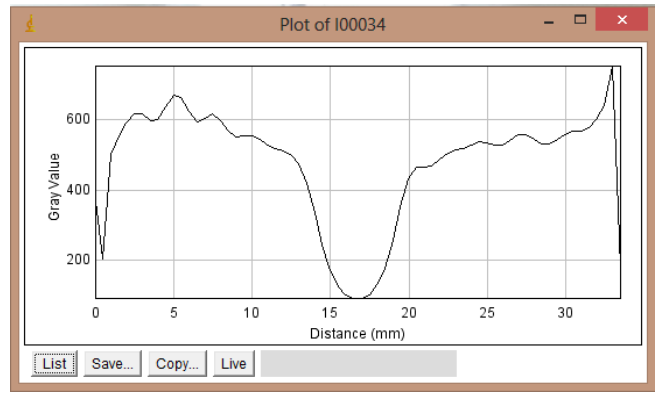

(b)

Figura 40: Imagem da leitura de ressonância utilizada no programa Image-J (a) Região analisada (b) perfil de intensidades referente à região selecionada. 
Como é possível observar através da imagem 40(b) o perfil de intensidades é relacionado à valores de "escala de cinza" em função da distância da fonte. Na região central, mais escura, dessa imagem, é a posição do aplicador inserido no gel. O diâmetro dessa região foi determinado e excluído das análises. É válido lembrar que no momento da inserção do aplicador no objeto simulador, por mais que se tente colocá-lo na vertical, há uma pequena inclinação e consequentemente a presença de ar no sistema.

A dose absorvida pelo objeto simulador é relacionada com o inverso dos valores da intensidade fornecidos pelo programa. Foi realizada a transformação dessa escala de intensidades, seguida pela normalização das mesmas em um mesmo ponto com os dados da simulação. Essa comparação é mostrada na figura 41.

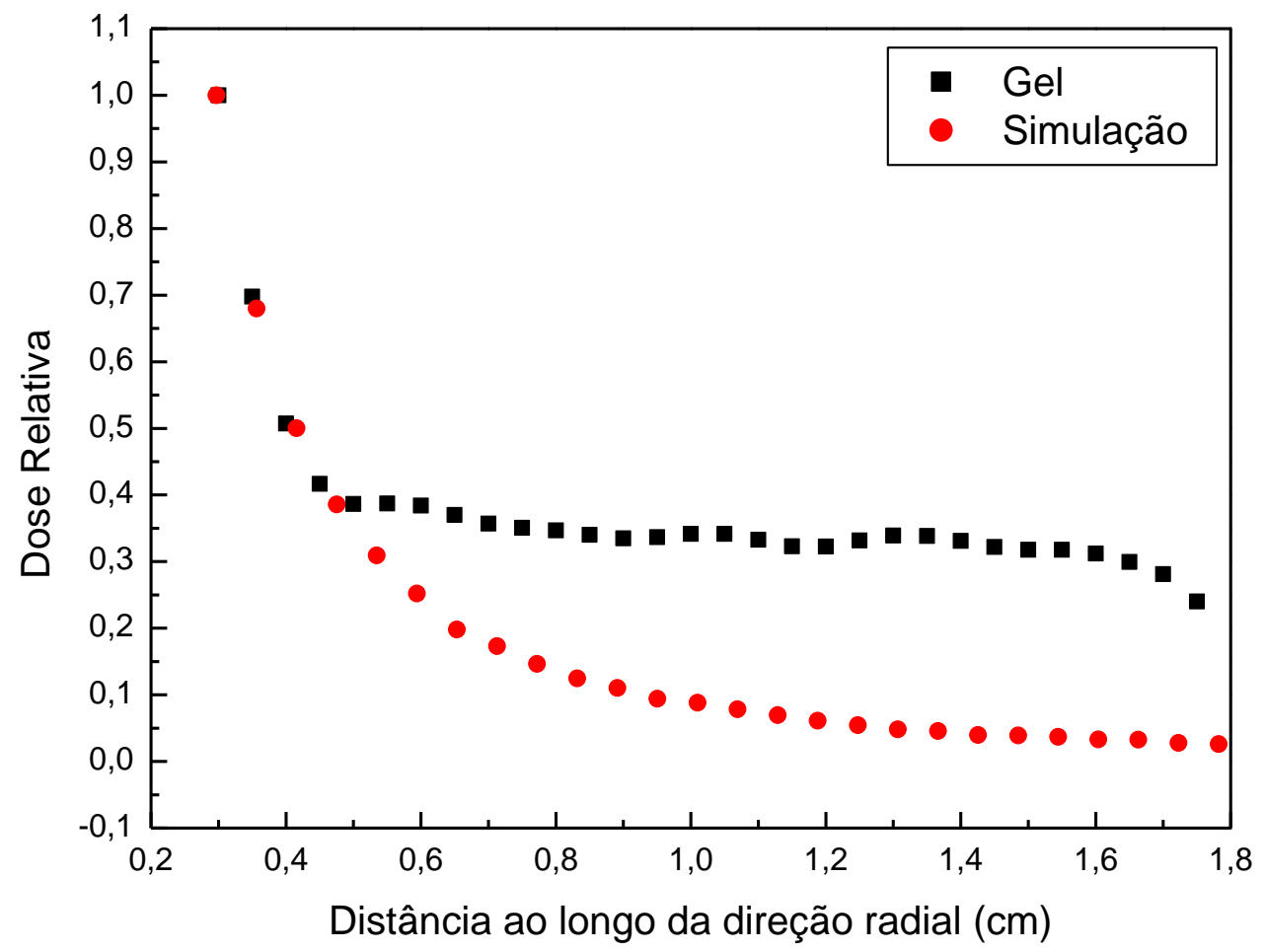

Figura 41: Dose relativa em função da distância ao longo da direção radial para o gel e para simulação Monte Carlo.

Através da figura 41 é possível observar que até, aproximadamente, $40 \%$ do valor máximo da dose, as doses obtidas com o gel e simulação apresentam concordância. Porém, para maiores distâncias da fonte, essa concordância diminui significativamente. Para o gel, é como se existisse dose para valores de distância radial maiores, o que não é apresentado na simulação. Uma saturação na resposta do gel é apresentada a partir desse ponto, o que não é notado na simulação. Como já mencionado, a região que não apresenta 
concordância com os dados obtidos na simulação, é a região que não apresenta linearidade em função da dose na resposta do gel.

Como houve uma discrepância significativa entre as doses obtidas através do gel MAGIC- $f$ e da simulação Monte Carlo, para distâncias maiores que aproximadamente 0,50 cm, comparou-se os dados obtidos computacionalmente nesse trabalho com o sistema de planejamento do HCFMRP. Os conjuntos de valores de dose relativa do sistema de planejamento e da simulação, são apresentados na figura 42.

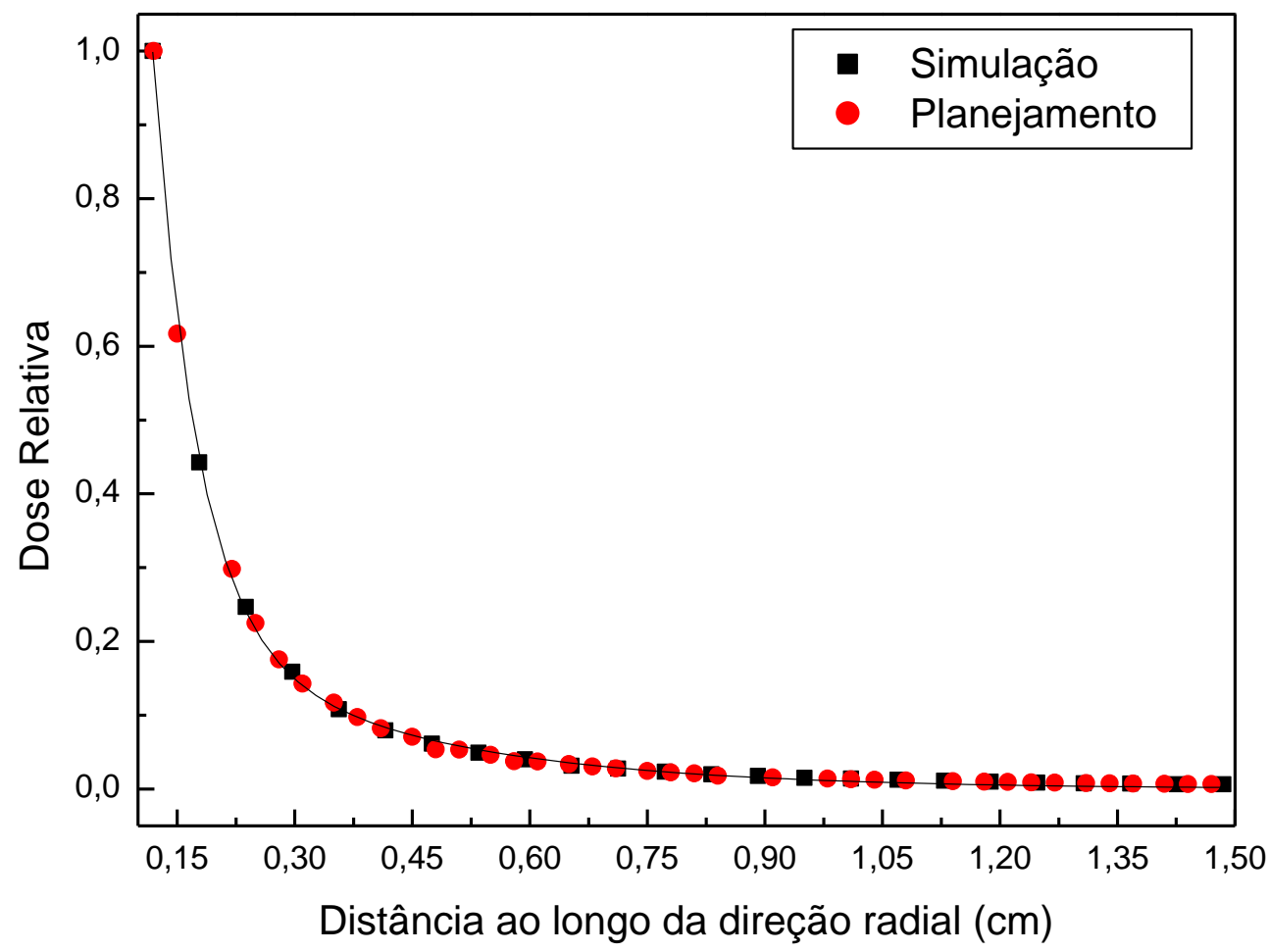

Figura 42: Dose relativa em função da distância ao longo da direção radial, para a fonte de ${ }^{192} \operatorname{Ir}$, para a simulação Monte Carlo e sistema de planejamento Varian BrachyVision.

Através da figura 42, é possível verificar que os dois conjuntos de dados possuem o mesmo comportamento. Como os dados do sistema de planejamento foram obtidos manualmente, não foi possível obter exatamente as mesmas distâncias radiais obtidas nas simulações. Foi realizado um ajuste de decaimento exponencial de segunda ordem que possui concordância entre os conjunto de dados do sistema de planejamento e os obtidos através de simulação Monte Carlo PENELOPE. O ajuste realizado obedece a equação (36):

$$
Y=Y_{0}+A_{1} e^{\left(\frac{-x}{t_{1}}\right)}+A_{2} e^{\left(\frac{-x}{t_{2}}\right)} \quad
$$


onde $Y$ são os valores de dose relativa e $x$ a distância ao longo da direção radial. Os valores dos parâmetros $Y_{0}, A_{1}, t_{1}, x_{0}, t_{2}$ e R2 são apresentados na tabela 12 .

Tabela 12: Parâmetros de ajuste de um decaimento exponencial de segunda ordem para os dados obtidos no sistema de planejamento e através da simulação Monte Carlo PENELOPE.

\begin{tabular}{cc}
\hline Parâmetros & Valores \\
\hline $\mathrm{y}_{0}$ & $(0,0099 \pm 0,0008)$ \\
\hline $\mathrm{A}_{1}$ & $(0,6932 \pm 0,0499)$ \\
\hline $\mathrm{t}_{1}$ & $(0,1849 \pm 0,0068)$ \\
\hline $\mathrm{A}_{2}$ & $(9,2670 \pm 0,5794)$ \\
\hline $\mathrm{t}_{2}$ & $(0,0442 \pm 0,0014)$ \\
\hline $\mathrm{R} 2$ & 0,9996 \\
\hline
\end{tabular}

Além da análise da resposta do gel, a comparação entre as doses simulada e do sistema de planejamento permitem, também, uma avaliação adicional acerca dos resultados dos parâmetros dosimétricos simulados mostrados anteriormente. Especificamente para a função de anisotropia, obtiveram-se diferenças de até $22 \%$ entre os resultados deste trabalho e o artigo utilizado para comparação. Os resultados da figura 41, entretanto, evidenciam uma ótima concordância entre as simulações realizadas e um segundo padrão de comparação, o sistema de planejamento utilizado na clínica em braquiterapia, indicando a adequação dos resultados obtidos neste trabalho.

\section{Análise através do Índice Gama}

As comparações realizadas através do índice gama foram feitas em planos transversal passando pelo centro da fonte foi adquirida no plano central, em um fantoma irradiado com $25 \mathrm{~Gy}$. Os valores utilizados como critérios foram: $3 \%$ e $3 \mathrm{~mm}, 3 \%$ e $1 \mathrm{~mm}$, $3 \%$ e 0,5 mm, de diferença de dose e distância aceitável, respectivamente, nas comparações. As distribuição de dose obtidas no plano transversal da fonte através da simulação Monte Carlo, MAGIC- $f$ e o índice gama com critérios $3 \%$ e $3 \mathrm{~mm}$ são mostrados na figura 43 em (a), (b) e (c), respectivamente. 


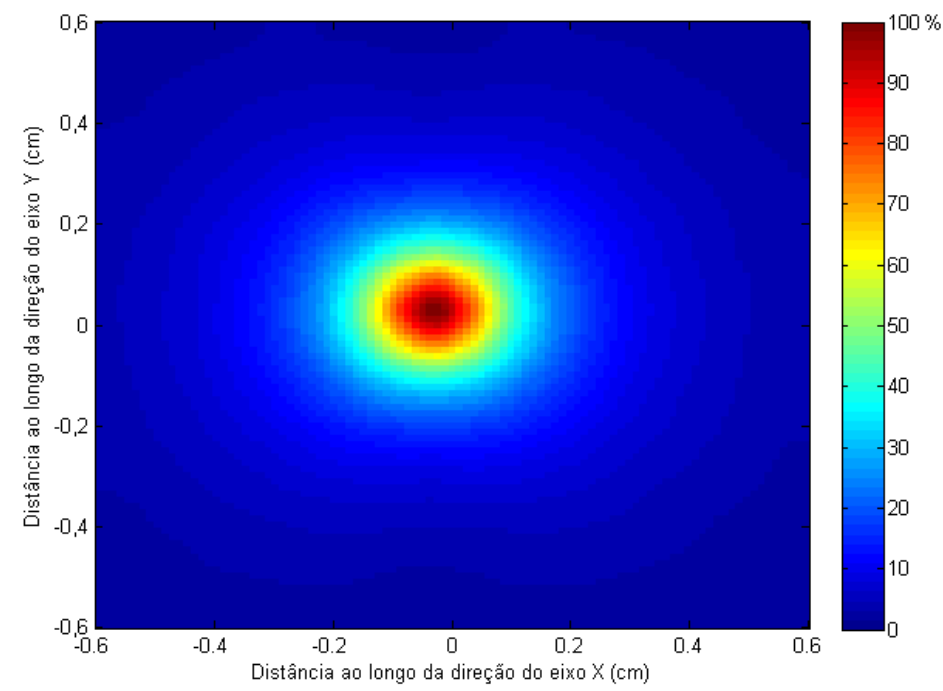

(a)

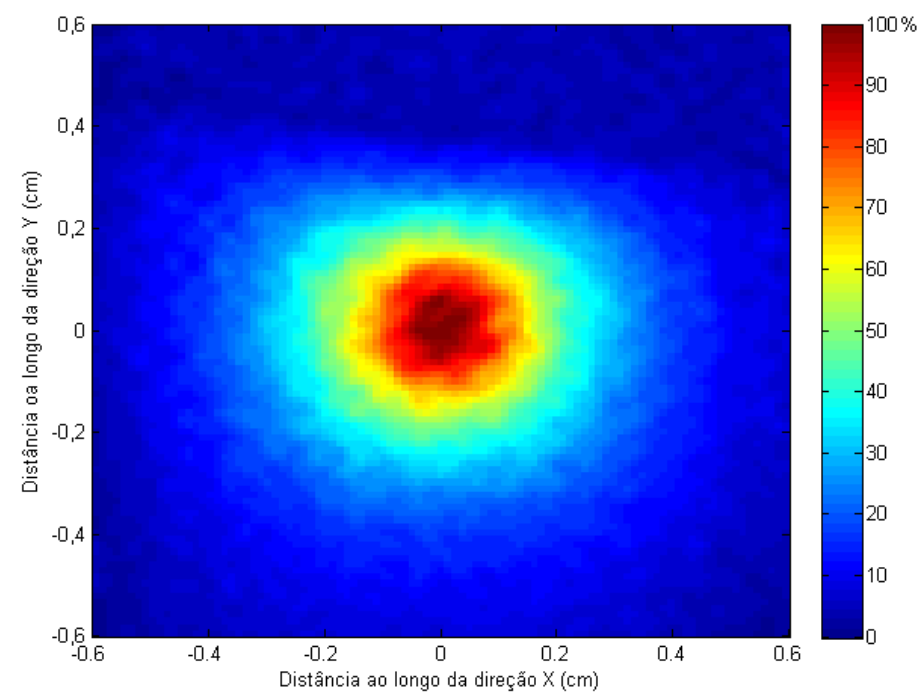

(b)

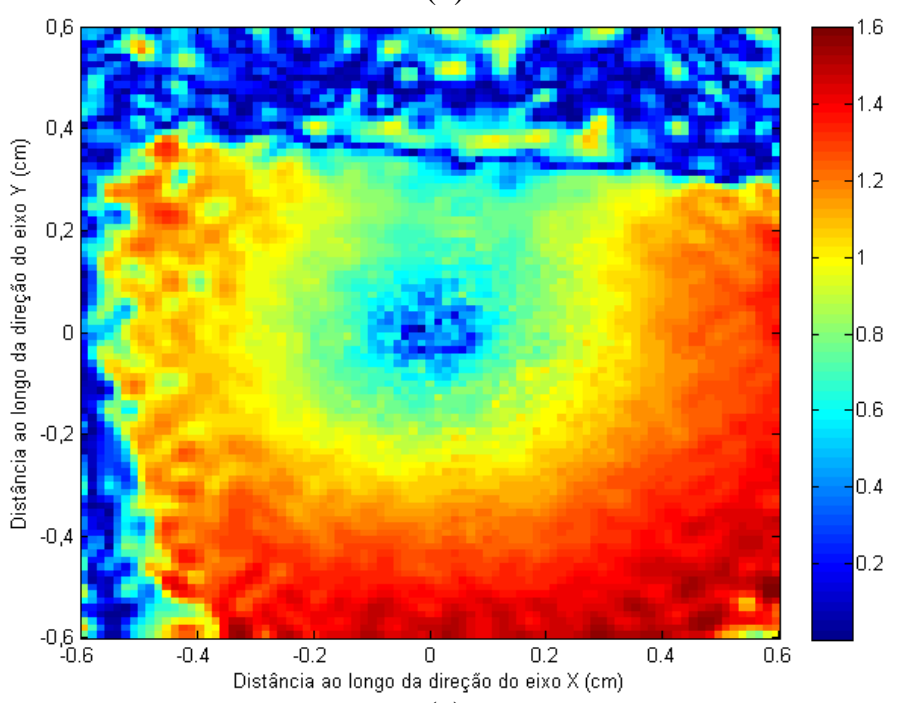

(c)

Figura 43: Imagens das distribuições de doses obtidas no plano transversal da fonte de ${ }^{192} \mathrm{Ir}$ através (a) da Simulação Monte Carlo e (b) do gel MAGIC-f. O Índice Gama que relaciona as duas imagens anteriores é mostrado em (c) para os critérios $3 \%$ e $3 \mathrm{~mm}$. 
Como é possível observar através da figura 43 (c), utilizando os critérios de $3 \mathrm{~mm}$ e 3\%, as concordâncias encontradas são maiores para as regiões mais próximas da fonte, onde o gradiente de dose é maior. Para regiões mais distantes da fonte de ${ }^{192} \mathrm{Ir}$, a leitura do gel sinaliza a presença de dose, o que não é evidenciada na simulação, assim como obtido na análise referente à distância radial.

Restringindo-se a região analisada para as isodoses de 50\% à 100\%, nota-se uma maior concordância como mostrada na figura 44 .

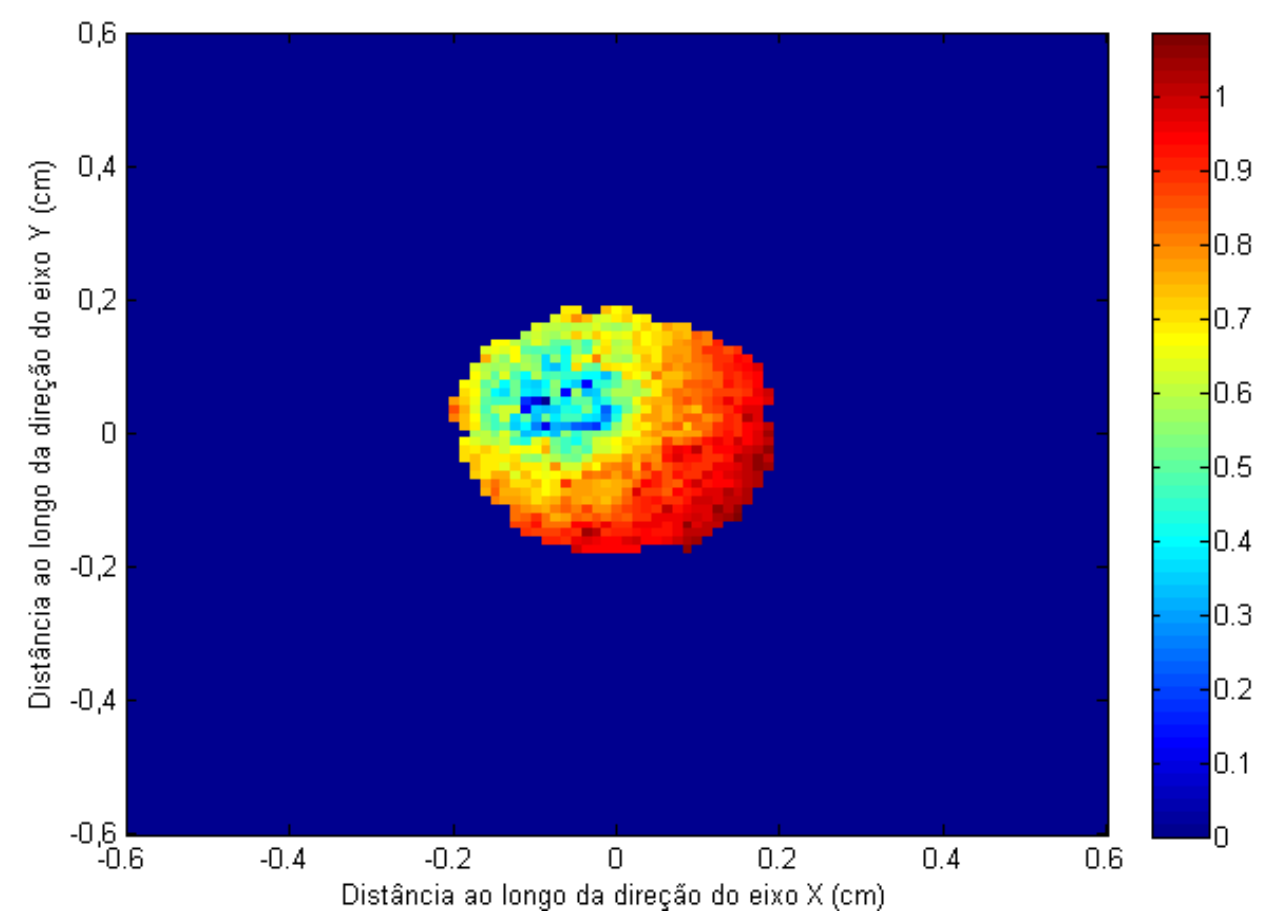

Figura 44: Avaliação do Índice Gama no plano transversal da fonte de ${ }^{192} \operatorname{Ir}$ para a região de isodoses maior que $50 \%$ para os critérios de $3 \%$ e $3 \mathrm{~mm}$.

Nessa nova região analisada, nota-se que a concordância entre a leitura do gel MAGIC- $f$ e os dados obtidos na simulação, ocorre em $97 \%$ dos pontos analisados. Desta forma, nas análises com critérios $3 \%$ e $1 \mathrm{~mm}$ e $3 \%$ e $0,5 \mathrm{~mm}$, foram comparadas as distribuições de dose apenas dentro da isodoses de $50 \%$.

Nas figura 45 e 46 são apresentados os mapas de índice gama para os planos transversais da fonte de ${ }^{192} \mathrm{Ir}$ com os critérios de $3 \%$ e $1 \mathrm{~mm}$ e de $3 \%$ e $3 \mathrm{~mm}$, respectivamente. 


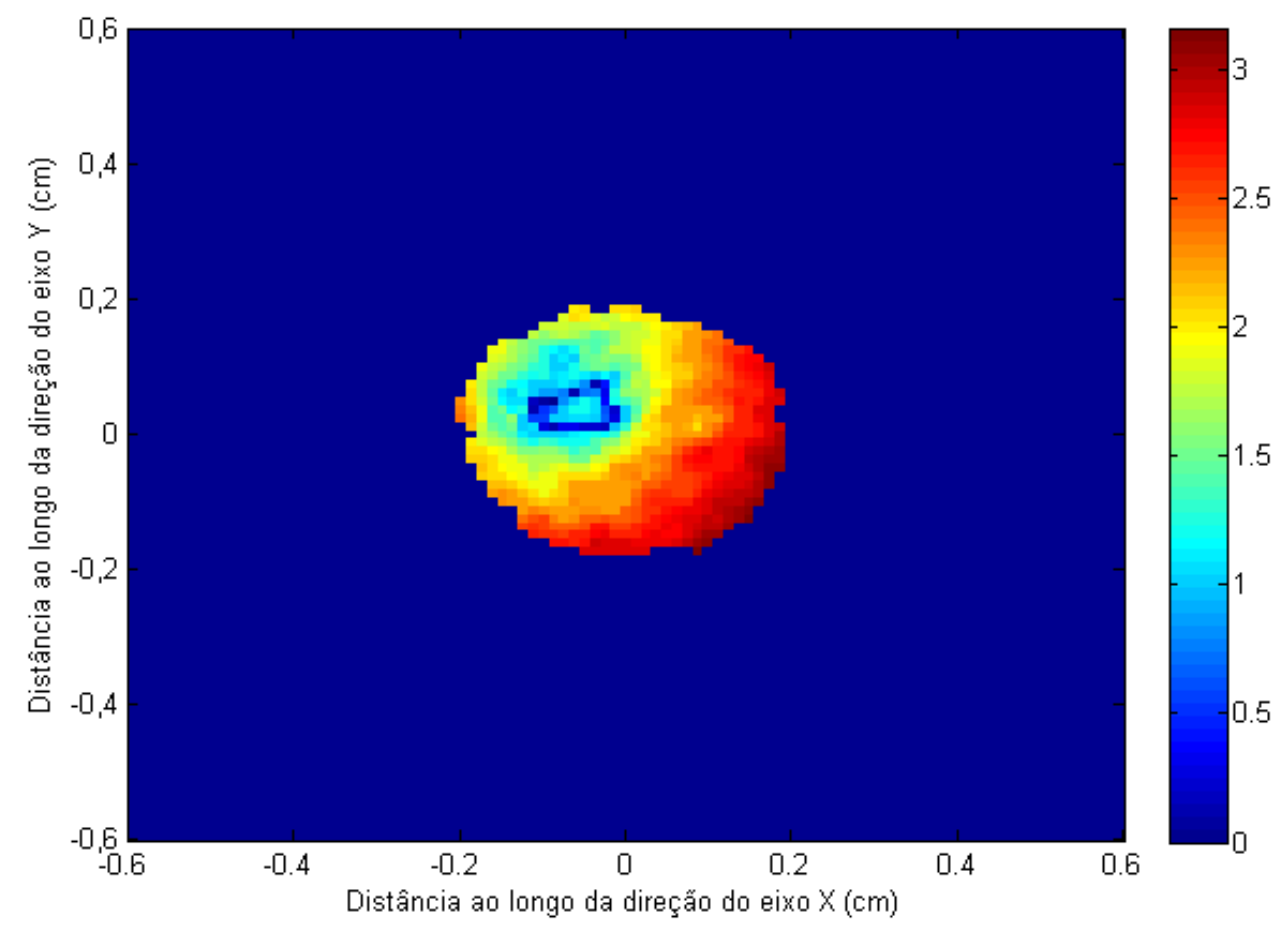

Figura 45: Avaliação do Índice Gama no plano transversal da fonte de ${ }^{192}$ Ir para a região de isodoses maior que $50 \%$ para os critérios de $3 \%$ e $1 \mathrm{~mm}$.

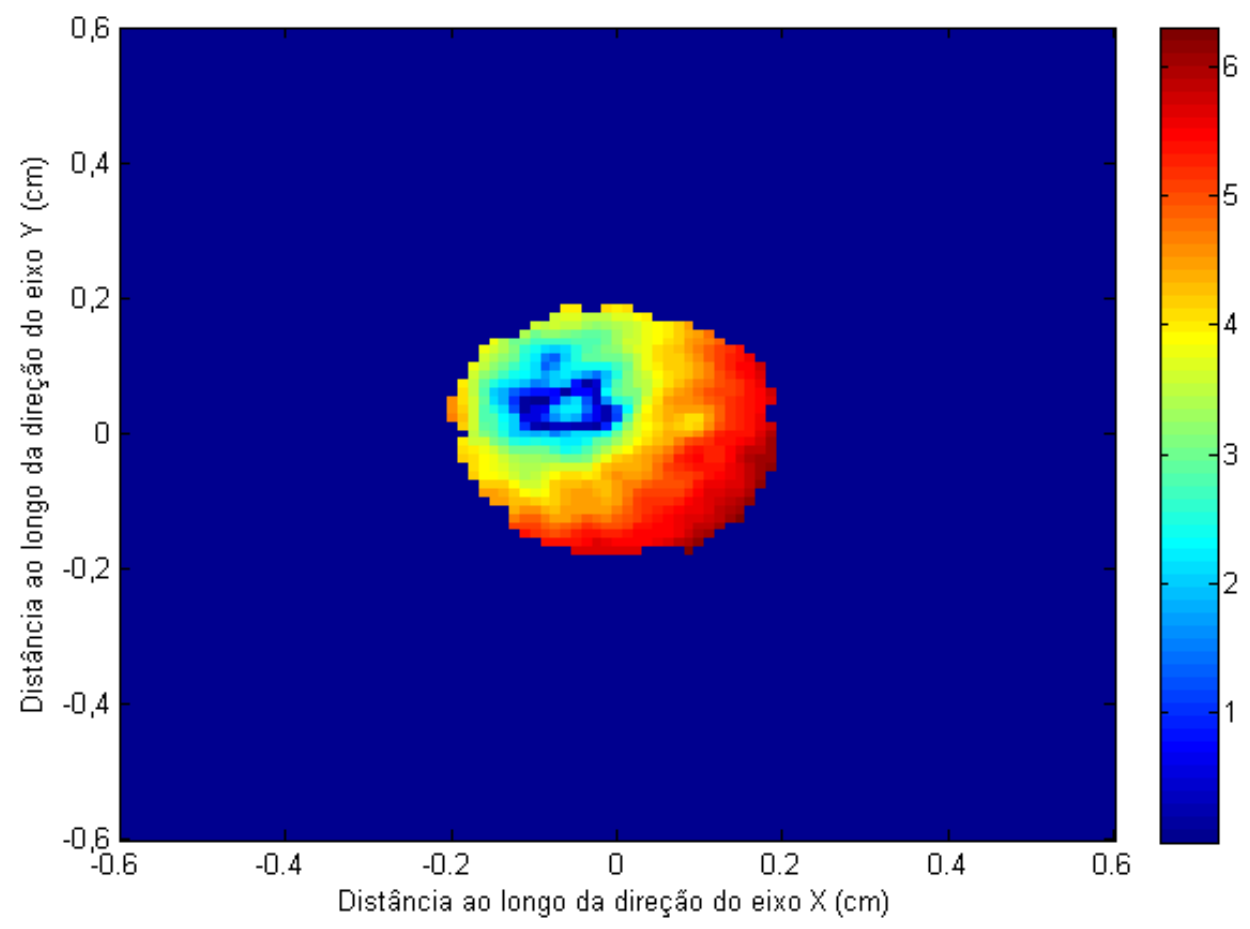

Figura 46: Avaliação do Índice Gama no plano transversal da fonte de ${ }^{192} \mathrm{Ir}$ para a região de isodoses maior que $50 \%$ para os critérios de $3 \%$ e $0,5 \mathrm{~mm}$.

Para os critérios de 3\% e 1,0 mm, a concordância entre a leitura do gel MAGIC- $f$ e os dados obtidos na simulação, ocorre em $35 \%$ dos pontos analisados dentro da isodoses 
de $50 \%$. Já para os critérios de $3 \%$ e $0,5 \mathrm{~mm}$, houve concordância em apenas $18 \%$ dos pontos analisados dentro dessas isodoses.

Isso indica que para regiões onde existe um alto gradiente de dose, o gel respondeu de maneira satisfatória, indicando que o mesmo tem potencial de uso em dosimetria em braquiterapia. Entretanto, as análises do índice gama, mostram que o critério de $3 \mathrm{~mm}$ utilizados na tolerância da aceitação da distância, é um amplo critério para braquiterapia. Quando esse critério é restringido para distâncias menores, o que é mais favorável em braquiterapia, a quantidade de aceitação de pontos diminui para o gel MAGIC- $f$ para os estudos realizados. Dessa forma, há a necessidade de um maior estudo do uso do gel polimérico MAGIC- $f$ em braquiterapia de alta taxa de dose, além de uma sistematização na sua manufatura e elaboração de um protocolo de leitura do gel, para que o mesmo possa ser utilizado em aplicações clínicas. 


\section{4 - Estudo Utilizando Fonte de ${ }^{60} \mathrm{Co}$}

Os estudos apresentados nessa seção referentes à energia do ${ }^{60} \mathrm{Co}$ foram realizados apenas computacionalmente através de simulação Monte Carlo com o código PENELOPE.

Atualmente, o isótopo mais utilizado em braquiterapia de alta taxa de dose é o ${ }^{192}$ Ir, devido à alta atividade específica e tamanho pequeno (STROHMAIER, ZWIERZCHOWSKI, 2011). Porém, devido à meia-vida do ${ }^{192}$ Ir ser relativamente baixa, 74 dias, o mesmo vem sendo substituído gradativamente pelas fontes de ${ }^{60} \mathrm{Co}$, acarretando vantagens econômicas de troca de fonte (ANDRÁSSY, NIATSETSKY, PÉREZCALATAYUD, 2012). Nesse sentido, é importante analisar os parâmetros dosimétricos dessas fontes.

$\mathrm{O}{ }^{60} \mathrm{Co}$ é um emissor gama em cascata que possui as energias mais prováveis em $1164,895 \mathrm{keV}$ e $1324,159 \mathrm{keV}$ e meia-vida de 5,3 anos (SALVAJOLI, 2013). Nas simulações realizadas nesse trabalho, a geometria da fonte de ${ }^{60} \mathrm{Co}$ (BEBIG, modelo Co0.A86), utilizada em braquiterapia, foi modelada no pacote de simulação Monte Carlo PENELOPE. O espectro de radiação primário, utilizado nas simulações, foi composto pelas linhas de emissão de fótons mais prováveis de uma fonte de ${ }^{60} \mathrm{Co}$ compreendidas de $0,84 \mathrm{keV}$ à $2504 \mathrm{keV}$ (NUDAT, 2004). O espectro de radiação primário da fonte de ${ }^{60} \mathrm{Co}$, simulada nesse trabalho, é apresentado na figura 47.

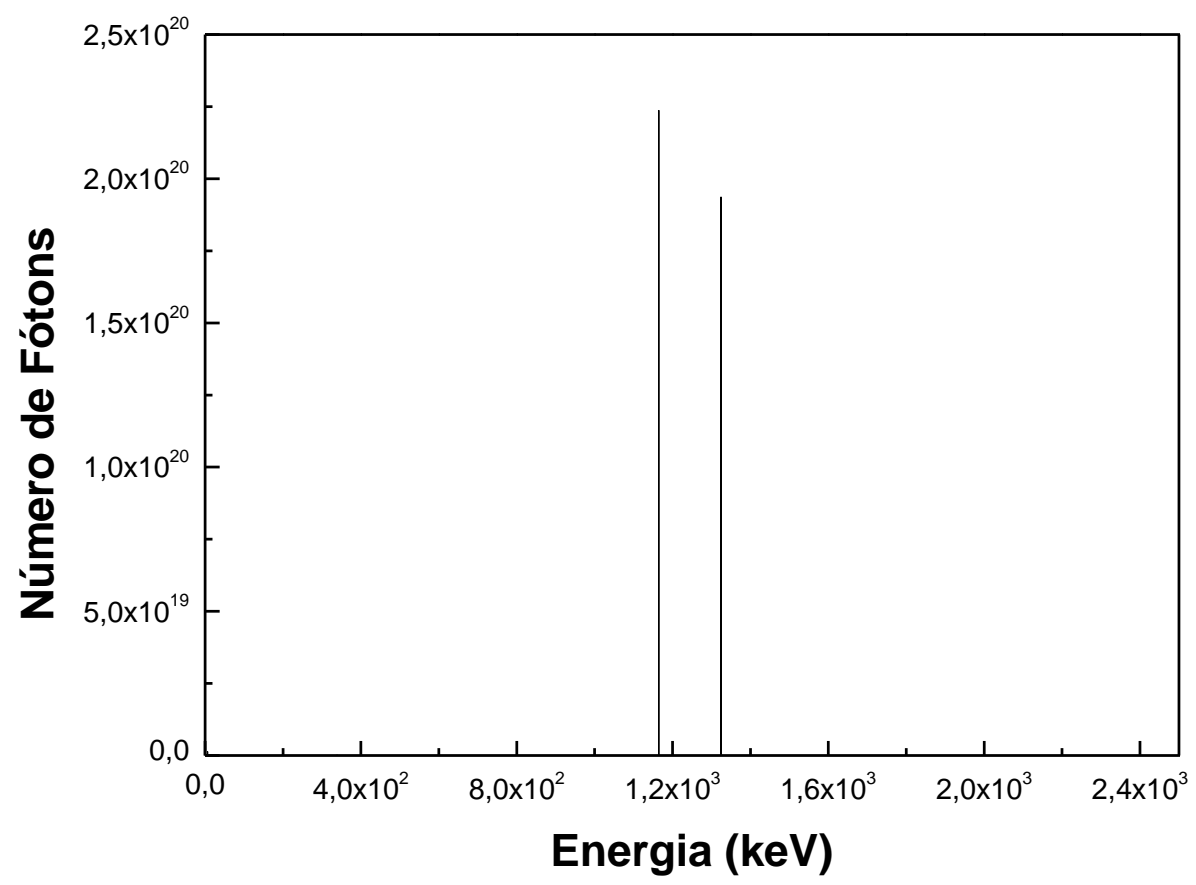

Figura 47: Espectro simulado para fonte de ${ }^{60} \mathrm{Co}$. 
O modelo da fonte utilizada possui parte ativa de $0,25 \mathrm{~mm}$ de raio e $3,5 \mathrm{~mm}$ de comprimento. $\mathrm{O}$ encapsulamento interno, preenchido com ar, possui raio de $0,25 \mathrm{~mm}$ e 3,5 mm de comprimento. O encapsulamento externo, possui formato cilíndrico, de aço inoxidável AISI 316L, tem $0,5 \mathrm{~mm}$ de raio e $5 \mathrm{~mm}$ de comprimento. As medidas da fonte de ${ }^{60}$ Co encontram-se em (GRANERO et al, 2007). Na figura 48 é apresentada geometria da fonte do artigo de referência (a) e a geometria da fonte construída no PENELOPE e visualizada no gview2d (b).

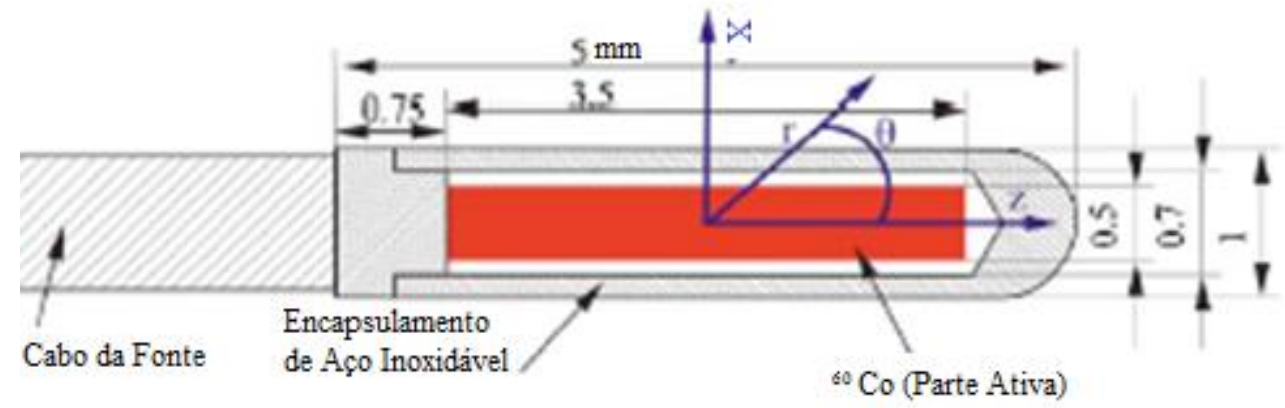

(a)

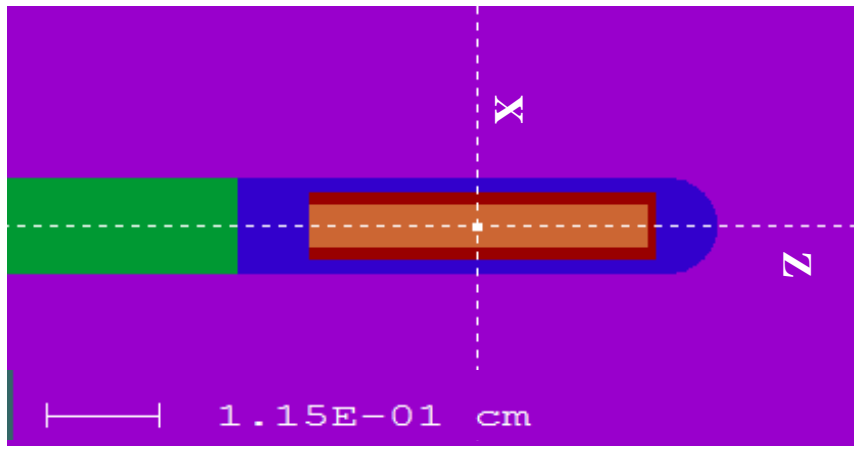

Corpo 1: Fonte

Corpo 2: Encapsulamento - Ar

Corpo 3: Encapsulamento

Corpo 4: Cabo

(b)

Figura 48: Esquemas da fonte de ${ }^{60} \mathrm{Co}$ BEBIG (a) adaptado de (GRANERO et al, 2007); (b) construída através da simulação Monte Carlo com o código PENELOPE.

\subsection{Equivalência do Gel com a Água para a Energia do ${ }^{60} \mathrm{Co}$}

No intuito de verificar a equivalência do gel com a água para a energia do ${ }^{60} \mathrm{Co}$, foi utilizado um objeto simulador cúbico de $30 \mathrm{~cm}$ de lado, homogêneo, preenchido com água ou gel, para as de distribuições de dose. Em todas as simulações, a fonte foi posicionada no centro do objeto simulador e as distribuições de dose foram amostradas em distâncias de até $6 \mathrm{~cm}$ em torno da fonte. Assim como nas simulações para a energia 
do ${ }^{192}$ Ir, o objeto simulador também foi dividido em 101 pixels em cada eixo de coordenadas e cada pixel teve dimensões de $0,0594 \times 0,0594 \mathrm{~cm}^{2}$.

O número de partículas primárias em cada simulação permaneceu constante em $10^{9}$ partículas e os parâmetros de simulação escolhidos, foram: energia de corte para fótons e elétrons igual a $10 \mathrm{keV}, \mathrm{C} 1$ e C2 (parâmetros de condensão de histórias) igual a 0,1, otimizando o tempo de simulação e mantendo detalhadas as simulações de eventos fortes.

Para análise dos resultados obtidos, foram construídos gráficos de dose relativa ao longo das direções radial e longitudinal da fonte, juntamente com mapas de distribuição de dose em que os planos passam pelo centro da fonte. Na figura 49 é apresentado o gráfico da dose relativa em função da direção radial para a água e para o gel e as diferenças absolutas das doses relativas para esses dois materiais.

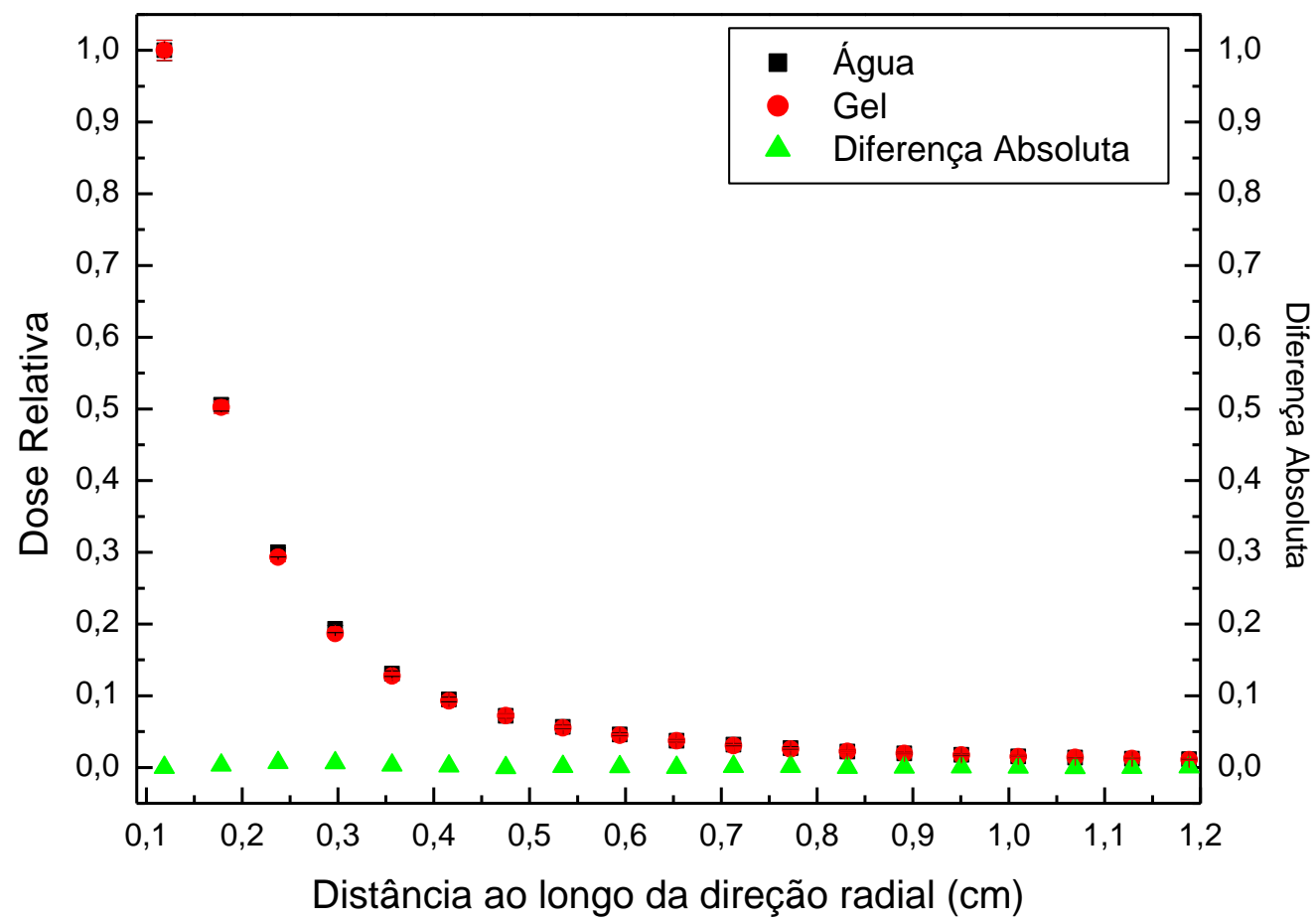

Figura 49: Dose Relativa em função da distância ao longo da direção radial, para a energia do ${ }^{60} \mathrm{Co}$ e diferença absoluta entre as doses relativas para a água e para o gel MAGIC-f.

Os dados obtidos, mostrados na figura 49, são referentes aos pontos que estão presentes no meio atenuador, excluindo os pixels pertencentes à fonte. Os maiores desvios encontrados nas doses foram de 1,42\% e 1,40\%, para a água e para o gel, respectivamente, ambos em 0,119 cm. A maior diferença absoluta encontrada entre as doses relativas foi de 0,007 em 0,238 cm. Houve uma diminuição da dose relativa de, aproximadamente, 
$50 \%$ para o conjunto de dados da água e do gel e, em $1 \mathrm{~cm}$, a dose é praticamente nula em ambos os conjuntos de dados.

A mesma análise foi realizada, porém na direção longitudinal no plano passando pelo centro da fonte. Na figura 50 são apresentadas as doses relativas da água e do gel, obtidas para a fonte de ${ }^{60} \mathrm{Co}$, com as respectivas diferenças absolutas desses materiais.

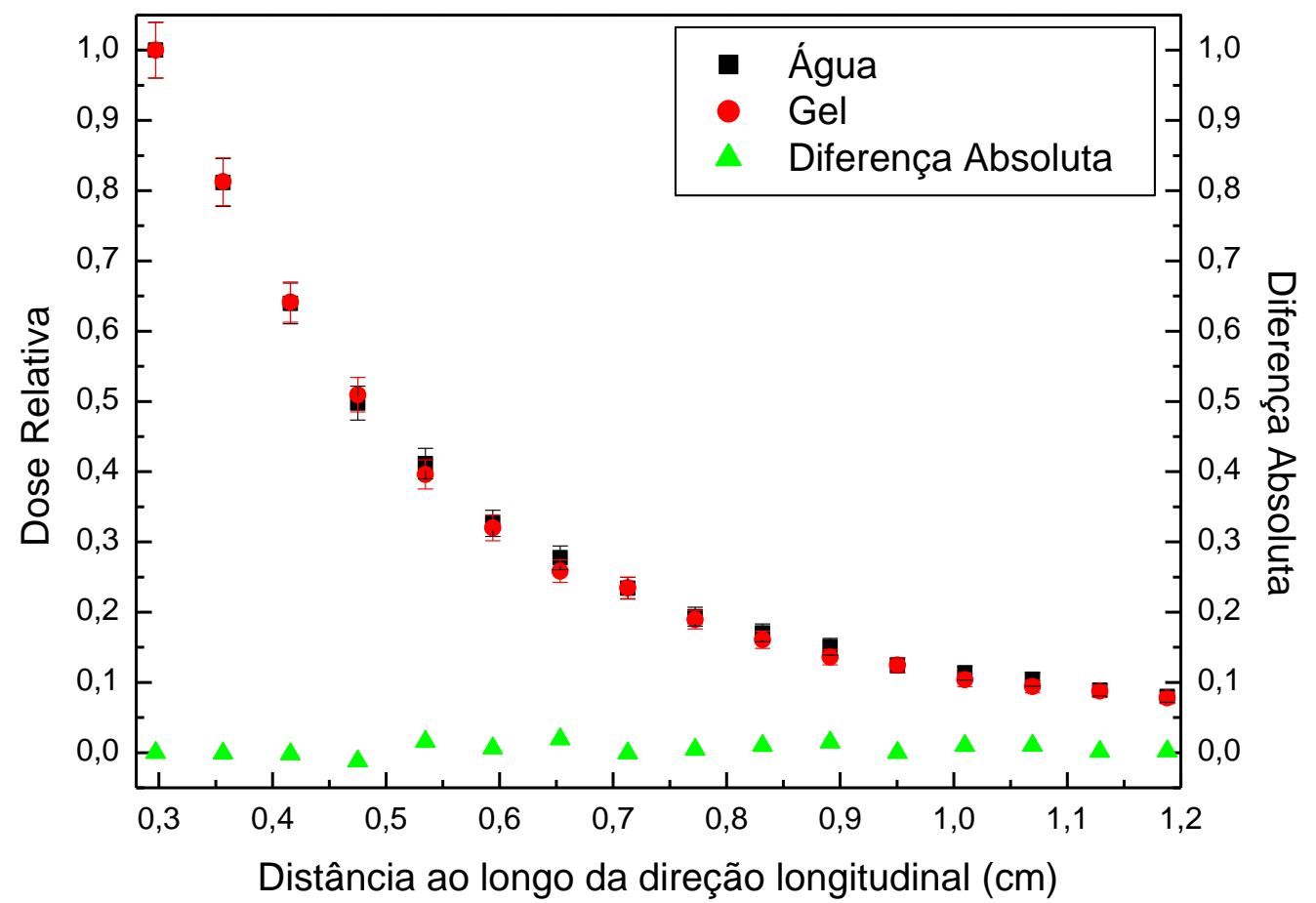

Figura 50: Dose Relativa em função da distância ao longo da direção longitudinal, para a energia do ${ }^{60} \mathrm{Co}$ e diferença absoluta entre a água e o gel MAGIC-f.

O máximo desvio encontrado, para ambos os conjuntos de dados, foi de $4 \% \mathrm{em}$ 0,297 cm enquanto que, a máxima diferença absoluta encontrada entre as doses relativas foi de 0,02 em 0,653 cm. Foi possível observar que a dose relativa, ao longo da direção longitudinal, diminuiu aproximadamente $18,85 \%$ nos dois primeiros pixels analisados, para a água e para o gel. Nessa direção analisada, foi encontrada maior variação da diferença absoluta entre os materiais, mas nunca ultrapassando o valor máximo mencionado.

Nas análises das duas direções, radial e longitudinal, pode-se observar uma boa concordância entre os dados obtidos para a água e para o gel MAGIC- $f$, evidenciando a equivalência entre ambos nessas direções.

Na continuidade da análise da equivalência entre a água e o gel, foram construídos os mapas de distribuições de dose em planos passando pelo centro da fonte. As figuras 
51 e 52 mostram os mapas de distribuições de dose para a água e para gel, respectivamente, no plano transversal da fonte. $\mathrm{Na}$ obtenção das distribuições de dose, o número total de pixels em cada eixo também foi mantido em 101, onde cada pixel apresentado nesses mapas corresponde à 0,0594 x $0,0594 \mathrm{~cm}^{2}$.

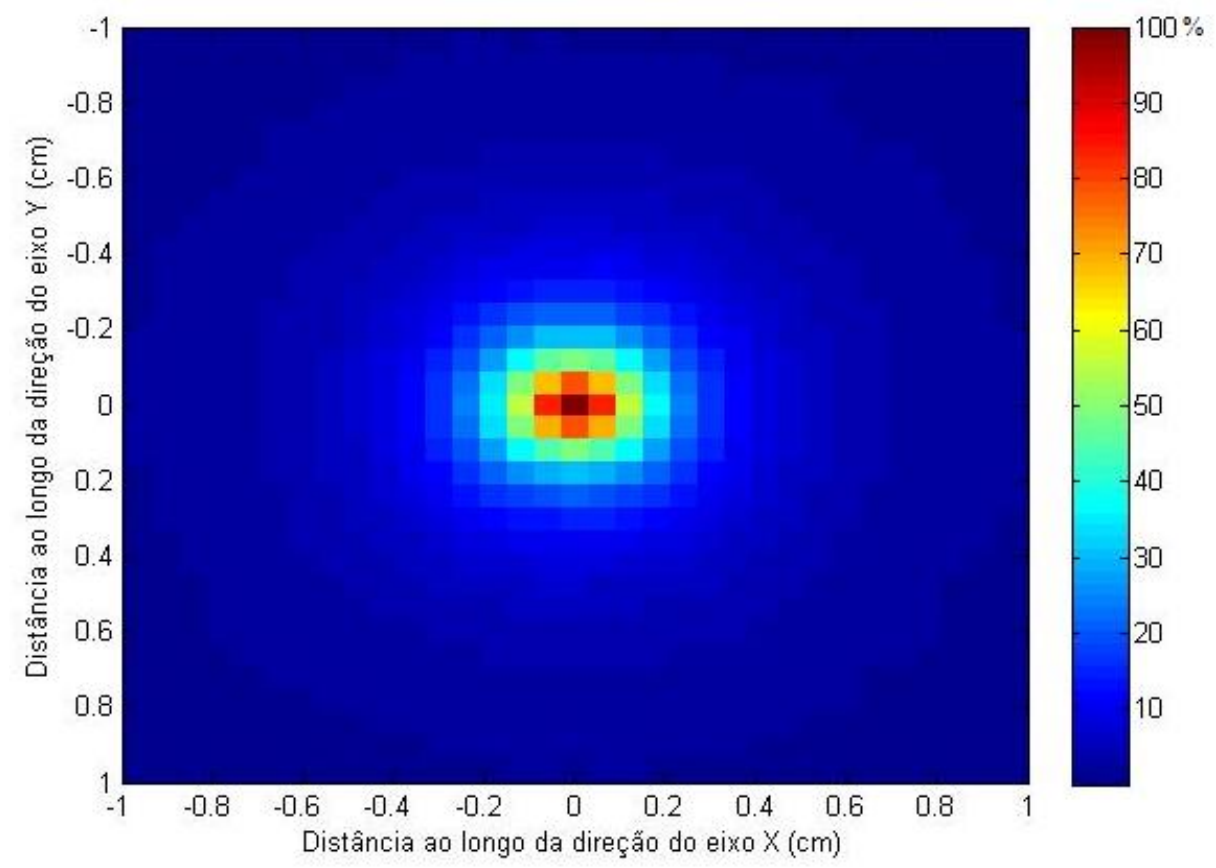

Figura 51: Mapa de distribuição de dose em plano transversal passando pelo centro da fonte, quando o material irradiado foi a água.

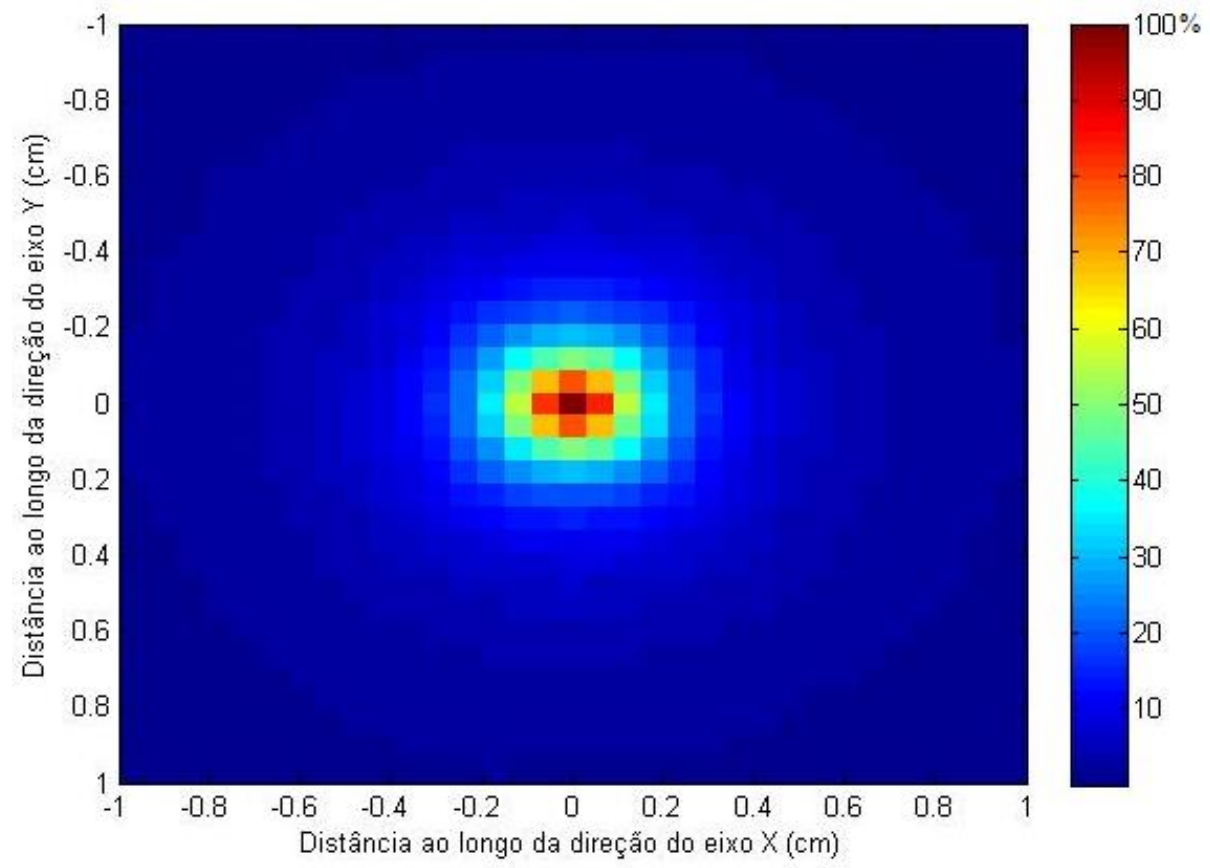

Figura 52: Mapa de distribuição de dose em plano transversal passando pelo centro da fonte, quando o material irradiado foi o gel MAGIC- $f$. 
Nos dois mapas de distribuição de dose apresentados nas figuras 51 e 52, a fonte foi retirada por completo do mapa, ou seja, no lugar da mesma não é apresentada a dose. Como é possível observar nos dois mapas, ambos possuem simetria com relação à origem do sistema e, em $1 \mathrm{~cm}$, a dose é aproximadamente zero, como mostrada também nos gráficos de dose relativa. No intuito de verificar a semelhança entre ambos, foi realizado a subtração entre o mapa da distribuição de dose da água pela distribuição de dose no gel, conforme mostrado na figura 53.

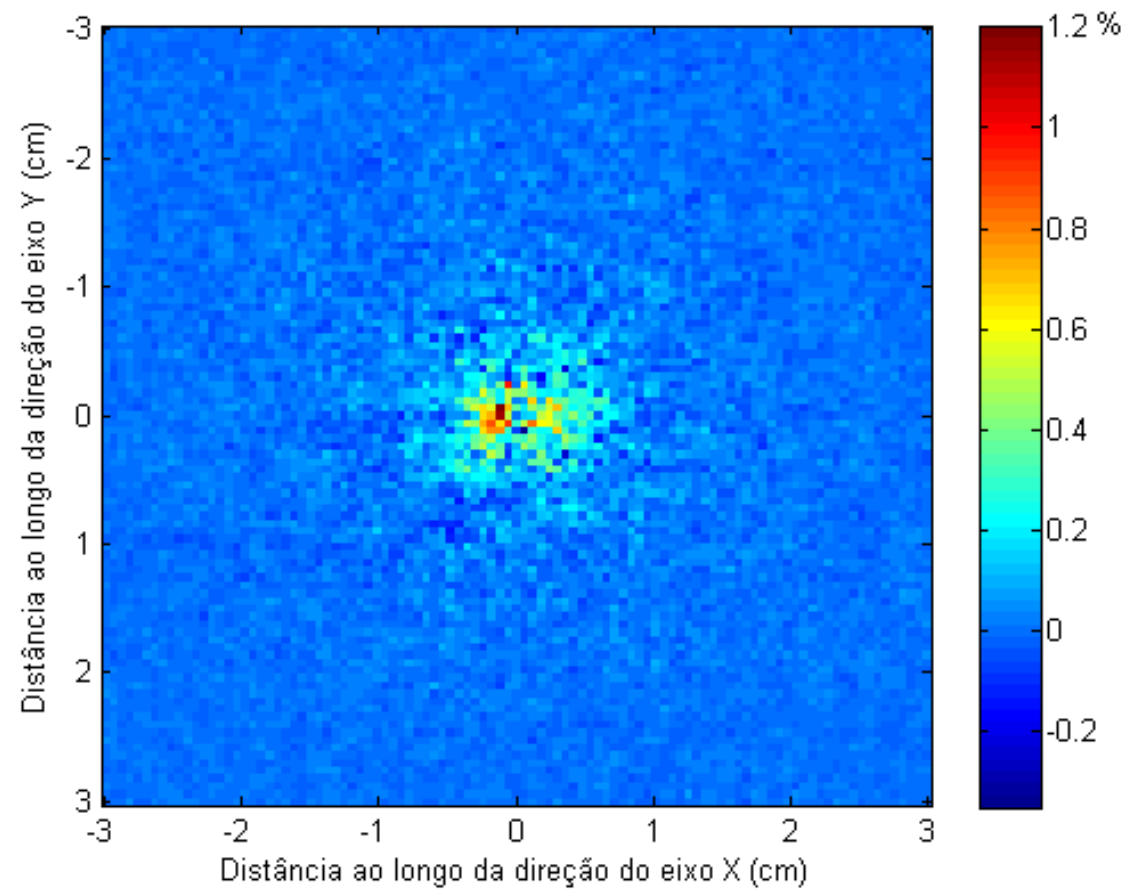

Figura 53: Mapa da subtração da distribuição de dose da água e do gel, para a energia do ${ }^{60}$ Co.

Embora os mapas de distribuição de dose tenham sido apresentados de $-1,0 \mathrm{~cm}$ à $+1,0 \mathrm{~cm}$, a subtração entre os mapas foi realizada envolvendo o plano do objeto simulador que foi de $-3,0$ à $+3,0 \mathrm{~cm}$. Foi escolhido realizar a subtração em toda essa distância para analisar a equivalência em toda a região simulada. Através da subtração dos mapas de distribuição de dose da água e do gel, foi obtida uma diferença percentual máxima de 1,2\%. A partir dessas análises realizadas computacionalmente, foi evidenciada a equivalência do gel polimérico MAGIC- $f$ com a água, para a energia do Cobalto, em toda a região calculada. Essa equivalência mostra que esse gel polimérico pode ser utilizado como material tecido equivalente. 


\section{2 -Parâmetros Dosimétricos para Fonte de ${ }^{60} \mathrm{Co}$}

Nessa seção serão apresentados os parâmetros dosimétricos definidos no TG-43, para o formalismo no cálculo de dose em braquiterapia, sendo eles: Fator Geométrico, Função de Dose Radial e Função de Anisotropia.

\subsubsection{Fator Geométrico}

O fator geométrico não leva em consideração a absorção e o espalhamento dos fótons na estrutura da fonte ou no meio atenuador, ou seja, a variação da dose relativa obtida através desse fator será devido às características geométricas da fonte. Esse fator representará a distribuição de dose levando somente em consideração a distribuição do material radioativo.

De acordo com as equações (7) à (9), que são aproximações para fontes pontuais e lineares utilizadas nos cálculos desse parâmetro, as grandezas envolvidas são: os ângulos entre o início e o final da parte ativa, as distâncias, comprimento ativo da fonte e as combinações trigonométricas entre os ângulos analisados. Portanto, como a dimensão da parte da ativa das duas fontes analisadas nesse trabalho é a mesma, os valores dos fatores geométricos para a fonte de ${ }^{60} \mathrm{Co}$ são os mesmos obtidos para a fonte de ${ }^{192} \mathrm{Ir}$. Logo, as mesmas discussões e análises feitas para a fonte de ${ }^{192} \mathrm{Ir}$, são válidas também para a fonte de ${ }^{60} \mathrm{Co}$.

\subsection{2 - Função de Dose Radial}

A função de dose radial mostra o comportamento da dose ao longo das distâncias que estão sob o eixo X (radial), levando em consideração os efeitos de absorção e espalhamento no meio ao longo desse eixo e excluindo a diminuição das doses devido à função geométrica.

Nesse trabalho foram determinados os valores da função de dose radial para distâncias entre $0,25 \mathrm{~cm}$ e 3,0 cm, seguindo as recomendações do protocolo TG-43. Através da equação (12) é possível observar que as grandezas que acrescentam incertezas 
no cálculo da função de dose radial são o valor de taxa de dose no ponto de interesse e o valor da taxa de dose no ponto de referência.

O artigo tomado como referência, com que os dados da função de dose radial determinados nesse trabalho foram comparados, foi de Granero e colaboradores (GRANERO, PÉREZ-CALATAYUD, BALLESTER, 2007), que realizou um estudo dosimétrico de uma fonte de ${ }^{60} \mathrm{Co}$, BEBIG modelo Co0.A86, utilizando código de simulação Monte Carlo GEANT4. Os valores da função de dose radial nesse artigo foram obtidos utilizando um objeto simulador de formato esférico com raio de $50 \mathrm{~cm} \mathrm{e}$ utilizando energia de corte para fótons e elétrons de $10 \mathrm{keV}$ e o número de histórias simuladas variando de $10^{8}$ à 6 x $10^{9}$.

Neste trabalho, os valores da função de dose radial também foram obtidos de acordo com o formalismo do TG-43. Foi utilizado um objeto simulador de formato cúbico de $30 \mathrm{~cm}$ de lado, energia de corte para fótons e elétrons de $10 \mathrm{keV}$, o tamanho do pixel foi de $0,0594 \mathrm{~cm}$ nas três direções do eixo cartesiano, o número de histórias simuladas foi de $10^{9}$ e os valores de $\mathrm{C} 1$ e C2 permaneceram constantes em 0,1 . Os valores da função de dose radial, obtidas para a energia do ${ }^{60} \mathrm{Co}$ e os valores do artigo de referência são apresentados na figura 54.

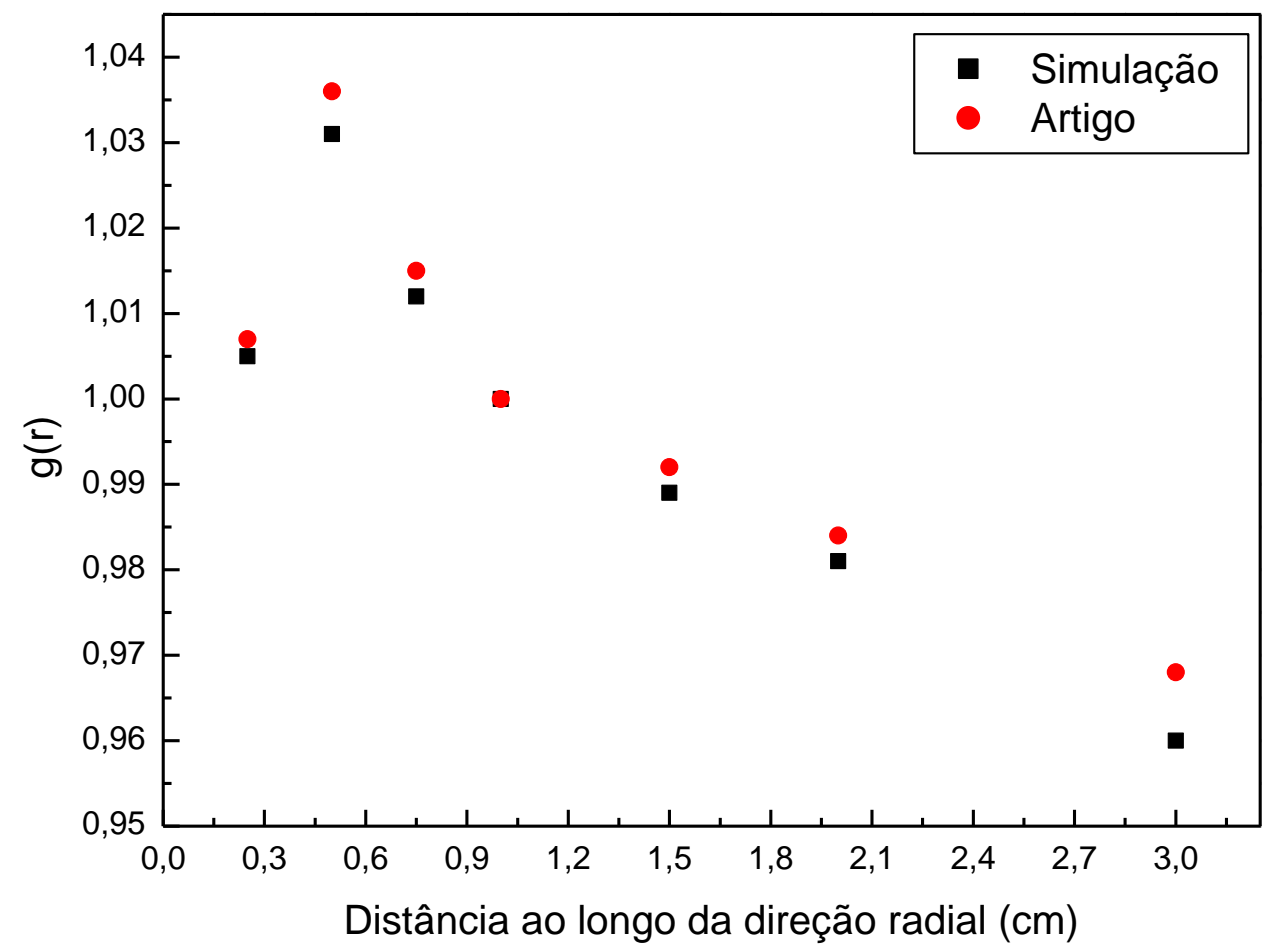

Figura 54: Função de dose radial em função da distância radial de Granero e colaboradores e obtidos computacionalmente (GRANERO, PÉREZ-CALATAYUD, BALLESTER, 2007). 
A incerteza desse parâmetro dosimétrico é de aproximadamente $1 \%$ para os valores obtidos nesse trabalho, enquanto que a incerteza encontrada por Granero e colaboradores foi de $0,7 \%$ para todos os pontos, exceto pontos localizados próximos à fonte, onde a incerteza foi de aproximadamente $1,1 \%$. Neste trabalho os valores da função de dose radial estão compreendidos entre 0,960 e 1,031 e os valores do artigo de referência variam de 0,968 à 1,036 . A maior diferença relativa encontrada, quando se comparou os dois conjuntos de dados, foi de $0,83 \%$ em $3 \mathrm{~cm}$. É possível observar, através da figura 54, um aumento da função de dose radial de, aproximadamente, 2,5\% e 2,8\% de $0,25 \mathrm{~cm}$ para $0,50 \mathrm{~cm}$, respectivamente, entre a simulação e o artigo. Após esse aumento os valores decrescem nos dois estudos.

Embora os dois conjuntos de dados possuam o mesmo comportamento e a máxima diferença relativa encontrada entre ambos seja menor que 1\%, o tamanho do pixel utilizado nas simulações pode influenciar nesses resultados. Outra influência que pode ocasionar a diferença entre os valores obtidos e os do artigo de referência, é o formato e o tamanho dos objetos simuladores utilizados nas simulações. Ainda assim, os dois estudos apresentam boa concordância nos pontos analisados.

\subsection{3 - Função de Anisotropia}

A função de anisotropia determina a variação da dose no volume irradiado considerando os efeitos de atenuação e espalhamento em torno da fonte. Essa função foi determinada através da equação (14) segundo as recomendações do protocolo de referência TG-43. No cálculo desse parâmetro dosimétrico estão envolvidos os valores das taxas de dose e valores do fator geométrico, ambos, no ponto de referência e no ponto de interesse. Portanto, somente os valores das taxas de dose adicionam incertezas para a função de anisotropia, uma vez que as grandezas envolvidas no cálculo do fator geométrico são o comprimento efetivo da fonte e funções trigonométricas.

Esse parâmetro dosimétrico foi determinado para valores de distâncias compreendidos de $0,5 \mathrm{~cm}$ à $3,0 \mathrm{~cm}$. Foi utilizado um objeto simulador cúbico de $30 \mathrm{~cm}$ de lado, homogêneo, que foi preenchido com água. A energia de corte de fótons e elétrons foi de $10 \mathrm{keV}$, o número de histórias simuladas permaneceu em $10^{9}$ e os parâmetros de condensão de histórias, C1 e C2, também permaneceram constantes em 0,1. Em todas essas simulações o tamanho do pixel utilizado foi de $0,0594 \times 0,0594 \mathrm{~cm}^{2}$. 
O artigo utilizado como referência foi de Granero e colaboradores (GRANERO, PÉREZ-CALATAYUD, BALLESTER, 2007), assim como para os outros parâmetros. Os valores da função de anisotropia do artigo de referência para a distância de $0,5 \mathrm{~cm}$, juntamente com os dados obtidos nesse trabalho, são mostrados na figura 55.

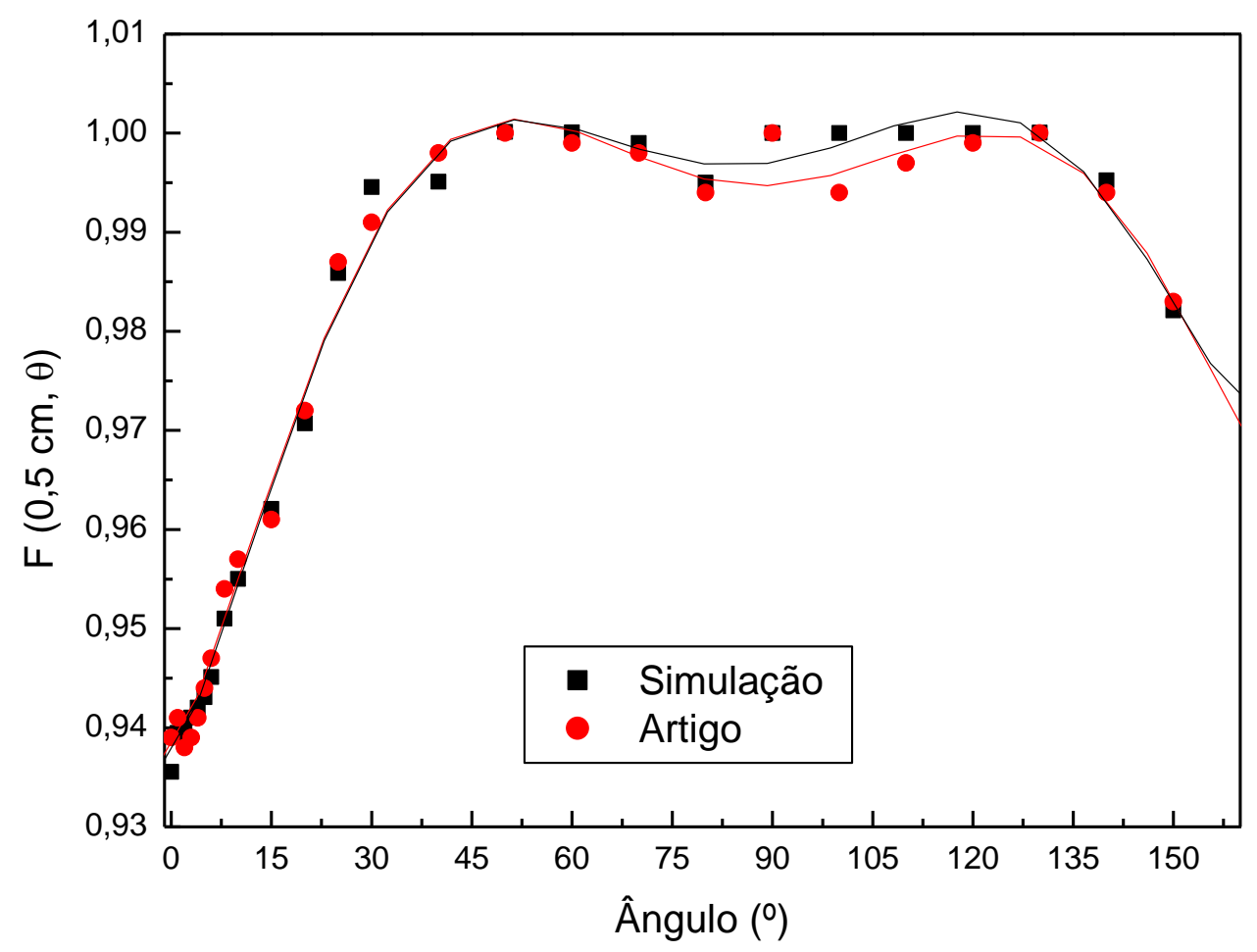

Figura 55: Função de Anisotropia em função do ângulo para distância de $0,5 \mathrm{~cm}$, simulado para a fonte de ${ }^{60} \mathrm{Co}$ e de Granero e colaboradores (GRANERO, PÉREZ-CALATAYUD, BALLESTER, 2007).

Através da figura 55 é possível verificar que os dados obtidos nesse trabalho e os dados do artigo de referência possuem o mesmo comportamento. Os valores da função de anisotropia neste trabalho variaram de 0,935 à 1,001 , enquanto que os valores do artigo de Granero e colaboradores variaram de 0,939 à 1. Comparando-se os dois conjuntos de dados, a máxima diferença relativa encontrada foi de $0,6 \%$ no ângulo de $100^{\circ}$. Foi utilizado um ajuste polinomial de sexta ordem nos dois conjuntos de dados que obedece à equação (34).

$$
Y=A+B 1 x+B 2 x^{2}+B 3 x^{3}+B 4 x^{4}+B 5 x^{5}+B 6 x^{6}
$$

onde Y e $X$ são a função de anisotropia e os ângulos, respectivamente. Os parâmetros de ajuste A, B1, B2, B3, B4 e B5 e B6, para os dois conjuntos de dados, estão contidos na tabela 13 . 
Tabela 13: Parâmetros de ajuste de um polinômio de sexta ordem para a função de anisotropia na distância de $0,5 \mathrm{~cm}$ para fonte de ${ }^{60} \mathrm{Co}$.

\begin{tabular}{ccc}
\hline \multirow{2}{*}{ Parâmetros } & \multicolumn{2}{c}{ Aalores } \\
\cline { 2 - 3 } & $(0,9370 \pm 0,0015)$ & $(0,9359 \pm 0,0014)$ \\
\hline A & $(0,0013 \pm 0,0004)$ & $(0,0014 \pm 0,0003)$ \\
\hline B1 & $(6,5570 \pm 2,9763) \times 10^{-5}$ & $(6,1187 \pm 2,6212) \times 10^{-5}$ \\
\hline B2 & $(-2,5376 \pm 0,8132) \times 10^{-6}$ & $(-2,4432 \pm 7,1625) \times 10^{-7}$ \\
\hline B3 & $(3,1785 \pm 1,0359) \times 10^{-8}$ & $(3,1082 \pm 0,9123) \times 10^{-8}$ \\
\hline B4 & $(-1,7032 \pm 0,6168) \times 10^{-10}$ & $(-1,6878 \pm 5,4322) \times 10^{-11}$ \\
\hline B5 & 0,9924 & $0,9943)$ \\
\hline B6 &
\end{tabular}

A mesma análise realizada para a distância de $0,5 \mathrm{~cm}$ foi repetida para a distância de $1,0 \mathrm{~cm}$, conforme mostrada na figura 56 .

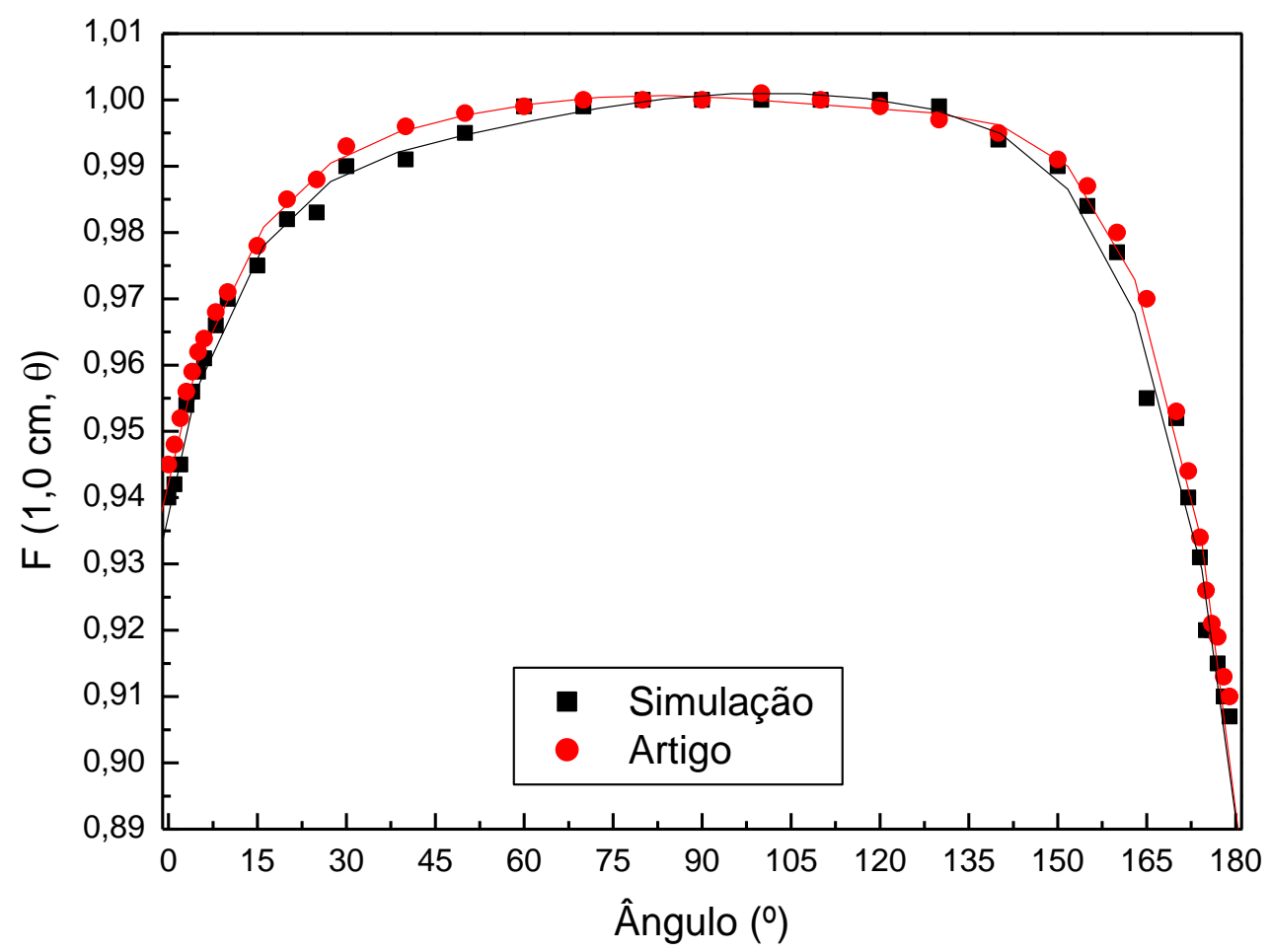

Figura 56: Função de Anisotropia em função do ângulo para distância de 1,0 cm, simulado para a fonte de ${ }^{60} \mathrm{Co}$ e de Granero e colaboradores (GRANERO, PÉREZ-CALATAYUD, BALLESTER, 2007).

Para a distância de 1,0 cm os valores obtidos através da simulação Monte Carlo com o código PENELOPE variaram de 0,907 à 1,000, enquanto que os valores do artigo de referência variaram de 0,910 à 1,001. A máxima diferença relativa encontrada entre os dois conjuntos de dados foi de $1,57 \%$ no ângulo de $165^{\circ}$. Os valores dos parâmetros $\mathrm{A}$, B1, B2, B3, B4 e B5 e B6, obtidos no ajuste realizado para a distância de 1,0 cm, encontram-se na tabela 14. 
Tabela 14: Parâmetros de ajuste de um polinômio de sexta ordem para a função de anisotropia na distância de $1,0 \mathrm{~cm}$ para fonte de ${ }^{60} \mathrm{Co}$.

\begin{tabular}{ccc}
\hline Parâmetros & \multicolumn{2}{c}{ Aalores } \\
\cline { 2 - 3 } & $(0,9457 \pm 0,0008)$ & $(0,9411 \pm 0,0015)$ \\
\hline A & $(0,0035 \pm 0,0001)$ & $(0,0037 \pm 0,0003)$ \\
\hline B1 & $(-1,0702 \pm 1,0844) \times 10^{-4}$ & $(-1,1561 \pm 0,1971) \times 10^{-4}$ \\
\hline B2 & $(1,8629 \pm 0,2446) \times 10^{-6}$ & $(1,9789 \pm 0,4447) \times 10^{-6}$ \\
\hline B3 & $(-1,8153 \pm 0,2572) \times 10^{-8}$ & $(-1,8479 \pm 0,4675) \times 10^{-8}$ \\
\hline B4 & $(9,1293 \pm 1,2643) \times 10^{-11}$ & $(8,8493 \pm 2,2982) \times 10^{-11}$ \\
\hline B5 & $(-1,8408 \pm 0,2348) \times 10^{-14}$ & $(-1,7141 \pm 0,4269) \times 10^{-13}$ \\
\hline B6 & 0,9981 & 0,9992 \\
\hline R $^{2}$ & &
\end{tabular}

Da mesma forma como foram analisados para os valores da função de anisotropia para as duas distâncias apresentadas, os resultados para a distância de 2,0 cm, estão mostrados na figura 57.

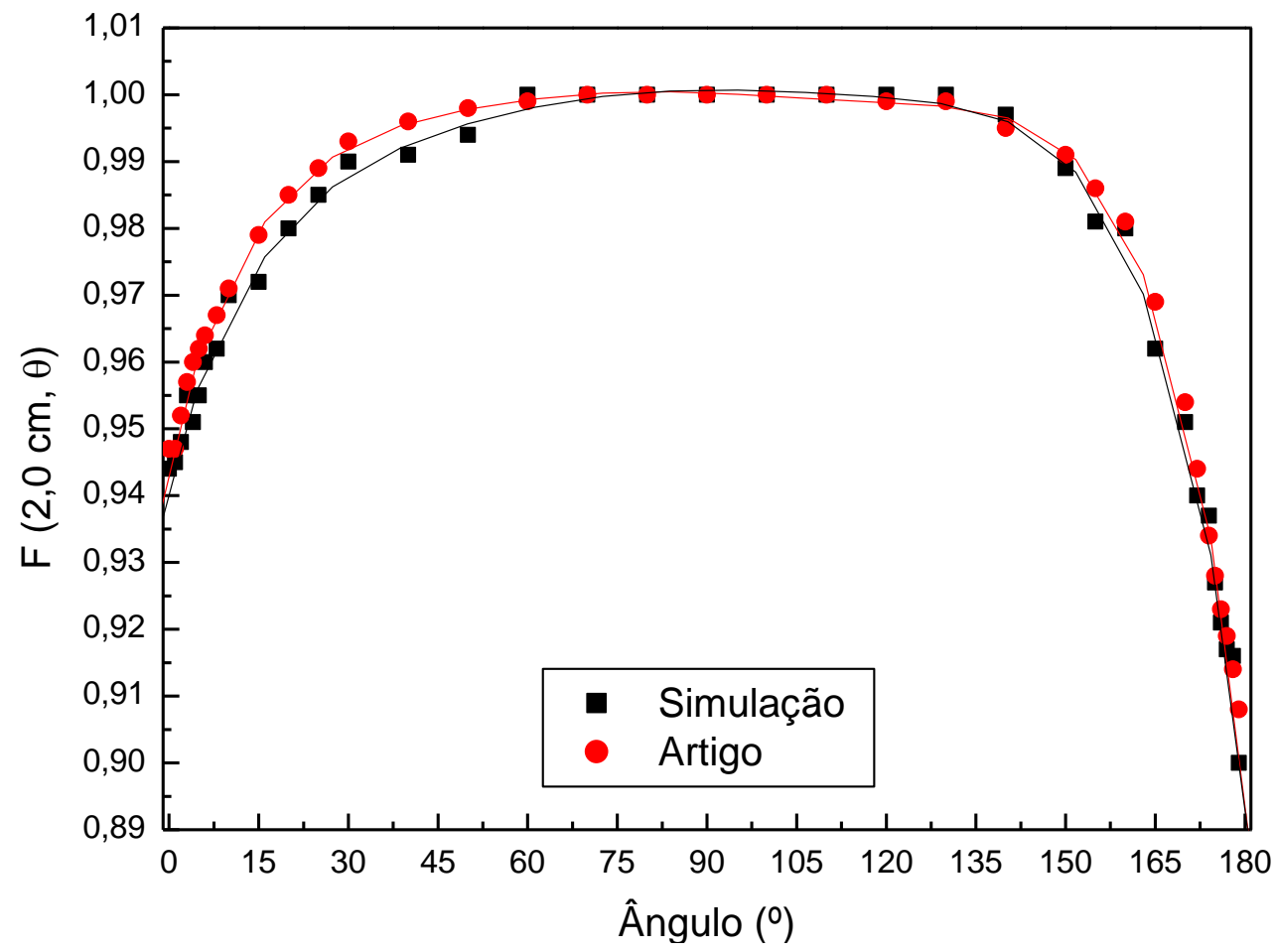

Figura 57: Função de Anisotropia em função do ângulo para distância de 2,0 cm, simulado para a fonte de ${ }^{60} \mathrm{Co}$ e de Granero e colaboradores (GRANERO, PÉREZ-CALATAYUD, BALLESTER, 2007).

O mesmo ajuste realizado nas outras distâncias radiais, foi repetido nesse caso. Os parâmetros do ajuste obtidos são mostrados na tabela 15 . 
Tabela 15: Parâmetros de ajuste de um polinômio de sexta ordem para a função de anisotropia na

\begin{tabular}{ccc}
\multicolumn{3}{c}{ distância de $2,0 \mathrm{~cm}}$. \\
\hline Parâmetros & \multicolumn{2}{c}{ Valores } \\
\cline { 2 - 3 } & $(0,9462 \pm 0,0006)$ & $(0,9428 \pm 0,0013)$ \\
\hline A & $(0,0034 \pm 0,0001)$ & $(0,0031 \pm 0,0003)$ \\
\hline B1 & $(-1,0383 \pm 0,0858) \times 10^{-4}$ & $(-8,7386 \pm 1,8102) \times 10^{-5}$ \\
\hline B2 & $(1,7804 \pm 0,1936) \times 10^{-6}$ & $(1,4666 \pm 0,4084) \times 10^{-6}$ \\
\hline B3 & $(-1,7242 \pm 0,2036) \times 10^{-8}$ & $(-1,4190 \pm 0,4293) \times 10^{-8}$ \\
\hline B4 & $(8,6719 \pm 1,0008) \times 10^{-11}$ & $(7,1809 \pm 2,1105) \times 10^{-11}$ \\
\hline B5 & $(-1,7554 \pm 0,1859) \times 10^{-13}$ & $(-1,4707 \pm 0,3920) \times 10^{-13}$ \\
\hline B6 & 0,9986 & 0,9977 \\
\hline R $^{2}$ & &
\end{tabular}

Os valores computacionais desse trabalho, como é possível observar na figura 56, variaram de 0,900 à 1,000 e os do artigo de referência estão compreendidos entre 0,908 e 1,000. A máxima diferença relativa encontrada foi de $0,94 \%$ referente ao ângulo de $4^{\circ}$. Da mesma forma, foram comparados os dados desse trabalho com o artigo de referência, para a distâncias de 3,0 cm, como é mostrado na figura 58 .

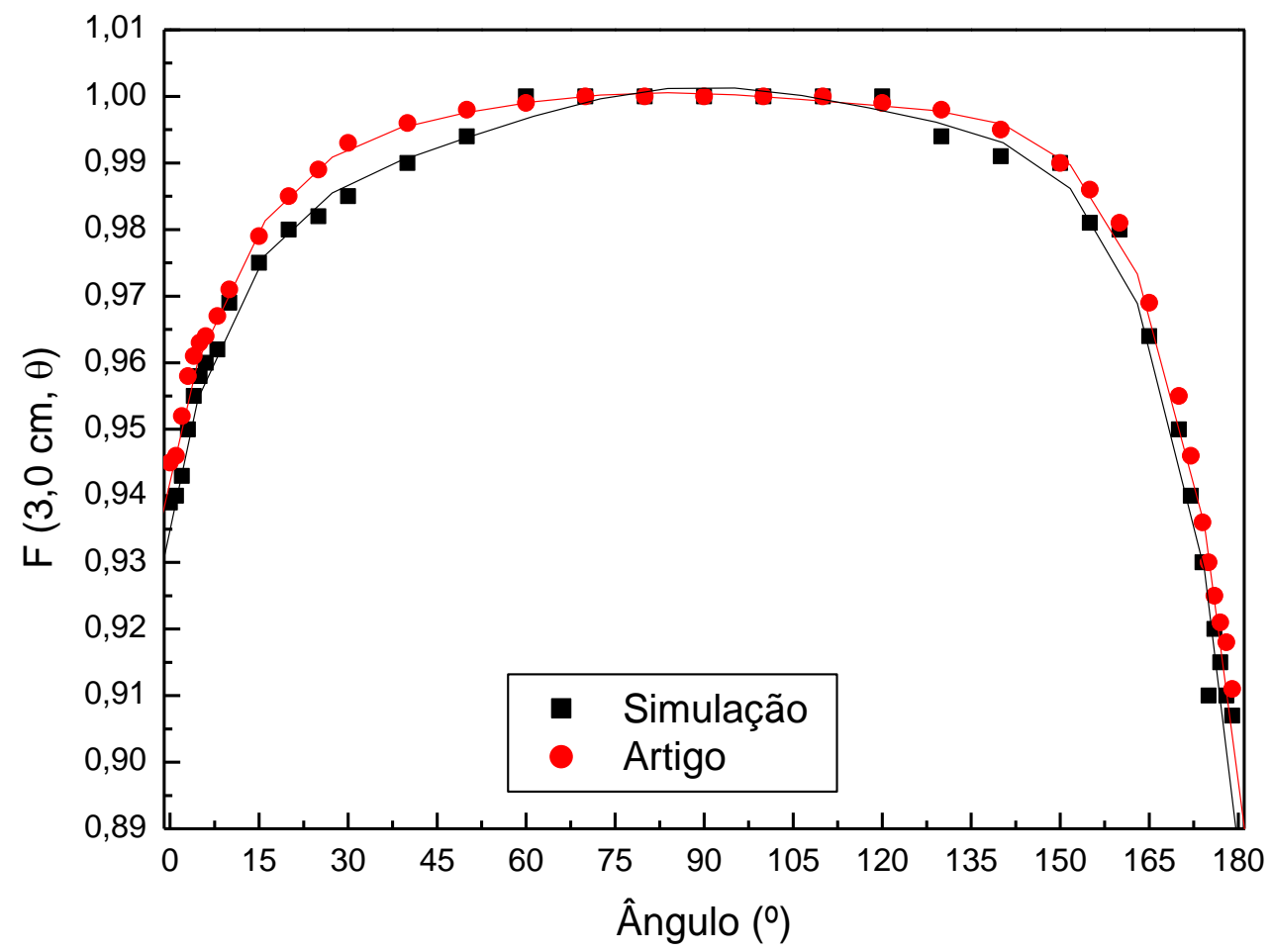

Figura 58: Função de Anisotropia em função do ângulo para distância de 3,0 cm, simulado para a fonte de ${ }^{60} \mathrm{Co}$ e de Granero e colaboradores (GRANERO, PÉREZ-CALATAYUD, BALLESTER, 2007).

Os dados obtidos nesse trabalho também possuem o mesmo comportamento que os dados do artigo de referência. Os valores obtidos computacionalmente através da simulação Monte Carlo PENELOPE variaram entre 0,907 à 1,000, enquanto que os do 
artigo oscilaram de 0,911 à 1,000, onde a máxima diferença relativa foi de $2,2 \%$ em $175^{\circ}$. Novamente, foi realizado um ajuste polinomial de $6^{\circ}$ grau e os parâmetros encontrados estão contidos na tabela 16 .

Tabela 16: Parâmetros de ajuste de um polinômio de sexta ordem para a função de anisotropia na distância de 3,0 cm para fonte de ${ }^{60} \mathrm{Co}$.

\begin{tabular}{ccc}
\hline Parâmetros & \multicolumn{2}{c}{ Valores } \\
\cline { 2 - 3 } & $(0,9457 \pm 0,0008)$ & $(0,9390 \pm 0,0020)$ \\
\hline A & $(0,0035 \pm 0,0001)$ & $(0,0038 \pm 0,0004)$ \\
\hline B1 & $(-1,1096 \pm 0,1050) \times 10^{-4}$ & $(-1,2907 \pm 0,2685) \times 10^{-4}$ \\
\hline B2 & $(1,9211 \pm 0,2369) \times 10^{-6}$ & $(2,4116 \pm 0,6060) \times 10^{-6}$ \\
\hline B3 & $(-1,8503 \pm 0,2491) \times 10^{-8}$ & $(-2,4097 \pm 0,6370) \times 10^{-8}$ \\
\hline B4 & $(9,1786 \pm 1,2244) \times 10^{-11}$ & $(1,2010 \pm 0,3131) \times 10^{-10}$ \\
\hline B5 & 0,9978 & 0,9970 \\
\hline B6 & $(-1,8273 \pm 0,2274) \times 10^{-13}$ & $(-2,3576 \pm 0,5817) \times 10^{-13}$ \\
\hline R $^{2}$ & &
\end{tabular}

Da mesma forma que ocorreu nas simulações para a energia do ${ }^{192} \mathrm{Ir}$, os valores da função de anisotropia são crescentes até o ângulo de $90^{\circ}$, ou seja, crescente para a rotação do vetor $r$ do eixo $\mathrm{Z}$ para o eixo X. A medida que esse ângulo aumenta de $90^{\circ}$ à $180^{\circ}$, o valor da função de anisotropia aproxima-se de um valor mínimo próximo ao cabo da fonte. Os valores das incertezas calculas são menores que $1 \%$ nas distâncias de $0,5 \mathrm{~cm}$ e 1,0 cm, enquanto que essas incertezas, para as distâncias de 2,0 cm e 3,0 cm são menores que $9,4 \%$.

Foi possível evidenciar, para a energia do ${ }^{60} \mathrm{Co}$, que alguns valores da função de anisotropia se mantiveram praticamente constantes em diferentes ângulos. Outro fator considerável, que também pode ser responsável pelo comportamento desses pontos, são os valores de energia da fonte analisada. Essa dependência energética existe, uma vez que para o cálculo desse parâmetro dosimétrico através da equação (14), os valores das taxas de dose nos pontos de interesse e de referência são necessárias. Com isso, podemos notar que tanto a variação dos dados do artigo de referência, quanto a permanência praticamente inalterada do valor da função de anisotropia em ângulos relativamente próximos, são mais observadas para a energia do ${ }^{192} \mathrm{Ir}$. Assim como foi discutido para a energia do ${ }^{192} \mathrm{Ir}$, a combinação desses ângulos com as distâncias e o tamanho do pixel, fazem com que esses valores de função de anisotropia sejam amostradas no mesmo pixel.

Embora esse trabalho não apresente dados referentes ao sistema de planejamento do ${ }^{60} \mathrm{Co}$, a concordância dos resultados das simulações e o sistema de planejamento para a fonte de ${ }^{192} \mathrm{Ir}$, permite associar confiabilidade aos resultados deste trabalho. 


\section{5 - Conclusão}

Neste trabalho foi realizado um estudo dosimétrico de duas fontes de braquiterapia, ${ }^{60} \mathrm{Co}$ e ${ }^{192} \mathrm{Ir}$. Foram obtidas as funções dosimétricas de fontes clínicas ${ }^{192} \mathrm{Ir}$ e ${ }^{60}$ Co através de simulação Monte Carlo com o código PENELOPE e as distribuições tridimensionais de dose do ${ }^{192}$ Ir utilizando o gel polimérico MAGIC- $f$.

O Fator Geométrico foi calculado analiticamente, enquanto que a Função de Dose Radial e Função de Anisotropia foram obtidas por simulação Monte Carlo. Todas essas funções foram comparadas com a literatura, mostrando concordância melhor que $98 \%$ para todos os resultados da fonte de ${ }^{60} \mathrm{Co}$. Para a fonte de ${ }^{192} \mathrm{Ir}$, diferenças de até $22 \%$, para regiões próximas à fonte, foram encontrados entre os resultados deste trabalho e a literatura. Porém, quando os dados obtidos neste trabalho foram comparados com o sistema de planejamento BrachyVision, obteve-se boa concordância, permitindo realizar um mesmo ajuste para o conjunto de dados do sistema de planejamento e os obtidos neste trabalho.

Para a fonte de ${ }^{192}$ Ir foram realizadas comparações entre e as doses simuladas e as doses medidas com o gel MAGIC-f através do Índice Gama. Foram utilizados diferentes critérios de tolerância com relação à distância de concordância. Utilizando os critérios comumente usados em teleterapia, $3 \%$ e $3 \mathrm{~mm}$, obteve-se concordância de $97 \%$ dos pontos dentro da isodoses de 50\%. Entretanto, esse critério de tolerância na distância de comparação não é adequado para o uso em braquiterapia, uma vez que a fonte proporciona um alto gradiente de dose. Um critério de até 0,5 $\mathrm{mm}$ foi estabelecido, porém obtendo-se resultados não satisfatórios clinicamente. Isso evidencia a potencialidade da aplicação desse gel na dosimetria em feixe de fótons, porém novos estudos são necessários antes de sua aplicação clínica em braquiterapia de alta taxa de dose.

Os resultados obtidos nesse trabalho mostram que o método Monte Carlo com o pacote PENELOPE e a dosimetria gel polimérica com MAGIC- $f$, são ferramentas que podem ser utilizadas em estudos de dosimetria de fontes de braquiterapia de alta taxa de dose e podem contribuir com o controle da qualidade em radioterapia. 


\section{Referências Bibliográficas}

ABTAHI, S. M.; AGHAMIRI, M. R.; KHALAFI, H. Optical and MRI Investigations of an Optimized Acrylamide-Based Polymer Gel Dosimeter. J Radioanal Nucl Chem, 300, p. 287-301, 2014.

ALEXANDER, P.; CHARLESBY, A.; ROSS, M. The Degradation of Solid Polymethylmethacrylate by Ionizing Radiations. Proc. R. Soc. A, p. 223-392, 1954.

ALI, O. A.; WILLEMSE, C. A.; SHAW, W. et al. Monte Carlo Electron Source Model Validation for na Elekta Precise Linac. Med Phys., 38 (5), p. 2366-2373, 2011.

ALJAMAL, M.; ZAKARIA, A.; SHAMSUDDIN, S. Radiological Properties of MAGIC Normoxic Polymer Gel Dosimetry. J Phys: Conf Series, 423, p. 1-8, 2013.

ANDRÁSSY, M.; NIATSETSKY, Y.; PÉREZ-CALATAYUD, J. Co-60 Versus Ir-192 in HDR Brachytherapy: Scientific and Technological Comparison. Rev Fis Med, 13(2), p. 125-130, 2012.

ANGELOPOULOS, A.; BARAS, P.; SAKELlIOU, L. et al. Monte Carlo Dosimetry of a new ${ }^{192}$ Ir High Dose Rate Brachytherapy Source. Med Phys 27(11), p. 2521-2527, 2000.

ARYAL, P.; MOLLOY, J. A.; RIVARD, M. J. A Modern Monte Carlo Investigation of the TG-43 Dosimetry Parameters for an ${ }^{125}$ I Seed Already Having AAPM Consensus Data. Med. Phys. 41 (2), p. 021702-1 - 021702-10, 2014.

ATTIX, F. H. Introduction to Radiological Physics and Radiation Dosimetry. WileyVCH - Publisher, 1991. 628 p. ISBN 0-47101146-0

BALCOM, B. J.; LEES, T. J.; SHARP, A. R. et al. Diffusion in Fe (II/III) Radiation Dosimetry Gels Measured by Magnetic Resonance Imaging. Phys Med Biol., 40, p. 1665-1676, 1995.

BAldocK, C.; BURGord, R. P.; BILlingham, N. C. et al. Phys Med Biol, 43, p. 695-702, 1998. 
BALDOCK, C.; DE DEENE, Y.; DORAN, S. et al. Polymer Gel Dosimetry. Phys Med Biol, 55(5), p. R1-R63, 2010.

BALTAS, D.; GIANNOULI, S.; GARBI, A. et al. Application of the Monte Carlo Integration (MCI) Method for Calculation of the Anisotropy of 192Ir Brachytherapy Sources. Phys. Med. Biol., 43, p. 1783-1801, 1998.

BURGER, J. Radioactive Sources in Brachytherapy. Radiol. Oncol, 37(2), p. 127-131, 2003.

BUSHONG, S. C. Radiologic Science for Technologists. $5^{\text {a }}$ edição. Houston: Editora Mosby, 1993, 713p.

CANDELA-JUAN, C.; PEREZ-CALATAYUD, J.; BALLESTER, F. et al. Calculated Organ Doses Using Monte Carlo Simulations in a Reference male Phantom Undergoing HDR Brachytherapy Applied to Localized Prostate Carcinoma. Med. Phys, 40(3), p. 033901-1 - 033901-10, 2013.

CARTHWRIGHT, L. E.; SUCHOWERSKA, N.; WIN, Y. et al. Dose Mapping of The Rectal Wall During Brachytherapy with an Array of Scintillation Dosimeters. Med. Phys., 37, p. 2247-2255, 2010.

CHAMPION, C.; INCERTI, S.; PERROT, Y. et al. Dose Point Kernels in Liquid Water: An Intra-Comparison Between GEANT4-DNA and a Variety of Monte Carlo Codes. Appl Radiat Isto., 83, p. 137-141, 2014.

CHAND, M. E.; RIVERA, S.; HENNEQUIN, C. et al. Brachytherapy of Breast Cancer. Cancer Radiother., 17(2), p. 125-129, 2013.

CHIAVASSA, S.; LEMOSQUET, A.; AUBINEAU-LANIÈCE, I. et al. Dosimetric Comparison of Monte Carlo Codes (EGS4, MCNP, MCNPX) Considering External and Internal Exposures of the Zubal Phantom to Electron and Photon Sources. Radiat. Prot. Dosimetry, 116, p. 631-635, 2005.

CHO, S. J.; SHIM, S. J.; KIM, C. Y. et al. Analysis of the Dosimetric Characteristics of Normoxic Polymer Gel by Magnetic Resonance Images. J Korean Phys Soc., 56(3), p. 874-879, 2010. 
Computing Radiation Dosimetry. Workshop Proceedings, Sacavém. Nuclear Energy Agency, CRD 2002.

DASKALOV, G. M.; LÖFFLER, E.; WILlIAMSON, J. F. Monte Carlo - Aided Dosimetry of a New High Dose-Rate Brachytherapy Source. Med Phys., 25, p. 22002208, 1998.

DAY, M. J.; STEIN, G. Chemical Effects of Ionising Radiation in Some Gels. Nature, 166, p. 141-147, 1950.

DAY, M.J. Radiation Dosimetry Using Nuclear Magnetic Resonance: an Introductory Review. Phys. Med. Biol, 35, p. 1605-1609, 1990.

DE DEENE, Y. How to Scan Polymer Gels with MRI? J. Phys. Conf. Ser., 444, 012003, 2013.

DE DEENE, Y.; VERGOTE, K.; CLAEYS, C. et al. The Fundamental Radiation Properties of Normoxic Polymer Gel Dosimeters: a Comparison Between a Methacrylic Acid Based Gel and Acrylamide Based Gels. Phys. Med. Biol, 51, p. 653-673, 2006.

DE DEENE, Y.; VENNING, A.; HURLEY, C. et al. Dose-Response Stability and Integrity of the Dose Distribution of Various Polymer Gel Dosimeters. Phys Med Biol., 47, p. 2459-2470, 2002.

DE DEENE, Y.; WALLE, R. V.; ACHTEN, E et al. Mathematical Analysis and Experimental Investigation of Noise in Quantitative Magnetic Resonance Imaging Applied in Polymer Gel Dosimetry. Signal Processing, 70, p. 85-101, 1998.

DEMPSEY, C: Methodology for Comissioning a Brachytherapy Treatment Planning System in the era of 3D Planning. Australas. Phys. Eng. Sci. Med., 330, p. 341-349, 2010.

DESBIENS, M.; D’AMOURS, M.; AFSHARPOUR, H. et al. Monte Carlo Dosimetry of High Dose Rate Gynecologic Interstitial Brachytherapy. Radiother. Oncol, 109, p. 425429, 2013.

ESTEVES, S. C. B.; OLIVEIRA, A. C. Z.; FEIJÓ, L. F. A. Braquiterapia de Alta Taxa de Dose no Brasil. Radiol Bras, 37 (5), p. 337-341, 2004. 
FAZLI, Z.; SADEGHI, M. ZAHMATKESH, M. H. et al. Dosimetric Comparisn Between Three Dimensional Treatment Planning System, Monte Carlo Simulation and Gel Dosimetry in Nasopharynx Phantom fot High Dose Rate Brachytherapy. J Cancer Res Ther., 9(3), p. 402-409, 2013.

FERNANDES, J. P.; PASTORELlO, B. F.; ARAUJO, D. B. et al. Formaldehyde Increases MAGIC Gel Dosimeter Melting Point and Sensitivity. Phys Med Biol, 53, p. N53-N58, 2008.

FONG, P. M.; KEIL, D. C.; DOES, M. D. et al. Polymer Gels for Magnetic Resonance Imaging of Radiation Dose Distributions at Normal Room Atmosphere. Phys. Med. Biol, 46, p. 3105-3113, 2001

FONSECA-RODRIGUES, S. S. O.; BEGALLI, M.; QUEIROZ-FILHO, P. P. et al. Monte Carlo Simulation of an Ir-192 Brachytherapy Source Spectra, Geometry and Anysotropy Factors Using Geant4Code. IEEE Nuclear Science Symposium Conference Record, N13-95, p. 544-549, 2009.

FOSTER, R. A.; COX, L. J.; BARRETT, R. F. et al. MCNP ${ }^{\mathrm{TM}}$ Version 5 . Nucl Instr and Meth in Phys Res B, 213, p. 82-86, 2004.

FURNARI, L. Controle de Qualidade em Radioterapia. Rev Bras Fis Med., 3(1), p. 77 90, 2009.

GOETSCH, S. J.; ATTIX, F. H.; PEARSON, D. W. et al. Calibration of 192Ir HighDose-Rate Afterloading Systems. Med. Phys., 18(3), p. 462-467, 1991.

GOULD, H.; TOBOCHNIK, J.; CHRISTIAN, W. et al. An Introduction to Computer Simulation Methods. Applications to Physical Systems. Third Edition. Addison-Wesley, 2006. ISBN 0-8053-7758-1.

GRANERO, D.; PÉREZ-CALATAYUD, J.; BALLESTER, F. Technical Note: Dosimetric Study of a New Co-60 Source Used in Brachytherapy. Med. Phys, 34 (9), p. 3485-3488, 2007. 
GUINOT, J. L.; PEREZ-CALATAYUD, J.; AZCOAGA, J. M. et al. Consensus on Treatment of Endometrium Carcinoma with Brachytherapy. Clinical \& Translational Oncology, 14(4), p. 263-270, 2012.

HASSANI, H.; NEDAIE, H. A.; ZAHMATKESH, M. et al. A Dosimetric Study of Small Photon Fiels Using Polymer Gel and Gafchromic EBT Films. Med. Dosim., 39(1), p. 102-107, 2014.

HAWORTH, A.; BUTLER, D. J.; WIFERT, L. et al. Comparison of TLD Calibration Methods for 192Ir Dosimetry. J Appl Clin Med Phys, 14(1), p. 4037, 2013.

HOECKER, F. E.; WATKINS, I. W. Radiation Polymerization Dosimetry. J Appl Radiat Isot., 3, p. 31-35, 1958.

Hospital do Câncer Antonio Cândido Camargo (HC AC Camargo - SP). Site: www. hcacc.org.br; http://slideplayer.com.br/slide/1232037/\#, acessado em 3 de janeiro de 2014.

Instituto Nacional de Câncer José Alencar Gomes da Silva. Coordenação de Prevenção e Vigilância. Estimativa 2014: Incidência de Câncer no Brasil. Rio de Janeiro: INCA, 2014. ISBN (versão eletrônica): 978-85-7318-237-8.

International Atomic Energy Agency. Absorbed Dose in External Radiotherapy: An International Code of Practive for Dosimetry Based on Standards of Absorbed Dose to Water, TRS 398, 2001.

International Atomic Energy Agency. Calibration of Brachytherapy Sources at Secondary Standard Dosimetry Laboratories (SSDLs) and Hospitals, IAEA-TECDOC 1079, 1999, ISSN 1011-4289.

International Atomic Energy Agency. Calibration of Photon and Beta Ray Sources Used in Brachytherapy, IAEA-TECDOC 1274. Vienna: International Atomic Energy Agency. Calibration of Photon and Beta Ray Sources Used in Brachytherapy, 2002, ISSN 10114289. 
International Commission on Radiation Units and Measurements. Rescribing, Recording and Reporting Photon Beam Therapy. ICRU Report 62. Bethesda: International Commission on Radiation Units and Measuremets; 1999.

International Commission on Radiation Units and Measurements. Fundamental Quantities and Units for Ionizing Radiation. ICRU Report 60. Bethesda: International Commission on Radiation Units and Measuremets, 1998.

International Commission on Radiation Units and Measurements. Dose and Volume Specification for Reporting Interstitial Therapy. ICRU Report 58. Bethesda: International Commission on Radiation Units and Measuremets, 1997.

JIRASEK, A.; HILTS, M. Dose Calibration Optimization and Error Propagation in Polymer Gel Dosimetry. Phys. Med. Biol., 59, p. 597-614, 2014.

JOHNS, H. E.; CUNNINGHAM, J. R. The Physics of Radiology. Charles C Thomas Publisher, 1983. 796 p. ISBN 0-39804669-7

JOHNSTON, H.; HILTS, M. CARRICK, J. et al. Na X-Ray CT Polymer Gel Dosimetry Prototype: II. Gel Characterization and Clinical Application. Phys Med Biol, 57(10), p. 3155-3175, 2012.

KALOS, M. H.; WHITLOCK, P. A. Monte Carlo Methods. Vol I: Basics. John Wiley \& Sons, New York Chichester Brisbance, Toronto Singapor, 1986. ISBN 0-471-89839-2.

KARAISKOS, P.; SAKELLIOU, L.; SANDILOS, P. et al. Limitations of the Point and Line Source Approximations for the Determination of Geometry Factors Around Brachytherapy Sources. Med. Phys, 27(1), p. 124-128, 2000.

KARAISKOS, P.; ANGELOPOUlOS, A.; SAKELlIOU, L. Monte Carlo and TLD Dosimetry on an ${ }^{192}$ Ir High Dose-Rate Brachytherapy Source. Med Phys., 25(10), p. 1975-1984, 1998.

KARAISKOS, P.; ANGELOPOULOS, A.; SAKELLIOU, L. et al. Monte Carlo and TLD Dosimetry of na 192Ir High Dose-Rate Brachytherapy Source. Med Phys, 22 (6), p. 809819, 1995. 
KAWAMURA, H.; SAKAE, T.; TERUNUMA, T. et al. Evaluation of ThreeDimensional Polymer Gel Dosimetry Using X-Ray and R2 MRI. Appl Rad Istop, 77, p. 94-102, 2013.

KHAN, F. M. The Physics of Radiation Therapy. $3^{\text {a }}$ Edição. Philadelphia: LIPPINCOTT WILLIAMS \& WILKINS, 2003. ISBN 0-7817-3065-1.

KHOEI, S.; TRAPP, J. V.; LANGTON, C. M. Quantitative Evaluation of Polumer Gel Dosimeters by Broadhand Ultrasound Attenuation. J. Phys.: Conf. Ser., 444, n. 012084, 2013.

KING, R. P. ANDERSON, R. S.; MILLS, M. D. Geometry Function of a Linear Brachytherapy Source. J Appl Clin Med Phys 2(2), p. 69-72, 2001.

KIRASEK, A.; HILTS, M.; MCAULEY, K. B. Polymer Gel Dosimeters with Enhanced Sensitivity for use in X-Ray CT Polymer Gel Dosimetry. Phys. Med. Biol, 55, p. 5269$5281,2010$.

KIRASEK, A.; HILTS, M. Dose Calibration Optimization and Error Propagation in Polymer Gel Dosimetry. Phys. Med Biol, 59, p. 597-614, 2014.

KISIELEWICZ, K.; SWIEBOCKA, J.; CZOPYK, L. et al. Dosimetric Properties of TL Foils Based on LiF:Mg, Cu,P (MCP-N) Phosphors for Clinical Applications. Radiat. Meas, 45, p. 716-718, 2010.

KLASSEN, N.; VAN DER ZWAN, L; CYGLER, J. GafChromic MD-55: Investigated as a Precision Dosimeter. Med Phys, 24, p. 1924-1934, 1997.

KLEIN, E. E.; HANLEY, J.; BAYOUTH, J. et al. Task Group 142 Report: Quality Assurance of Medical Accelerators. Med Phys., 36(9), p. 4197-4212, 2009.

KOIVUNORO, H.; SIISKONEN, T.; KOTILUOTO, P. et al. Accuracy of the Electron Transport in MCNP5 and its Suitability for Ionization Chamber Response Simulations: A Comparison with the EGSNRC and PENELOPE Codes. Med. Phys., 39(3), p. 13351344, 2012. 
Laboratório Nacional de Metrologia das Radiações Ionizantes. Grandezas e Unidades para Radiação Ionizante (Recomendações e Definições), LNMRI, 2012, Laboratório Designado pelo INMETRO - IRD/CNEN/MCT, Rio de Janeiro, 2002.

LESPERANCE, M.; MARTINOV, M. THOMSON, R. M. Monte Carlo Dosimetry for 103Pd, 125I, 131Cs Ocular Brachytherapy With Various Plaque Models Using na Eye Phantom. Med. Phys, 41, p. 031706-1 - 031706-14, 2014.

LLOVET, X.; FERNÁNDEZ-VAREA, J. M.; SEMPAU, J. et al. Monte Carlo Simulation of X-Ray Emission Using the General-Purpose Code PENELOPE. Surf. Interface Anal. 37, p. 1054-1058, 2005.

LOVE, P. A.; LEWIS, D. G.; AL-AFFAN, I.A.M. Comparison of EGS4 and MCNP Monte Carlo Codes When Calculating Radiotherapy Depth Doses. Phys Med Biol., 43 (5), p. 1351-1357, 1998.

LOW, D. A.; HARMS, W. B.; MUTIC, S. et al. A Technique for the Quantitative Evaluation of Dose Distributions. Med. Phys., 25(5), p. 656- 661, 1998.

LUCAS, P. A.; AUBINEAU-LANIĖCE, I.; LOURENÇO, V. et al. Using LiF:Mg,Cu,P TLDs to Estimate the Absorbed Dose to Water in Liquid Water Around an 192Ir brachytherapy source. Med. Phys. 41 (1), p. 011711-1 - 011711-12, 2014.

LUCI, J. J.; WHITNEY, H. M.; GORA, J. C. Optimization of MAGIC Gel Formulation for Three-Dimensional Radiation Therapy Dosimetry. Phys Med. Biol., 52, p. 241-248, 2007.

MAINEGRA, E.; CAPOTE, R.; LÓPEZ, E. Radial Dose Functions for ${ }^{103} \mathrm{Pd},{ }^{125} \mathrm{I},{ }^{169} \mathrm{Yb}$ and ${ }^{192}$ Ir Brachytherapy Sources: na EGS4 Monte Carlo Study. Phys Med Biol, 45, p. 703-717, 2000.

MANTINI, G.; ALITTO, A. R.; FIONDA, B. et al. Radiotherapy in Men with Prostate Cancer: Indications, Evolutions and Integrated Approaches. Urologia, 80(3), p. 188-201, 2013

MARTISKIKOVÁ, M.; JÄKEL, O. Dosimetric Properties of Gafchromic® EBT FIlms in Monoenergetic Medical Ion Beams. Phys. Med. Biol, 55, p. 3741-3751, 2010. 
MARYANSKI, M. J.; ZASTAVKER, Y. Z.; GORE, J.C. Radiation Dose Distributions in Three Dimensions From Tomographic Optical Density Scanning of Polymer Gels. 2. Optical Properties of the BANG Polymer Gel. Phys. Med. Biol, 41(12), p. 2705-2717, 1996.

MARYANSKI, M. J.; SCHULZ, R.J.; IBBOTT, G.S. et al. Magnetic-ResonanceImaging of Radiation-Dose Distributions Using a Polymer-Gel Dosimeter. Phys. Med. Biol, 39(9), p. 1437-1455, 1994

MARYANSKI, M. J.; GORE, J. C.; KENNAN, R. P. et al. NMR Relaxation Enhancement in Gels Polymerized and Cross-Linked by Ionizing Radiation: a New Approach to 3D Dosimetry by MRI. Magn Reson Imaging, 11, p. 253-258, 1993.

MCJURY, M.; OLDHAM, M; COSGROVE, V. P. et al. Radiation Dosimetry Using Polymer Gels: Methods and Applications. The British Journal of Radiology, 73, p. 919929, 2000.

MODE, C. J. Applications of Monte Carlo Methods in Biology, Medicine and Other Fields of Science. India, 2011. 438 p. ISBN: 978-953-307-427-6.

MOHAN, R.; MAHAJAN, A.; MINSKY, B. D. New Strategies in Radiation Therapy: Exploiting the Full Potential of Protons. Clin. Cancer Res, 19, p. 6338-6343, 2013.

MORRISON, H.; GEETHA, M.; R. S. SLOBODA. Radiochromic Film Calibration for Low-Energy Seed Brachytherapy Dose Measurement. Med. Phys., 41 (7), p. 072101-1 072101-11, 2014.

MOWLAVI, A. A.; CUPARDO, F.; SEVERGNINI. Monte Carlo and Experimental Relative Dose Determination for na Iridium-192 Source in Water Phantom. Iran. J. Radiat. Res., 6(1), p. 37-42, 2008.

MURPHY, M. K.; PIPER, K.; GREENWOOD, L. R. et al. Evaluation of the New Cesium-131 Seed for use in Low-Energy X-Ray Brachytherapy. Med. Phys., 31(6), p. 1529-1538, 2004. 
NATH, R.; ANDERSON, L. L.; LUXTON, G. et al. Dosimetry of Interstitial Brachytherapy Sources: Recommendations of the AAPM Radiation Therapy Committee Task Group No. 43. Med Phys., 22, p. 209-234, 1995.

NATH, R.; MEIGOONI, A. S.; MELI, J. A. Dosimetry on Transverse Axes of 125I and ${ }^{192}$ Ir Interstitial Brachytherapy Sources. Med Phys, 17(6), p. 1032-1040, 1990.

NIROOMAND-RAD, A.; BLACKWELL, C. R.; COURSEY, B. M. et al. Radiochromic Film Dosimetry: Recommendations of AAPM Radiation Therapy Committee Task Group 55. Med Phys, 25 (11), p. 2093-2115, 1998.

NuDat 2.0 National Nuclear Data Center Nuclear data from NuDat (2004)/ Site: http://www.nndc.bnl.gov/nudat2

OKUNO, E.; YOSHIMURA, E. M. Física das Radiações. São Paulo: Oficina de Textos, 2010. ISBN 978-85-7975-005-2.

PANTELIS, E.; KARLIS, A. K.; KOZICKI, M. et al. Polymer Gel Water Equivalence and Relative Energy Response with Emphasis on Low Photon Energy Dosimetry in Brachytherapy. Phys. Med. Biol, 49, p. 3495-3514, 2004.

PARK, D.; KIM, T.S.; PARK, S.H. et al. A Comparison of Dose Distributions of HDR Intracavitary Brachytherapy Using Different Sources and Treatment Planning Systms. Appl Rad Isot, 67, p. 1426-1431, 2009.

PAVONI, J. F.; PIJE, T. L., SNOW, J. et al. Dosimetria Tridimensional Usando Gel MAGIC com Formaldeído. Rev Bras Fis Med, 4 (1), p. 15-18, 2010.

PAVONI, J. F. Dosimetria Tridimensional por Imagens de Ressonânca Magnética com Gel MAGIC Modificado. 186f. Tese de Doutorado - Faculdade de Filosofia, Ciências e Letras de Ribeirao Preto da Universidade de São Paulo - Área de Concentração: Física Aplicada à Medicina e Biologia. Ribeirão Preto, 2009.

PEREZ, C. A.; BRADY, L. W.; HALPERIN, E. C. et al. Principles and Practice of Radiation Oncology. Phuladelphia: Wolters Kluwer Health / Lippincott Williams \& Wilkins, 2013. ISBN 978-07-8176-369-1. 
PERONI, C. M.; CIRIO, R.; BRUSACO, C. et al. A New 2-D Ion Chamber Detector for Radiotherapy Quality Assurance. Confer 49th Annual Meeting of the American-Society for Therapeutic Radiology and Oncology, Los Angeles. Int J Rad Oncol Biol Phys, 69 (3), p. S733-733, 2007.

PETROKOKKINOS, L.; KOZICKI, M.; PANTELIS, E. et al. Characterizaton of a new Polymer Gel for Radiosurgery Dosimetry using Magnetic Resnonance Imaging. J. Inst., 4, P060818, 2009.

PODGORSAK, E. B. Radiation Oncology Physics: A Handbook for Teachers and Studens. Viena: Ed: II International Atomic Energy Agency (IAEA), 2005. ISBN 92-0107304-6.

QIAN, X.; ADAMOVICS, J.; WUU, C.S. Performance of an Improved First Generation Optical CT Scanner for 3D Dosimetry. Phys Med Biol., 58 (24), p. N321-N331, 2013.

RICHTER, J.; BAIER, K.; FLENTJE, M. Comparison of ${ }^{60}$ Cobalt and ${ }^{192}$ Iridium Sources in High Dose Rate Alterloading Brachytherapy. Strahlenther Onkol., 4, p. 187-192, 2008

RIVARD, M. J.; BEAULIEU, L.; MOURTADA, F. Enhancements to Commissioning Techniques and Quality Assurance of Brachytherapy Treatment Planning Systems that use Model-Based Dose Calculation Algorithms. Med. Phys., 37(6), p. 2645-2658, $2010 a$.

RIVARD, M. J.; GRANERO, D.; PEREZ-CALATAYUD, J. et al. Influence of Photon Energy Spectra From Brachytherapy Sources on Monte Carlo Smulations of Kerma and Dose Rates in Water and Air. Med. Phys., 37, p. 869-876, $2010 b$.

RIVARD M.J.; COURSEY, B.M.; DEWERDM, L.A. et al. Update of AAPM Task Group No. 43 Report: A Revised AAPM Protocol for Brachytherapy Dose Calculations. Med Phys., 31(3), p. 633-674, 2004.

RIVARD, M. J. Comment on "Dosimetry of Interstitial Brachytherapy Sources: Recommendations of the AAPM Radiation Therapy Committee Task Group 43". Med Phys, 26, p.2514, 1999. 
ROGERS, D.W.O. Review: FIfty Years of Monte Carlo Simulation for Medical Physics. Phys Med Biol., 51, p. r287-r301, 2006.

ROMANO, S.; FUSI, F.; BOLLA, E. et al. Optical Fibers and Radiochromic Films for Dosimetry in Radiotherapy. In: Proceedings of the Society of Photo-Optical Intrumentation Engineers (SPIE), 2928, p. 276-283, 1996.

SADEGHI, M.; SAIDI, P.; TENREIRO, C. Dosimetric Characteristics of Brachytherapy Souces Based on Monte Carlo Method. In: MODE, C. J. Applications of Monte Carlo Methods in Biology, Medicine and Other Fields of Science. India: InTech, 2011, ISBN 92-0-107304-6, Capítulo 10, p.155-176.

SALATA, C.; SIBATA, C. H.; FERREIRA, N. M. et al. Simulação Computacional de um Feixe de Fótons de 6 MV em Diferentes Meios Heterogêneos Utilizando o Código PENELOPE. Radiol Bras., 42(4), p. 249-253, 2009.

SALVAJOLI, J. V.; SOUHAMI, L.; FARIA, S. L. Radioterapia em Oncologia. $2^{\text {a }}$ Edição. São Paulo: Editora Atheneu, 2013. ISBN 978-85-388-0381-2.

SALVAT, F; FERNÁNDEZ-VAREA, JM; SEMPAU, J. PENELOPE, a Code System for Monte Carlo Simulation of Electron and Photon Transport. Barcelona, Espanha: Nuclear Atomic Agency - Organisation for Economic Co-Operation and Development, 2009. 319 p. ISBN 978-92-64-99066-1.

SALVAT, F.; FERNÁNDEZ-VAREA, J.; SEMPAU, J. et al. Monte Carlo Simulation of Bremsstrahlung Emission by Electrons. Radiat. Phys. Chem, 75, p. 1201-1219, 2006.

SCHUMER, W.; FERNANDO, W.; CAROLAN, M. et al. Verification of Brachytherapy Dosimetry with Radiochromic Film. Med Dosimetry, 24(3), p. 197-203, 1999.

SCHWOB, N.; ORION, I. Film Dosimetry Calibration Method for Pulsed-Dose-Rate Brachytherapy with an Ir 192 Source. Med. Phys, 34(5), p. 1678-1683, 2007.

SELLAKUMAR, P.; SAMUEL, E. J. J.; SUPE, S. S. Water Equivalence of Polymer Gel. Radiat. Phys. and Chemistry, 76, p. 1108-1115, 2007. 
SEMPAU, J.; FERNÁNDEZ-VAREA J. M.; ACOSTA, E.; SALVAT, F. Experimental Benchmarks of the Monte Carlo Code PENELOPE. Nucl. Instrum. Meth. B, 207, p. 107-123, 2003.

SHARMA, R.; JURSINIC, P. A. In Vivo Measurements For High Dose Rate Brachytherapy with Optically Stimulated Luminescent Dosimeters. Med. Phys., 40 (7), p. 071730-1 - 071730-12, 2013.

Shielding Aspects of Accelerators, Targets and Irradiation Facilities. Workshop Proceedings Tennessee, USA. Nuclear Energy Agency, SATIF 41998.

SILVA, A. O. Comparação da Dose Absorvida no Tratamento do Câncer Ginecológico por Braquiterapia de Alta Taxa de Dose Utilizando o Planejamento Convencional do Tratamento e Simulação por Monte Carlo. 2010. 107f. Dissertação de Mestrado - Instituto de Radioproteção e Dosimetria - Comissão Nacional de Energia Nuclear, Rio de Janeiro, 2010.

STATHAKIS, S.; MAVROIDIS, P.; SHI, C. et al. $\gamma_{+}$Index: A New Evaluation Parameter for Quantitative Quality Assurance. Comput. Meth. Prog. Bio, 114 (1), p. 60-69, 2014.

STROHMAIER, S.; ZWIERZCHOWSKI, G. Comparision of 60Co and 192Ir Sources in HDR Brachytherapy. J Contemp Brachyther, 3(4), p. 199-208, 2011.

SUNTHARALINGAM, N.; PORGORSAK, E. B.; TÖLLI, H. Brachytherapy: Physical and Clinical Aspects. In: Radiation Oncology Physics: A Handbook for Teachers and Studens. Viena: Ed: II International Atomic Energy Agency (IAEA), 2005, ISBN 92-0107304-6, Capítulo 13, p. 451-484.

SYMONDS, R. P.; DEEHAN, C.; MEREDITH, C. et al. Textbook of Radiotherapy: Radiation Physics, Therapy and Oncoly. Seventh Edition, Churchill Livingstone, 2012. ISBN: 978-0443074868.

TANDERUP, K.; PÖTTER, R.; LINDEGAARD, J. C. et al. PTV Margins Shoul nod be Used to Compensate for Uncertainties in 3D Image Guided Intracavitary Brachytherapy. Radiother Oncol., 97, p. 495-500, 2010. 
TEDGREN, A. C.; HEDMAN, A.; GRINDBORG, J. E. et al. Response of LiF:Mg,Ti Thermoluminescent Dosimeters at Photon Energies Relevant to the Dosimetry of Brachytherapy. Med. Phys., 38 (10), p. 5539 - 5550, 2011.

The American Brachytherapy Society Consensus Guidelines for Plaque Brachytherapy of Uveal Melanoma and Retinoblastoma - The American Brachytherapy Society Ophthalmic Oncology Task Force - The ABS OOTF Committee. Brachytherapy, 2013.

The International Commission on Radiation Units and Measurements: Dosimetry of Beta Rays and Low-Energy Photons for Brachytherapy with Sealed Sources. ICRU Report 72. Oxford University Press. ISBN 0198566794, 2004.

TURONOK, O.; DIACHENKO, O. V.; ALOKHUNA, M. Y. et al. Three-Dimensional Polymer Dosimetry. WDS'13 Proceedings of Contributed Papers, Part III, p. 58-61, 2013. ISBN 978-80-7378-252-8.

UN, A. Water and Tissue Equivalency of Some Gel Dosimeters for Photon Energy Absorption. Appl. Radiat. Isot, 82, p. 258-263, 2013.

VANDECASTEELE, J.; DE DEENE, Y. On the Validity of 3D Polymer Gel Dosimetry: I. Reproducibility study. Phys. Med. Biol., 58, p. 19-42, $2013 a$.

VANDECASTEELE, J.; DE DEENE, Y. On the Validity of 3D Polymer Gel Dosimetry: III. MRI-Related Error Sources. Phys. Med. Biol., 58, p. 63-85, $2013 b$.

VANDECASTEELE, J.; DE DEENE, Y. Evaluation of Radiochromic Gel Dosimetry and Polymer Gel Dosimetry in a Clinical Dose. Phys. Med. Biol., 58, p. 6241-6262, $2013 c$.

WATANABE, Y.; HITOSHI, K. A Variable Echo-Number Method for Estimating R2 in MRI-Based Polymer Gel Dosimetry. Med.Phys., 38, p. 975-982, 2011.

WILKINSON, D. A. High Dose Rate (HDR) Brachytherapy Quality Assurance: a Practical Guide. Biomed Imaging Interv J, 2(2), p. 1-7, 2006.

WILLIAMSON, J. F.; NATH, R. Clinical Implementation of AAPM Task Group 32 Recommendations on Brachytherapy Source Strength Specification. Med Phys, 18, p. 439-448, 1991. 
WONG, C. J.; ACKERLY, T.; HE, C. et al. High-Resolution Measurements of Small Field Beams Using Polymer Gels. Appl Radiat Isot., 65, p. 1160-1164, 2007.

WOOTEN, C. E.; RANDALL, M.; EDWARDS, J. et al. Implementation and Early Clinical Results Utilizing Cs-131 Permanent Interstitial Implants or Gynecologic Malignancies. Gynecol. Oncol, 133, p. 268-273, 2014.

WU, C. H.; LIAO, Y. J.; LIU, Y. W. H. et al. Dose Distribution of an ${ }^{192}$ Ir Brachytherapy Source in Different Media. Biomed Res Int., ID 946213, 2014.

YE, S. J.; BREZOVICH, I. A.; PAREEK, P. et al. Benchmark of PENELOPE Code for Low-Energy Photon Transport: Dose Comparisons with MCNP4 and EGS4. Phys. Med. Biol, 49, p. 387-397, 2004.

YI, C. Y.; CHUN, K. J.; HAH, S. H. KIM, H. M.; LIM, C. Dosimetry Parameters of the IRH10 ${ }^{192}$ Ir High Dose Rate Brachytherapy Source. J Radiat Res., 51, p. 485-492, 2010. YORIYAZ, H. Método de Monte Carlo: Princípios e Aplicações em Física Médica. Rev Bras Fis Méd., 3(1), p. 141-149, 2009

ZILIO, V. L.; JONEJA, O. P.; POPOWSKI, Y. et al. Dosimetric Characterization of Radioactive Sources Employed in Prostate Cancer Therapy. Brachytherapy, 3, p. 201$214,2004$. 


\section{ANEXO I - Arquivo entrada.in}

TITLE Parâmetros de Entrada para Simulação Utilizando Fonte de Irídio

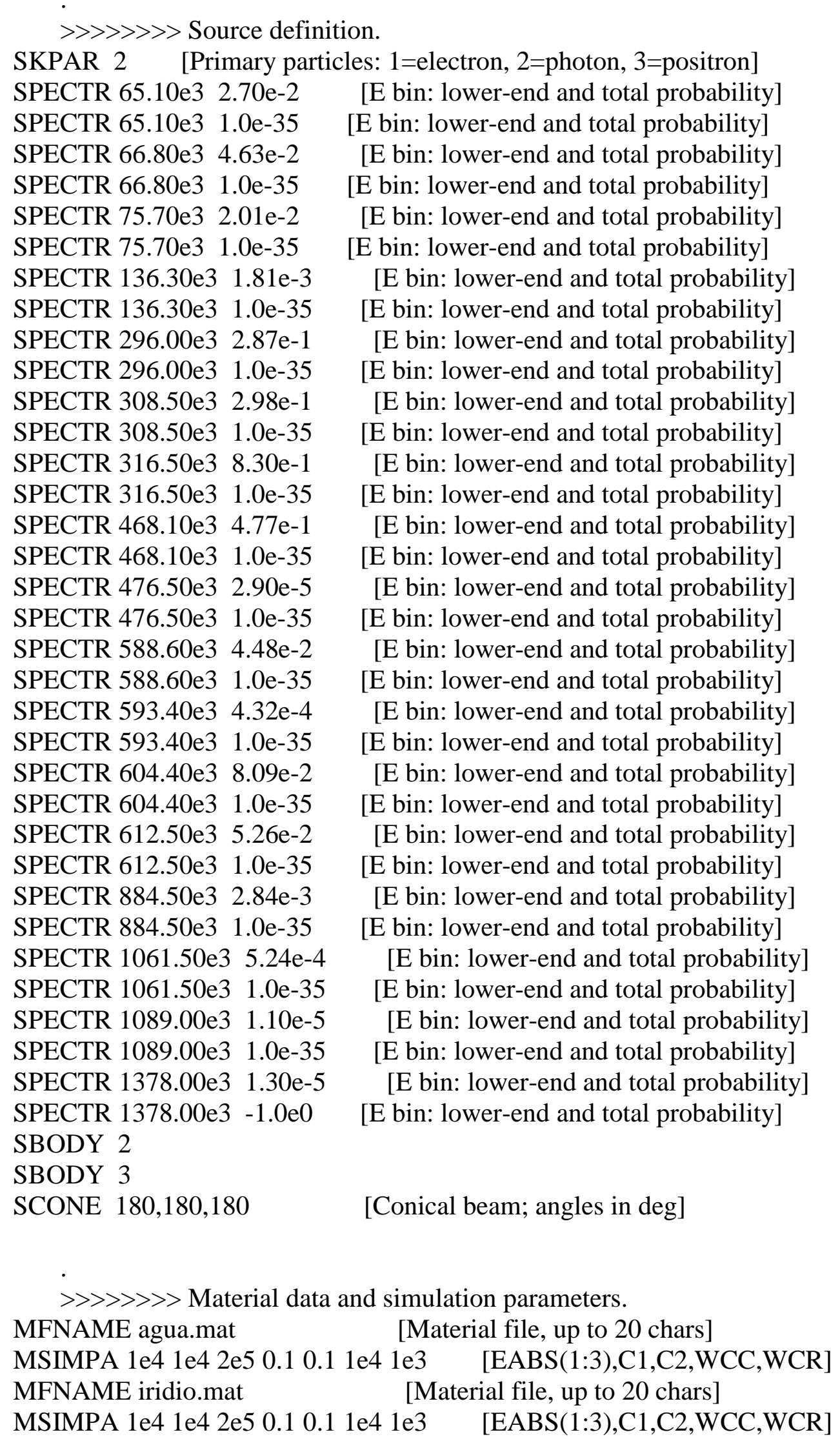


MFNAME aco.mat

[Material file, up to 20 chars]

MSIMPA 1e4 1e4 2e5 0.1 0.1 1e4 1e3 [EABS(1:3),C1,C2,WCC,WCR]

MFNAME cabo.mat

[Material file, up to 20 chars]

MSIMPA 1e5 1e4 2e5 0.1 0.1 1e4 1e3

[EABS(1:3),C1,C2,WCC,WCR]

MFNAME agulha.mat

[Material file, up to 20 chars]

MSIMPA 1e5 1e4 2e5 0.1 0.1 1e4 1e3 [EABS(1:3),C1,C2,WCC,WCR]

>>>>>>> Geometry definition file.

GEOMFN cilindroag.geo

[Geometry file, up to 20 chars]

>>>>>> Dose distribution.

GRIDX -33 [X coordinates of the enclosure vertices]

GRIDY -3 3 [Y coordinates of the enclosure vertices]

GRIDZ -3 3 [Z coordinates of the enclosure vertices]

GRIDBN 100100100

[Numbers of bins]

>>>>>>> Job properties

RESUME dump.dmp

DUMPTO dump.dmp

DUMPP 600

[Resume from this dump file, 20 chars]

[Generate this dump file, 20 chars]

NSIMSH 1e9

[Dumping period, in sec]

TIME 1e9

[Desired number of simulated showers]

[Allotted simulation time, in sec]

END

[Ends the reading of input data] 
ANEXO II - Arquivo geometria.geo

\section{XXXXXXXXXXXXXXXXXXXXXXXXXXXXXXXXXXXXXXXXXXXXXXXXX XXXXXXXXXXXXXXX}

Geometria: Geometria da Fonte de Irídio Utilizada nas Simulações

0000000000000000000000000000000000000000000000000000000000000000

SURFACE ( 1) Cilindro $R=0.03 \mathrm{~cm}$

INDICES $=(1,1,0,0,-1)$

$\mathrm{X}-\mathrm{SCALE}=(+0.030000000000000 \mathrm{E}+00,0) \quad(\mathrm{DEFAULT}=1.0)$

$\mathrm{Y}-\mathrm{SCALE}=(+0.030000000000000 \mathrm{E}+00,0) \quad($ DEFAULT $=1.0)$

0000000000000000000000000000000000000000000000000000000000000000

SURFACE ( 2) Plano Duplo R=0.175 cm

INDICES $=(0,0,1,0,-1)$

$\mathrm{Z}-\mathrm{SCALE}=(+0.175000000000000 \mathrm{E}+00,0) \quad(\mathrm{DEFAULT}=1.0)$

0000000000000000000000000000000000000000000000000000000000000000

SURFACE ( 3) Cilindro R=0,055 cm

INDICES $=(1,1,0,0,-1)$

$\mathrm{X}-\mathrm{SCALE}=(+0.055000000000000 \mathrm{E}+00,0) \quad(\mathrm{DEFAULT}=1.0)$

$\mathrm{Y}-\mathrm{SCALE}=(+0.055000000000000 \mathrm{E}+00,0) \quad(\mathrm{DEFAULT}=1.0)$

0000000000000000000000000000000000000000000000000000000000000000

SURFACE ( 4) Plano Duplo R=0.25 cm

INDICES $=(0,0,1,0,-1)$

$\mathrm{Z}$-SCALE $=(+0.250000000000000 \mathrm{E}+00,0) \quad(\mathrm{DEFAULT}=1.0)$

$\mathrm{Z}-\mathrm{SHIFT}=(-0.075000000000000 \mathrm{E}+00,0) \quad(\mathrm{DEFAULT}=1.0)$

0000000000000000000000000000000000000000000000000000000000000000

SURFACE ( 5) Esfera $\mathrm{R}=0,055 \mathrm{~cm}$

INDICES $=(1,1,1,0,-1)$

$\mathrm{X}-\mathrm{SCALE}=(+0.055000000000000 \mathrm{E}+00,0) \quad(\mathrm{DEFAULT}=1.0)$

$\mathrm{Y}-\mathrm{SCALE}=(+0.055000000000000 \mathrm{E}+00,0) \quad(\mathrm{DEFAULT}=1.0)$

$\mathrm{Z}-\mathrm{SCALE}=(+0.055000000000000 \mathrm{E}+00,0) \quad(\mathrm{DEFAULT}=1.0)$

$\mathrm{Z}-\mathrm{SHIFT}=(+0.175000000000000 \mathrm{E}+00,0) \quad($ DEFAULT $=1.0)$

0000000000000000000000000000000000000000000000000000000000000000

SURFACE ( 6) Cilindro $\mathrm{R}=0,055 \mathrm{~cm}$

INDICES $=(1,1,0,0,-1)$

$\mathrm{X}-\mathrm{SCALE}=(+0.055000000000000 \mathrm{E}+00,0) \quad(\mathrm{DEFAULT}=1.0)$

$\mathrm{Y}-\mathrm{SCALE}=(+0.055000000000000 \mathrm{E}+00,0) \quad(\mathrm{DEFAULT}=1.0)$

0000000000000000000000000000000000000000000000000000000000000000

SURFACE ( 7) Plano Duplo R=75 cm

INDICES $=(0,0,1,0,-1)$

$\mathrm{Z}-\mathrm{SCALE}=(+5.000000000000000 \mathrm{E}+00,0)$

$\mathrm{Z}-\mathrm{SHIFT}=(-5.325000000000000 \mathrm{E}+00,0)$

$($ DEFAULT $=1.0)$

0000000000000000000000000000000000000000000000000000000000000000

SURFACE ( 8) Cilindro $\mathrm{R}=0,0825 \mathrm{~cm}$

INDICES $=(1,1,0,0,-1)$

$\mathrm{X}-\mathrm{SCALE}=(+0.082500000000000 \mathrm{E}+00,0) \quad(\mathrm{DEFAULT}=1.0)$

$\mathrm{Y}-\mathrm{SCALE}=(+0.082500000000000 \mathrm{E}+00,0) \quad(\mathrm{DEFAULT}=1.0)$

0000000000000000000000000000000000000000000000000000000000000000

SURFACE ( 9) Plano Duplo $R=10 \mathrm{~cm}$ 
INDICES $=(0,0,1,0,-1)$

$\mathrm{Z}-\mathrm{SCALE}=(+10.00000000000000 \mathrm{E}+00,0) \quad($ DEFAULT $=1.0)$

0000000000000000000000000000000000000000000000000000000000000000

SURFACE ( 10) Cilindro R=4.75 cm

INDICES $=(1,1,0,0,-1)$

$\mathrm{X}-\mathrm{SCALE}=(+4.750000000000000 \mathrm{E}+00,0) \quad(\mathrm{DEFAULT}=1.0)$

$\mathrm{Y}-\mathrm{SCALE}=(+4.750000000000000 \mathrm{E}+00,0) \quad(\mathrm{DEFAULT}=1.0)$

0000000000000000000000000000000000000000000000000000000000000000

SURFACE ( 11) Plano Duplo R=7.25 cm

INDICES $=(0,0,1,0,-1)$

$\mathrm{Z}-\mathrm{SCALE}=(+7.250000000000000 \mathrm{E}+00,0) \quad($ DEFAULT $=1.0)$

0000000000000000000000000000000000000000000000000000000000000000

BODY ( 1) Fonte

MATERIAL( 2)

SURFACE ( 1), SIDE POINTER $=(-1)$

SURFACE ( 2), SIDE POINTER $=(-1)$

0000000000000000000000000000000000000000000000000000000000000000

BODY ( 2) Encapsulamento

MATERIAL( 3)

SURFACE ( 3), SIDE POINTER $=(-1)$

SURFACE ( 4), SIDE POINTER $=(-1)$

BODY ( 1$)$

0000000000000000000000000000000000000000000000000000000000000000

BODY ( 3) Encapsulamento

MATERIAL( 3)

SURFACE ( 5), SIDE POINTER $=(-1)$

SURFACE ( 4$),$ SIDE POINTER $=(+1)$

0000000000000000000000000000000000000000000000000000000000000000

BODY ( 4) Cabo

MATERIAL( 4)

SURFACE ( 6), SIDE POINTER $=(-1)$

SURFACE ( 7), SIDE POINTER $=(-1)$

0000000000000000000000000000000000000000000000000000000000000000

BODY ( 5) Agulha

MATERIAL( 5)

SURFACE ( 8), SIDE POINTER $=(-1)$

SURFACE ( 9), SIDE POINTER $=(-1)$

BODY ( 1$)$

BODY ( 2)

BODY ( 3)

BODY ( 4)

0000000000000000000000000000000000000000000000000000000000000000

BODY ( 6) PHANTOM

MATERIAL( 1)

SURFACE ( 10), SIDE POINTER $=(-1)$

SURFACE ( 11), SIDE POINTER $=(-1)$

BODY ( 1)

BODY ( 2)

BODY ( 3$)$

BODY ( 4) 
BODY ( 5)

0000000000000000000000000000000000000000000000000000000000000000

END 0000000000000000000000000000000000000000000000000000000 